\title{
$\frac{1}{2+11}$ \\ Universidad Nacional de la Plata
}

\author{
Facultad de Humanidades y Ciencias de la Educación \\ Secretaría de Posgrado
}

Doctorado en Ciencias de la Educación

Estudio de las transiciones y trayectorias que realizan niñas y niños entre la Educación Inicial, el Preescolar y la Educaciôn Básica Primaria en Medellín-Colombia.

Tesis presentada para la obtención del grado de

Doctora en Ciencias de la Educación

Mg. Nataly Restrepo Restrepo

Directora: Dra. Viviana I. Seoane

Fecha de presentación: Mayo 2020

La Plata, Argentina 


\section{Presentación y Agradecimientos}

Pensar en la escritura de esta tesis es remitirme a 4 años atrás, cuando en mi mente surgían miles de preguntas frente a la educación de las infancias, es pensar en un proyecto de vida que se inició con muchas expectativas y que se dio gracias al apoyo incondicional de mi familia (padre, madre y hermana), quienes siempre insistieron en motivarme para que no desistiera, en ayudarme en los momentos complejos y darme una voz de aliento que me ayudara a cruzar el camino y concretar este pasaje de mi vida. Encontrar el tema, la pregunta

y el problema de investigación me llevaron por varios caminos (infancia, discapacidad, transiciones, escolarización). No obstante, y con la ayuda de los profesores de la Universidad Nacional de la Plata en cada uno de los seminarios, logré concretar las ideas y forjar lo que se convertiría en mi proyecto de tesis.

Mi proyecto de tesis ha sido un camino por el que he transitado durante estos últimos cuatro años, indagando frente a la configuración de las transiciones y trayectorias que viven los niños y niñas en su experiencia por el sistema de Educación Infantil en Colombia, por ello debo agradecer la hospitalidad, acogida y apoyo que me brindaron en el Programa de Buen Comienzo-Jardín Infantil la Aurora y la Institución Educativa Ciudadela Nuevo Occidente. Gracias a sus maestras, agentes educativas, coordinadoras y directivos que siempre tuvieron un gesto amplio, amable para coordinar mis visitas, para disponer los espacios de trabajo y para escuchar, siempre estuvieron atentas para lo que necesitara; gracias por disponer el primer momento de su agenda de trabajo (muy temprano) para compartir conmigo sus años de experiencia, sus saberes y pensamientos.

Este itinerario de asombro, aprendizaje, reflexión no hubiera sido posible sin las voces, experiencias y sentires de los niños y niñas; a ellos/as infinitos agradecimientos por brindarme la oportunidad de conocer sus más diminutos pensamientos, por incluirme en su cotidianidad, por esperarme con abrazos y cartas en los encuentros; por mostrarme su realidad. Sin ellos/as y sus narraciones esta investigación no tendría el mismo significado, gracias por mostrarme otra forma de hacer investigación y por ayudarme a comprender el mundo y la educación de las infancias. 
Al igual que no hubiera sido posible sin el apoyo incondicional de mi asesora la Dra. Viviana I. Seoane, gracias por ayudarme a concretar las ideas, por compartir su saber y experiencia; por responderme a pesar de la distancia cada uno de los correos e inquietudes que se me presentaban, por estar disponiendo todo el tiempo para leer y ayudarme a comprender este proceso de la investigación. Miles de Bendiciones y agradecimientos especiales a ella.

A mí pareja que desde que inició este proceso de mi tesis me ha tenido paciencia, me ha escuchado y siendo de otras áreas disciplinares ha puesto en conversación mis ideas, me ha cuestionado y me ha hecho ver otras realidades posibles, gracias por estar todo el tiempo disponible para mis crisis existenciales.

A mi perra Luna que todo el tiempo trasnocho, madrugo y estuvo a mi lado incondicionalmente, gracias por su ternura y sostén, a mi otro perro Toni quien llego indiscutiblemente para hacer mis pausas activas al llegar con sus paticas a llamarme la atención.

Por último, a mi otra familia los colegas y amigos/as de la Institución Universitaria Tecnológico de Antioquia gracias por sus aportes, por sus discusiones, por sus enseñanzas, sus tiempos, sus saberes, por compartir el mismo deseo de pensar en educar y comprender a las infancias de este país. 


\section{Resumen}

La relevancia de estudiar las transiciones y las trayectorias se debe a la necesidad de comprender la función social educativa de la Educación Infantil, el grado y modalidad de articulación entre la Educación Inicial-Atención Integral a la Primera Infancia y la Educación Formal (grado transición y grado primero). El cambio que realizan los niños y niñas entre los escenarios y niveles educativos representa un desafío en cuanto la forma como es recibido en el otro entorno; por las expectativas que tienen las maestras, las familias, y el mismo niño y niña, además, por los estilos de enseñanza, el ambiente, los tiempos, los currículos, las metodologías.

El objetivo de esta investigación se centró en analizar los modos en que se configuran las trayectorias y transiciones educativas de los niños y niñas de 0 a 8 años, desde el momento que ingresan al sistema de Educación Inicial Atención Integral (Programa Buen Comienzo) y transitan al Preescolar y a la Educación Básica Primaria en escuelas públicas de la ciudad de Medellín. Así mismo se buscó comprender las representaciones sociales de infancia y la conceptualización de trayectoria y transición educativa que subyace en los lineamientos de la atención integral a la primera infancia y la Política Nacional de Cero a Siempre (1804/2016) en la que se sustenta el programa Buen Comienzo en la ciudad de Medellín.

Colombia actualmente enfrenta retos significativos en cuanto al acompañamiento que se le está realizando a los niños y niñas por el sistema educativo; ellos/as y sus familias recorren estos sistemas de forma diversa y es por ello que se tiene como punto de partida la experiencia de los sujetos (niños- niñas, maestras/maestras, agentes educativas); para comprender sus subjetividades, revelar la temporalidad y los recorridos oportunos, regulares, discontinuos o continuos que el sujeto experimenta, así como las experiencias y momentos de cambio que viven entre la educación inicial y la educación formal. 
Abstract 


\author{
Abreviaturas \\ AWID-Asociación para los Derechos de la Mujer y el Desarrollo \\ BC-Buen Comienzo \\ CONPES-Consejo Nacional de Política Económica y Social \\ CONPES 109- Política Pública Nacional "Colombia por la primera infancia". \\ CLADE - Campaña Latinoamericana por el Derecho a la Educación \\ CDPD- Derechos de las Personas con Discapacidad \\ PCD-personas con discapacidad \\ DANE-Departamento Administrativo Nacional de Estadística \\ DBA-Derechos Básicos de Aprendizaje \\ DINIECE-Dirección Nacional de Información y Evaluación de la Calidad Educativa \\ DNP-Departamento Nacional de Planeación \\ EIAIPI-Educación Inicial y Atención Integral a la Primera Infancia \\ EIAI-Educación Inicial Atención Integral \\ FECODE- Federación Colombiana de Educadores \\ ICBF-Instituto Colombiano de Bienestar Familiar \\ MEN-Ministerio de Educación Nacional \\ OCDE-Organización para la Cooperación y el Desarrollo Económicos \\ OEA-Organización de los Estados Americanos \\ OG -Observación General \\ PEI-Proyecto Educativo Institucional \\ POAI-Plan Operativo de Atención Integral \\ SDQ-Síntomas emocionales, problemas de conducta, hiperactividad y actitud prosocial \\ SITEAL- Sistema de Información de Tendencias Educativas en América Latina \\ UNICEF- Fondo de las Naciones Unidas para la Infancia
}




\section{Tabla de Contenidos}

\section{PRIMERA PARTE \\ CONTEXTUALIZACIÓN DEL PROBLEMA}

Capítulo I:Iniciando el camino hacia la comprensión del fenómeno estudiado ........... 14

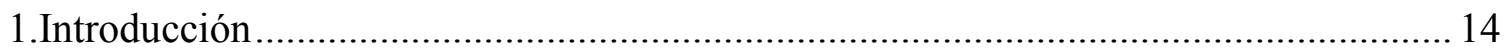

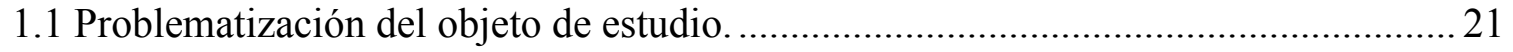

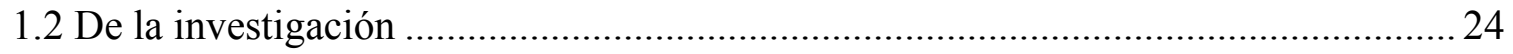

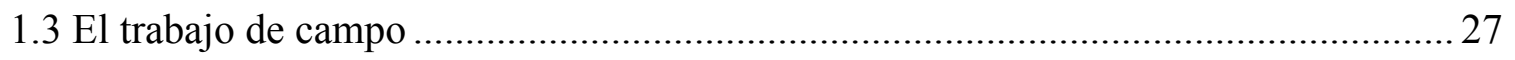

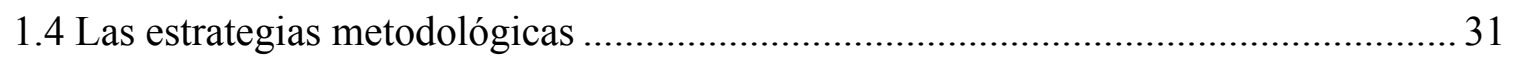

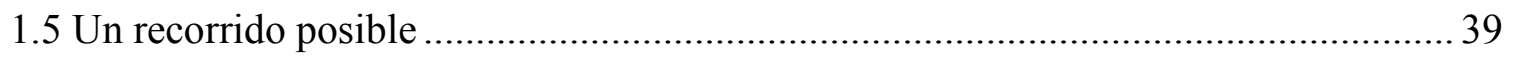

\section{SEGUNDA PARTE \\ APROXIMACIÓN AL CAMPO DE ESTUDIO}

Capitulo II:Trayectorias y transiciones en la Educación Infantil................................... 44

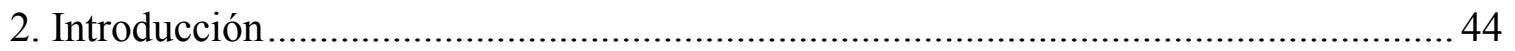

2.1 Corrientes del curso de vida: trayectorias y transiciones en la Educación ................. 45

2.1.1 El curso de vida y la Psicología del Desarrollo .................................46

2.1.2 El Curso de vida en el campo de la sociología ................................4 47

2.1.3 El Curso de vida como enfoque teórico metodológico.........................48

2.1.4 Perspectiva curso de vida en Colombia ..........................................51

2.2 Trayectorias en la educación: debates y perspectivas ............................................5 53

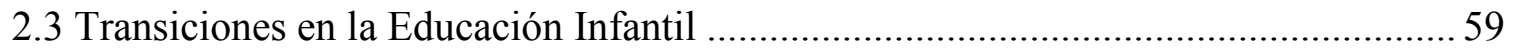

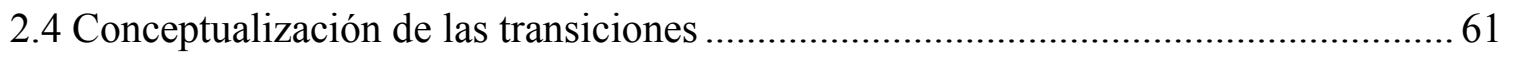

2.4.1 Transiciones de carácter social-cultural .............................................62 62

2.4.2 Transiciones de carácter educativo .................................................64

2.4.3 Transiciones de carácter individual ................................................67

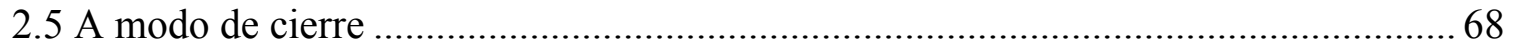

Capítulo III: Marcos políticos que regulan las transiciones en Colombia ..................... 73

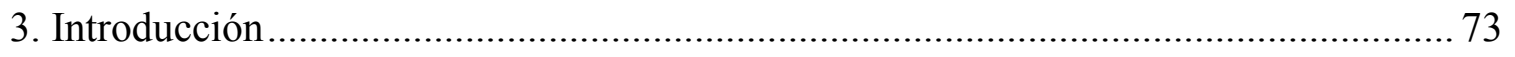

3.1 Antecedentes de la Política de Primera Infancia en Colombia................................. 78 
3.2 Pasado y presente del proceso de transiciones en la Educación Inicial en Colombia 81

3.3 Encrucijadas del proceso de transición entre lo exitoso y armonioso ....................... 90

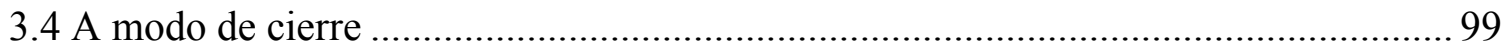

\section{TERCERA PARTE \\ ARTICULACIONES ENTRE LA EDUCACIÓN INFANTIL}

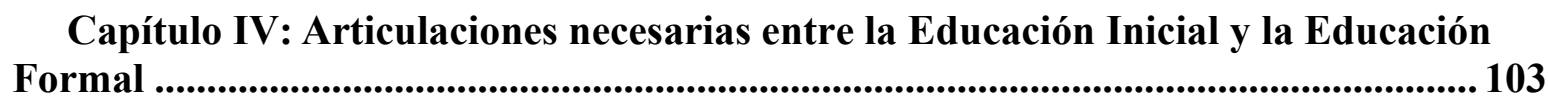

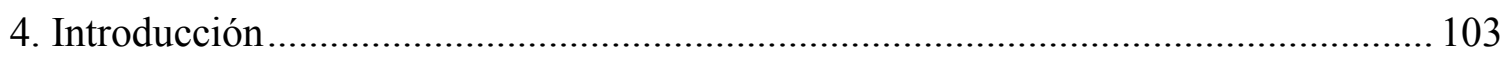

4.1 Transiciones entre las instituciones de Educación Infantil.................................... 105

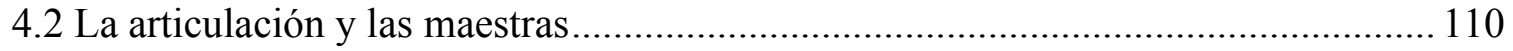

4.3 Dicotomía entre la Educación Inicial - Atención Integral a la Primera Infancia y la Educación Formal - Preescolar y Básica Primaria....................................................... 115

4.4 Estructura curricular de la Educación Infantil en Colombia .................................. 126

4.5 Formalizar lo informal en una escuela para la niñez ........................................ 137

4.6 A modo de cierre ............................................................................................. 142

\section{CUARTA PARTE \\ CONFIGURACIÓN DE LAS TRAYECTORIAS Y TRANSICIONES EN LAS VOCES DE LAS MAESTRAS Y AGENTES EDUCATIVOS}

Capítulo V: Modos en que se configuran las trayectorias y transiciones de los niños y niñas 145

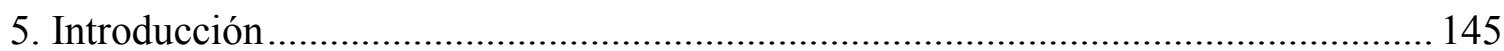

5.1 Modos en que se configuran las trayectorias de los niños y niñas ......................... 148

5.2 Itinerarios que experimentan los niños y niñas entre el sistema de atención integral, el

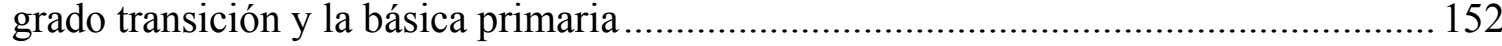

5.3 Modo en los que se configuran las transiciones de los niños y las niñas ................ 160

5.4 Como viven los niños y niñas el proceso de transición en la Educación Infantil..... 165

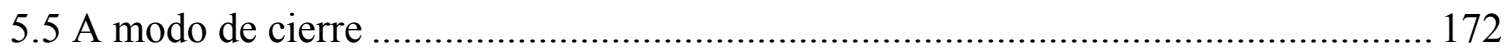

Capítulo VI: Sentires de las maestras frente al proceso de trayectoria y transición . 175

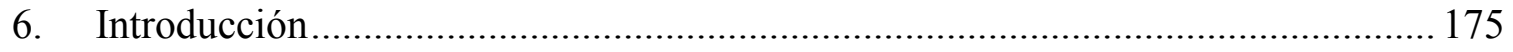


6.1 Sentires de las agentes educativas y maestras frente al proceso de transición.

6.2 Acompañamientos a los niños y niñas para favorecer su proceso de adaptación y transición por la Educación Infantil.

6.3 Recomendaciones de las maestras y agentes educativas para el proceso de articulación y transición por la Educación Infantil.

6.4 A modo de cierre

\section{QUINTA PARTE \\ CONFIGURACIÓN DE LAS TRAYECTORIAS Y TRANSICIONES EN LAS VOCES DE LOS NIÑOS Y NIÑAS}

\section{Capítulo VII: Construcción de la transición de los niños y niñas entre la Educación Inicial, el Preescolar y la Educación Básica Primaria................................................. 198}

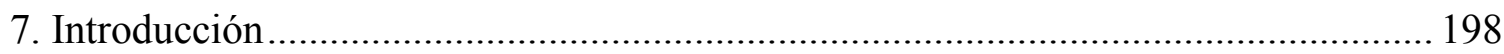

7.1 Quienes somos y como nos configuramos en el paso por la escolarización ............ 201

7.2 Ser niño y niña en la Educación Infantil................................................................. 208

7.3 Chupar teta, gatear, caminar, jugar y hacer tareas: experiencias significativas de los niños-niñas en sus trayectos de vida entre el hogar, la guardería y la escuela.

7.4 La "escuela de antes" y "la escuela de ahora": reflexiones de los niños y niñas frente

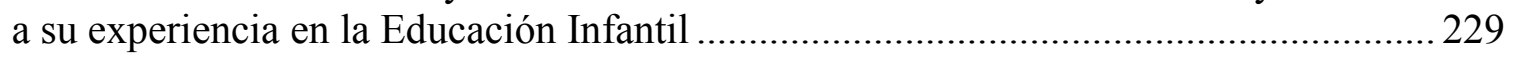

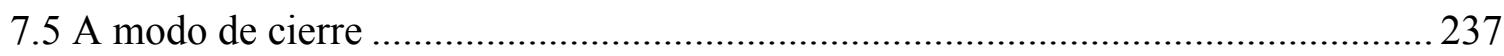

Capítulo VIII: Experiencias y sentires de los niños y niñas frente a su proceso de

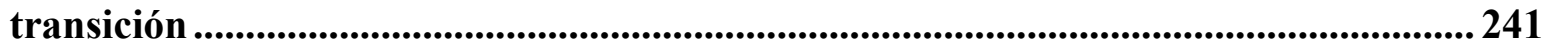

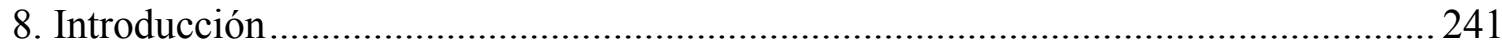

8.1 Sentidos y sentires de los niños y niñas frente a su proceso de transición (separación,

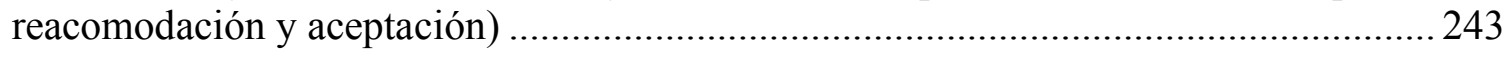

8.2 Qué se aprende y qué se debe saber en los recorridos escolares por la Educación

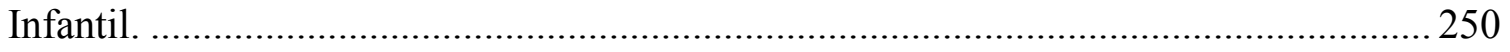

8.3 ¿Y qué pasa con los vínculos afectivos y el juego en el paso entre niveles en la

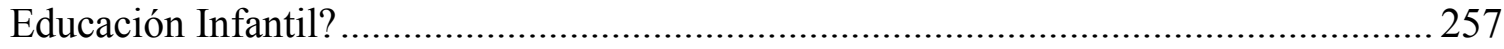

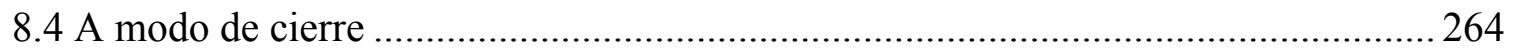


Reflexiones y Consideraciones Finales 269

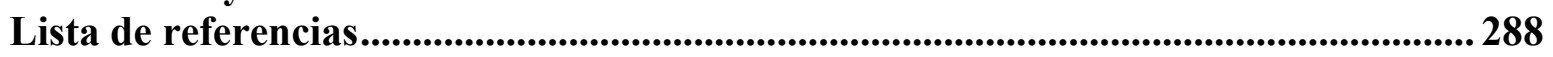

Anexos... 


\section{Lista de tablas}

Tabla 1 Herramientas Método Mosaico implementadas en la Investigación .......................34

Tabla 2 Entrevistas y encuentros de trabajo de campo.................................................... 38

Tabla 3 Tramos de escolarización obligatorios, Colombia 2017 .................................. 75

Tabla 4 Tasa de escolarización de los niños de 5 y 6 años............................................ 76

Tabla 5 Avances desafíos y retos en los procesos de transición educativa en Colombia..... 76

Tabla 6 Orientaciones técnicas y administrativas a nivel municipal .............................. 85

Tabla 7 Procesos y condiciones para garantizar el éxito en la Transición Educativa ..........93

Tabla 8 Proceso a Implementar para garantizar el transito armónico ............................... 96

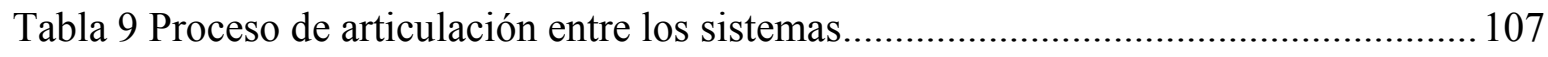

Tabla 10 Perfil y saberes de los niños y niñas en la Educación Infantil........................... 132 


\section{Lista de ilustraciones}

Ilustración 1 Estructura Sistema Educativo en Colombia .............................................22

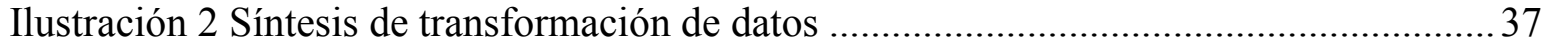

Ilustración 3 implicaciones de lo armonioso-exitoso en la transición................................98

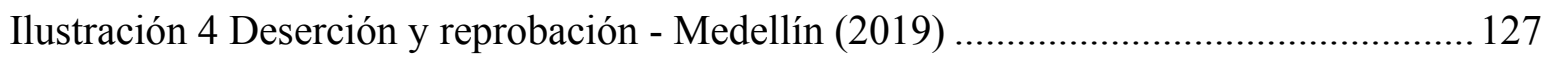

Ilustración 5 Estructura Curricular de la Educación Infantil ............................................ 134

Ilustración 6 configuración de la trayectoria y transiciones educativas en el campo de la

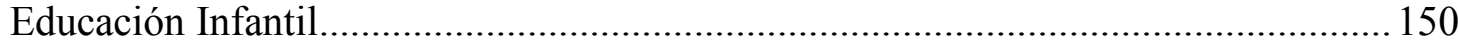

Ilustración 7 Gráfico Modos de transición en la trayectoria ............................................ 152

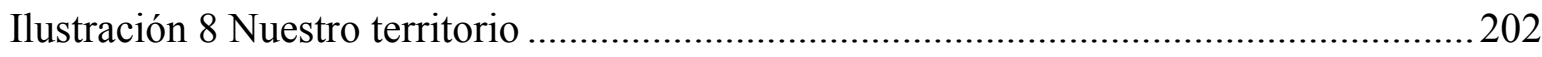

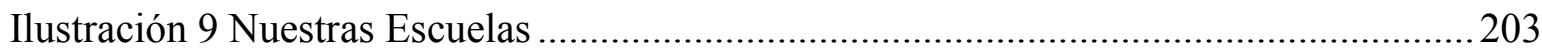

Ilustración 10 Dibujos tipología familiar realizada por los niños/as .............................206

Ilustración 11 características de los niños y niñas según las y agentes educativas ............210

Ilustración 12: Dibujos de los niños y niñas "significado de ser niño y niña”..................220

Ilustración 13 Taller con los niños y niñas- Encuentro 3 ..............................................2229

Ilustración 14 Dibujo de los niños y niñas Preescolar y Primero " La escuela de antes"... 234

Ilustración 15 "la escuela de ahora" niños preescolar-primero .................................... 235

Ilustración 16-dibujos de los niños/as de transición que se aprende en preescolar............252

Ilustración 17-fotografías y dibujos de los lugares más significativos de la escuela-

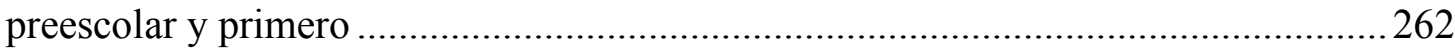

Ilustración 18-fotografías y dibujos de los lugares más significativos del Jardin Infantil

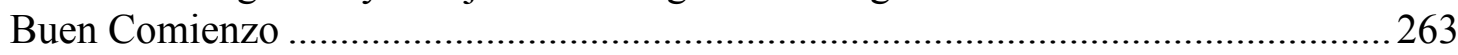

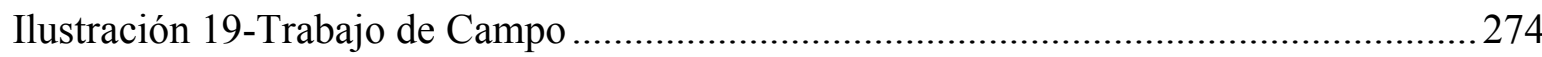




\section{PRIMERA PARTE}

\section{CONTEXTUALIZACIÓN DEL PROBLEMA}

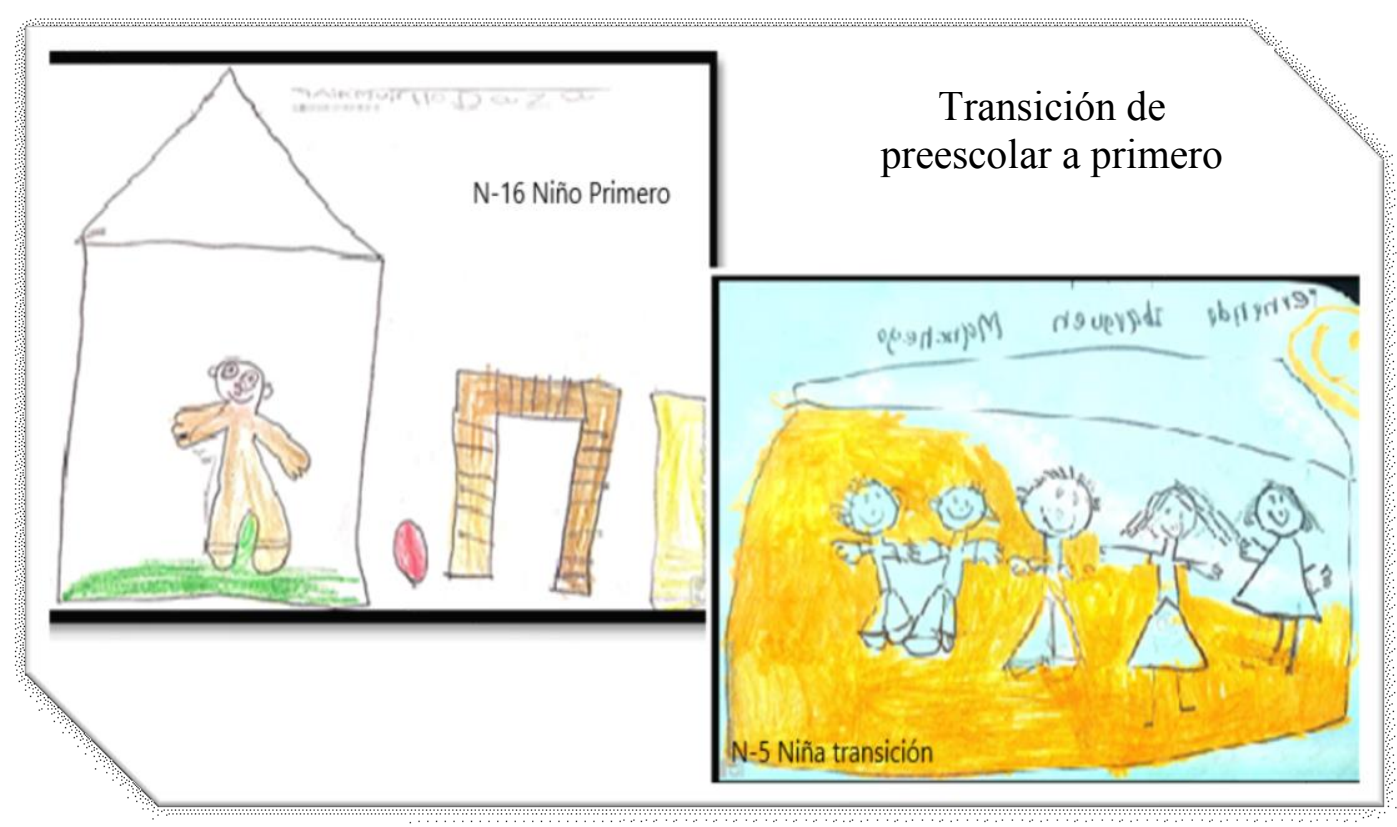

"Los niños son como cemento fresco, todo lo que cae en ellos deja huella"

(Haim G. Ginott, 1922-1973) 


\section{Capítulo I}

\section{Iniciando el camino: hacia la comprensión del fenómeno estudiado}

\section{Introducción}

La trayectoria escolar es un tema que ha tomado impulso desde los trabajos realizados en el campo escolar en la década de 1960 por los sociólogos franceses Pierre Bourdieu y Jean-Claude Passeron, en el marco de la sociología crítica, y ha permitido identificar las experiencias que presentan los/as estudiantes y la posición que ocupan a lo largo de su historia escolar en el campo educativo. Dichos autores analizan la forma y ritmo en que se produce el tránsito por el sistema escolar, al mismo tiempo destacan la relación entre la educación y el origen social. Bourdieu refiere al concepto de trayectorias sosteniendo que es necesario analizar la historia individual de los sujetos, de sus familias y de su contexto para poder entender determinados procesos sociales. Define trayectoria como una "serie de las posiciones sucesivamente ocupadas por un mismo agente (o un mismo grupo) en un espacio en sí mismo en movimiento y sometido a incesantes transformaciones” (Bourdieu, 1977: 82)

La relación entre la trayectoria escolar y los procesos sociales de los/as estudiantes se convierten, para Bourdieu y Passeron, en un análisis predominante frente al sistema educativo. La tesis principal de los autores es que el sistema educativo no permite la igualdad de oportunidades, sino que sus efectos terminan reproduciendo y legitimando las diferencias sociales de los/as estudiantes, alcanzando a configurar trayectorias de exclusión. Bourdieu desarrolla la noción de campo social refiriéndolo como tal a espacios sociales estructurados a partir de un conjunto de relaciones que se dan en su seno, que gozan de una autonomía relativa y de una lógica de funcionamiento propia (Bourdieu, 2001).

La trayectoria es un concepto que permite identificar las múltiples formas de transitar por los ciclos escolares y constituye una forma de revelar la temporalidad y los recorridos oportunos, regulares, discontinuos o continuos que el sujeto experimenta en relación a los procesos institucionales, familiares, sociales y culturales que interseccionan el paso de cada individuo por el proceso escolar. Un aspecto relevante de las trayectorias reside en su relación con la noción de transición de una etapa a otra. La trayectoria permite dar cuenta de las 
posiciones que logra ocupar el sujeto en el campo educativo para futuras inserciones. La transición implica un proceso de adaptación y aprendizaje en los entornos escolares, se relaciona con el cambio que experimentan los niños y sus familias cuando pasan de un lugar o fase de la educación a otro, es decir de la casa al preescolar, o del preescolar a la escuela.

En el análisis realizado frente a los diferentes estudios e investigaciones que durante los últimos años se han preguntado por el proceso de transición y las trayectorias en la Educación Infantil en América Latina se observa que la trayectoria se ha estudiado, por un lado, desde una postura que analiza el ingreso- egreso medido por las tasas de deserción y repitencia en el sistema escolar, es decir, las posibilidades de acceso y permanencia de los jóvenes en los diferentes niveles de educación y la salida de los mismos del sistema. Y por el otro, esta línea de investigación instala la pregunta por la configuración del contexto y las trayectorias escolares de los sujetos que están en condiciones de desigualdad, por ejemplo, niños/as y jóvenes trabajadores de sectores vulnerables de la sociedad.

Flavia Terigi $(2007 ; 2009)$ es quien propone una distinción entre trayectorias teóricas y reales centrando el análisis en el ingreso-egreso y las oportunidades que brinda el sistema escolar. La autora refiere que el recorrido teórico de un sujeto por el sistema educativo esta mediado por un conjunto de normas, reglas escritas, orientaciones técnicas y administrativas que establecen la edad, obligatoriedad, promoción y gradualidad del ciclo escolar. Así mismo describe que las trayectorias escolares de muchos de los que asisten a las escuelas están desacopladas de los recorridos esperados por el sistema, la relación entre lo real y lo ideal deja ver marcadas diferencias en correspondencia con los procesos que se interpelan y movilizan en las escuelas; con las ideas respecto al "aprendizaje" el "éxito" y "fracaso". A su vez la gradualidad del currículum y la anualización de los grados ha delineado un recorrido esperado y una duración estándar-lineal prevista por el sistema educativo que en ocasiones difiere de lo que efectivamente sucede al sujeto en su tránsito por las distintas instituciones educativas.

En concordancia con las investigaciones realizadas por Terigi, el trabajo de Briscioli (2013) pone de manifiesto que existen diversos recorridos escolares que se diferencian de los "esperados", y permiten constatar que en la vida de los adolescentes conviven diversas actividades (la escolaridad, entre otras) o se alternan, por arreglos familiares, o por 
situaciones vitales específicas. De este modo, los recorridos de los sujetos se direccionan por un entramado en el que se interponen múltiples factores y situaciones vitales que determinan una variación en los recorridos y, por tanto, una diferencia en sus trayectorias.

Otras investigaciones socioeducativas muestran que los itinerarios que los sujetos experimentan se componen de trayectorias desiguales. Así, Guzmán Gómez (2004) analizando las experiencias de los jóvenes que trabajan observa que las formas de organizar los tiempos, las estrategias de estudio, la participación en actividades extracurriculares se vive de forma conflictiva y, en ocasiones, genera interrupciones en su trayectoria real. Por su parte, Legarralde, Cotignola, y Margueliche (2017) se preguntan por las trayectorias típicas de los estudiantes de la Facultad de Humanidades y Ciencias de la Educación (FaHCE/UNLP) de Argentina considerando el conjunto de normas y reglas formales, las políticas académicas y las decisiones de enseñanza de la facultad. Destacan que se configuran trayectorias reales heterogéneas, desiguales según las experiencias estudiantiles y prácticas que los estudiantes despliegan en el territorio, ya sea en el marco del desplazamiento como a las diferentes instancias de apropiación de los lugares por los que transita. Entre las experiencias se puede mencionar: el viaje de iniciación, los diferentes traslados y desplazamientos por la ciudad y lugares de encuentro de los estudiantes que forman parte de las mismas cohortes de ingreso.

En el estudio del dispositivo escolar y la forma como este interfiere en las trayectorias de las mujeres profesionales que trabajan en escuelas secundarias técnicas de la provincia de Buenos Aires-Argentina, Seoane (2013) señala que existen variaciones en sus recorridos en tanto la escuela convalida un sistema de sexo/género, a través de una serie de regulaciones que rigen sobre los espacios escolares, sobre los cuerpos de alumnas/os y profesoras/es, que terminan esencializando las identidades de género. Estas regulaciones y formas de organización escolar también se evidencian en el estudio de Toscano, Briscioli, y Morrone (2015) quienes abordan las trayectorias escolares, dando cuenta de los recorridos de los sujetos por las instituciones escolares a lo largo del tiempo y en interdependencia con las diferentes esferas de sus vidas, en este sentido detectan momentos críticos, transiciones, dificultades en los pasajes de ciclo, años con mayor repitencia y rezago, períodos de abandono y momentos de egreso de la escuela del grupo etario destinatario de la iniciativa. Los autores postulan la noción de trayectorias escolares como superadora de la dicotomía 
entre determinismo social y voluntarismo, introduciendo y atribuyéndole un papel relevante a la dimensión institucional en la construcción de estas.

Desde una postura psicológica la investigación de Failache, Salas y Vigorito (2018) analiza el papel de la trayectoria nutricional y las habilidades no cognitivas de las/los jóvenes que abandonaron y/o repitieron la escuela de enseñanza media en Uruguay. En su estudio demuestran que el ingreso del hogar al inicio del ciclo primario son fuertes predictores de la repetición. Un mal desempeño en las escalas psicométricas del cuestionario de fortalezas y dificultades (SDQ, -síntomas emocionales, problemas de conducta, hiperactividad y actitud prosocial) se correlaciona con haber experimentado algún episodio de repetición. A la vez, ésta predice fuertemente el abandono. Estos hallazgos se encuentran en línea con la literatura que sostiene que el desarrollo en etapas tempranas condiciona los desempeños en la adolescencia, lo que sugiere la necesidad de apoyar a los hogares con intervenciones pedagógicas desde las edades tempranas como una manera de acompañar todo el ciclo vital.

Otro grupo de investigadores también han analizado la posición de los sujetos en el sistema escolar y el riesgo que enfrentan amplios grupos de niños/as por sus condiciones culturales para culminar la trayectoria. Por ejemplo, Salva y Lago (2012) analizaron las trayectorias escolares de niños/as y jóvenes inmigrantes o hijos/as de inmigrantes, de niños/as trabajadores, para comprender y reflexionar sobre cómo vivencian los niños/as y maestras sus trayectorias escolares y cuáles son los principales condicionamientos dado que tienen una doble tarea, trabajar y estudiar. Vemos como el desempleo y la desigualdad de oportunidades impactan fuertemente en las transiciones y trayectorias educativas de sujetos (niñas, niños y jóvenes) que ven privado su derecho de estudiar en igualdad de condiciones y acceder a la misma educación de calidad que otros grupos sociales.

Castillo (2011) hace un análisis con respecto al concepto de trayectoria espacial, entendido como un recorrido experiencial por el territorio que un sujeto habita y que da origen a una geografía personal cuyas coordenadas son observables en acciones y palabras, es decir, están presentes en el discurso existencial del ser humano. El autor analiza las trayectorias espaciales observadas en el juego infantil en niños de 3 a 5 años de diferentes posiciones sociales. Los resultados de esta investigación muestran diferencias en las 
trayectorias espaciales de los niños/as relacionado con los temores y expectativas de los adultos/as y con el lugar que les asignan a los niños.

La Dirección Nacional de Información y Evaluación de la Calidad Educativa (DINIECE) de Argentina, junto a UNICEF (2004) ha realizado un estudio con el propósito de indagar en las dificultades que presentan las trayectorias escolares de los alumnos/as que asisten a la escuela primaria. Para ello, el estudio puso en consideración las tensiones entre las condiciones en que llegan las/los niñas/niños y jóvenes a las escuelas de educación básica, las formas en que las escuelas los reciben, los resultados educativos y las capacidades y limitaciones de las políticas educativas para enfrentar estas tensiones. Problematizan en torno de cómo son recibidos los niños en las escuelas, y pone de manifiesto que las escuelas requieren del diseño de políticas educativas integrales, continuas, que comprometan a las autoridades del nivel nacional como provincial para el cumplimiento de los objetivos de atención a la primera infancia.

Después de analizar las diferentes investigaciones frente a las trayectorias educativas se hace necesario para este estudio recuperar el concepto de transición. Encontramos que ha sido trabajado con más profundidad principalmente desde un enfoque de articulación interinstitucional, es decir, aquél que observa los problemas que se suscitan en el pasaje de una institución a otra, de un nivel educativo a otro. Los países de América Latina que han adoptado este enfoque de acuerdo a la OEA han sido Venezuela, Chile, Perú, Colombia, Costa Rica, México, Argentina y Honduras. Los estudios relativos a las transiciones educativas han estado enfocados desde la articulación a partir de la práctica pedagógica, y las diferencias entre los niveles, sin embargo "aun cuando los países presentan en sus marcos normativos estrategias para lograr una transición efectiva, existen altos porcentaje de repitencia, al no alcanzar los niños/as los logros de aprendizaje esperados en la transición del preescolar a la escuela primaria" (OEA, 2009).

El alcance de la articulación entre la educación inicial y la educación primaria ha sido largamente estudiado en Venezuela. Los trabajos más relevantes son los de Juana Medina (2006) quien llevó a cabo una investigación orientada a verificar la capacitación que poseen las maestras en relación a la articulación que debe prevalecer entre el nivel de educación inicial, educación primaria y la etapa de educación básica. León Zorelys (2011) indaga 
específicamente la transición entre la Educación Inicial y la escuela. Por último, Carmen Machado (2012) estudia las estrategias y elementos que orientan el proceso de articulación entre el nivel preescolar y el primer grado de Educación Básica.

Los resultados de estas investigaciones evidencian que en las escuelas las/os maestras desconocen las orientaciones que el ministerio da frente a las transiciones y continúan tratando estos dos niveles en forma aislada. Dichos autores coinciden que en el primer grado la mayoría de las maestras siguen trabajando con una práctica tradicional, diferente a preescolar, sin conjugar la práctica con la teoría. Según estos trabajos, la problemática se da cuando el niño-niña accede al primer grado de educación primaria porque los programas académicos y las diferentes concepciones metodológicas utilizadas en ambos niveles son distintos. En cuanto al rol del docente en educación preescolar es muy diferente al rol del docente de primer grado.

En una misma línea, el trabajo de Ana Gajardo (2010) muestra que Educadores/as de Párvulos y Profesores/as de Educación General Básica de Chile desconocen los contenidos que se trabajan en el nivel de enseñanza distinto al suyo y, entre otros aspectos, que requieren de mayor tiempo para realizar una labor en conjunto. Esto permite concluir que no existe articulación curricular efectiva y eficaz, lo que incide en la calidad de la formación brindada.

Otro aspecto que se ha trabajado en las investigaciones es el relacionado con las percepciones de las maestras, niños-as y padres de familia frente a la transición, siendo los trabajos más relevantes los que se realizaron en Colombia, México, y Perú. En el caso de Colombia, la investigación realizada por Rocío Abello (2008) indagó en las directrices escolares que presentaba la institución de carácter privado para manejar las transiciones, y en las expectativas y perspectivas de niños/as, padres, maestras y directivos. Según este estudio, la institución no tiene directrices institucionales para el manejo de las transiciones, y destaca que existen temores de niños/as y padres para enfrentar la transición.

Este último dato también está presente en el estudio realizado en México por Castro, Argos y Ezquerra (2015) en el que destaca la presencia en las voces de niños-as de miedo, ansiedad, nerviosismo e inseguridad ante lo que les espera, razón por la cual los niños/as reclaman un mayor conocimiento de los nuevos espacios escolares. En la misma línea Ames y Rojas (2011) recuperan las expectativas, inquietudes y experiencias de niños-as peruanos 
provenientes de cuatro distritos, durante su transición de la escuela primaria a la secundaria. El estudio encontró que los niños/as identifican una serie de cambios relacionados con una organización y un enfoque pedagógico diferentes en el colegio secundario, considerado por ellas/ellos un difícil desafío en términos académicos y sociales, pero también como una oportunidad para disfrutar de mayor libertad, autonomía, y para crecer y progresar en sus trayectorias educativas.

Finalmente hay un grupo de investigaciones que abordan los desafíos, expectativas, temores y problemáticas de la trayectoria escolar y el tránsito con poblaciones diversas que se desarrollaron en países como Perú, México, Argentina, España y Colombia. Estos trabajos dejan entrever que el tema de las diferencias y el respeto por la diversidad continúa siendo un desafío para el proceso de transición educativa, en tanto requiere de otras estrategias de abordaje a nivel de la escuela para acercarse a los niños-niñas indígenas, con discapacidad, o capacidades diferentes (Rojas, Ames \& Portugal, 2010).

En países como México la investigación sobre las trayectorias y transiciones escolares de los alumnos con capacidades diferentes devela que no existe un proyecto específico que permita su educación en condiciones de equidad. La falta de acompañamiento para brindarles condiciones que permitan su plena inclusión dificulta su trayectoria académica (Pineda, Méndez, Saucedo \& Rodríguez, 2010). En Argentina, los trabajos de Laura Santillán (2012) recorren la pregunta en torno del significado que tiene para las personas el hecho de educar a los hijos/as en un lugar estigmatizado, indaga en las trayectorias de los niños y niñas en condición de pobreza y explora las formas en que transitan la escolarización y otras iniciativas escolares. La autora desmitifica el desinterés de las madres y padres de sectores populares por la educación de sus hijos/as, y discute el concepto de educabilidad asociado a la pobreza, así como las formas de la participación de los padres en la autogestión, la asistencia y la religiosidad.

En Colombia, la situación frente al acompañamiento de las trayectorias y las transiciones de los grupos marginados evidencia una mayor atención. Sarmiento (2010), en su estudio sobre la situación de la educación en Colombia, revela que los niños y niñas con discapacidad tienen menos probabilidades de ingresar a la escuela, por ejemplo, aquellos que no presentan discapacidad entre 3 a 5 años, asisten un 11\% más que los niños y niñas con 
discapacidad en el nivel de preescolar, lo que evidencia alarmas relacionadas a la garantía del derecho a la educación de este grupo poblacional. Este autor insiste en resaltar que la población escolar con discapacidad requiere mayor atención si se desea un mayor acceso y permanencia de todos los niños-as en el sistema educativo, sin importar sus características diversas.

En este mismo orden González, Sánchez y Araque (2013) estudian los procesos transicionales en niños y niñas indígenas de primera infancia en Colombia. Los autores indican que la principal dificultad que tienen los niños/as de comunidades indígenas en su ingreso a la escuela pública es la distancia que separa la casa de la escuela, y el consecuente traslado para vivir en otro hogar. Otro obstáculo es el idioma. Muchos de los niños y las niñas no hablan el español y eso los pone en situación de desventaja, tanto en la escuela como en otros contextos sociales. De este modo su inclusión en la escuela y en la sociedad se ve truncada ante la falta de políticas que atiendan sus demandas y derechos y acompañen su escolaridad.

La investigación socioeducativa ha podido mostrar que los caminos que recorren los niños y niñas a través del sistema educativo no son homogéneos, lineales y predecibles en todos sus aspectos. Tal como se evidencia en las investigaciones anteriormente citadas, el sistema educativo en tanto espacio social muestra un conjunto de situaciones en las que factores como las diferencias sociales, la desigualdad en las oportunidades, la condición sexo-género, las políticas educativas, las acciones institucionales son fundamentales en los recorridos escolares. Si bien es real que se pueden establecer tipos de itinerarios frecuentes e ideales, coincidentes con la estructura escolar (grados, ciclos, niveles), no es menos cierto que gran parte de los niños y jóvenes transitan su escolarización de modos heterogéneos, variables y contingentes.

\subsection{Problematización del objeto de estudio.}

El concepto de trayectoria recupera la experiencia vivida por los niños-as en el recorrido que realizan por el sistema educativo y presenta como eje fundamental la temporalidad de la experiencia en términos de permanencia y tránsito (oportunos, regulares, continuos o discontinuos). La trayectoria no solo refiere a los recorridos personales del niño- 
niña sino que interpela a la institución por la que transita. Estudiar las trayectorias escolares obliga a centrar la mirada específicamente en el lugar que adquiere la institución/escuela/jardín infantil, puesto que las formas en que éstas se organizan desde sus estructuras, currículos, prácticas, formas de concebir al sujeto pedagógico, delinean itinerarios posibles que favorecen o dificultan el paso por la escuela. En nuestra investigación, pondremos el acento en el recorrido que hacen los niños/as entre la Educación Inicial y Atención Integral a la Primera Infancia (EIAIPI) y la Educación Formal la cual comprende la educación preescolar (niños y niñas de 5 años) y la educación básica primaria (niños-niñas de 6 a 10 años) que de ahora en adelante denominaremos Educación Infantil ${ }^{1}$. Para su mayor comprensión, presentamos a continuación la estructura del sistema educativo de Colombia:

Ilustración 1 Estructura Sistema Educativo en Colombia

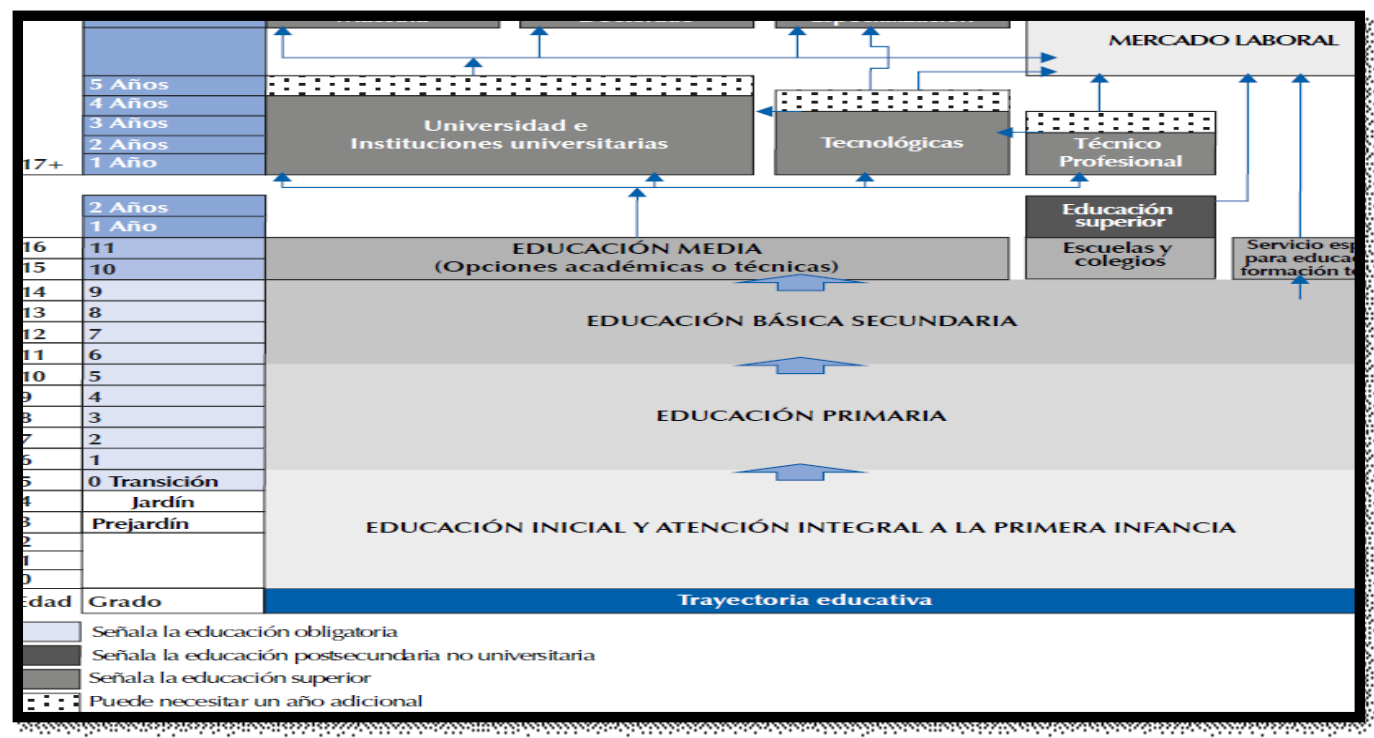

Fuente: Revisión de Políticas nacionales de Educación. La educación en Colombia (Ministerio de Educación Nacional-MEN 2016:25)

${ }^{1}$ En Colombia la Educación Infantil se compone de dos estrategias de atención educativa. La primera, Educación Inicial en el marco de la atención Integral a la primera infancia (EIAIPI), del cual forma parte el Programa Buen Comienzo: proyecto estratégico para promover el desarrollo integral, diverso e incluyente de los niños y niñas menores de 6 años en la ciudad mediante la construcción de estrategias pedagógicas flexibles y se estructura en Modalidades de atención (Familiar-Institucional) bajo la política de cero a siempre (1804/2016). La segunda, la Educación Formal, comprende la Educación Preescolar con el grado obligatorio de transición y la Educación Básica Primaria. Ambas serán ampliadas en el Capítulo III. 
Las instituciones educativas y los dispositivos de acompañamiento a las trayectorias tienen un papel relevante en el tránsito educativo de las/los niñas/niños. El cambio que realizan los niños-as desde el nivel de Educación Inicial Atención Integral a la Primera Infancia (Programa Buen Comienzo), al nivel de Educación Formal-Preescolar y posteriormente al primer grado de la básica primaria representa un desafío por la forma como es recibido en el nuevo entorno; por las expectativas que tienen las/os maestras, las familias, y el mismo infante; por los estilos de enseñanza, el ambiente, los tiempos, los currículos, las metodologías, haciendo del proceso algo intenso y con demandas crecientes que inciden en las posibilidades de adaptación y de aprendizaje del niño-niña.

Actualmente Colombia enfrenta retos significativos en cuanto al acompañamiento de los niños y niñas por el sistema educativo, dado que aun cuando se ha priorizado el tema de la atención a la primera infancia y sancionado políticas públicas para orientar a las instituciones y a sus maestras, los datos arrojan la siguiente información:

- Las políticas sobre primera infancia no logran impactar en el 100\% de la población. Si bien se observa un aumento en las tasas de matriculación de niños-niñas en el nivel inicial y en la atención integral a la primera infancia, luego no son matriculados en el nivel preescolar grado transición evidenciando un quiebre entre estos dos escenarios.

- Son altos los índices de deserción y repitencia. Quienes más repiten el año escolar son aquellos niños y niñas que pasan de preescolar-grado transición al grado primero, y los niños/as con discapacidad, por causas como la falta de articulación y continuidad en las metodologías entre los sistemas, por las diferencias curriculares, por el complemento nutricional, entre otras.

- Existen discrepancias en la funcionalidad que se le otorga al nivel de atención integral, al nivel de educación preescolar y al primer grado de la educación básica, evidenciando una tensión entre la función asistencial y la educativa, y entre preparar para la educación formal o potenciar el desarrollo.

- Se observa poca articulación entre el nivel de educación inicial, nivel de educación preescolar, y nivel de básica primaria, que favorezca el aprendizaje de los niños/as. El componente educativo en el nivel de educación inicial atención integral está poco desarrollado, la falta de un énfasis en el aprendizaje es particularmente problemático, probablemente por la falta de un currículo común. 


\subsection{De la investigación}

El contexto para realizar esta investigación es la ciudad de Medellín-Colombia, ciudad que en los últimos años ha venido consolidando procesos políticos para hacer que la primera infancia ocupe un lugar relevante en la agenda pública, expresado en programas como Buen Comienzo y proyectos que inciden en la generación de mejores condiciones para el desarrollo integral de los niños y niñas. El objetivo de esta investigación se centró en analizar los modos en que se configuran las trayectorias y transiciones educativas de los niños y niñas de 0 a 8 años, desde el momento que ingresan al nivel de Educación Inicial Atención Integral (Programa Buen Comienzo) y transitan al Preescolar y a la Educación Básica Primaria en escuelas públicas de la ciudad de Medellín. Así mismo se buscó comprender las representaciones sociales de infancia y la conceptualización de trayectoria y transición educativa que subyace en los lineamientos de la atención integral a la primera infancia y la Política Nacional de Cero a Siempre (1804/2016) en la que se sustenta el programa Buen Comienzo en la ciudad de Medellín.

La relevancia de estudiar las transiciones y las trayectorias se debe a la necesidad de comprender la función social educativa de la Educación Infantil, el grado y modalidad de articulación entre la educación inicial-atención integral a la primera infancia y la Educación Formal-grado transición y grado primero. Los niños, niñas, familias recorren estos sistemas de forma diversa pues su itinerario no solo empieza cuando nace, pasa del hogar a la guardería o jardín, transita entre las modalidades del nivel de educación inicial atención integral, sino cuando cambia a la educación formal nivel preescolar-grado transición y posteriormente a la básica primaria, es decir, hay un universo de instituciones que tienen una influencia directa sobre la forma en que se desarrolla la vida de los niños y niñas en estos tránsitos que realizan de un sistema a otro.

Esta investigación se centra en el campo de la Educación Infantil comprendido como un periodo vital del desarrollo, que abarca desde el nacimiento hasta los 8 años de edad (Observación General ${ }^{2}$ a $\mathrm{OG} \mathrm{N}{ }^{\circ}$, 2006). No estamos ante un ciclo de preparación, ni de

\footnotetext{
${ }^{2}$ Observaciones generales son aprobadas por el Comité de Derechos Económicos, Sociales y Culturales. El Comité de los Derechos del Niño es un organismo de las Naciones Unidas que tiene la función de examinar los progresos realizados en el cumplimiento de las obligaciones contraídas por los Estados Partes que han ratificado la Convención sobre los Derechos del Niño.
} 
espera, o de maduración, se trata de un ciclo de vida que tiene sentido propio y un valor en sí mismo. Tal como lo expone Mayol Lassalle en la asamblea anual de la Organización Mundial para la Educación Preescolar (OMEP) ${ }^{3}$ del año 2015,

La Educación Infantil se reconoce como un proceso de humanización para el niño o la niña, organizado en diversos entornos y modalidades convencionales y diversificadas, bajo lineamientos de educación formal, informal y no formal; lo que facilita su comprensión como un proceso transversal a las dinámicas sociales y culturales de la infancia y el grupo poblacional al cual pertenece. Educación que, ofrecida de manera sistemática, se constituye en el resultado de la interacción mediadora entre lo social, lo cultural, lo histórico, lo público y lo privado o la articulación de responsabilidades familiares, comunitarias, estatales e institucionales, las cuales redundan en la educabilidad de los niños y las niñas como oportunidad para aprender, desarrollar, representar, pensar, potenciarse y formarse para toda la vida (Mayol, 2015: 50).

El trabajo que aquí se presenta busca comprender subjetividades, revelar la temporalidad y los recorridos oportunos, regulares, discontinuos o continuos que las/los niñas/niños experimentan, así como las experiencias y momentos críticos de cambio que viven. En el marco de un trabajo sociológico la revisión de los procesos de escolarización de los niños y niñas colabora con la comprensión de las trayectorias y transiciones por el sistema educativo. En los recorridos de los niños y niñas se ponen en juego un sinnúmero de factores (históricos, jurídicos, institucionales, familiares, culturales) que producen cambios significativos en las experiencias de vida del sujeto y las posiciones que ocupan en dichas estructuras sociales. Por ello rescatar sus voces facilita la recuperación de su historia de vida y la comprensión de su proceso de transición.

Las transiciones no las comprendemos como el paso de un escenario educativo a otro sino desde una perspectiva holística en el que se establecen cambios que dependen de los factores-institucionales y acontecimientos individuales que, en su conjunto, producen nuevas relaciones y eventos que se pueden representar en desafíos o apuestas interesantes para los niños y niñas al presentarse en períodos y momentos claves de su vida, es decir, la forma

${ }^{3}$ La OMEP es una organización internacional no gubernamental y sin fines de lucro, con Estatus Consultivo en Naciones Unidas y UNESCO, que se ocupa de todos los aspectos relacionados con los Cuidados y la Educación de la Primera Infancia. 
como él/ella experimenta esos itinerarios afecta directamente su trayectoria, por eso comprendemos que los modos de transición que viven los niños/as van configurando su trayectoria.

En esta tesis no hablamos de infancia sino de infancias en tanto participaron niños y niñas que por sus condiciones sociales, culturales, económicas reflejaron distintas posiciones en las que las particularidades de los contextos, los dispositivos institucionales y sus atributos personales intercedieron de forma que dieron lugar a experiencias positivas, pero también complejas en los recorridos vividos entre ambos escenarios. De esta forma retomamos el concepto propuesto por Frigerio (2006) quien refiere que:

/.../ el singular "infancia" nunca dio cuenta de la diversidad de modos de transcurrir un tiempo cronológico. Sabemos que una noción de infancia no alcanzó nunca a dar cuenta de los habitantes que nombra. No encontramos ningún correlato entre la pretensión de universalidad y el universo de los que se intenta nombrar (Frigerio, 2006: 40).

La autora referencia que la infancia siempre tuvo tantos rostros como sujetos singulares, tantas figuras como clases sociales, la noción de infancia corresponde a unos rasgos físicos, una seña de identidad, una conducta, una posición en la familia, un lugar en la sociedad por ello pensar en las infancias requiere pensar en términos de una identidad entendida como un trabajo psíquico y social siempre en reformulación por el que cada sujeto no cesa de construirse y ser construido (Frigerio, 2006: 328).

El interés puesto sobre las experiencias que los niños y niñas tienen en el tránsito educativo entre el nivel de educación inicial y atención integral para la primera infancia, el nivel de educación formal preescolar y el primer grado de básica primaria en escuelas públicas de la ciudad de Medellín y las expectativas de maestras frente a la trayectoria y transiciones de sus estudiantes se justifica en la ausencia de estudios culturales y socioeducativos que releven las experiencias de este grupo poblacional en el campo de la Educación Infantil. Debido a esta vacancia nos propusimos analizar las formas en que transitan y tienen lugar los pasajes de un nivel a otro porque sabemos que incidirán en las trayectorias que los niños-niñas irán configurando desde su ingreso a la educación formal hasta concluir su escolaridad obligatoria. 
El análisis frente a las trayectorias y las transiciones en la educación inicial y su articulación con la educación formal tuvo como punto de partida la experiencia de los sujetos (niños- niñas, maestras, agentes educativas); desde allí comenzamos nuestra indagación en base a un conjunto de preguntas que actuaron como guía del trabajo de campo:

- ¿Cómo configuran las trayectorias los niños-as, desde su experiencia por la transición que realizan entre el nivel de educación inicial atención integral (EIAI) -programa Buen Comienzo Medellín- el nivel de preescolar grado transición y el nivel de básica primaria-grado primero? ¿De qué forma esta experiencia favorece o desfavorece su escolarización?

- ¿Cuáles son las acciones que realiza el escenario educativo del nivel de educación inicial atención integral -programa Buen Comienzo Medellín- y el nivel de educación formal -grado transición y grado primero- para acompañar sus transiciones?

- ¿Qué mirada tienen las maestras, agentes educativas y coordinadoras frente a la trayectoria y transiciones de sus estudiantes en el paso que dan desde el nivel de (EIAI) al nivel de educación preescolar-grado transición y el primer grado de básica primaria en relación a la concepción de infancia, los currículos, las metodologías, la articulación, y las expectativas de aprendizaje para cada escenario?

- ¿Cuál es la representación social de infancia y la conceptualización de trayectoria y transición educativa que subyace en los lineamientos del nivel de educación inicial atención integral a la primera infancia y la Política de Cero a Siempre en Colombia?

\subsection{EI trabajo de campo}

El desarrollo de esta investigación se dio en dos escenarios educativos: por un lado, el nivel de educación inicial atención integral (EIAI)-Programa Buen Comienzo de la ciudad de Medellín y, por otro, el nivel de educación preescolar-grado transición y nivel de básica primaria grado primero. El programa Buen Comienzo fue creado por el Concejo de Medellín en el año 2004, y comenzó a operar en noviembre de 2006 con el objetivo de ofrecer una atención integral de manera universal a los niños-niñas desde la gestación hasta los seis años para promover el desarrollo integral, diverso e incluyente, en una perspectiva interdisciplinaria del ciclo vital, y a través de la protección de los derechos, mediante la 
coordinación inter-institucional de acciones y servicios. Según el Consejo Nacional de Política Económica y Social $\left(\mathrm{CONPES}^{4}\right)$,

El objetivo del Programa "Buen Comienzo", es el de promover el desarrollo integral, diverso e incluyente de los niños y niñas menores de 6 años, de los niveles I, II y III del Sisbén y los no afiliados al régimen contributivo, ni subsidiado, ni a los regímenes de excepciones; desde la perspectiva de áreas de derechos y por ciclos vitales de desarrollo humano, mediante el trabajo intersectorial, dirigido hacia la formulación e implementación de una política pública de infancia para la ciudad de Medellín, en cuatro grandes acciones: Seguridad Alimentaria y Nutricional, Cobertura Educativa y en Salud, Participación y Recreación, articulando éstas a los programas de la Administración que versen sobre estos mismos temas (CONPES ${ }^{5} 109$, 2007).

El programa reconoce que el cuidado y las condiciones adecuadas desde la gestación hasta los cinco años son vitales para el desarrollo humano y para la transformación social, cultural y económica de los países en vía de desarrollo. Por ello moviliza, a través de políticas que tienen como principio la universalidad, la indivisibilidad e interdependencia, planes y acciones estratégicas en temas de salud, nutrición, educación, protección y participación, con los cuales busca intervenir en las condiciones de vulnerabilidad y pobreza para prevenir, mitigar y proteger los derechos de las infancias. Los servicios ofrecidos dentro del programa están orientados a promover cuatro componentes básicos para el desarrollo integral de los niños-as: la atención en salud, la nutrición, la educación, la recreación, mediante la articulación inter-institucional e intersectorial orientada a la protección integral. Este se organiza bajo modalidades de atención como son: modalidad entorno familiar, modalidad jardines infantiles, modalidad institucional 8 horas, modalidad entorno institucional 5 horas

${ }^{4}$ El Consejo Nacional de Política Económica y Social — CONPES — fue creado por la Ley 19 de 1958. Ésta es la máxima autoridad nacional de planeación y se desempeña como organismo asesor del Gobierno en todos los aspectos relacionados con el desarrollo económico y social del país. Para lograrlo, coordina y orienta a los organismos encargados de la dirección económica y social en el Gobierno, a través del estudio y aprobación de documentos sobre el desarrollo de políticas generales.

${ }^{5}$ El Conpes 109 Es un documento que presenta, la política Pública Nacional de Primera Infancia "Colombia por la primera infancia". La política nacional, surge como resultado de un proceso de movilización social, orientada a dar un nuevo significado a la temática de oportunidades efectivas de desarrollo de la primera infancia en el país. 
ludotekas, modalidad institucional complementaria (atención en la noche) y modalidad fortalecimiento a centros educativos privados.

El nivel de Educación formal es aquel que se imparte en establecimientos educativos aprobados, en el marco de la Constitución de 1991 y la Ley General de Educación №115/94, en una secuencia regular de ciclos lectivos con sujeción a pautas curriculares progresivas, conducentes a grados y títulos. La educación en Colombia es un derecho ciudadano y una prioridad del gobierno. Actualmente la obligatoriedad es de 10 años, desde los 5 hasta los 15 años de edad, y se organiza en (3) niveles: a) El preescolar ${ }^{6}$ que comprenderá mínimo un grado obligatorio (denominado Grado Transición); b) La educación básica con una duración de nueve (9) grados que se desarrollará en dos ciclos: educación básica primaria de cinco (5) grados y educación básica secundaria de cuatro (4) grados; c) La educación media con una duración de dos (2) grados. En esta investigación participan los niños-niñas, maestras y directivos maestras que forman parte del nivel de preescolar-grado transición y nivel de la básica primaria-grado primero de la Institución Educativa Ciudadela Nuevo Occidente Medellín.

De esta investigación participaron las seis (6) agentes educativas maestras que forman parte de la modalidad jardines infantiles (Jardín Infantil la Aurora). A través de esta modalidad se ofrece atención integral a niños y niñas desde los dos (2) años y hasta los cinco (5) años, en jornadas de ocho (8) horas diarias, durante cinco (5) días a la semana y niños y niñas desde los tres meses y hasta los 23 meses. Su infraestructura ofrece diferentes espacios de interacción y disfrute entre los que se pueden encontrar: sala cuna, sala de lactancia, lactario, sala de gateadores, salas de desarrollo, nichos para juegos, zonas de espacio libre, huerta, patio, servicio de alimentación, zonas verdes, cocina, sala de agentes educativos y unidades sanitarias. Allí cuentan con materiales polivalentes que favorecen el juego, la imaginación y la expresión creadora.

Las instituciones que se seleccionaron se corresponden con el sector Nuevo Occidente zona de expansión del sector de Pajarito (Robledo) y Zona rural de Corregimiento de San

\footnotetext{
${ }^{6}$ El decreto (2247/97) reglamenta la prestación del servicio público educativo del nivel Preescolar. Comprende tres (3) grados, así: Pre-jardín, dirigido a educandos de tres (3) años de edad. 2. Jardín, dirigido a educandos de cuatro (4) años de edad. 3. Transición, dirigido a educandos de cinco (5) años de edad y que corresponde al grado obligatorio constitucional de la Educación Formal. Por ello de ahora en adelante cuando hablemos del grado transición- estamos haciendo referencia a preescolar
} 
Cristóbal, lugar que la alcaldía destinó para la reubicación de familias que vivían en lugares por donde construyeron autopistas, parques, centros recreativos y obras públicas del desarrollo urbano, familias desplazadas provenientes de todas las regiones del país y de los barrios en conflicto, familias que depositaron sus ahorros en la compra de vivienda de los programas de interés social y familias reubicadas por situaciones sociales y biológicas afectados por incendios y desastres naturales.

Uno de los criterios de inclusión en esta investigación fue que las instituciones trabajaran de forma articulada en el sector, por ello se seleccionó el Jardín de Calidad de la Aurora Institución de Educación Inicial Atención Integral a la Primera Infancia que participa del programa Buen Comienzo de la alcaldía de la ciudad de Medellín, y la Institución Educativa Ciudadela Nuevo Occidente de carácter oficial que ofrece los niveles de preescolar, básica y media académica, y fue creada para dar solución a la demanda educativa de las familias que llegaron a las diferentes urbanizaciones provenientes de barrios vulnerables por la pobreza y la violencia. De este modo, los niños y niñas que participaron de esta investigación transitaron del jardín de calidad la Aurora a la institución educativa Ciudadela Nuevo Occidente para continuar con su ciclo escolar.

La población objeto para esta investigación, estuvo constituida por maestras, directivos docentes, maestra de apoyo, agentes educativas y niños-niñas entre los 5 y 8 años de edad. Se realizaron 14 entrevistas en profundidad a maestras y agentes educativas de ambos sistemas estructuradas de la siguiente forma:

- Institución de Educación Inicial Jardín de calidad la Aurora-Buen Comienzo: se entrevistaron 6 agentes educativas de la siguiente forma: (3) entrevistas a agente educativa docente, (1) entrevista a agente educativa educadora especial psicosocial, (1) entrevista a la coordinadora del Jardín Infantil, (1) entrevista a la coordinadora del componente de transiciones del programa Buen Comienzo.

- Instituciones de Educación Formal Ciudadela Nuevo Occidente (grado transición-grado primero): se realizaron 8 entrevistas de la siguiente forma: (3) entrevistas a maestras de preescolar grado transición, (3) a maestras del grado primero, (1) a la coordinadora académica de la institución y (1) a la maestra de apoyo. 
Del mismo modo en esta institución se trabajó con 11 niños/as de los grados de transición [6 niñas y 5 niños], entre los 5 y 6 años de edad; y con 6 niños/as de los grados de primero [2 niñas y 4 niños] entre los 6 y 7 años algunos próximos a cumplir los 8 años de edad. Con ellos se realizaron 14 encuentros, 6 con los de transición y 6 con los niños/as de primero más 2 encuentros todos juntos, bajo diferentes técnicas interactivas como el dibujo, la fotografía, los videos, los juegos de roles, las visitas guiadas, las líneas de tiempo, las entrevistas grupales, los diálogos individuales, los cuentos pictográficos, entre otros. El principal criterio de inclusión que se tuvo en cuenta fue que los niños-niñas contaran con entre 5 y 8 años de edad y que estuvieran matriculados en los grados de transición y primero en una institución de Educación Formal pública, que a su vez articulara con una institución del programa Buen Comienzo, así mismo que en su totalidad todos hubieran pasado por el programa Buen Comienzo- Jardín Infantil.

\subsection{Las estrategias metodológicas}

Con el fin de alcanzar los objetivos de esta investigación que buscaba develar, desde las voces de los niños/as, la experiencia construida alrededor de la trayectoria y transiciones educativas, así como las expectativas y visiones de las/los maestras, se asumió un diseño cualitativo encuadrado dentro del paradigma hermenéutico-interpretativo cuyo interés se centró en interpretar lo narrado por los niños/as y maestras-agentes educativas para conocer de manera natural como configuraban y que sentidos atribuían a sus trayectorias y transiciones infantiles. Aquí, la categoría experiencia se presentó como un "articulador conceptual fuerte, en tanto permitió vincular analíticamente la realidad social con los modos en que es incorporada y procesada por los sujetos (y al mismo tiempo, permanentemente producida)" (Cerletti, 2016: 85).

Creswell (2007) plantea que las investigaciones hermenéuticas permiten la comprensión de los fenómenos sociales. Este proceso es de tipo circular, ya que se respetó los criterios de validez y confiabilidad, se volvió al campo a profundizar en preguntas para confirmar los hallazgos. En este sentido, Patton (1982) expone que las investigaciones inscritas en este enfoque parten de la descripción detallada de situaciones, eventos, personas, conductas, y/o interacciones y de sus manifestaciones, las cuales se generan en 
circunstancias, contextos o situaciones que emergen socialmente de la práctica y que, en última instancia, se configuran como modelos culturales construidos por el inconsciente y transmitidos por los otros a partir de la experiencia personal.

Este estudio permitió analizar y comprender las diferentes situaciones y significados que le dan los niños y niñas a los recorridos y tránsitos que realizan entre el nivel de educación inicial atención integral para la primera infancia y la educación formal nivel de preescolar y básica primaria. Sus voces acompañadas por las de las maestras, directivos y agentes educativas evidenciaron diversos significados relacionados directamente con sus realidades y experiencias. La realidad social es, así concebida, una realidad construida con base en los marcos de referencia de los actores. Tal como lo define Guber, "lo real se compone de fenómenos observables y de la significación que los actores le asignan a su entorno y a la trama de acciones que los involucra; en él se integran prácticas y nociones, conductas y representaciones" (Guber, 2004: 47).

Se utilizaron los procedimientos de la teoría fundada (Corbin y Strauss, 2002) para establecer las categorías a partir de la recolección de datos en las entrevistas en profundidad y en el enfoque mosaico implementado para los niños y niñas, agentes educativas y maestras. Ello posibilitó la construcción de conceptos y teorías que emergieron de los discursos. Es importante explicar que dicha teoría fundada se empleó como estrategia metodológica, no como teoría en sí, debido a que se elaboró un marco teórico con el cual se llegó al trabajo de campo. Los autores señalan sobre este aspecto que "La teoría fundada, se refiere a una teoría derivada de datos recopilados de manera sistemática y analizados por medio de un proceso de investigación" (Corbin y Strauss, 2002: 13).

Para rescatar las voces y la experiencia de los sujetos se hizo uso de diversas técnicas e instrumentos de indagación, entendidas estas como las "herramientas del investigador para acceder a los sujetos de estudio y su mundo social; dentro de una reflexividad en sentido específico, las técnicas son una serie de procedimientos, con grado variable de formalización -y ritualización-, que permiten obtener información en una situación de encuentro, en el marco de una relación social.” (Guber, 2004: 56). Con las maestras y agentes educativas se utilizó la entrevista en profundidad que consiste en una serie de intercambios discursivos 
entre alguien que interroga y alguien que responde. Taylor y Bogdan (1986) definen la entrevista en profundidad como:

/.../ reiterados encuentros cara a cara entre el investigador y los informantes, encuentros éstos dirigidos hacia la comprensión de las perspectivas que tienen los informantes respecto de sus vidas, experiencias o situaciones, tal como las expresan con sus propias palabras. Las entrevistas en profundidad siguen el modelo de una conversación entre iguales, y no de un intercambio formal de preguntas y respuestas. Lejos de asemejarse a un robot recolector de datos, el propio investigador es el instrumento de la investigación, y no lo es un protocolo o formulario de entrevista. El rol implica no sólo obtener respuestas, sino también aprender qué preguntas hacer y cómo hacerlas (Taylor y Bogdan, 1986: 194).

Para esta entrevista se utilizó un guion que se elaboró a partir de la necesidad de dar respuesta a los objetivos de investigación, los cuales establecen la ruta desde la cual se determinan las preguntas que orientaron el proceso de recolección de información. La guía se encuentra estructurada en cuatro partes destinada a caracterizar su historia de vida, obtener información sobre la configuración, contenidos, prácticas y experiencias de las participantes. Esta guía fue sometida a la evaluación de pares expertos, así como a una prueba piloto. (Ver Anexo II)

Con los niños/as las técnicas a utilizar partieron del Enfoque Mosaico comprendido como una forma productiva de conocer e incluir la perspectiva de los niños en los procesos de investigación respecto a los ambientes escolares donde se desenvuelven. El método mosaico fue desarrollado por Alison Clark y Peter Moss (2001), se compone de actividades prácticas y dinámicas que permiten la participación de los niños y niñas y se centra en las experiencias vividas por ellos/as, quienes se convierte en los principales ejecutores del método y en los/as protagonistas durante el proceso investigador. Es un multimétodo que considera a los niños/as como sujetos competentes, activos y creadores de experiencias significativas en sus ambientes sociales. Representa la unión de diferentes métodosherramientas como él dibujo, las fotografías, las conversaciones, las grabaciones, entre otras. Para sus autores es importante comprender que «escuchar» no es un proceso limitado al mundo hablado. 
Escuchar las voces de los niños incluye, además de la información oral, otras muchas formas creativas de expresar la vida y las experiencias de los participantes, como son el dibujo, la fotografía, los mapas, las visitas guiadas por los espacios en los que se encuentran o el juego de roles. Estas formas de «lenguajes» son, además, accesibles incluso a los niños más pequeños o a aquellos con limitaciones en la comunicación. Es la conjunción de estas estrategias la que viene a configurar un «mosaico» de perspectivas para entender más ampliamente la visión de los niños (Clark y Moss, 2006: 205).

A continuación, se detallan las herramientas usadas en el trabajo de campo con las niñas y los niños siguiendo el enfoque mosaico. Dichas herramientas fueron:

Tabla 1 Herramientas Método Mosaico implementadas en la Investigación

\begin{tabular}{|c|c|}
\hline HERRAMIENTA & DESCRIPCIÓN \\
\hline Dibujos y gráficos - Plástico & $\begin{array}{l}\text { Los niños plasmaron sus ideas de manera visible mediante dibujos } \\
\text { registro gráficos y representaciones plásticas }\end{array}$ \\
\hline Conversación con los niños & Preguntas abiertas para dialogar de manera individual o en grupo \\
\hline Toma de fotografías & Los niños fotografiaron aquellas situaciones relevantes para ellos \\
\hline $\begin{array}{l}\text { Conformación del álbum-Línea de } \\
\text { tiempo-discusión de imágenes }\end{array}$ & $\begin{array}{l}\text { Los niños acomodaron diversas fotografías e imágenes conversando } \\
\text { alrededor de ellas y estructurando una línea de tiempo }\end{array}$ \\
\hline Recorridos - salida guiada & $\begin{array}{l}\text { Los niños-as realizaron recorridos por los lugares más significativos de } \\
\text { su institución- salida guiada }\end{array}$ \\
\hline Elaboración de mapas & $\begin{array}{l}\text { Representaciones de espacios con algún acontecimiento mostrado por } \\
\text { fotos o dibujos }\end{array}$ \\
\hline Conversaciones & Pláticas informales con los pedagogos, asistentes o familiares \\
\hline Cuentos y video-reportaje & $\begin{array}{l}\text { Los niños cuentan historias y realizan grabaciones- entrevistas a sus } \\
\text { amigos frente a sus propias experiencias- además de cuentos } \\
\text { pictográficos }\end{array}$ \\
\hline
\end{tabular}

Fuente: Elaboración propia-adaptada de la tabla de Clark, 2008:33-Actividades realizadas en los 14 encuentros con los niños/as

La aplicación de esta herramienta permitió la participación activa de los niños y niñas. La mayoría de estos métodos fueron de carácter grupal, aunque también se aplicaron métodos participativos de carácter individual, en el marco de las entrevistas, con actividades de dibujo y juego (ver anexo III). La realización de las actividades se realizó bajo el consentimiento de los padres de familia, de las maestras y de los mismos niños y niñas (ver anexo IV). Para iniciar los encuentros se realizaron actividades grupales en las que se 
presentó la investigación y los objetivos, se contestaron todas sus dudas y se les proporcionó la información que ellos solicitaron. Los encuentros no se limitaron a responder preguntas sino a una comunicación bidireccional e igualitaria en la construcción conjunta de experiencias en las que se articularon formas creativas de expresar la vida y las experiencias biográficas.

Los niños y niñas tuvieron distintas oportunidades y formas de expresar sus puntos de vista, con actividades que involucraban el juego, el dibujo, la conversación, la fotografía, el video, el sociodrama, los paseos por la escuela y la comunidad. Se hicieron adaptaciones sobre el mismo método para su aplicación a cada grupo de edad de acuerdo a sus características. En este sentido, se puede señalar que la información generada en las entrevistas en profundidad a las maestras, agentes educativas y las técnicas implementadas con los niños y niñas se convirtieron en datos significativos en tanto evidenciaron su realidad, sus pensamientos, sentimientos, percepciones y experiencias, lo que contribuyó significativamente en la construcción de cada uno de los capítulos.

Así mismo se utilizó la indagación documental referida como el proceso de búsqueda, evaluación y selección de fuentes de información sobre el problema o la pregunta de investigación. De esta forma se realizó un rastreo en los diferentes documentos oficiales del Ministerio de Educación Nacional (MEN) que hacen referencia a la educación inicial y educación preescolar, especialmente en lo relacionado a transiciones y trayectorias. Se empleó el análisis de contenido como técnica para describir objetiva y sistemáticamente el contenido manifiesto en los documentos (Fernández, 2002).

La información obtenida se analizó desde un enfoque interpretativo, describiendo lo que se comprendió del fenómeno social estudiado. Para analizar la información se utilizó el método de comparación constante para construir categorías emergentes, el análisis fue inductivo; es decir, se hizo de lo particular a lo general, a partir de la información concreta se descubren y construyen las categorías generales que permitieron hacer interpretaciones. De acuerdo con Glaser \& Straus y Lincoln \& Guba “el método de comparación constante es una de las maneras para conducir un análisis inductivo de datos cualitativos" (en Maykut y Morehouse, 1999: 127). De esta forma se realizó una triangulación de información a partir de procedimientos de codificación abierta, axial y selectiva los cuales permitieron organizar, 
ordenar y estructurar la información de acuerdo con las unidades de análisis, códigos, para sintetizar y analizar los datos en categorías.

El procedimiento inició por la codificación abierta donde se desarrolló el proceso analítico por medio del cual se identificaron los conceptos y se descubrieron los datos, sus propiedades y dimensiones. "En la conceptualización de fenómenos, como representación abstracta de un acontecimiento, los datos se descomponen en incidentes, los cuales se nombran, suelen llamarse códigos" (Glaser y Strauss, 1967). Posteriormente, se continuó con la codificación selectiva en la cual se integraron y se depuro la teoría; en este proceso se eligieron varias categorías que representaban el tema central de la investigación a partir de técnicas como la escritura del argumento de la historia, diagramación, escritura de memorandos, discusión con la asesora. Por último, se refinó la teoría, se quitaron datos excedentes y se completaron las categorías poco desarrolladas. Se utilizó el Software: Atlas ti 6.0.

También se aplicó la codificación axial, donde "se relacionan categorías a sus subcategorías, ocurre alrededor del eje de una categoría, y enlaza las categorías en cuanto a sus propiedades y dimensiones" (Corbin y Strauss, 2002: 134). Los ejes preestablecidos para esta codificación axial se unieron a los que emergieron de los datos recopilados.

Para el análisis de las entrevistas y actividades realizadas con los niños y niñas se tuvieron en cuenta las notas del diario de campo en el que se detallaron aspectos como: lenguaje corporal, contexto en el que se hicieron las entrevistas, emociones y sentimientos expresados por los participantes, todos ellos permitieron ampliar la posibilidad de interpretación de lo dicho y lo no dicho durante el proceso. Se utilizó grabadora de voz, con previo consentimiento de los/as entrevistadas, los registros fueron transcritos y luego analizados detalladamente.

Se realizó muestreo intencional para las entrevistas en profundidad, que es aquel en el que los sujetos de la muestra no son elegidos al azar sino de acuerdo a las características establecidas según los objetivos. En este sentido, se eligieron los actores que respondían a las características establecidas en la investigación. Este tipo de muestreo facilita la transferibilidad de la investigación (Guba, 2008). El principio para establecer la cantidad de participantes a entrevistar fue el de saturación teórica de las categorías (Corbin y Strauss, 
2002), la cual se alcanzó cuando la información recopilada de los participantes no tuvo novedades que fueran susceptibles de reportar.

Ilustración 2 Síntesis de transformación de datos

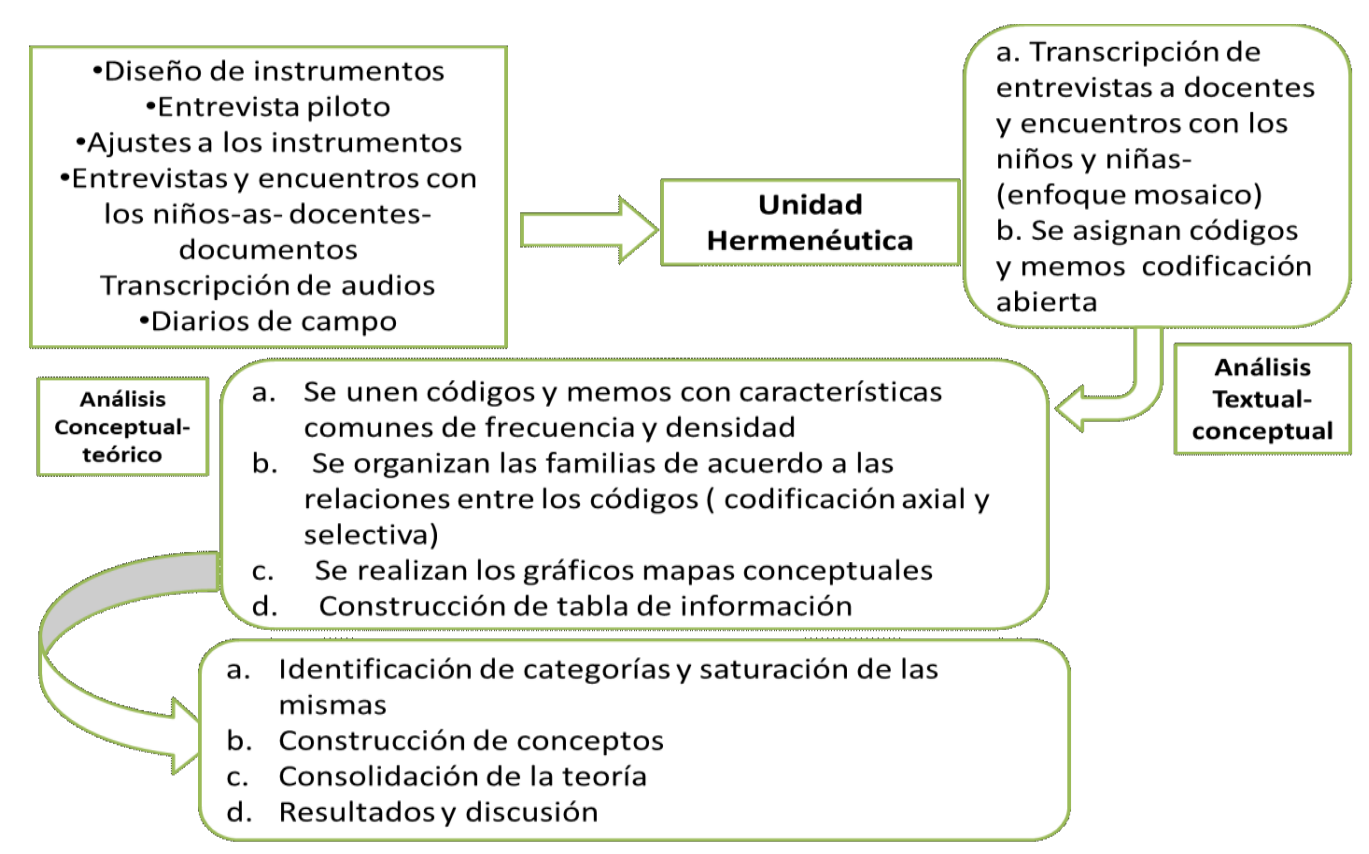

Fuente: elaboración propia

A partir del análisis textual y con los datos ya transcritos, se realizó el análisis de la información asignando códigos. Estos se determinaron de acuerdo con las características comunes, y a partir de la frecuencia y densidad que se presentaban en los documentos primarios se dio paso a la organización de las familias de acuerdo a la relación entre los códigos; posteriormente surgieron los mapas conceptuales, y de allí se inició el proceso de consolidación de la teoría que emerge del discurso de las maestras directivos, maestras agentes educativas, niños y niñas, guardando un estricto manejo de la información.

Como marco que guió la investigación se tuvieron consideraciones éticas con los maestras agentes educativas y niños-niñas. Para ello se les entregó a las maestras previamente el formato del consentimiento informado, donde se presentó la información de la investigación, los objetivos, el tiempo que demandaba las entrevistas y se les indicó que la participación por parte de ellas en el proyecto era estrictamente voluntaria (Ver Anexo V). 
Se clarificó que la información era confidencial, no tenía ningún tipo de retribución económica y se realizaría grabación. Las grabaciones no se difundieron en ningún medio, constituyeron un apoyo para el trabajo de investigación. Con los niños y niñas se tuvieron presente de acuerdo con lo planteado por Cocks (2006) tres momentos claves: la presentación de la información, la comprensión por parte del niño y la emisión de una respuesta al respecto en el consentimiento informado.

Tabla 2 Entrevistas y encuentros de trabajo de campo

\begin{tabular}{|c|c|c|c|}
\hline \multicolumn{2}{|c|}{$\begin{array}{c}\text { Entrevista a profundidad maestras y agentes } \\
\text { educativos }\end{array}$} & \multicolumn{2}{|c|}{ Encuentros con los niños y niñas } \\
\hline Entrevista & Fecha & Encuentros & Fecha \\
\hline Docente de Transición 01 & $10 / 10 / 2017$ & Encuentro-01 transición & $12 / 09 / 2017$ \\
\hline Docente de Transición 02 & $11 / 10 / 2017$ & Encuentro-01 Primero & $19 / 09 / 201$ \\
\hline Docente de Transición 03 & $12 / 10 / 2017$ & Encuentro-02 transición & $20 / 09 / 2017$ \\
\hline Docente de Primero 01 & $24 / 10 / 2017$ & Encuentro-02 Primero & $3 / 10 / 2017$ \\
\hline Docente de Primero 02 & $25 / 10 / 2017$ & Encuentro-03 transición & $5 / 10 / 2017$ \\
\hline Docente de Primero 03 & $26 / 10 / 2017$ & Encuentro-03 Primero & $5 / 10 / 2017$ \\
\hline Maestra de apoyo & $21 / 11 / 2017$ & Encuentro-04 transición & $17 / 10 / 2017$ \\
\hline Directivo docente & $1 / 12 / 2017$ & Encuentro-04 Primero & $24 / 10 / 2017$ \\
\hline $\begin{array}{l}\text { Grupo Focal maestras de } \\
\text { primero y transición }\end{array}$ & $30 / 11 / 2017$ & Encuentro-05 transición & $8 / 12017$ \\
\hline Agente Educativa docente 01 & $11 / 12 / 2017$ & Encuentro-05 Primero & $15 / 11 / 2017$ \\
\hline Agente Educativa docente 02 & $12 / 12 / 2017$ & Encuentro-06 transición & $22 / 11 / 2017$ \\
\hline Agente Educativa docente 03 & $13 / 12 / 2017$ & Encuentro-06 Primero & $22 / 11 / 2017$ \\
\hline Agente educativa psicosocial & $14 / 12 / 2017$ & Encuentro Colectivo & $7 / 09 / 2017$ \\
\hline Agente Educativo coordinador & $15 / 12 / 2017$ & Encuentro Colectivo & $23 / 02 / 2018$ \\
\hline $\begin{array}{l}\text { Coordinadora programa Buen } \\
\text { Comienzo }\end{array}$ & $7 / 03 / 2018$ & & \\
\hline
\end{tabular}

Fuente: Elaboración propia 


\subsection{Un recorrido posible}

Esta tesis se estructura en 6 partes:

1. Primera parte: recoge la contextualización del problema-en el capítulo I Problema objetivos y justificación

2. Segunda Parte: comprende la aproximación al campo de estudio- recoge los capítulos II- trayectorias y transiciones en la educación Infantil y Capitulo III- Marcos políticos que regulan las transiciones en Colombia

3. Tercera parte: Articulaciones entre la Educación Infantil- recoge el capítulo IV: Articulaciones necesarias entre la Educación Inicial y la Educación Formal

4. Cuarta Parte: Configuración de las trayectorias y transiciones en las voces de las maestras y agentes educativas- recoge el Capítulo V: Modos en que se configuran las trayectorias y transiciones de los niños y niñas; el Capítulo VI: Sentires de las maestras frente al proceso de trayectoria y transición

5. Quinta parte: configuración de las trayectorias y transiciones en las voces de los niños y niñas- recoge capitulo VII Construcción de la transición de los niños y niñas entre la Educación Inicial y la Educación Formal y capítulo VIII-Experiencias y sentires de los niños y niñas frente a su proceso de transición

6. Sexta parte: reflexiones y consideraciones finales

\section{PRIMERA PARTE}

La primera parte recoge la contextualización del problema, presenta la problematización del objeto de estudio, contexto de la investigación, trabajo de campo y las estrategias metodológicas; se compone del capítulo I contextualización del problema, en donde el lector identificará los retos que enfrenta Colombia en cuanto al acompañamiento de los niños y niñas por el sistema educativo, especialmente en el cambio que hacen desde la Educación Inicial-Atención Integral para la Primera Infancia (EIAIPI) a la Educación Formal-Preescolar (grado transición) y posteriormente al primer grado de la Educación Básica Primaria. 


\section{SEGUNDA PARTE}

La segunda parte comprende la aproximación al campo de estudio. Presenta una contextualización frente a la construcción epistemológica del concepto de trayectoria y transición y se responde a la pregunta ¿cuál es la representación social de infancia y la conceptualización de trayectoria y transición educativa que subyace en los lineamientos del nivel de educación inicial atención integral a la primera infancia y la Política de Cero a Siempre en Colombia?

Reúne los capítulos II- trayectorias y transiciones en la Educación Infantil el que releva las diferentes conceptualizaciones desde diversas disciplinas en torno del concepto de trayectorias y transiciones. Aquí se analizan las corrientes psicológicas y socioculturales que han abordado estas categorías y sus implicancias en el campo de la educación en Colombia; y el capítulo III- Marcos políticos que regulan las transiciones en Colombia que tiene como objetivo relevar en los documentos oficiales que regulan el proceso de transiciones educativas en Colombia las representaciones sociales sobre infancia, la concepción y perspectivas teóricas que sustentan la trayectoria y transición.

\section{TERCERA PARTE}

La tercera parte articulaciones entre la Educación Infantil presenta un análisis con respecto a la articulación entre la Educación Inicial y la Educación Formal, responde a la pregunta ¿cuáles son las acciones que realiza el escenario educativo del nivel de educación inicial atención integral -programa Buen Comienzo Medellín- y el nivel de educación formal -grado transición y grado primero- para acompañar sus transiciones?

Se compone del capítulo IV: Articulaciones necesarias entre la educación inicial y la educación formal y centra el análisis en la articulación horizontal y vertical, en la entrega y la recepción pedagógica de los niños y niñas entre el sistema de Educación Inicial Atención Integral a la Primera Infancia (EIAIPI) y el sistema de Educación Formal grado transición y primero; asimismo caracteriza las experiencias que tienen las maestras con respecto a la articulación inter-institucional contemplando los puntos críticos con los que un sujeto se puede encontrar en su tránsito por el sistema educativo y las implicancias que tendría formalizar lo informal -propio de la educación inicial- en una escuela para la niñez. 


\section{CUARTA PARTE}

La Cuarta parte: configuración de las trayectorias y transiciones en las voces de las maestras y agentes educativas presenta la configuración de las trayectorias y transiciones en las voces de las maestras y agentes educativas. Responde a las preguntas ¿qué mirada tienen las maestras, agentes educativas y coordinadoras frente a la trayectoria y transiciones de sus estudiantes en el paso que dan desde el nivel de EIAI al nivel de educación preescolar-grado transición y el primer grado de básica primaria en relación a la concepción de infancia, los currículos, las metodologías, la articulación, y las expectativas de aprendizaje para cada escenario?

Se compone del capítulo $\underline{\mathrm{V} \text {-Modos en que se configuran las trayectorias y transiciones }}$ de los niños y niñas en el que se analizan los modos en que se configuran las trayectorias educativas de los niños y niñas de 0 a 8 años desde el momento que ingresan a la Educación Inicial (Programa Buen Comienzo- modalidad institucional) y pasan por el Preescolar y la Educación Básica Primaria. A su vez, en este capítulo se nombran y describen los ámbitos educativos, factores y/o variables que conforman las trayectorias y se describe la forma como los niños y niñas viven la experiencia de la transición en el cambio entre escenarios educativos; y finalmente el capítulo VI: Sentires de las maestras frente al proceso de trayectoria y transicion, apartado que muestra los sentires que expresan las maestras del sistema de educación formal y agentes educativas del sistema de educación inicial frente a los temores y las angustias que les ocasiona este proceso de transición entre ambos sistemas. Asimismo describe las acciones de acompañamiento a los niños-niñas y las recomendaciones que ellas realizan.

\section{QUINTA PARTE}

Quinta parte: configuración de las trayectorias y transiciones en las voces de los niños y niñas responde a la pregunta ¿cómo configuran las trayectorias los niños-as, desde su experiencia por la transición que realizan entre el nivel de educación inicial atención integral (EIAI) -programa Buen Comienzo Medellín- el nivel de preescolar grado transición y el nivel de básica primaria-grado primero? ¿de qué forma esta experiencia favorece o desfavorece su escolarización? Se trabaja el ámbito personal de la trayectoria en tanto se referencia la historia de vida de los niños y niñas, sus atributos, dominios, saberes, estado 
emocionales, se describen las relaciones interpersonales culturales y sociales, es decir, se analizan los factores y variables que inciden en la construcción de su identidad y la configuración de su trayectoria.

Este apartado recoge los capítulos VII Construcción de la trayectoria de los niños y niñas entre la Educación Inicial y la Educación Formal en el que se describe y analiza la forma como son nombrados los niños y niñas dentro del contexto escolar; conjuga las voces de los niños y niñas con la de las maestras y agentes educativos, y busca analizar de manera interseccionada los factores sociales, familiares e individuales que interceden en las historias de vida de las niñas-niños y en la forma como los niños y niñas construyen su trayectoria educativa. Y finalmente el capítulo VIII-Experiencias y sentires de los niños y niñas frente a

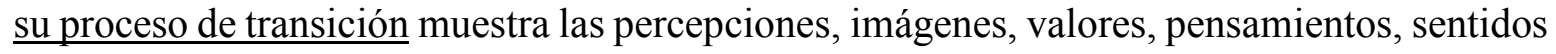
y símbolos que los niños y niñas construyen frente a su experiencia en los tránsitos que establecen de un nivel a otro o entre escenarios educativos, analiza las implicaciones de una transición en cuanto a la estructura de los saberes, aprendizajes, y el currículo; además recoge y sistematiza la valoración que hacen los niños y niñas de su experiencia escolar, los vínculos afectivos que tejen con sus pares y maestros, el juego, las actividades rectoras, el lugar de los espacios educativos y zonas de esparcimiento.

\section{SEXTA PARTE}

Sexta parte: reflexiones y consideraciones finales presenta las principales conclusiones que se recogen en cada uno de los capítulos, da cuenta del resultado de la tesis. 


\section{SEGUNDA PARTE}

\section{APROXIMACIÓN AL CAMPO DE ESTUDIO}

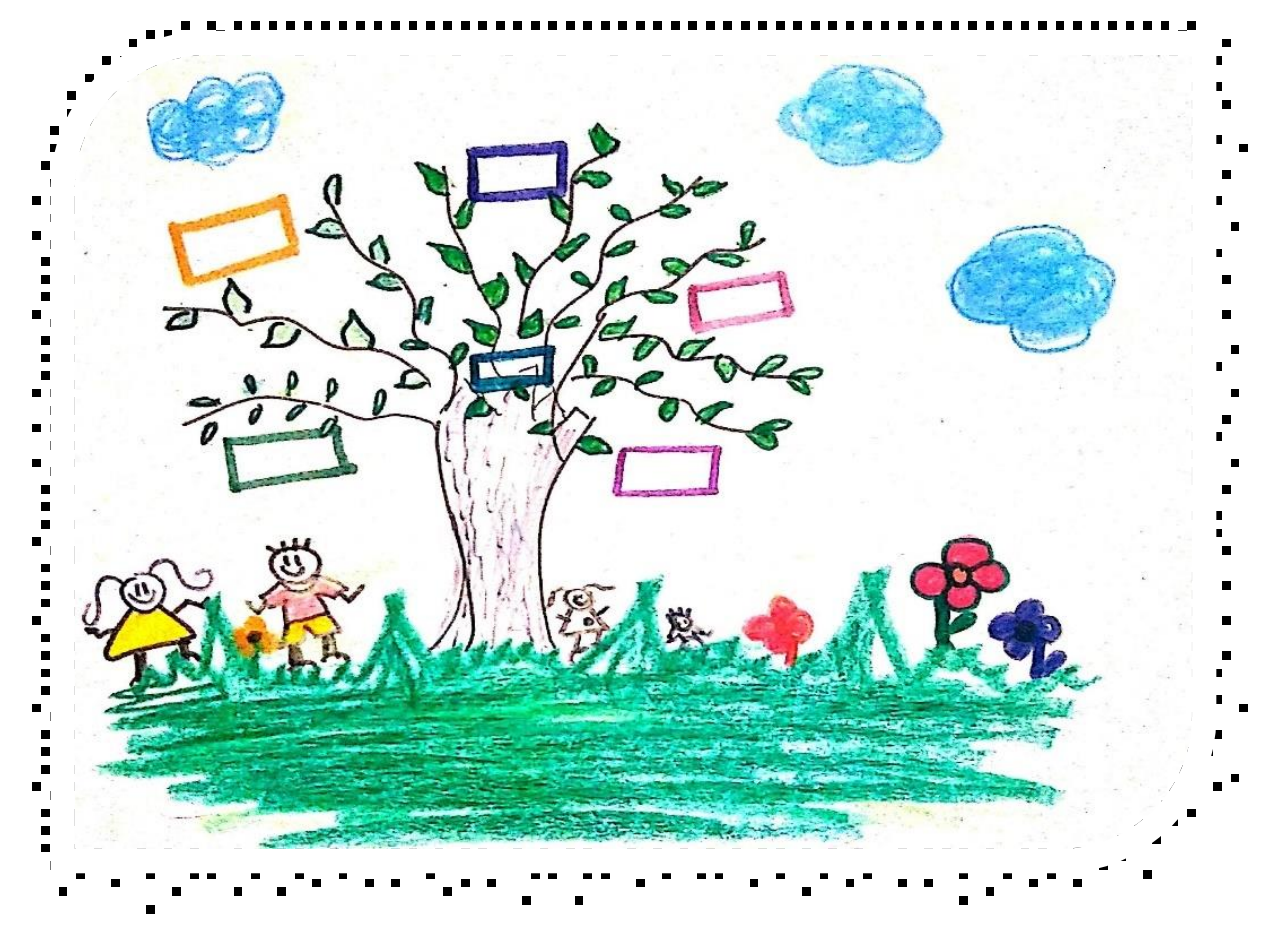

Frecuentemente hay más que aprender de las preguntas inesperadas de un niño que de los discursos de un hombre (John Locke 1632-1704) 


\section{Capitulo II}

\section{Trayectorias y transiciones en la Educación Infantil}

\section{Introducción}

El concepto de trayectoria recupera la experiencia de los sujetos a lo largo de su vida, en tanto no solo refiere a los recorridos del sujeto sino que al interpelar a las instituciones educativas se convierte en un eje trasversal para comprender las respuestas que dan los sujetos frente a las propuestas pedagógicas, las expectativas y exigencias en cada uno de los contextos escolares por el que las niñas y niños transitan. El ingreso a la escolaridad y los pasos que se dan entre ellos constituye un desafío tanto para las maestras, los agentes educativos, los niños y niñas, las familias respecto al logro de los aprendizajes y la adaptación al nuevo contexto educativo.

Para analizar las trayectorias escolares es necesario considerar tanto al sujeto como a la institución que lo recibe, producir una mirada compleja que incluya la dimensión individual como colectiva, dado que el sujeto sigue un recorrido en el que se apropia de un conjunto de prácticas y saberes que a su vez afectan a las transiciones porque se pone en juego un sin número de factores que cada persona va sorteando en él camino. Por ejemplo, en la Educación Infantil el cambio en las metodologías de enseñanza, los mecanismos institucionales que regulan el tiempo de trabajo, y las construcciones políticas que orientan el proceso de transición en los entornos educativos representan componentes determinantes en las experiencias, aprendizajes y adaptaciones. De ahí que se afirme que si hay una buena transición los niños y niñas van a desarrollar su capacidad de adaptarse a otros cambios que vendrán en su vida y contar con oportunidades de aprendizaje que potenciarán su desarrollo. Por el contrario, si el paso de estas transiciones es doloroso esto influirá en la adaptación, en los procesos cognitivos, emocionales y afectará su trayectoria escolar.

En este sentido, y teniendo presente que Colombia enfrenta actualmente retos significativos en cuanto al acompañamiento de los niños y niñas por el sistema educativo, especialmente en la transición que hacen desde la atención integral para la primera infancia y la educación preescolar y primer grado de la básica primaria. En esta investigación las 
transiciones se centran como foco problemático y de interés para comprender las trayectorias individuales de los niños-niñas, sus experiencias de vida, y la incidencia de los factores sociales, políticos, culturales, familiares, institucionales y personales, en el campo educativo de la Educación Infantil. Cada cambio que el niño-niña hace de ciclo, grado, modalidad, representa y constituye una forma de apropiar, comprender e incorporar, diversos códigos que en correlación con las estructuras de ese campo inscriben formas de ser, actuar y de pensar.

A continuación, presentaremos las diferentes perspectivas y enfoques utilizados en la investigación socioeducativa dirigida a comprender los recorridos seguidos por niñas-niños y jóvenes en el sistema educativo.

\subsection{Corrientes del curso de vida: trayectorias y transiciones en la Educación}

La corriente de curso de vida surge como una propuesta enmarcada en diferentes disciplinas como la sociología, la historia, la psicología y la demografía. Desde los años 60 del siglo XX, esta perspectiva surge en el campo de la Psicología Evolutiva a partir de estudios longitudinales que se enfocaban en el envejecimiento, el desarrollo humano, el estudio de la salud de la población como un fenómeno dinámico y heterogéneo ( $\mathrm{O}^{\prime}$ Rand y Krecker, 1990: 248). En la década de 1970 comenzó a desarrollarse plenamente esta perspectiva, y desde entonces se han destacado las contribuciones de uno de sus principales creadores, el sociólogo estadounidense Glen Elder (1974, 1999). Esta perspectiva se ha difundido a través de dominios sustantivos y límites disciplinarios en las ciencias sociales y del comportamiento y ha construido redes conceptuales entre el desarrollo, el entorno cambiante del individuo, las influencias históricas, y la naturaleza dinámica recíproca del cambio continuo de las macroestructuras y las vidas humanas.

Para la década de 1990 esta perspectiva se orientó de acuerdo a los estudios de Elder como una orientación teórica para el estudio de las vidas individuales. Sin embargo, es preciso señalar que el curso de vida fue caracterizado en un primer momento como una perspectiva (Elder, 1975), años más tarde como un paradigma (Elder, 1995), y a partir de 1997 se ha estructurado como teoría, atravesada por debates y tensiones que ponen en duda su alcance (Elder, 1997, 1999; Elder, Johnson y Crosnoe, 2003; Elder y Shanahan, 2006). De 
esta forma, más allá de las múltiples interpretaciones que se hacen como corriente, perspectiva o teoría, el curso de vida ha encontrado su máximo desarrollo en el campo de la psicología, la sociología y, en los últimos años, como enfoque teórico metodológico.

\subsubsection{El curso de vida y la Psicología del Desarrollo}

La Psicología del Desarrollo retoma los primeros usos del concepto de curso de vida para referir a las etapas que componen el ciclo de vida. El curso de vida supone una secuencia basada en la edad y eventos producidos socialmente sobre un tiempo y espacio situado históricamente. Las líneas prioritarias de la psicología del desarrollo intentaban explicar los cambios del desarrollo ontogenético a partir de un patrón universal del desarrollo, determinado por la herencia genética y la evolución biológica y vinculado a la fuerte presencia de las corrientes innatistas (Lombardo \& Krzemien, 2008). No obstante, a partir del desarrollo de una perspectiva que coloca para su mayor comprensión la vida de las personas en un contexto histórico social y cultural, se replantean categorías clásicas como es la división en etapas basada en la psico-biología, dando lugar al surgimiento de una Sociología del desarrollo social y cultural de la vida humana (Christian Lalive d'Epinay Lalive dÊEpinay, Bickel, Cavalli y Spini, 2005). Confluyen en este nuevo campo de conocimientos un modelo explicativo acerca de las interacciones e interdependencias entre los procesos de desarrollos biológicos y psicológicos; el contexto socio-histórico y las dinámicas que lo afectan (Elder, 1998) ${ }^{7}$.

\footnotetext{
${ }^{7}$ Elder contempla el curso de la vida como una intersección particular de influencias temporales, temporalizadas y cambiantes. Esta temporalidad inherente al curso de la vida tendría al menos tres sentidos diferentes: 1. Existe un tiempo de vida, que se refiere a la etapa o posición de la persona dentro del proceso de desarrollo y envejecimiento. La edad cronológica es el índice que marca cuál es esta posición, y esta edad indica al investigador de algunos tipos de cambios que tienen más probabilidad de ocurrir en cierto momento. 2. Una segunda dimensión de la temporalidad del ciclo vital es el tiempo social, que se refiere al patrón de cambios, transiciones y secuencias de eventos que una determinada sociedad espera que ocurran en determinados momentos de la vida. 3. Por último, una tercera dimensión de la temporalidad es el tiempo histórico, que indica la posición de la persona dentro de una corriente de cambios históricos y definirá ciertos acontecimientos que le tocará vivir (ver un ejemplo en el estudio explicado en Elder, 1998: 1-3)
} 


\subsubsection{El Curso de vida en el campo de la sociología}

En el campo de la sociología el curso de vida como perspectiva teórica cobra fundamental importancia ya que considera a la vida humana y a su desarrollo como "una totalidad que abarca el desarrollo individual, en contextos sociales, culturales e históricos cambiantes, y se concentra en las trayectorias de vida individuales, así también como en el engranaje de las carreras de los individuos, a través de sus vidas" (Gastrón y Oddone , 2008: 2-3).

En este sentido hay una redefinición del concepto de desarrollo y curso de vida, en donde Elder empieza a tener en cuenta los factores históricos y sociales (la sociedad cambiante) y adquiere importancia la estructura social y en concreto, los cambios en esa estructura social, para la configuración de las trayectorias evolutivas del individuo en desarrollo (Elder, 1998: 944). Bajo esta perspectiva el trayecto de vida es un conjunto de procesos que transcurren desde el nacimiento hasta la muerte. La dimensión biológica, psicológica y social reafirman la existencia social del sujeto no solo como un individuo único sino también como partícipe de un ambiente social que lo precede. Los trayectos de vida son los trayectos sociales configurados por fuerzas históricas y están usualmente estructurados por las instituciones sociales; los individuos generalmente resuelven sus cursos de vida y trayectorias en relación a los trayectos institucionalizados y los patrones normativos. Están sujetos al cambio que deviene del impacto de los contextos más amplios en los que se encuentran envueltos como de los impactos de la agregación de vidas que siguen estos trayectos. Tal como lo refiere Schutz \& Luckmann (2003),

Todo ser humano tiene una vida y esa vida es una dinámica que transcurre en un tiempo (infancia, juventud, vejez) que se experimenta como un tiempo interior pero que también se inserta en un tiempo socialmente compartido en un mundo intersubjetivo (citado por Gustavo Mariluz, 2013: 2). 


\subsubsection{El Curso de vida como enfoque teórico metodológico}

El enfoque teórico metodológico del curso de vida emerge de la interacción compleja de las fuerzas descritas previamente. En tanto orientación teórica que guía la investigación sobre las vidas humanas en contexto, constituye ciertamente una plataforma necesaria para el estudio de los nexos que existen entre las vidas individuales y el cambio social (Elder, Kirkpatrick y Crosnoe, 2006; Elder y Giele, 2009), y provee un marco para estudiar los fenómenos en el nexo con trayectos sociales, trayectorias de desarrollo y cambio social. Es decir, explica las transiciones vitales considerando los itinerarios que se desenvuelven en cualquiera de las esferas de la vida de los sujetos (educación, trabajo, familia).

Uno de los caminos que esta perspectiva ha utilizado es considerar simultáneamente los niveles macroestructurales y microsociales en tanto analiza las interrelaciones de los eventos históricos y los cambios económicos, demográficos, sociales, culturales y las trayectorias de vida de los individuos. En este sentido, se presenta como un enfoque interdisciplinario que toma como unidad de análisis el curso de vida de un sujeto reconociendo el impacto de la historia sobre las vidas individuales, poniendo de manifiesto las modificaciones que factores sociales, culturales e históricos producen en las biografías. Para Schütz (1962),

/.../ la situación biográfica es la manera específica, dado nuestro origen social, en que cada individuo se sitúa en la vida. Es la totalidad de experiencias que una persona construye en el curso de una existencia concreta; define para un individuo el modo de ubicar su escenario de acción, interpretar sus posibilidades y enfrentar sus desafíos. Incluso influye en lo que un individuo puede o no modificar. Cada persona durante toda su vida sigue interpretando lo que encuentra en el mundo según la perspectiva de sus particulares intereses (Schütz, 1962: 2324).

Así la biografía individual del sujeto no está aislada, está determinada por el contexto y el tiempo en el que se desarrolla la misma, de modo que es necesario tener en cuenta los entornos y las relaciones en las que se halla inmerso el sujeto a la hora de analizar su vida.

Como enfoque teórico-metodológico, el curso de vida aporta tres conceptos básicos a partir de los cuales es posible estudiar los recorridos seguidos por un individuo a lo largo 
de su vida: trayectoria, transición y turning point (Elder, 1985, 1991; Elder y Kirkpatrick, 2002; Elder, Kirkpatrick y Crosnoe, 2006; Elder y Shanahan, 2006).

La trayectoria se refiere a una línea de vida o carrera, a un camino a lo largo de toda la vida que puede variar y cambiar en dirección, grado y proporción; abarca una variedad de ámbitos o dominios interdependientes (trabajo, escuela, familia, entre otros); y analiza el entrelazamiento de las trayectorias vitales tanto en un mismo individuo como en su relación con otros individuos. Las transiciones refieren a un cambio de estado, posición o situación de un individuo en un momento determinado durante la trayectoria, estas se pueden presentar en diferentes momentos sin estar predeterminadas, lo que implica un proceso de adaptación.

Para Blanco \& Pacheco (2003) la transición es una dimensión analítica fundamental del curso de vida porque están contenidas en las trayectorias. Señalan que mientras la transición "representaría el pasaje de un estado a otro (de la juventud a la adultez, del ciclo básico al superior, del desempleo a la actividad, etc.) la trayectoria se definiría como el conjunto de esos pasajes y estados" (2003: 163).

Las transiciones presentan cinco propiedades importantes (Elder, 1998; citado en Vega y Belén, 1999: 801)

- Una misma transición puede influir de manera diferente a personas de diferentes edades o que ocupan diferentes roles.

- Las nuevas situaciones a las que conduce una transición implican generalmente nuevas expectativas y demandas comportamentales para la persona, que tendrá que adaptarse y esforzarse por cumplir.

- Las transiciones pueden suponer que la persona pierda, al menos momentáneamente, el control de la situación vital que experimenta, pérdida que es seguida por un esfuerzo por recuperar ese control.

- Las transiciones que experimentan estas personas pueden afectarnos indirectamente a nosotros mismos.

- La dinámica de acentuación de ciertos aspectos de nuestra vida contribuye a que nuestra trayectoria se diferencie de la de los demás. 
Por otro lado, el término turning point o punto de inflexión hace referencia a momentos de cambio especialmente significativos que provocan fuertes modificaciones en la vida de la persona. Estos momentos de inflexión "representan un cambio en la dirección del curso de vida en relación con la trayectoria pasada y tienen un impacto en las probabilidades de los destinos de vida futura" (Gobtlb y Wheaton, 1997: 5).

El enfoque curso de vida se sustenta además en cinco principios básicos fundamentales, aunados a los conceptos señalados, que son los siguientes (George, 2006: 678)

1) Principio de desarrollo a lo largo del tiempo: el desarrollo humano es un proceso que abarca del nacimiento a la muerte. Tener una perspectiva a largo plazo es necesaria para estudiar las vidas a lo largo de períodos, para la comprensión de las biografías en correspondencia con el cambio social, desarrollo individual, y el tiempo históricosocial.

2) Principio de tiempo y lugar: el curso de vida de los individuos está inmerso y moldeado por los tiempos históricos y lugares que le toca experimentar al sujeto, es decir los momentos políticos, sociales, culturales que marcan ese período histórico y el lugar geográfico que habita.

3) Principio de timing: Estudia la incidencia de los acontecimientos y eventos que experimenta el sujeto en un momento de su vida (por ejemplo, nacimiento de un hijo, la muerte de un ser amado) y la forma en que repercute de acuerdo a la edad, el contexto, el ámbito familiar, social, cultural.

4) Principio de vidas interconectadas (linked lives): una persona no se construye aisladamente; existe una red de relaciones compartidas, razón por la cual se analiza la interdependencia de las diversas trayectorias de un mismo individuo respecto de otros individuos y grupos (por ejemplo, las relaciones de familia, los vínculos en el trabajo, el grupo de vecinos, maestros, estudiantes).

5) Principio de libre albedrío: en la relación entre lo individual y lo estructural los sujetos construyen su propio curso de vida haciendo elecciones y llevando a cabo actividades y acciones que permiten la construcción de su autobiografía. En pocas palabras, el libre albedrío individual está inevitablemente atado a las fuerzas históricas y sociales; de esta manera, "las personas pueden moldear sus vidas, pero 
lo hacen dentro de límites socialmente estructurados, como se refleja en las oportunidades y las limitaciones que, a su vez, van cambiando históricamente" (Shanahan \& Elder, 2002: 176)

Bajo este análisis es preciso decir que el estudio de curso de vida se ha convertido en un campo floreciente que ha sido apropiado por múltiples disciplinas sociales y que desde su apropiación representa actuaciones que visibilizan posturas y perspectivas políticas-sociales que abarcan realidades, significados y usos diferentes. Alwin (2012) analiza la literatura en torno del curso de vida y señala que este enfoque contiene una multiplicidad de significados y que los usos más implementados son: (1) curso de la vida como tiempo o edad, (2) curso de la vida como etapas, (3) curso de la vida como eventos, transiciones y trayectorias, y (4) curso de la vida como desarrollo humano.

\subsubsection{Perspectiva curso de vida en Colombia}

En Colombia el enfoque de curso de vida es una teoría reciente que emerge especialmente en las políticas de Infancia y Adolescencia. Inicialmente su comprension se establecía desde la postura de ciclo vital enmarcada en las consideraciones biológicas y psicológicas que ordenan el desarrollo del individuo por etapas (embarazo, niñez, adolescencia), desde esta perspectiva en la atención integral para la primera infancia se reconocía que las experiencias se acumulan a lo largo de la vida in útero y nacimiento, primera infancia (0-5 años), infancia (6-11 años), adolescencia (12-18 años) y por ello desde esta visión se buscaba el desarrollo de intervenciones y acciones a tempranas edades para minimizar las vulnerabilidades de los sujetos en etapas posteriores, la misión crear ambientes de ayuda desde los programas y fomentar opciones saludables en todas las etapas de la vida.

Actualmente dicha concepción está transitando hacia una perspectiva orientada bajo la corriente sociológica es decir, constituye una ampliación del enfoque de desarrollo humano y una perspectiva que permite reconocer en los distintos momentos de vida- trayectorias, sucesos, transiciones, ventanas de oportunidad y efectos acumulativos que inciden en la vida cotidiana de los sujetos, se fundamenta en el análisis y reflexión permanentes de la situación, condiciones de vida y desarrollo integral de los sujetos (individuales y colectivos), 
reconociendo la incidencia de múltiples condiciones históricas, sociales, culturales, biológicas y psicológicas. (Presidencia de la República, 2018). De acuerdo con lo planteado por el Instituto Colombiano de Bienestar Familiar (ICBF),

Este enfoque constituye un salto cualitativo de un enfoque evolutivo por etapas a un enfoque interrelacional, es decir un proceso donde las variables sociales históricas, culturales y psicobiológicas explican la situación de vida de los sujetos, y no solo la edad o las características estándar de cada etapa de la vida (ICBF, 2016: 20).

Es decir, busca analizar lo que ocurre en los diferentes momentos de la vida, lo cual permite comprender no solo lo que sucede en las distintas edades y etapas, sino identificar la manera en que las experiencias vividas en esta etapa se relacionan con los desarrollos y los contextos tal como lo menciona el ICBF,

/.../ se pretende que la garantía de los derechos pase de centrarse en las características de los niños, niñas y adolescentes en sus diferentes etapas, a considerar los múltiples efectos que pueden tener las acciones de política sobre sus trayectorias de vida” (ICBF, 2016: 12).

Desde esta perspectiva el curso de vida impone una visión integral del ser humano y de la familia en sus etapas y sus transiciones; de acuerdo con la política pública de primera infancia. Buen Comienzo el curso de vida se define como:

/.../ un enfoque integral progresivo - acumulativo, del desarrollo humano integral y de la perspectiva de los derechos humanos; es relacional e interrelacional, que incluye elementos como el contexto histórico, social y político, y diferenciales como lo territorial, el género, la etnia, entre otros, que permite interpretar las transiciones del individuo y su familia como parte de un proceso continuo e interactivo de cambio histórico (Política Pública de Primera Infancia, Acuerdo 54 de 2015).

Asumir el enfoque de curso de vida en la política de primera infancia en el país significa que está enmarcado en una perspectiva de derechos y desarrollo humano lo que por un lado posibilita atenciones oportunas en cada generación, por el otro permite explicar las inequidades sociales y problematizarlas, definiendo categorías de análisis y comprensión jerarquizadas, dado que el curso de vida "está influenciado por las condiciones biológicas, psicológicas, sociales presentes en los entornos en los que desenvuelve el individuo" 
(Presidencia de la república, 2018: 26). Asimismo comprende un paso hacia la comprensión de las transiciones armónicas que refieren al reconocimiento de aquellos momentos sensibles y determinantes en el desarrollo de los sujetos y que implican:

- Identificar momentos o sucesos clave en la vida de los sujetos, sus familias y sus comunidades, para definir "acciones anticipatorias" con miras a promover desarrollo o prevenir situaciones de riesgo.

- Definir acciones que constituyan apoyos a transiciones en la vida que generan tensión y son significativos para las personas.

- Considerar las trayectorias vitales y sus diferentes roles, y posiciones de sujeto (trabajo, escolaridad, vida conyugal, madre- padre adolescente, adolescente trabajador).

En consecuencia, implica la comprensión frente a los recorridos de los niños y niñas

por el sistema educativos y su interrelación con otros individuos, su familia, la sociedad, el fin último desde este enfoque es potenciar la capacidad de agencia y protagonismo de niñas, niños y adolescentes, fortalecer las capacidades de las familias y los colectivos humanos como agentes que facilitan la construcción de las trayectorias vitales de los niños, niñas.

\subsection{Trayectorias en la educación: debates y perspectivas}

Los planteamientos expuestos con relación a la trayectoria de los individuos permiten identificar en el campo de la educación dos perspectivas o modos de orientar su estudio: investigaciones que ponen el foco en los procesos de escolarización y estudios orientados al análisis de procesos socioeducativos. En el primer caso, los procesos educativos se relacionan directamente con las trayectorias escolares. Una de las principales autoras en este campo es Flavia Terigi quien formula el concepto de trayectorias escolares para dar cuenta de los modos en que efectivamente los sujetos transitan por el sistema educativo.

La autora distingue entre trayectorias teóricas y trayectorias reales. Sostiene que el sistema educativo define, a través de su misma organización, trayectorias escolares teóricas que expresan itinerarios que siguen la progresión lineal prevista por el sistema en los tiempos 
marcados por una periodización estándar (Terigi, 2008). La trayectoria teórica estipula el ingreso de los sujetos al sistema escolar a determinada edad, establece el discurso jurídico sobre la educación escolar y forma parte de desarrollos teóricos y pedagógico-didácticos, curriculares y de política educacional que expresan aquello que debería acontecer en las biografías escolares de los sujetos. Los itinerarios que los sujetos realizan a través del sistema educativo son homogéneos y lineales: el avance se produce a razón de un grado por año, estando preestablecidas las transiciones entre niveles escolares y el tiempo teórico de duración de una cohorte escolar (Terigi, 2010). Así mismo Terigi considera que tres rasgos del sistema educativo son especialmente relevantes para la estructuración de estas trayectorias: la organización del sistema por niveles, la gradualidad del currículo y la anualización de los grados de instrucción. Estos "tres rasgos que suelen considerarse indistintamente, como si fueran solidarios cada uno de los otros dos, pero en rigor se trata de tres arreglos independientes cuya asociación produce determinados efectos en las trayectorias" (Terigi, 2008: 162).

Frente a las trayectorias teóricas se observan trayectorias reales que refieren a aquello que efectivamente le acontece al sujeto alumno en su paso por la escuela, y pueden ser analizadas a partir de las estadísticas educativas. Terigi plantea que las condiciones socioeducativas de las/los alumnas/os que se observan en la escuela difieren de la teoría porque en los recorridos por el sistema educativo los sujetos experimentan "itinerarios desestandarizados" y "puntos críticos", es decir, itinerarios que no siguen ese cauce y que denomina "trayectorias no encauzadas". Gran parte de las/los niñas/niños y jóvenes transitan su escolarización de modos heterogéneos, variables y contingentes. La relación entre trayectorias teóricas y trayectorias reales permite hacer referencia a las trayectorias escolares encauzadas y no encauzadas (Terigi, 2008).

Ahora bien, mientras Terigi establece la trayectoria en relación con los tránsitos o itinerarios que el sujeto realiza por el sistema educativo, Santillán (2007) considera que la trayectoria "implica un camino vivencial y la apropiación de un conjunto de prácticas producidas dentro de un denso marco de intervenciones" (2007: 915). Así concebidas, las trayectorias refieren no solamente a los itinerarios de entrada y salida hacia instituciones educativas y entre ellas, sino que constituyen campos de experiencias. 
Para Kaplan y Fainsod (2001) las trayectorias escolares deben comprenderse en el marco de las complejas interacciones entre condicionantes estructurales y contextuales, las mediaciones institucionales y las estrategias subjetivas puestas en juego por cada individuo. Las trayectorias escolares sintetizan los itinerarios que los agentes van delineando a lo largo de su vida, los caminos que recorren las/los alumnas/alumnos a través del sistema educativo no son homogéneos, lineales y predecibles en todos sus aspectos. "Los condicionamientos sociales, y también las subjetividades que se construyen en la escuela, juegan un papel crucial" (Kaplan, 2006).

Briscioli (2013) retoma los postulados de Terigi y Kaplan y plantea que el concepto de trayectoria permite el análisis de procesos complejos. De esta forma, pone en evidencia que en sus recorridos por el sistema educativo los sujetos presentan trayectorias escolares interrumpidas, inconclusas o intermitentes. Asimismo, postula la noción de trayectorias escolares como superadora de la dicotomía entre determinismo social y voluntarismo, al introducir y atribuirle un papel relevante a la dimensión institucional en la producción de dichas trayectorias.

Debido a estas consideraciones, la trayectoria (Nicastro y Greco, 2009; Greco, 2015) supone sostener una mirada múltiple y reúne dos tiempos en uno, produciendo un recorte y una ampliación a la vez. No se trata de mirar sólo a un sujeto ni de centrar la atención sólo en la organización escolar.

El sujeto habla a su manera, a lo largo de su recorrido educativo o formativo e incluso de vida, de la organización formativa y ésta no hace más que decir en su cotidianeidad, de distintos modos, quiénes son los sujetos que educa o forma. Es por esto que las dicotomías y las oposiciones no alcanzan nunca a dar cuenta de una trayectoria educativa: no es el sujeto o la institución, son ambos a la vez, sin que cada uno de ellos pierda su singularidad, sus rasgos propios, sus dimensiones, su modo de presentación particular" (Nicastro \& Greco, 2009: 57).

En la trayectoria se articula lo universal de la educación y las múltiples formas de encarnarlo en singularidades. En el mismo sentido, no sólo se producen "entrecruzamientos" con los niveles de análisis, sino en el modo de concebir el "espacio como entramado que en sí mismo es una forma de relación entre sujetos" (Nicastro \& Greco, 2009: 132) 
Bajo este análisis es preciso decir que la trayectoria escolar pone de manifiesto diversos factores que interseccionan las experiencias de vida de los sujetos, describe el modo en que efectivamente los sujetos transitan por el sistema educativo, comprende el marco de complejas interacciones entre condicionantes socioeducativas, individuales, estructurales y contextuales. Las estrategias subjetivas puestas en juego por cada individuo y las disposiciones del sistema para objetivar los tramos o recorridos se vinculan y entrelazan creando itinerarios particulares, lineales, heterogéneos y discontinuos.

Sin duda la articulación entre lo individual y lo social evidencia que la trayectoria no puede analizarse sin la comprensión del "espacio social y sus transformaciones"; cada trayectoria problematiza el vínculo entre la sociedad/individuo, la acción/estructura/decisión y condicionamiento. Tal como lo plantea Bourdieu, la noción de "trayectoria" refiere a una serie de las posiciones sucesivamente ocupadas por un mismo agente (o un mismo grupo) en un espacio jerarquizado y sometido a incesantes transformaciones. (Bourdieu, 1997: 82).

En correspondencia con lo anterior en esta tesis retomamos lo propuesto por Bourdieu, su marco teórico contribuye con esta investigación porque en la trayectoria de los niños y niñas se ponen en juego un sin número de factores (históricos, jurídicos, institucionales, familiares, culturales) que producen cambios significativos en las experiencias de vida del sujeto y las posiciones que ocupan en dichas estructuras sociales. Los niños y niñas están inmersos en campos estructurados como el nivel de educación inicial y nivel de educación formal, en los que encontramos jerarquizaciones y reglas de juego que le son propias. Las/los niñas/niños forman parte de una compleja red de relaciones que involucra a varios agentes (familia, maestras, directivos, normas jurídicas), y que inciden en sus trayectorias.

Para comprender el concepto de trayectoria es necesario partir de las discusiones que el autor hace sobre objetivismo/subjetivismo a propósito del análisis del "espacio social y sus transformaciones", al señalar que el mundo social no sólo se compone de estructuras objetivas sino también de representaciones, percepciones y visiones (subjetivismo). Por ello para Bourdieu el objetivismo y el subjetivismo son perspectivas parciales porque ambas representan dos momentos del análisis y se conforman en una relación dialéctica. El objetivismo analiza los campos de posiciones relativas y relaciones objetivas entre las 
posiciones, es decir, las "estructuras sociales externas" [el escenario escolar, nivel de Educación Infantil, formal], y el momento subjetivista, analiza los puntos de vista que los agentes tienen sobre la realidad en función de su posición en el espacio social objetivo, es decir, las "estructuras sociales internalizadas", la inscripción de significados y sentidos que emergen, construyen y aprenden en ese campo. (Bourdieu, 1980; 2007)

De acuerdo con Bourdieu la noción de campo se refiere como tal a espacios sociales estructurados a partir de un conjunto de relaciones que se dan en su seno, que gozan de una autonomía relativa y de una lógica de funcionamiento propia, es un espacio social de acción e influencia en el que confluyen relaciones sociales, cada campo posee reglas, desafíos específicos o retos de otros campos. Este es un 'sistema' o un 'espacio' estructurado de posiciones, en el que se dan luchas alrededor de la apropiación de un capital específico del campo. Dicho de otra manera, el autor establece que existen diferentes campos, un ejemplo de ello es el campo educativo el cual está inmerso en el campo social, de esta manera cada campo tiene sus lógicas de validación y argumentos que le atañen (Bourdieu, 2000: 52).

Los agentes (niños-niñas) transitan en su vida cotidiana por diferentes campos (educación inicial-formal) en los cuales aprenden lógicas, códigos, ideologías, en términos del autor capitales que les otorgan un posicionamiento en los diferentes espacios sociales. Sin embargo, el capital está desigualmente distribuido dentro del campo y existen, por tanto, dominantes y dominados. A cada campo le corresponde un hábito (sistema de disposiciones incorporadas), cada agente del campo se caracteriza por su trayectoria social, sus hábitos y su posición en el campo.

De esta forma la articulación entre lo individual y lo social da origen al concepto de hábitos para dar cuenta de procesos sociales colectivos. Los hábitos son sistemas de disposiciones duraderas, interiorizadas por los agentes a lo largo del curso de su vida, que los predispone a actuar, sentir, pensar de una determinada forma. Son las estructuras externas internalizadas por el agente (niño-niña) y están relacionadas con la posición que este ocupa en el espacio social. La construcción del mundo de los agentes opera bajo condiciones estructurales, 
/.../ por lo tanto, las representaciones de los agentes varían según su posición (y los intereses asociados) y según sus hábitos, como sistema de esquemas de percepción y apreciación, como estructuras cognitivas y evaluativas que adquieren a través de la experiencia duradera de una posición en el mundo social (Bourdieu, 1988: 134).

De acuerdo con Bourdieu, en su esquema conceptual, el espacio social se compone de tres dimensiones fundamentales: "el volumen del capital, la estructura del capital y la evolución en el tiempo de estas dos propiedades" (Bourdieu, 1979: 113). En primer lugar el volumen del capital se relacionan con la estructura de oportunidades del mundo externo, entendida como las probabilidades de acceso a bienes, servicios o el desempeño de actividades con las que el sujeto (niño-niña) se encuentra; la estructura del capital es el conjunto de disposiciones y capacidades de los niños-niñas puestas en juego en la vida cotidiana (sus saberes, características culturales, lógicas que orientan su acción, habilidades, proyectos de vida, etc.); en tercer lugar, la variable del tiempo que traspasa los dos ejes y define su mutua relación en el pasado y el presente, y la proyecta hacia el futuro (Frassa y Muñiz Terra, 2004).

Por tanto, la posición de origen no es otra cosa que el punto de partida de una trayectoria (de un individuo o grupo) en función del volumen y la estructura del capital definidos puntualmente, o de su evolución para comprender la trayectoria pasada y potencial en el espacio social (Bourdieu, 1979). De esta forma intentar comprender una vida como una serie única y suficiente en sí misma, de acontecimientos es interpretar:

La noción de trayectoria como serie de las posiciones sucesivamente ocupadas por un mismo agente (o un mismo grupo) en un espacio en sí mismo en movimiento y sometido a incesantes transformaciones. Tratar de comprender una vida como una serie única y suficiente en sí de acontecimientos sucesivos sin más vínculo que la asociación a un «sujeto» cuya constancia no es sin duda más que la de un nombre propio, es más o menos igual de absurdo que tratar de dar razón de un trayecto en el metro sin tener en cuenta la estructura de la red, es decir la matriz de las relaciones objetivas entre las diferentes estaciones (Bourdieu, 1989: 31).

En este orden la posición y la trayectoria individual depende a menudo de acontecimientos colectivos que comúnmente son descritos como "casualidades" aunque ellas mismas dependen estadísticamente de la posición y de las disposiciones de aquellos a quienes 
afectan. Esto significa que existe una correlación muy fuerte entre las posiciones sociales y las disposiciones de los agentes que las ocupan.

Haciendo referencia a una posición determinada en las distribuciones de las propiedades materiales y del capital simbólico, Bourdieu (1991) señala que la representación que los agentes se hacen de su propia posición y de la de los demás en el espacio social, así como la representación que ofrecen de ella consciente o inconscientemente mediante sus prácticas, son el producto de un sistema de principios de percepción y de apreciación que es, a su vez, el producto incorporado de una condición.

Analizar las trayectorias de los niños y niñas supone una mirada integral de las posiciones ocupadas en el campo educativo, y permite identificar la historia individual de los sujetos, de sus familias y de su contexto, no todos los sujetos experimentan los mismo recorridos o trayectos, puesto que el proceso es heterogéneo, con contingencias, encuentros y desencuentros, en términos de Bourdieu "Los individuos no se desplazan al azar en el espacio social, por una parte, porque las fuerzas que confieren su estructura a este espacio se imponen a ellos (mediante, por ejemplo, los mecanismos objetivos de eliminación y de orientación), y por otra parte porque ellos oponen a las fuerzas del campo su propia inercia, titulaciones (Bourdieu, 2000 [1979]).

Un aspecto relevante de las trayectorias reside en su relación con la noción de transición de una etapa a otra. Siendo la trayectoria la que permite dar cuenta de las posiciones que logra ocupar el sujeto en el campo educativo para futuras inserciones y la transición como un proceso de adaptación y aprendizaje en los entornos escolares.

\subsection{Transiciones en la Educación Infantil}

Hasta aquí se ha enfatizado en los recorridos seguidos por las/los niñas/niños, en los modos de experimentar la institucionalidad y escolaridad en la educación, en los condicionamientos contextuales, estructurales e institucionales que se entrelazan y nutren mutuamente de forma que interceden en los cambios o transiciones que el sujeto realiza por su vida escolar. 
Cuando hablamos de transiciones nos referimos a un proceso continuo donde las acciones que se realizan antes, durante y después son relevantes para los procesos de adaptación y aprendizaje en los entornos escolares. Etimológicamente, "la palabra transición significa cambio en el ser o estar, cambio de un estado a otro, de una situación inicial a otra” (Real Academia Española, 1984), hecho que confirman autores como Fabián y Dunlop (2006), Arnold, Barlett, Gowvani y Merali (2006), y Abello (2008), quienes definen las transiciones como el cambio que experimentan los niños y sus familias cuando pasan de un lugar o fase de la educación a otro, es decir de la casa al preescolar, o del preescolar a la escuela. En estas transiciones se presentan desafíos en cuanto a las relaciones sociales, el ambiente, el espacio, los contextos de aprendizaje, el tiempo y el estilo de enseñanza, haciendo del proceso algo intenso, crítico y con demandas crecientes. Dichos autores señalan que el cambio puede ser una oportunidad para aprendizajes nuevos, o puede ser la causa de aprensión frente a lo nuevo que genera confusión y ansiedad, sensaciones que pueden afectar el comportamiento de un individuo a largo plazo y su trayectoria por el sistema educativo.

Numerosas investigaciones se han desarrollado en este campo de saber. Autores como Figuera, Dorio y Forner (2003), Álvarez González y Fita (2005), Briscioli (2013) realizan aportaciones en el ámbito educativo al considerar al sujeto y su contexto educativo, social y familiar de forma interrelacionada. Definen transiciones como la articulación entre niveles, grados e instituciones, y analizan la práctica pedagógica, los planes curriculares, la evaluación y las estrategias de continuidad entre niveles como dimensiones importantes de las transiciones.

Otros estudios ponen en consideración las voces de los sujetos niños, niñas, jóvenes, adolescentes, familias y maestras, resaltando aspectos emocionales, subjetivos, psicosociales, cognitivos, que influyen en el recorrido del sujeto y su posición en el espacio, y en los cambios de niveles educativos (West, Patrick, Sweeting, Helen y Robert, 2010). De esta forma se relatan las experiencias que los niños tienen entre períodos y entre las esferas de su vida (Kagan y Neuman, 1998), los momentos de potencial desafío y estrés para los niños y sus familias (Hirst, Jervis, Visagie, Sojo y Cavanagh, 2011), la existencia de temores para enfrentar la transición, así como los miedos, ansiedad, nerviosismo e inseguridad (Castro, Argos y Ezquerra, 2015), y las expectativas, inquietudes experiencias y desafíos en 
términos académicos y sociales, pero también las oportunidades para disfrutar mayor libertad y autonomía, y para crecer y progresar en sus trayectorias educativas (Ames y Rojas, 2011).

Por último, otros estudios han centrado la atención en los procesos de articulación inter-institucional para el éxito de las transiciones en los niveles educativos, mediante el análisis de factores y variables que, como lo expone Pérez (2011), permiten la comprensión de la influencia que el contexto tiene sobre las relaciones entre las familias, la escuela, la comunidad, el estado. No obstante, aunque estos estudios se han relacionado con perspectivas educativas, sociales, personales, históricas, es preciso decir que la definición y conceptualización del concepto articulación es heterogénea, que en la educación inicial se ha centrado en la articulación inter-institucional y en los procesos educativos más que en los aspectos sociales y personales que inciden en las transiciones de las niñas y niños (Pianta, 1999; Dockett y Perry, 2001).

\subsection{Conceptualización de las transiciones}

Peralta (2007) refiere que existen diferentes tipos de transiciones que van desde el nacimiento hasta los 8 años, con incidencia en los ciclos de vida y en el éxito escolar. La primera, refiere a la transición que sucede desde el espacio familiar-social a un círculo de relaciones extendida al grupo de pares y/o a la comunidad más cercana. La segunda transición implica el paso de un ambiente familiar-social a alguna institución externa que puede ser de la casa de cuidado hasta un colegio, pasando por muchas otras posibilidades como preescolares, programas de educación inicial, guarderías, programas no convencionales, jardines infantiles y guarderías. La tercera transición tiene mayor desarrollo en la bibliografía especializada, y es la del último grado o nivel de la educación inicial hacia la educación primaria.

Sin embargo, para el desarrollo de esta tesis en correspondencia con la postura asumida desde la trayectoria y después de los análisis teóricos realizados con los primeros hallazgos del trabajo de campo con maestras, agentes educativos y niños-niñas hemos podido caracterizar las transiciones desde un carácter social-cultural, de carácter educativo y de carácter individual en tanto las interacciones y experiencias que los sujetos tienen con los dispositivos institucionales, las condiciones del contexto, y las características propias de los 
sujetos se relacionan e interconectan de forma que inciden en las trayectorias que realizan por el sistema escolar.

\subsubsection{Transiciones de carácter social-cultural}

Las transiciones de carácter social se relacionan con el contexto, con el proceso de cambio y posicionamiento, rol o situación que experimenta el individuo en un momento determinado de su vida. Hace referencia a los itinerarios no necesariamente predeterminados o absolutamente previsibles, sino heterogéneos en el que los momentos significativos que explora el sujeto con la familia, los miembros de la comunidad, las características del contexto, las condiciones históricas, culturales, afectan las transiciones que vive el sujeto a lo largo de su vida e implica la adaptación a nuevos entornos sociales y culturales.

Pia Vogler, Gina Crivello y Martin Woodhead (2008) definen las transiciones como "acontecimientos y/o procesos clave que ocurren en períodos o coyunturas específicos a lo largo del curso de la vida" (p. 2), se vinculan con cambios que se producen en el aspecto, las actividades, la condición, los roles y las relaciones de una persona, además de las transformaciones relacionadas con el uso del espacio físico y social. De este modo, las transiciones se ligan a sucesos de la vida previstos o inesperados en el que las particularidades de los contextos, los dispositivos institucionales, la disposición de los estamentos culturales económicos interviene en la adquisición de las posiciones sociales que proyecta al sujeto.

Uno de los autores más importantes en esta conceptualización es Gimeno Sacristán (1997) quien a partir del modelo ecológico de Bronfenbrenner rescata la importancia del contexto como espacio que potencia o dificulta el desarrollo de la transición, señalando que las transiciones son momentos de alumbramiento de nuevas realidades, etapas de crisis o de indefiniciones, en las que se sabe desde dónde se sale pero no se tiene claro a donde se va a llegar y en qué estado se quedará en la nueva situación. El autor diferencia transiciones sincrónicas relativas a la participación en diferentes ámbitos (escuela, familia, deportes) de transiciones diacrónicas las que se relacionan con la línea de progreso (autobiografía del sujeto). De esta forma, en las relaciones que el sujeto establece se nutre de estímulos y "capitales culturales" que ofrecen oportunidades positivas para crecer, siempre y cuando se 
presenten las condiciones más favorables para que ocurran estas transiciones satisfactoriamente. Asimismo, las transiciones poseen un carácter público y a la vez privado, pues no sólo en ella se va transformado el sujeto sino también la situación social, los papeles y roles que asume y corresponden desarrollar dentro del grupo (Gimeno Sacristán, 2007). Según Casal,

La transición es un sistema de dispositivos institucionales y procesos biográficos de socialización que de forma articulada entre sí (articulación compleja) intervienen en la vida de las personas desde que asumen la pubertad, y que son conductores hacia la adquisición de posiciones sociales que proyectan al sujeto joven hacia la consecución de la emancipación profesional, familiar, social (Casal, 1996: 298).

Para estudiar las transiciones de este carácter se asume un enfoque sociológico dado que, desde el punto de vista social, el sujeto en su trayecto de vida explora un proceso de cambios heterogéneos que implican adecuación y redistribución de roles en tanto es miembro de un grupo (familia, escuela, comunidad). Los efectos biológicos, sociales, familiares, los cambios de entorno, las configuraciones institucionales, los estamentos gubernamentales, determinan los itinerarios de los sujetos y su posición. Por ello la transición es un proceso de cambio complejo que implica un nuevo posicionamiento y redistribución de roles. Bajo esta mirada este mismo autor establece tres dimensiones o niveles que articula y constituye un sistema de transición.

- El contexto socio histórico y territorial (marco de referencia territorial, cultural y político)

- Los dispositivos institucionales de transición (red compleja de instituciones sociales que intervienen configurando y reglamentando la oferta de la transición)

- El proceso biográfico o conjunto de toma de decisiones y significados y códigos

En este sentido las miradas y proyecciones de los estudios se relacionan con factores de contexto socio-histórico, territorial, disposiciones institucionales y las variables institucionales, centradas en ámbitos que sobrepasan los contextos más próximos a la 
persona, pero que tienen un efecto directo (la institución formativa, las instituciones culturales y recreativas del barrio, la ciudad, la sociedad en general).

\subsubsection{Transiciones de carácter educativo}

Las transiciones de carácter educativo se corresponden con los pasos que viven los sujetos desde un ambiente familiar-social a una institución educativa, programas no convencionales, guarderías, jardines, modalidades y niveles educativos. La transición guarda relación con el concepto de etapa, período, recorrido que experimenta el individuo a lo largo de su vida.

Las transiciones educativas se establecen en el marco de los ritos de paso, expresión ampliamente utilizada para describir acontecimientos significativos que vive el sujeto. De acuerdo a Arnold van Gennep en su libro Les rites de passage (1908), la noción de rito de paso se establece como un indicador de cambios vitales tales como el nacimiento, la atribución del nombre, el paso a la escuela, la llegada a la madurez y la muerte. Para el autor, los ritos de paso a menudo tienen que ver con desplazamientos relativos a la condición social y señalan el grado de preparación (o las expectativas sociales implicadas) para asumir nuevas responsabilidades. Frecuentemente están relacionados con la “edad social” del individuo más que con su edad biológica citado en (Hockey, 2002: 212).

Las transiciones son procesos dinámicos que siguen un modelo secuencial tripartito: en primer lugar, los ritos preliminares ("ritos de separación" respecto a un "mundo" anterior); en segundo lugar, los ritos liminares o rituales de umbral (ejecutados durante la fase transicional); por último, los ritos postliminares que marcan la reincorporación al mundo del individuo dotado de una nueva condición (van Gennep, 1960: 21).

En la educación inicial la palabra transición se refiere al proceso de cambio que es experimentado por las familias y los niños y niñas cuando se mueven del hogar al centro de Educación Infantil o de la educación inicial a la escuela. Tal como refieren Fabian y Dunlop (2002) la "transición" se utiliza sobre todo para definir el traslado de un año al siguiente o de una escuela a otra, dentro de contextos educacionales formales. Estos períodos específicos suponen nuevos retos, actividades, situaciones y experiencias que impactan de manera 
significativa el desarrollo de los niños y niñas. Para Ames Rojas (2011) la palabra transición incluye el período de tiempo que toma hacer el cambio de un espacio a otro, desde cualquier visita previa a la instalación, hasta cuando el niño está completamente establecido como miembro del nuevo escenario. Éste es usualmente un tiempo de demandas de desarrollo aceleradas e intensas que están socialmente reguladas.

Los ritos de pasos o cambios que vive el sujeto entre modalidades, instituciones, grados, ambientes se caracterizan por ser heterogéneos, Peralta (2007) refiere que la transición implica un proceso, en la cual se distinguen tres sub procesos: continuidad, progresión y diferenciación, dando la impresión de una interrelación y en algunos momentos de secuencialidad, en donde cada uno de ellos juega un rol en el "paso" al nuevo estado: uno da estabilidad, otro complejiza lo alcanzado, y el tercero, ofrece el cambio a lograr.

Para Gimeno Sacristán (1996) las transiciones son verticales comprendidas en relación con el sistema educativo, y el currículo como organizador, es decir, a aquellas que se dan entre el hogar y el centro de cuidado, entre este último y el preescolar y posteriormente la escuela y las transiciones horizontales referidas a los desplazamientos entre los diferentes escenarios como la escuela, la familia y la comunidad. Desde el punto de vista de la experiencia de los estudiantes, las transiciones "son ambivalentes para cada sujeto y tienen signos distintos para individuos diferentes" (1996: 18).

En el análisis de las transiciones educativas prevalece un enfoque llamado Ecológico porque centra la relación entre el contexto escuela-institucional con el contexto ya sea personal, social. Los niños y niñas forman parte de una comunidad en la que participan activamente de ambientes como el hogar, la escuela, la comunidad, en estos (medios ecológicos), transitan de forma simultánea y establecen relaciones que potencian o limitan la transición escolar.

El potencial evolutivo de los entornos ecológicos, por los que transita simultáneamente o no, se ve incrementado si las demandas de roles de los diferentes entornos son compatibles y si los roles, las actividades y las díadas en las que participan la persona en desarrollo estimulan la aparición de la confianza mutua y una orientación positiva” (Bronfenbrenner, 1987: 237).

Este enfoque, siguiendo a Bronfenbrenner (1977, 1987), tiene presente los factores socio-políticos y económicos del macrocontexto, como también a la familia, la escuela y la 
comunidad que conforman el mesocontexto, denominadas por "factores mediadores del potencial evolutivo de la transición" que inhiben o estimulan el potencial evolutivo del proceso de la transición. De acuerdo con Álvarez González y Bisquerra (2005), las personas se desenvuelven en un contexto que combina ambiente físico, social, político y económico negociando algunos rasgos de identidad, sus sistemas de creencias y cursos de vida. Estos contextos varían de persona a persona y su influencia es continua y dinámica. Por ello en cada transición hay acomodación a los cambios del entorno, ajustes de estilo de vida ante las exigencias y posibilidades del nuevo ambiente, cambios de roles. Las principales características a tener en cuenta en este enfoque son (Bronfenbrenner, 1979):

- Microsistemas: abarcan las experiencias e interacciones de los niños con sus compañeros, maestros y cuidadores en los entornos cotidianos, en el hogar, la escuela, la guardería.

- Mesosistemas: están compuestos por las relaciones entre estos distintos microsistemas, por ejemplo, las prácticas y sistemas de valores complementarios y/o conflictivos vigentes en el hogar y la escuela y las comunicaciones informales/formales entre los padres y los maestras.

- Exosistemas: son áreas de la vida social en las que no participan los niños mismos, pero sin embargo influyen en su existencia y bienestar mediante interconexiones con los microsistemas.

- Macrosistemas: están relacionados con las convicciones predominantes y la organización de las instituciones omnipresentes que contribuyen a determinar los ambientes culturales en que se desarrollan los niños/as.

- Cronosistemas: reconocen el contexto histórico de sus estudios y examinan cuál es el impacto de los cambios históricos en las transiciones de la vida individual y comunitaria.

Entre las variables más importantes para tener en cuenta en estas transiciones de acuerdo a la perspectiva de Pérez (2011) están:

- variables de centro (cambio de centro, procedencia, diversidad socio cultural de los estudiantes, la elección de centro) 
- variables de relaciones sociales (entre iguales, familia, propia institución)

- variables de cambio de clima en educación (la arquitectura escolar, las relaciones humanas entre profesorado y estudiantes, disciplina, participación de los estudiantes, relaciones con ambos sexos, niveles de exigencia, estímulos intelectuales)

- variables de rendimiento (personales, escolares, familia y sociales).

\subsubsection{Transiciones de carácter individual}

Estas transiciones se relacionan con el sujeto, su vida individual, sus cambios físicos biológicos, desarrollos, atributos personales, autoestima, motivaciones y bienestar, tiene que ver con los acontecimientos y situaciones que experimenta una persona y que afecta directamente sus emociones, sentimientos, pensamientos e identidad. Para Abrego y Brammer (1992), "las transiciones son eventos internos de la persona que la pueden perturbar en su continuidad vital generando confusión, malestar, preocupación, o ansiedad" (1992: 236). Los niños y niñas no solo transitan por los contextos educativos culturales o sociales, en su curso de vida experimentan pérdidas, cambios en sus ciclos vitales (como la caída de un diente, la muerte de la mascota, el destete, la separación de los padres, el nacimiento de un hermano, el cambio de profesor, entre otras situaciones importantes) que determinan comportamientos, actuaciones y que impactan de manera directa y particular su desarrollo emocional y los espacios sociales en los que el interactúa (microcontexto y mesocontexto).

El enfoque para estudiar estas transiciones se centra desde la perspectiva psicológica, en donde la transición se entiende como acontecimientos o situación en que la persona experimenta una discontinuidad importante en su trayectoria vital teniendo que desarrollar nuevas conductas como respuesta a dicha situación.

La transición incluye variables personales: la percepción del proceso, las emociones, los sentimientos, la autoestima, la identidad vocacional, las experiencias previas, el soporte social, la autoeficacia, estudia (1) la dinámica personal del proceso, sin obviar, las características del contexto, (2) los sentimientos y las emociones que acompañan cada una de las fases y estrategias de la transición, (3) estudia la dinámica personal en el contexto personal, familiar, relacional y la influencia del ambiente social, físico y cultural (4) evalúa La forma de enfrentarse a las emociones negativas, positivas y a la evaluación que se hace 
de los estímulos recibidos producto de la personalidad (rasgos, creencias, valores, motivos, intereses, etc.) y del ambiente en interacción (percepción y la configuración de la situación).

\subsection{A modo de cierre}

Tras haber realizado un recorrido teórico y conceptual, se sintetizan aquí los aportes centrales de la perspectiva de las trayectorias y transiciones en la Educación Infantil.

El curso de vida se puede analizar como una totalidad que abarca el desarrollo individual, en contextos sociales, culturales e históricos cambiantes, y se concentra en las trayectorias de vida individuales como un conjunto de procesos que transcurren desde el nacimiento hasta la muerte. En el curso de vida la trayectoria se comprende como una línea de vida o carrera, a lo largo de toda la vida que puede variar y cambiar en dirección, grado y proporción; abarca una variedad de ámbitos o dominios (trabajo, escuela, familia, comunidad, entre otros) y analiza el entrelazamiento de las transiciones vitales tanto en un mismo individuo como en su relación con otros individuos.

Como enfoque teórico-metodológico, el curso de vida aporta tres conceptos básicos a partir de los cuales es posible estudiar los recorridos seguidos por un individuo a lo largo de su vida: trayectoria, transición y turning point. La transición se comprende como un cambio de estado, posición o situación de un individuo en un momento determinado durante la trayectoria, por lo que mientras la transición representa el pasaje de un estado a otro (de la niñez a la juventud, del ciclo inicial al preescolar y la básica primaria, etc.), la trayectoria se define como el conjunto de esos pasajes y estados que atraviesa el individuo. El turning point se define como un momento en la vida de una persona en el cual sucede un evento importante que marca su trayectoria, por ejemplo, la muerte de un ser querido.

El curso de vida de los individuos está inmerso y moldeado por los tiempos históricos y lugares que le toca experimentar a cada uno/una en una red de relaciones familiares, sociales, educativas. En la relación entre lo individual y lo estructural los sujetos construyen su propia trayectoria haciendo elecciones, y llevando a cabo actividades y acciones que permiten la construcción de su autobiografía. 
En Colombia el curso de vida se presenta en la política de primera infancia como un enfoque que busca reconocer los entornos de los sujetos, la familia, las condiciones sociales e históricas, busca transcender la mirada biologicista que define la vida como la suma de etapas vinculadas a un criterio etario hacia una visión integral en donde las variables sociales, históricas, culturales y psicobiológicas explican la situación de vida de los sujetos. Así, este enfoque pretende definir acciones anticipatorias que constituyan apoyos a las transiciones con miras a promover el desarrollo de los niños y las niñas o prevenir situaciones de riesgo.

Ahora bien, para comprender los efectos que puede tener este enfoque en las acciones políticas del país se hace necesario caracterizar y definir la categoría trayectoria. En Colombia, especialmente en el campo de la Educación Infantil, se hace referencia específicamente a las transiciones y no se contempla el desarrollo conceptual para la categoría trayectoria. Esto explica la ausencia de estudios e investigaciones que centralicen esta perspectiva y la vincule a los procesos educativos, sociales, históricos y culturales en los que están inmersos los niños, niñas y familias. Si bien se asume el curso de vida como enfoque que transita de lo psicológico a lo sociológico aún persisten ambigüedades en tanto la mirada se ha enfocado particularmente en las transiciones (articulaciones interinstitucionales) y cambios que se dan entre niveles educativos. No se han realizado estudios que analicen los recorridos o itinerarios seguidos por las/los niñas/niños, sobre los modos de experimentar la institucionalidad y escolaridad en la Educación Infantil.

Del mimos modo encontramos que la trayectoria escolar da cuenta de los modos en que efectivamente los sujetos transitan por el sistema educativo, sintetiza los itinerarios que los agentes van delineando a lo largo de su vida, los caminos que recorren las/los niños/niñas a través del sistema educativo. Refiere no solamente a los itinerarios de entrada y salida hacia instituciones educativas y entre ellas, sino que constituyen campos de experiencia interceptados por un marco de complejas interacciones entre condicionantes estructurales y contextuales, entre las mediaciones institucionales y las estrategias subjetivas puestas en juego por cada individuo. La trayectoria no es lineal si bien es real que se pueden establecer tipos de itinerarios frecuentes e ideales, coincidentes con la estructura escolar (grados, ciclos, niveles). Sin embargo, no es menos cierto que gran parte de los niños y jóvenes transitan su escolarización de modos heterogéneos, variables y contingentes. 
Las trayectorias socioeducativas se relacionan con los espacios sociales, estructurados en campos como el nivel de educación inicial y formal, en los que encontramos jerarquizaciones y reglas de juego que le son propias. La posición inicial de una trayectoria educativa puede ser compartida por los miembros del grupo social, pero eso no implica que alcancen el mismo punto de llegada. Los condicionantes del contexto, la historia, lo cultural, y los capitales adquiridos no siempre permiten las mismas condiciones de avance en el campo y por ello las trayectorias son heterogéneas y singulares.

En este sentido vemos que la posición y la trayectoria individual depende a menudo de acontecimientos colectivos por la estructura de oportunidades del mundo externo, entendida como las probabilidades de acceso a bienes, servicios o el desempeño de actividades con las que el sujeto (niño-niña) se encuentra. La trayectoria no se puede analizar sin la comprensión del espacio social. Cada trayectoria problematiza el vínculo entre la sociedad/individuo, la acción/estructura/decisión y el condicionamiento social; en este orden, las interacciones entre las dimensiones estructurales, personales y educativas configuran itinerarios particulares y heterogéneos que determinan la posición de los sujetos en el campo educativo y social. La trayectoria permite dar cuenta de las posiciones que logra ocupar el sujeto en el campo educativo y la transición remite al proceso de adaptación y aprendizaje en los entornos escolares.

Observamos que el estudio de las transiciones en la educación inicial en Colombia ha puesto mayor atención en los procesos de articulación inter-institucional y en el éxito de las transiciones. Sin embargo, concebimos que las transiciones pueden ser algo más que la articulación, la comprendemos como un proceso de cambio en el que niños/niñas, agentes educativos y familias experimentan diversas situaciones y acontecimientos que implican nuevas expectativas. El cambio puede ser una oportunidad para aprendizajes nuevos, o puede ser la causa de aprensión frente a lo nuevo lo que puede generar confusión y ansiedad. Existen diferentes tipos de transiciones desde el espacio familiar a lo educativo, de lo familiar a lo social o comunitario, de lo educativo a lo social.

En esta investigación después de los análisis teóricos realizados y los primeros hallazgos del trabajo de campo con maestras, hemos caracterizado las transiciones en unos ámbitos que se han denominado ámbito sociocultural, ámbito socioeducativo y ámbito 
personal. Estos ámbitos se componen de unas variables que son determinantes en la trayectoria educativa que van construyendo niñas y niños por el sistema escolar.

Las trasiciones de carácter social-cultural involucran el ámbito sociocultural incorpora el contexto, la familia y la configuración en cuanto a la producción discursiva, las estructuras internas y externas de las instituciones educativas, el medio social y cultural con sus códigos y prácticas, la estructura política y cultural del momento, la estructura familiar y las condiciones sociales económicas y culturales que presenta el sujeto. Las variables de análisis en este ámbito se relacionan con las características de los contextos, la posición social de los sujetos y sus familias, los saberes, prácticas y los mecanismos de control presentes en las instituciones de educación inicial y educación formal. Para estudiar las transiciones de este ámbito se propone un enfoque sociológico dado que, desde el punto de vista social, el sujeto en su trayecto de vida explora un proceso de cambios heterogéneos que implican adecuación y redistribución de roles en tanto los niños/niñas hacen parte de un grupo familia, escuela, comunidad en la que viven.

La transición de carácter educativo permite definir el traslado de un año al siguiente o de una escuela a otra, dentro de contextos educacionales formales, las transiciones son ambivalentes para cada sujeto y tienen signos distintos para individuos diferentes. Involucran el ámbito socioeducativo porque implica lo escolar, los dispositivos institucionales; la institución como escenario educativo con sus fines, objetivos, currículo metodología, dinámica y estructura de oportunidades. En esta transición se pone énfasis en los ritos de paso, expresión ampliamente utilizada para describir acontecimientos significativos que vive el sujeto en los desplazamientos que realiza entre niveles, modalidades o entornos educativos. Las variables de análisis se relacionan con los mecanismos y acciones institucionales en cuanto a la articulación y los ritos de paso. El enfoque para estudiarlas es el ecológico porque permite analizar las experiencias e interacciones de los niños/niñas con sus compañeros, maestros y cuidadores en los entornos cotidianos de la escuela o la guardería.

Las transiciones de carácter individual involucran el ámbito personal refieren a la biografía del individuo, sus cambios físicos biológicos, desarrollos, atributos personales, autoestima, motivaciones y bienestar. Hace referencia a la relación individuo-sociedad partiendo del reconocimiento de la influencia del contexto sociocultural y las relaciones 
interpersonales en la construcción de la identidad y en la configuración de la propia historia de vida. Esta transición destaca cuestiones como la percepción del proceso, las emociones, los sentimientos, la autoestima, Las variables de análisis son sus capitales acumulados, experiencias significativas, dominios y saberes, capacidad de agencia, proyecto de vida, y estado emocional. Estudiar estas transiciones requiere de una perspectiva psicológica, en donde la transición se entiende como acontecimiento o situación en que la persona experimenta una discontinuidad importante en su trayectoria vital teniendo que desarrollar nuevas conductas como respuesta a dicha situación. 


\section{Capítulo III}

\section{Marcos políticos que regulan las transiciones en Colombia}

\section{Introducción}

La situación de la Primera Infancia es una de las mayores preocupaciones de los gobiernos de nuestro país. Actualmente se identifican diversas alarmas relacionadas con la transición que realizan los niños/niñas menores de 8 años y con la trayectoria que hacen por los diferentes niveles educativos, en particular, por los altos niveles de deserción y repitencia. Las transiciones en la primera infancia se refieren a los procesos de cambio que viven los infantes por distintos servicios educativos (el hogar, el centro de educación y cuidado temprano, el preescolar y la escuela primaria). Este cambio que da lugar a unas fases de la educación y representa un desafío afecta no solo al niño sino a su entorno y la institución por la que transita.

En Colombia la Educación Inicial y Atención Integral a la Primera Infancia (EIAIPI), atiende a los infantes desde el nacimiento hasta los 6 años. En teoría, los niños y niñas entran al sistema educativo oficial en el año de transición (Grado 0-5 años de edad), porque la estructura del sistema educativo ${ }^{8}$ señala la educación obligatoria a partir del grado transicióngrado cero. No obstante, se desarrollan dos grandes estrategias de atención educativa a la primera infancia que se enmarcan en el nivel de educación inicial y el nivel de educación formal ${ }^{9}$.

La primera estrategia de educación inicial se establece de acuerdo con lo previsto en la Política Nacional para la Atención Integral a la Primera Infancia De Cero a Siempre, atiende desde la gestación hasta los 5 años, promueve un enfoque holístico basado en los derechos que busca abordar la atención y educación de los niños/niñas además de su salud, nutrición, enseñanza, recreación y socialización. En la ciudad de Medellín es

\footnotetext{
${ }^{8}$ El sistema educativo colombiano lo conforman: la educación inicial, la educación preescolar, la educación básica (primaria cinco grados y secundaria cuatro grados), la educación media (dos grados y culmina con el título de bachiller.), y la educación superior.

${ }^{9}$ La educación formal en Colombia es aquella que se imparte en instituciones aprobadas por el Estado, en una secuencia regular de niveles, sujeta a pautas curriculares progresivas, y que lleva a obtener título
} 
operacionalizada por el programa Buen Comienzo que nace como un proyecto estratégico creado por el Concejo de Medellín y es el referente para la creación de la Estrategia Nacional de Cero a Siempre. Esta estrategia de atención a la primera infancia se da en escenarios convencionales y no convencionales como centros de desarrollo infantil, hogares comunitarios, jardines infantiles, hospitales, ludotecas, museos, bibliotecas, y se organiza en modalidades de atención institucional, familiar y comunitaria:

- Modalidad entorno familiar: brinda atención integral en cuidado, nutrición y educación inicial a familias gestantes, niñas y niños menores de 2 años y educados por sus familias, fortaleciendo la labor educativa que se brinda en el hogar en compañía de un equipo interdisciplinario (nutricionistas, pedagogos, trabajadores sociales, psicólogos, artistas y recreacioncitas). Los encuentros educativos son grupales y en el hogar, y favorecen el desarrollo de competencias para la vida.

- Modalidad entorno comunitario: brinda atención integral a las niñas y los niños menores de 5 años acogidos actualmente por los hogares comunitarios del Instituto Colombiano de Bienestar Familiar (ICBF), como complemento educativo a los servicios de cuidado y nutrición.

- Modalidad entorno institucional: dirigida a niñas y niños ubicados en zonas rurales y urbanas entre 2-5 años atendidos por instituciones especializadas en atención integral donde se ofrecen los componentes de cuidado, nutrición y educación inicial durante 5 días de la semana, en jornadas de 8 horas diarias y en articulación con la escuela.

La segunda estrategia de atención educativa a la primera infancia se enmarca en la educación formal nivel de preescolar que comprende el grado obligatorio destinado a los infantes entre los 5 y 6 años (grado transición). Su objetivo es potenciar el desarrollo integral de las niñas y niños en los aspectos biológicos, cognoscitivo, psicomotriz, socio-afectivo y espiritual a través de experiencias de socialización pedagógicas y recreativas (Ley General de Educación 115/1994, Art. 15). Este nivel comprende tres grados: prejardín, jardín y transición siendo el último un grado obligatorio para la educación formal y en el que siempre haremos referencia en esta tesis.

La Educación Básica es identificada en el artículo 356 de la Constitución Política como Educación Primaria y Secundaria. La Educación Básica Primaria corresponde al ciclo 
de los (5) primeros grados- de primero a quinto (desde los 6 hasta los 10 años de edad) y la Educación Básica Secundaria corresponde al ciclo de los cuatro (4) grados de sexto a noveno (desde los 11 hasta los 15 años de edad). La Educación Básica comprende nueve grados y se estructura en torno a un currículo común conformado por las áreas fundamentales del conocimiento y de la actividad humana (Ley 115. Art.19). Finalmente, la Educación Media comprende dos grados, decimo y onceavo, enfocados en una educación académica o técnica.

De esta forma la educación en Colombia es un derecho ciudadano y una prioridad del gobierno. De conformidad con la Constitución de 1991 y la Ley General de Educación de 1994, todos los colombianos tienen derecho a acceder a la educación para su desarrollo personal y para el beneficio de la sociedad. La educación obligatoria actualmente es de 11 años, desde los 5 hasta los 16 años de edad.

En este sentido vemos que los itinerarios que debe recorrer un estudiante se componen de diferentes grados y niveles por los que transita para el logro efectivo de su trayecto. Por ejemplo, se espera que un estudiante a los 16 o 17 años pueda culminar un primer ciclo escolar y avanzar hacia una etapa de profesionalización. Sin embargo, en los itinerarios que el estudiante realiza entre entornos educacionales diferentes y grados escolares, se observan altos índices de deserción y repitencia en los grados de transición y primero de la Educación Básica lo que se convierten, para el país, en una situación crítica que exige el compromiso y análisis de la comunidad académica y de las burocracias locales.

Tabla 3 Tramos de escolarización obligatorios, Colombia 2017

\begin{tabular}{|c|c|c|c|c|c|c|c|c|c|c|c|c|c|c|}
\hline Edad & 3 & 4 & 5 & 6 & 7 & 8 & 9 & 10 & 11 & 12 & 13 & 14 & 15 & 16 \\
\hline Estandarización & NI & NI & NI & $\mathrm{P}$ & $\mathrm{P}$ & $\mathrm{P}$ & $\mathrm{P}$ & $\mathrm{P}$ & M & M & M & M & M & M \\
\hline $\begin{array}{l}\text { Escolarización } \\
\text { obligatoria }\end{array}$ & & & \multicolumn{10}{|c|}{ OBLIGATORIO } & & \\
\hline $\begin{array}{l}\text { Denominación } \\
\text { original del nivel }\end{array}$ & \multicolumn{3}{|c|}{$\begin{array}{l}\text { Educación } \\
\text { Preescolar }\end{array}$} & \multicolumn{5}{|c|}{$\begin{array}{c}\text { Educación General Básica - } \\
\text { Primaria }\end{array}$} & \multicolumn{4}{|c|}{$\begin{array}{c}\text { Educación General Básica - } \\
\text { Secundaria }\end{array}$} & \multicolumn{2}{|c|}{$\begin{array}{c}\text { Educación } \\
\text { Media }\end{array}$} \\
\hline
\end{tabular}

Fuente: SITEAL- TABLA. Equivalencias en los niveles educativos establecidos en la Ley Nacional de Educación y la Clasificación Normalizada de la Educación* (1997).

De acuerdo con esta estructura y equivalencias se espera que a los 5 años los niños y niñas estén escolarizados en el nivel inicial, grado transición en tanto este nivel es obligatorio en Colombia. En el período 2003-2016 se observó una expansión de la escolarización a la 
edad de 5 años de 11 puntos porcentuales, alrededor del 88,7\% de los niños de esta edad se hallaban matriculados. No obstante, como lo muestra la tabla 5, el porcentaje de niñas-niños de 5 años de sectores bajos matriculados está por debajo del $80 \%$ en tanto supera el $90 \%$ en niñas-niños de 6 años lo que estaría mostrando que aun los niños y niñas no asisten en un 100\% a los programas de Educación Inicial y Preescolar.

Tabla 4 Tasa de escolarización de los niños de 5 y 6 años

\begin{tabular}{|c|c|c|c|c|c|c|c|c|c|c|}
\hline \multicolumn{11}{|c|}{$\begin{array}{l}\text { Tasa de escolarización de los niños de } 5 \text { y } 6 \text { años según nivel socioeconómico del hogar y nivel educativo al que } \\
\text { asisten- Colombia 2003-2016 }\end{array}$} \\
\hline \multirow{2}{*}{ Edad } & \multicolumn{2}{|c|}{ Bajo } & \multicolumn{2}{|c|}{ Medio } & \multicolumn{2}{|c|}{ Alto } & \multicolumn{2}{|c|}{ TOTAL } & \multicolumn{2}{|c|}{$\begin{array}{l}\% \text { que asiste al primario } \\
\text { entre quienes asisten }\end{array}$} \\
\hline & 2003 & 2016 & 2003 & 2016 & 2003 & 2016 & 2003 & 2016 & 2003 & 2016 \\
\hline 5 años & 64,5 & 80,4 & 86,0 & 90,2 & $*$ & 95,6 & 77,7 & 88,7 & $\mathrm{n} / \mathrm{c}$ & $\mathrm{n} / \mathrm{c}$ \\
\hline 6 años & 84,7 & 93,3 & 94,7 & 97,5 & 97,9 & 98,4 & 90,6 & 96,6 & 77,6 & 78,1 \\
\hline
\end{tabular}

Fuente: SITEAL con base en Encuesta Nacional de Hogares (ECH) 2003 y Gran Encuesta Integrada de Hogares (GEIH) 2016 - DANE

Sin embargo, es importante destacar que en los informes del Ministerio de Educación Nacional (MEN, 2015 y 2016); del Departamento Nacional de Planeación (DNP, 2017) y de la Organización para la Cooperación y el Desarrollo Económicos (OCDE, 2018) se destacan avances pero también desafíos y retos en correspondencia con el ingreso al sistema de educación formal, la continuidad entre los servicios de primera infancia-escolarización y los mecanismos para facilitar la transición desde los servicios de primera infancia hacia el grado de transición y primero.

Tabla 5 Avances desafíos y retos en los procesos de transición educativa en Colombia

\section{Avances desafíos y retos en los procesos de transición educativa en Colombia}

Informes

Ministerio de Educación

Nacional (2015)

\section{Descripción}

A pesar de los esfuerzos de ampliar el número de inscritos en preescolar, la existencia de múltiples proveedores implica que aproximadamente 1 millón de niños con edades entre 3 y 6 años son atendidos en las modalidades de educación inicial atención integral a la primera infancia (EIAIPI) y no han 
ingresado al sistema de educación formal (MEN, 2015). Solo dos tercios de los niños de 5 años son matriculados en el grado de transición antes de iniciar la escuela primaria, Si bien Colombia promueve un enfoque integrado de EIAIPI, el componente educativo está poco desarrollado

Aunque el índice bruto de niños matriculados entre 5 años en Colombia es del $89 \%$, solo el 57\% están en el grado apropiado (el año de transición), lo cual está

Ministerio de Educación Nacional (2016)

Organización para la cooperación $\quad \mathrm{y}$ desarrollo económicos (OCDE, 2016)

Departamento Nacional de Planeación (DNP 2017). Plan Nacional de desarrollo 2014-2018)

Organización para la cooperación y el desarrollo económicos (OCDE, 2018)
20 puntos porcentuales por debajo del promedio de la OCDE. Se destaca la necesidad de garantizar que todos los niños colombianos efectúen la transición escolar a los cinco años, así como la importancia de reforzar la continuidad entre los servicios de primera infancia y escolarización, para garantizar que el grado de transición cumpla con eficacia la función de puente

Los porcentajes de participación son bajos respecto a los estándares de la OCDE: solo el $48 \%$ de los niños de 3 años y el $75 \%$ de los niños de 4 años están matriculados en educación para la primera infancia, frente a los promedios respectivos del $70 \%$ y el $82 \%$ de la OCDE (OCDE, 2014)

La deserción escolar afecta a los niños más que a las niñas, tanto en la educación primaria como en la secundaria y la tasa de abandono es mayor en áreas rurales que en urbanas y en los niveles más altos. Entre 2015 y 2016, la tasa de deserción intra-anual de educación preescolar, básica y media aumentó de $3,26 \%$ (2015) a $3,74 \%$ (2016)11 DNP (2017)

Existen pocos mecanismos para facilitar la transición desde los servicios de primera infancia hacia el grado de transición y a la escolarización. Colombia tendrá que llenar estos vacíos si quiere ofrecer a sus niños una transición exitosa a la escuela y romper patrones de ingreso tardío y escasa preparación, que son perjudiciales para el aprendizaje y poco eficientes para el sistema

Fuente: Elaboración Propia

Por lo anterior se puede decir que actualmente los servicios de educación inicial y atención integral a la primera infancia (EIAIPI) han mejorado; la expansión del acceso a la educación y el cuidado de la primera infancia con la política de Cero a Siempre han contribuido a ofrecer a todos los niños y niñas un Buen Comienzo. No obstante, los informes dan cuenta de la necesidad de incrementar la cobertura y la articulación entre los escenarios 
de nivel inicial y formal para facilitar las transiciones de los niños y niñas, aun cuando destacan los esfuerzos que viene sosteniendo el Ministerio de Educación Nacional para asegurar el acceso y la permanencia, promover la pertinencia y calidad del proceso pedagógico.

En este sentido, y para comprender cuales son las representaciones sociales, los sentidos y significados que se asignan a las categorías infancia, transiciones y trayectorias, en los próximos apartados se realiza un análisis de contenido en el que se retomaron un total de 24 documentos clasificados en lineamientos técnicos, conceptuales, administrativos, educativos, orientaciones, rutas, acuerdos municipales, resoluciones, decretos, leyes, documentos orientadores e informes de balance a nivel Nacional y Municipal desde el 2006 al 2018 dado que es el período en el que se encuentran registros con orientaciones para el proceso de transición entre niveles e instituciones educativas que atienden a la infancia. ${ }^{10}$

Esta información se organiza de la siguiente manera: en el primer apartado, se analizan los antecedentes históricos de la Política de Primera Infancia en Colombia y como se ha transformado la organización del sistema para la Educación Infantil; en el segundo apartado, se analiza la concepción del niño-niña y la conceptualización que se hace en relación a la transición, articulación y la educación inicial; finalmente, el tercer apartado refiere al proceso de transición entre lo exitoso y armonioso presente en las políticas públicas de atención a la primera infancia.

\subsection{Antecedentes de la Política de Primera Infancia en Colombia}

Durante los últimos 30 años se han efectuado reformas importantes en la política educativa destinada a las niñas y niños (EIAIPI). El interés por la primera infancia emerge fundamentalmente a mediados de la década de los ochenta cuando, en el proceso de producción de una política para el desarrollo de la primera infancia en Colombia, se crea en el año 1985 el Plan Nacional para la Supervivencia y el Desarrollo Infantil (SUPERVIVIR) con el propósito de promover el desarrollo infantil y mejorar las condiciones de salud y

\footnotetext{
10 Anexo VI se encuentra la información sistematizada en la tabla №11 anexo 6 "Normas políticas y
} orientaciones para el proceso de transición en Colombia". 
nutrición de las niñas y los niños. Este plan fue innovador en varios sentidos: la concepción del proceso de salud, el papel que se atribuye a las prácticas y conocimientos de las personas, su perspectiva intersectorial y sus estrategias metodológicas, definiciones que por primera vez se introdujeron en las acciones estatales y sociales a favor de la infancia. (CONPES-109: 2007)

En el año 1986 se adopta el programa de hogares comunitarios del Instituto Colombiano de Bienestar Familiar $(\mathrm{ICBF})^{11}$ como la principal estrategia de atención a los menores de 7 años. En esta época, el país avanza considerablemente en el proceso de diseñar una Política Nacional de Primera Infancia cuando ratifica la Convención Internacional sobre los Derechos del Niño (1990) a través de la Ley Nº12 del 22 de enero de 1991. Esta norma introduce un cambio en la concepción social de la infancia, en tanto las niñas y niños comienzan a ser reconocidos como sujetos sociales y como ciudadanos con derechos en contextos democráticos.

Dado este importante evento de la convención internacional sobre los derechos de los niños/as a nivel mundial y nacional, para el año 1992 los gobiernos realizan esfuerzos orientados a lograr la coordinación intersectorial entre las entidades gubernamentales como el sistema de Bienestar Familiar, los programas para el desarrollo de la primera infancia en las administraciones locales que venían adelantando debates con respecto a la protección, el desarrollo de los niños/as y la perspectiva de derechos como marco ético para la planeación de políticas y programas en beneficio de la infancia; finalmente el sector salud que para la época estaba desarrollando el programa de Crecimiento y Desarrollo ${ }^{12}$. Sin embargo, de acuerdo a Torrado y Guaqueta (2009) a mediados de los años noventa el tema de la primera infancia pierde relevancia en la agenda pública en Colombia, en tanto se instaura un gobierno neoliberal que desmonta el estado de bienestar dejando al ICBF y al programa de hogares comunitarios la responsabilidad de los niños/niñas menores de 6 años.

\footnotetext{
${ }^{11}$ El Instituto Colombiano de Bienestar Familiar - ICBF, es la entidad del estado colombiano que trabaja por la prevención y protección integral de la primera infancia, la niñez, la adolescencia y el bienestar de las familias en Colombia, brindando atención especialmente a aquellos en condiciones de amenaza, inobservancia o vulneración de sus derechos.

12 Este programa venia incorporando concepciones de desarrollo integral, trascendiendo el énfasis en la enfermedad y promoviendo una atención más integral del bienestar de niños y niñas, a la vez que estaba permitiendo la asimilación de propuestas con el enfoque del ciclo vital.
} 
A partir del año 2002 la atención para la primera infancia vuelve a posicionarse en la agenda pública del país como resultado de dos importantes acciones gubernamentales: el plan de desarrollo hacia un estado comunitario y el foro de primera infancia que contribuyeron al aumento de la inversión y la implementación de estrategias políticas en pro de la primera infancia. La primera acción, plan de desarrollo "hacia un estado comunitario", tuvo como propósito la ampliación de la cobertura para garantizar el acceso a la educación de la población más pobre, a través de una serie de programas de desarrollo infantil; la segunda, foro "primera infancia y desarrollo: el desafio de la década", puso de manifiesto los altos índices de mortalidad infantil, desnutrición, repitencia en el primer grado, la situación de desplazamiento y violencia que viven las niñas y niños en Colombia, y la necesidad de que esta problemática se vuelva una prioridad para el Estado contando para ello con políticas públicas específicas y una mayor inversión social.

Tras años de debate y construcción colectiva de movilizaciones sociales que contaron con la participación de diferentes actores del ámbito de la salud, educación y bienestar, se aprueba en el (2007) la política pública nacional de primera infancia, Colombia por la primera infancia (CONPES 109). Enmarcado en el Plan Nacional de Desarrollo y consolidado por los compromisos adquiridos en la Convención Internacional sobre los Derechos de los Niños, promueve el desarrollo integral de los niños y niñas desde la gestación hasta los 6 años de edad respondiendo a sus necesidades y características específicas, y contribuyendo así al logro de la equidad e inclusión social en Colombia.

Paralelamente a la formulación de esta política, el país fue testigo también de todo un proceso de discusión alrededor de los derechos de la niñez. La ratificación de la convención de los derechos del Niño (1989) cambia la perspectiva desde donde históricamente se pensaba la infancia, esto es, de considerarlos objetos de protección y tratamiento especial a representarlos como sujetos activos y protagonistas de su propia vida. Este cambio de paradigma se cristaliza con la promulgación de la Ley 1098 de 2006 o Código de Infancia y Adolescencia, con la cual se institucionalizó la perspectiva de derechos como la forma de entender el papel de la niñez en la sociedad colombiana (Viscaíno, Ramirez, y Cuéllar, 2010).

El cambio de paradigma y orientaciones legislativas en el país se convierten en prioridad para las agendas públicas y abre el camino para visibilizar y trazar acciones en 
busca de garantizar el derecho a una educación inicial de calidad que tienen todas las niñas y los niños menores de seis años. En el año 2011 la Educación Inicial Atención Integral a la Primera Infancia (EIAIPI) se convirtió en una prioridad gracias a la adopción de la Estrategia para la Atención Integral de la Primera Infancia-De Cero a Siempre, dirigida a promover y garantizar el desarrollo infantil de las niñas y los niños, estrategia que articula y promueve el desarrollo de planes, programas, proyectos y acciones en favor de la atención integral para cada niño y niña de acuerdo con su edad, contexto y condición; cobijando aspectos básicos que ellos requieren para su normal y adecuado desarrollo, como educación inicial, nutrición, protección, salud y cuidado. Dicha estrategia busca avanzar hacia el trabajo intersectorial tanto en el sector privado como en el sector público, además de reducir las brechas de desigualdad, aumentar la calidad y la cobertura de los programas de primera infancia. Es una política de estado para el Desarrollo Integral de la Primera Infancia (Ley Nº1804/2016).

Actualmente la regulación del sistema educativo colombiano está prevista en la Constitución Política de Colombia de 1991, mientras que la Ley General de Educación (Ley $\left.\mathrm{N}^{\circ} 115 / 1994\right)$ responde al principio constitucional del derecho que tiene toda persona a recibir educación y se define como "un proceso de formación permanente, personal, cultural y social que se fundamenta en una concepción integral de la persona humana, de su dignidad, de sus derechos y de sus deberes" (Ley N¹15/1994:1).

\subsection{Pasado y presente del proceso de transiciones en la Educación Inicial en Colombia}

En Colombia hablar del proceso de transiciones tiene como punto de partida la década de los años 60, época en la que se pone de manifiesto la desarticulación entre los grados de transición y primer grado de la básica primaria como una preocupación nacional, y se evidencia el fracaso escolar en las alarmantes tasas de deserción y repitencia en los grados de primaria, en la escasa flexibilidad del currículo y la enseñanza. Este estado de situación exige tomar medidas y acciones para mejorar la calidad del sistema educativo. De acuerdo con lo planteado por Abello (2008), para este periodo se replantearon algunas directrices que buscaban una mayor articulación entre el preescolar y la primaria, y perseguían (1) garantizar una continuidad que permitiera superar las fracturas reconocidas entre estos dos niveles, (2) 
mejorar las condiciones de calidad de la educación y (3) disminuir el fracaso escolar especialmente en el grado primero.

Dichas medidas permitieron que en el año 1987 se revisaran los objetivos del primer grado de cara a un replanteamiento del currículo. En dicha oportunidad, se consideró que la flexibilización del primer grado no era suficiente y se vio necesario ampliar la cobertura para el grado preescolar considerándolo el primer grado de básica primaria Así, en 1992 surge el grado cero o transición como modalidad alternativa de atención al preescolar que constituyó el inicio mínimo obligatorio de la educación básica. Este grado, además de aportar al logro de los propósitos generales del sistema educativo, tenía como finalidad contribuir al desarrollo integral y armónico de los niños y niñas de 5 a 6 años, y facilitar la transición de los infantes entre la vida de la familia, la comunidad y la vida escolar, así como el reconocimiento y apropiación de la escuela por parte de los niños/niñas como espacio de socialización (Cerda, 1996: 121).

Al considerarse el grado transición como el primer nivel de la básica primaria se esperaba que este contrarrestara los índices de repitencia y mejorara la calidad de la educación colombiana. Curiosamente al no existir una norma que diera piso legal a esta modalidad no se resuelve el problema de cobertura esperada dentro del contexto de preescolar, y se acrecienta el problema de la edad en tanto los niños y niñas empiezan a ingresar al grado primero sin realizar transición y sin cumplir con las competencias para este nivel evidenciando, de esta forma, un problema con la articulación entre niveles y las expectativas de aprendizaje.

En correspondencia con esta situación el Ministerio de Educación, alertado por los altos índices de deserción y repitencia registrados, realiza un estudio denominado “Articulación del preescolar y el primer grado: diagnóstico sobre saberes, prácticas y sugerencias de los maestras" en el cual se observa que la articulación es uno de los principales problemas en los procesos de transición entre niveles e instituciones, y constituye un proceso complejo que requiere de cambios organizativos, investigativos y de gestión curricular (Alvarado y Suárez, 2002). Esta investigación fue fundamental para que el Ministerio diera relevancia al tema de la articulación en los procesos de transiciones, propuesta clave para las agendas políticas nacionales y locales. De esta forma se elabora el 
marco general para un modelo de articulación del preescolar y la primaria como un fundamento de la política pública de primera infancia desde la gestación hasta los seis años, y se producen una serie de documentos dirigidos a las escuelas normales y a los maestros en ejercicio.

Es preciso señalar que las referencias específicas al tránsito educativo en las políticas públicas de primera infancia tienen lugar a partir del año 2007 con la Política Pública Nacional de Primera Infancia, "Colombia por la primera infancia”, en la que se establecen siete aspectos $^{13}$ necesarios para ofrecer una educación de calidad en la primera infancia. (MEN, 2007). Sin embargo, según Alvarado y Suárez (2010), aun cuando se hacen referencias puntuales al tema de transiciones, el documento no conceptualiza las transiciones escolares ni los mecanismos y estrategias de articulación hogar-preescolar-primaria. Asimismo, no hace ninguna referencia al tema de transiciones en poblaciones rurales, indígenas y de fronteras, y no establece cuáles deberían ser las estrategias de articulación para materializar los proyectos pedagógicos pertinentes que respondan a criterios de flexibilidad para adaptarse a las realidades cambiantes en que se desenvuelve el niño y la niña.

Tomando en consideración estos resultados y la preocupación nacional de cobertura, accesibilidad y calidad, el Ministerio de Educación Nacional como rector de la política pública de Educación Inicial y el Instituto Colombiano de Bienestar Familiar -entidad operadora de los servicios de educación inicial en el marco de la atención integral-articulan acciones para poder definir los lineamientos técnicos y operativos para dicho desarrollo. Así, el ICBF presenta en el año 2014 la Guía Orientadora № 8 "Guía para la transición de los niños y las niñas desde los Programas de atención a la Primera Infancia del ICBF al grado transición”. Esta guía plantea la necesidad no solo de centrar la mirada en el proceso de

\footnotetext{
13 Aspectos necesarios para ofrecer una educación de calidad en la primera infancia: Que todos los niños alcancen un nivel satisfactorio en su desarrollo; Asumir la educación inicial como una estrategia primordial de equidad; Generar una oferta pertinente de educación inicial; Construir orientaciones pedagógicas que den cuenta de acciones educativas con sentido a través del juego, el arte y el desarrollo del lenguaje; Lograr un tránsito exitoso de los niños a la educación básica, asumiendo institucionalmente las articulaciones requeridas entre los niveles de educación inicial y básica; Desarrollar un programa supra sectorial de formación de agentes educativos; El fortalecimiento de los entes territoriales en la implementación de la Política Educativa de Primera Infancia.
} 
matrícula sino empezar a pensar la articulación sobre el quehacer pedagógico mismo, en el que se favorezca la transición armónica de las niñas y niño en el entorno educativo (ICBF, 2014: 23).

En el año 2016 el ICBF presenta el documento anexo de servicio preescolar integral cuyo objetivo principal es garantizar la atención integral de los niños y niñas matriculados en los grados pre jardín, jardín y transición de acuerdo a las orientaciones, líneas técnicas y disposiciones generales de la Ley 1804/2016. De este modo, se contempló no solo los niños y niñas pertenecientes a la modalidad institucional, sino que se movilizó hacia la educación formal comprendiendo la transición como los momentos críticos de cambio que viven los niños y las niñas al pasar de un ambiente a otro. Finalmente presenta en el año 2017 la Guía Orientadora para el tránsito de los niños y niñas desde los Programas de atención a la Primera Infancia del ICBF al nivel de Educación Formal, la cual se constituye como un complemento a la Guía Orientadora $N^{\circ} 8$. En esta guía se oficializan las estrategias para la articulación de acciones en términos de acceso, en los sistemas de información y en las condiciones de operación y de los procesos pedagógicos, evidenciando un traslado del concepto de transiciones armónicas a transiciones educativas. ${ }^{14}$

Por su parte el Ministerio de Educación Nacional (MEN) establece para el año 2016 la ruta del proceso de transición armónica de los niños y niñas al Sistema de Educación Formal al que llama "grado transición". En este documento se habla de transición armónica o tránsito que alude al proceso de paso entre niveles y grados educativos. Los momentos que se plantean en dicha ruta se relacionan con la capacidad institucional para la gestión de matrícula, asignación de cupos, ampliación de cobertura y demanda en la atención.

En este mismo tiempo (2016) se construye el documento Todos Listos $^{15}$ que se constituye en uno de los referentes técnicos de la Educación Inicial de calidad en el marco de la Estrategia de Atención Integral a la Primera Infancia "De Cero a Siempre” y la política

\footnotetext{
${ }^{14}$ Este traslado de concepto se está realizando especialmente en el Instituto colombiano de Bienestar familiarLas demás instituciones como por ejemplo el programa Buen comienzo y el sistema de Educación Formal aún siguen hablando de transiciones armoniosas y exitosas en sus documentos y orientaciones técnicas pedagógicas. ${ }^{15}$ El presente documento está organizado en 4 apartados: en el primero se abordan las transiciones en el entorno educativo; en el segundo se describen los actores involucrados en las transiciones de las niñas y niños, en el tercero se presenta la RIA Ruta Integral de Atenciones para acompañar las transiciones y por último, se presentan las orientaciones metodológicas las cuales contienen una serie de guías y herramientas de trabajo que orientan la puesta marcha de la estrategia.
} 
educativa de Colombia. Con este documento el Estado busca direccionar acciones para acompañar las transiciones de las niñas y los niños en su ingreso al sistema educativo, busca asegurar el acceso, la permanencia de los niños y niñas y promover la pertinencia y calidad del proceso pedagógico, plantea estrategias de trabajo articulado para la organización del trabajo pedagógico (MEN, 2016). A nivel municipal la Secretaria de Educación de la ciudad de Medellín y el programa Buen Comienzo definen las siguientes orientaciones técnicas y administrativas.

Tabla 6 Orientaciones técnicas y administrativas a nivel municipal

Objeto de la norma

Concejo de Medellín [Acuerdo 58 de 2011] Política Pública de Atención Integral a la Primera Infancia.Programa Buen Comienzo

Secretaria de Educación Resolución Número 501 de (2012).

Concejo de Medellín Acuerdo 54 de (2015) Por medio del cual se redefine la regulación municipal sobre la Política Pública de Primera Infancia y el Programa Buen Comienzo Gaceta Oficial 4356 Alcaldía de Medellín
Por medio del cual se adopta la Política Pública de Atención Integral a la Primera Infancia Buen Comienzo, se desarrolla un Sistema de Atención Integral y se modifica el Acuerdo 14 de 2004 cuyo objetivo es garantizar que los niños y las niñas del Municipio de Medellín, desde la gestación hasta los cinco años de edad, puedan disfrutar de un desarrollo adecuado, integral, diverso e incluyente en su primera infancia. El programa Buen Comienzo, será desarrollado con un enfoque inter-institucional de educación inicial desde la atención integral por todas las secretarias comprometidas con el mismo teniendo en cuenta el ciclo vital, la protección de los derechos y la articulación inter-institucional e intersectorial.

Por medio de la cual se regula la prestación del servicio de Atención Integral a la Primera Infancia en desarrollo del Programa Buen Comienzo uno de sus objetivos es acompañar el proceso de articulación educativa y entrega pedagógica, el diseño, orientación e implementación de estrategias que garanticen la continuidad de la participación de los niños, las niñas y sus familias evitando su deserción

Por medio del cual se redefine la regulación municipal sobre la Política Pública de Primera Infancia y el Programa Buen Comienzo. La educación inicial en el marco de la atención integral será concebida en el Municipio de Medellín como el primer nivel en el continuo de la educación, la cual se desarrollará en Medellín hasta los ocho (8) años, mediante la articulación y la búsqueda de las condiciones para que se dé un tránsito exitoso con la educación regular. En esta versión se incorpora una visión frente al curso de vida tal enfoque precisa elementos como el contexto histórico, social y político, y diferenciales como lo territorial, el género, la etnia, entre otros, que permite interpretar las transiciones del individuo y su familia como parte de un proceso continuo e interactivo de cambio histórico 
Por medio de la cual se regula la prestación del servicio de Atención Integral a la Primera Infancia en desarrollo del programa Buen Comienzo. Precisa el tema de la cobertura entendida como Secretaria de Educación (2016). la garantía del cupo para la atención integral del niño y la niña y Resolución Número 010548 Por el cual su permanencia. De allí que esta sea una gestión permanente de se reglamenta el acuerdo 58 de la acompañamiento a las familias, articulaciones y procesos de Alcaldía de Medellín seguimiento que, aunque inician con la matrícula, deben permanecer durante todo el proceso de atención. Este componente incluye procesos relacionados con la focalización, matrícula y manejo del sistema de información.

Ruta que busca fortalecer el proceso de transición armónica de Secretaria de Educación Antioquia niños y niñas al sistema educativo formal garantizar el acceso al (SEDUCA) Circular 000228 grado transición de los niños y las niñas entre los 5 y los 6 años. (K2017090000228) Orientaciones para Plantea la necesidad de una articulación educativa interfortalecer el proceso de transición institucional e intersectorial que posibiliten un tránsito armónico armónica de la educación inicial a la a la educación y su permanencia en el sistema educativo. Además, educación formal para el año 2017 busca asegurar el acceso, permanencia y, por otro, promover la Gerencia de Infancia, Adolescencia y pertinencia y calidad del proceso pedagógico. Realizar el tránsito Juventud. armónico permite garantizar el derecho a la educación de los niños y las niñas.

Secretaría de Educación Programa Buen Comienzo Medellín (2018/2019) Las transiciones representan los momentos de cambio o Lineamientos Conceptuales y Técnicos transformación que se suceden a lo largo de la vida, resultado de para la operación de las modalidades de situaciones o acontecimientos importantes que se viven, incluso, Atención del Programa Buen Comienzo desde antes de nacer, plantea la visión de espacios transicionales, Municipio de Medellín Secretaría de define como acciones fundamentales la entrega y la recepción Educación Programa Buen Comienzo pedagógica Medellín (2018).

Fuente: Elaboración Propia

Analizando estas orientaciones se puede señalar que en lo referente al proceso de transición y trayectoria el foco está puesto en posibilitar una articulación educativa interinstitucional e intersectorial que posibiliten la continuidad y permanencia de los niños, las niñas en el sistema educativo. Por ello la búsqueda de estrategias y condiciones que hagan posible la ampliación de la cobertura, así como el acompañamiento a las familias constituyen actualmente una prioridad pues se busca evitar la deserción y lograr, por un lado, la permanencia y, por el otro, un tránsito armonioso hacia la educación regular.

Tanto a nivel nacional como regional los documentos oficiales conciben la educación inicial como un proceso educativo-pedagógico continuo, intencionado, que propone oportunidades, situaciones y ambientes para promover el desarrollo de interacciones oportunas pertinentes y estructuradas a través de las cuales los niños y niñas, de acuerdo con 
sus circunstancias, condiciones y posibilidades, desarrollan su potencial, capacidades, habilidades y adquieren competencias para la vida. Se fundamenta en el juego, el arte, la literatura y la exploración del medio, no busca como fin último su preparación para la escuela primaria, sino que les ofrece experiencias retadoras que impulsen su desarrollo; allí juegan, exploran su medio, se expresan a través del arte y disfrutan de la literatura y las interacciones.

En este orden de ideas la Atención Integral a la Primera Infancia se comprende como la forma a través de la cual los actores responsables de garantizar el pleno desarrollo de los niños y las niñas, materializan de manera articulada el conjunto de acciones para garantizar el goce efectivo de los derechos de los niños y las niñas de primera infancia y promover el máximo potencial de su desarrollo y aprendizaje. Esta atención se fundamenta en el reconocimiento del niño y la niña, desde la gestación hasta cumplidos los seis (6) años, y se enmarca desde el enfoque de derechos, el desarrollo humano, la protección integral y el curso de vida, bajo los siguientes criterios:

- Sistemática: Procesual, planeada, monitoreada y evaluada mediante registro documental permanente.

- Oportuna y pertinente: Desarrolla acciones de acuerdo con el momento del ciclo vital y con las características de los sujetos participantes.

- Con calidad. Consolidándose como un modelo de atención orientador, con parámetros y estándares de calidad claros desde lo conceptual, lo metodológico y lo evaluativo.

- Transdisciplinar: Orientada por una comprensión de la primera infancia desde las ciencias sociales, de la educación, de la salud, y económicas, entre otras, abordando la complejidad, diversidad y particularidad de este momento del ciclo vital.

- Articuladora: Propende por la garantía de todos los derechos de la primera infancia, por lo cual todas las instancias responsables y corresponsables actuarán de manera coordinada y efectiva.

- La educación inclusiva: Promoción de ambientes sin barreras actitudinales, de conocimiento, prácticas y de comunicación para la participación y el aprendizaje de todos los niños y las niñas. 
Desde su estructura y organización administrativa la educación inicial busca articular los procesos de interacción educativa con los niños y niñas reconociendo las particularidades que caracterizan su desarrollo infantil, y propone como uno de sus objetivos ampliar la cobertura y continuidad en el sistema de Educación Preescolar y formal. De allí, que esta sea una gestión permanente de acompañamiento a las familias, articulaciones y procesos de seguimiento que, aunque inician con el proceso de matrícula desde el nivel de atención integral en este caso programa Buen Comienzo deben permanecer durante todo el proceso de atención educativa.

La concepción de niño y niña presente en los documentos oficiales responde a una perspectiva de derechos humanos, y hace foco en la protección, el desarrollo, la integralidad, la participación y corresponsabilidad en la atención de la infancia. Asimismo, considera a niñas y niños protagonistas en la construcción de sus aprendizajes, con capacidades para crear, imaginar, resolver situaciones de la vida cotidiana y enfrentar desafíos, encontrando oportunidades necesarias para su desarrollo con el acompañamiento afectuoso e inteligente de adultos/as significativos.

Se aprecia en esta construcción que la configuración de niño-niña asume una perspectiva holística de los derechos y el desarrollo infantil, implicando la coparticipación en su propio desarrollo, reconociendo las características y capacidades de niños y niñas como sujetos contextuados; seres activos que se desenvuelven en la vida social y que no solo construyen su propia subjetividad a partir de las interacciones que establecen, sino que cuentan con capacidades para expresar y darle sentido a su propia vida.

En consecuencia, es esta noción de niño y niña la que ha conducido al desarrollo de acciones, estrategias y orientaciones para brindarles una atención adecuada y la que ha puesto en debate el proceso de transición y articulación de las instituciones educativas en el país. Garantizar que los niños y niñas puedan continuar con la atención integral en el sistema de educación formal es el punto de quiebre por las diferencias que presentan ambos sistemas.

Esta representación asociada directamente al desarrollo infantil y al paso entre modalidades y entornos de la educación (hogar, modalidad familiar, comunitaria, preescolar) constituye un reto para el sistema educativo. En la búsqueda por aumentar las tasas de cobertura, disminuir las desigualdades, detectar y dar respuesta a las condiciones de las 
salidas, ausencias y transiciones de los niños y niñas de los programas de Primera Infancia, el Ministerio de Educación concentra todos los esfuerzos en mejorar la articulación interinstitucional.

La articulación es entendida como una acción colectiva horizontal, donde diversos actores, sectores e instituciones aúnan esfuerzos y recursos para alcanzar objetivos comunes en aras de generar transformaciones y nuevas oportunidades; una acción relevante dentro de los procesos educativos porque garantiza los tránsitos exitosos a lo largo de los primeros años de los niños y niñas. En correspondencia con los documentos oficiales, una adecuada articulación da los cimientos para una educación con calidad que inicia en la primera infancia y que se continúa a lo largo de la vida, marca de manera determinante los procesos de socialización y el desarrollo infantil.

La estructura de la articulación se establece con orientaciones antes, durante y después de la transición, ligadas al componente pedagógico, administrativo y familiar para garantizar proximidad y continuidad, es decir, experiencias que faciliten al niño un acercamiento a ese nuevo contexto. La articulación se establece a partir de:

1. Entrega pedagógica: se refiere a la entrega y la recepción pedagógica. La recepción se refiere a la acogida y recibimiento intencionados y afectuosos de los niños y las niñas por parte de las familias, adultos/as, personas significativas, agentes educativos, maestras y otros actores comprometidos en los procesos de transiciones; la entrega es el paso que dan la familia, el agente educativo y otras personas significativas para que los niños y las niñas sean recibidos en otros escenarios para la atención integral o la educación formal.

2. Intercambios pedagógicos: Espacios pensados para que los niños y las niñas puedan tener experiencias cercanas a las IED y a las modalidades, a través del reconocimiento y apropiación de los nuevos espacios; se estructura a través de las pasantías (visitas de una jornada o de un día completo viviendo la experiencia del grado, o acompañando una experiencia pedagógica intencionada).

3. Encuentros con familias: se plantean como estrategias que convocan y generan espacios de participación de las familias de los niños y las niñas, con el propósito de que conozcan el sentido de cada nivel educativo y su incidencia en el desarrollo y 
aprendizaje, entendiendo el contexto familiar como actor corresponsable de la garantía de los derechos de las niñas y los niños.

4. Mesas de trabajo: Concertar, diseñar y planear con las Secretarias de Educación y las modalidades de educación inicial en el marco de la atención integral encuentros con los agentes educativos para el dialogo inter-institucional.

5. Estrategias con los niños y niñas: disponer a los niños y niñas para el proceso de cambio que van a experimentar, realizar charlas, actividades pedagógicas y experiencias motivadoras que generen expectativa y motivación frente a la nueva etapa de su vida.

En síntesis, la representación social sobre la infancia presente en las actuales orientaciones políticas del país se ha ido reconstruyendo a partir de nuevos mapas conceptuales que han evolucionado en el tiempo y la historia, y de un debate público en el que se ha puesto en cuestión la conceptualización sobre las infancias y los recorridos escolares, la transición educativa como el proceso que puede contrarrestar la deserción y la repitencia presentada entre los dos sistemas.

\subsection{Encrucijadas del proceso de transición entre lo exitoso y armonioso}

Lo exitoso y lo armonioso son dos términos centrales que se presentan como los fundamentos teóricos de los documentos analizados para este estudio. El nivel de Educación Inicial en Colombia y el nivel de Educación Formal han hecho uso de estos conceptos de forma diferenciada. Comprender lo exitoso o armonioso de una transición implica caracterizar el papel que le otorgamos a los niños y niñas en estos recorridos y se convierte en un punto de partida para recuperar las perspectivas y las construcciones discursivas que configuran las orientaciones de la política para la Primera Infancia. Inicialmente en el país se hacía mención a las transiciones exitosas pero en los últimos años se ha avanzado hacia la comprensión de lo que implica pensar en términos de una transición armoniosa. 


\section{Transiciones exitosas}

Con el propósito de comprender que es lo exitoso de una transición, retomamos la raíz de éxito del latín "exĭtus" que significa salida. La RAE lo define como "resultado acertado de una acción", "resultado feliz de una actuación". Si unimos este significado al concepto de transición en la primera infancia como el proceso de cambio que se da al pasar de una modalidad de educación inicial en el marco de la atención integral a la educación prescolar y educación básica primaria, podemos inferir una connotación del éxito en términos de resultados acertados y eficaces. Según Córmack y Dulkenberg (2009) la transición exitosa se concibe como:

El paso que da el niño/a acompañado de sus padres y maestras, de una institución educativa o de cuidado a otra; paso para el que se encuentra preparado y en el que experimenta proximidad y continuidad con el nuevo ambiente debido a un currículo que se ajusta a su nivel de desarrollo, y a profesores preparados que están interesados en conocer al niño/a y su experiencia pasada. En ese paso, los padres deben sentirse acogidos y apoyados por la nueva institución educativa o cuidado, en función a políticas que promueven su participación (Córmack y Dulkenberg, 2009: 16).

Así, la idea de éxito en el tránsito escolar se relaciona directamente con un resultado que permita visibilizar la proximidad y continuidad en los procesos curriculares y pedagógicos que se establecen entre los niveles educativos o grados. Los autores vinculan la posibilidad de éxito escolar a los procesos de articulación curricular, a la preparación de las maestras, diferente a lo propuesto por las orientaciones políticas de Colombia donde el éxito se relaciona con la garantía en la articulación inter-institucional, es decir el éxito se centra en dos procesos: por un lado, el logro frente a la matrícula/ cobertura y, por el otro, el logro en la permanencia/continuidad entre ambos niveles.

/.../ son relevantes los procesos de articulación dentro de los procesos educativos porque garantizan los tránsitos exitosos a lo largo de los primeros años de los niños y niñas: del hogar a una modalidad de atención, entre modalidades de atención y de la educación inicial al grado transición. Una adecuada articulación da los cimientos para una educación con calidad que inicia en la primera infancia y que se continúa a lo largo de la vida (Concejo de Medellín [Anexo 5] 2011: 3). 
Garantizar el derecho que tienen todos los niños y niñas menores de cinco años a una oferta que permita el acceso a una educación inicial, en el marco de una atención integral, así como la generación de estrategias que fomenten su permanencia y continuidad en el sistema educativo requiere de una efectiva articulación (MEN, 2008: 25).

Las orientaciones políticas y normativas son claras cuando afirman que para lograr el tránsito exitoso se debe, por un lado, definir e implementar acciones de articulación con otras modalidades de atención y de educación formal, en vía de asegurar el derecho y la continuidad en la atención; por el otro, acompañar el proceso de articulación educativa y entrega pedagógica, además de implementar estrategias que garanticen la continuidad de la participación de los niños, las niñas y sus familias evitando su deserción, es decir, garantizar mecanismos regulatorios que favorezcan dichos procesos en las instituciones educativas.

La configuración del éxito constituye un proceso que requiere de condiciones centradas en la familia, las maestras y en la institucionalidad, demarca acciones frente al acompañamiento y la articulación inter-institucional, es decir, requiere de que las mismas condiciones que se ofrecen en el nivel de Educación Inicial en cuanto a nutrición, infraestructura, equipo interdisciplinario, dotación de materiales, presupuesto, entre otras, sea implementado y continúe bajo las mismas garantías en el nivel de Educación formal.

Como refiere Peralta para lograr el éxito en la transición contamos con factores internos y externos o articulatorios: los internos se relacionan directamente con los/las niños/niñas, mientras que los factores externos con el entorno y marco educativo-normativo (2007: 6). Tal como lo señalan Córmack y Dulkenberg (2009), se requiere de un marco regulatorio y político común que favorezca la continuidad de las experiencias educativas, en tanto las limitaciones de tipo curricular, metodológico, pedagógico, intersectorial, estructural, político denotan fracasos y obstáculos para lograr efectivamente este resultado.

El éxito en la transición está ligado a factores que permiten el logro efectivo en la trayectoria. Para Ladd (2005) el éxito se da en el plano de (1) lo individual, es decir, el desarrollo de actitudes positivas hacia la escuela, hacia los aprendizajes, sentirse a gusto en la clase, estar interesado y motivado por aprender y participar de las actividades propuestas; (2) lo institucional, y el establecimiento de vínculos sociales favorables hacia los maestros y sus compañeros (Ladd, 2005: 3). Vegas y Petrow (2007), por su parte, identifican los 
siguientes factores: la edad del niño/a, el desarrollo cognitivo, las experiencias previas y la habilidad innata. En el desarrollo cognitivo las autoras de este documento agregarían también el desarrollo socio emocional. (2007: 31)

Otros autores como Pianta, Cox, Taylor y Early (1999), Fabian y Dunlop (2007), Moreno y Van Dongen (2006), Zill y Resnick (2005), Myers y Landers (1989), Sensat (2004), y organizaciones como la UNESCO (2007) realizan una clasificación de los factores que inciden directamente en el éxito efectivo, veraz y oportuno. Estos autores clasifican los factores en individuales y familiares, externos vinculados a las instituciones educativas, y factores relacionados con la política educativa y de primera infancia.

Tabla 7 Procesos y condiciones para garantizar el éxito en la Transición Educativa

\section{Proceso a implementar para garantizar el transito exitoso}

Factores individuales y familiares

Estado nutricional del niño

Desarrollo cognitivo y socio-emocional

Nivel socio económico de la familia

Nivel de conocimiento y valoración de los padres de familia sobre la infancia

Actitud hacia la educación

\begin{abstract}
Factores externos vinculados a las Instituciones Educativas

Factores relacionados con la Política Educativa y de Primera Infancia
\end{abstract}

Tamaño del grupo y la proporción niños/a docente

Participación de la familia

Continuidad en la metodología de trabajo (en el currículo)

Elementos comunes en la formación tanto del personal de primaria como de los primeros años.

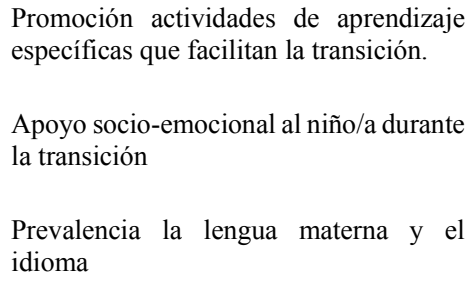

Fuente: Elaboración propia
Regulación atención educativa y el ingreso antes de ingresar a la escuela.

Calidad de los servicios

Orientaciones en el contenido curricular

Estrategias de acompañamiento y participación de los padres

Formación Docente

Estándares de calidad-seguimiento (n)

\section{y}


las transiciones, por ello hablar de éxito connota acciones institucionales pero también voluntades de los actores involucrados en el proceso. Si bien, tanto en el nivel de atención integral a la primera infancia como el nivel de educación formal, preescolar y básica primaria se establecen orientaciones para acompañar el proceso de transición de los niños y niñas, las diferencias de tipo metodológico, pedagógico, curricular, misional e institucional entre los niveles, los proyectos educativos institucionales, $y$ las construcciones teóricoepistemológicas que sostienen cada modalidad educativa frente a la primera infancia revelan diferencias que aún no permiten el diálogo igualitario y la continuidad de algunos procesos.

\section{Transiciones armoniosas}

Actualmente el Ministerio de Educación Nacional, a través de la Dirección de Educación Inicial en coordinación con la Dirección de Calidad y Cobertura, ha diseñado una serie de recomendaciones, guías e instrumentos para acompañar la promoción de las transiciones, la continuidad y calidad en el proceso. Se puede observar un traslado discursivo, un cambio en la relevancia otorgada a lo "exitoso" de la transición para recuperar lo “armónico” como valor en sí. De esta forma, la transición armónica se ha empezado a instalar en el campo educativo desde que el Ministerio de Educación (MEN) propuso que, para acompañar la promoción de las transiciones, la continuidad y calidad en el proceso, los niños no son los que tienen que adaptarse al entorno educativo sino el entorno los debe acoger respetando sus características, particularidades, capacidades y potencialidades desde una actuación armónica. Lo armónico resulta de las interacciones y experiencias que puede tener el sujeto en la transición entre niveles.

El potencial de las transiciones radica en su capacidad para promover interacciones que permitan a los estudiantes comprender la importancia de enfrentarse a nuevos retos, conocer nuevas personas o espacios y entender el desarrollo y el aprendizaje como un proceso permanente de la vida. Una transición armónica no radica en protegerlos de sentir miedo, incertidumbre, frustración o de vivir los obstáculos y tropiezos que el proceso trae, sino en ayudarles a enfrentarlos, a tomar decisiones, a vivir en la incertidumbre y a afectar el mundo en el que viven (MEN, 2016: 7). 
El transito es armónico, cuando todos los actores que acompañan el recorrido planean, proponen y ejecutan acciones intencionadas que potencien el desarrollo de los niños y las niñas en su entorno y en el paso al grado de transición y el inicio de la educación básica primaria (Alcaldía de Bogotá, 2018: 10).

Para que exista armonía en la transición se debe dar continuidad a las experiencias educativas y la articulación inter-institucional en lo que hace a la organización del trabajo pedagógico, la organización de las rutinas y jornadas, la concepción de infancia que tienen maestras, agentes educativos y familias, las expectativas sobre los aprendizajes. Así queda plasmado en el documento "Todos Listos" (MEN, 2016: 9-10):

- Tiempos: organización de las rutinas ya la duración de la jornada de atención.

- Rol de las niñas y los niños: concepciones que tienen maestras, agentes educativos, y familias acerca de las niñas y los niños.

- Rol de los maestros, maestras y agentes educativos: concepciones, expectativas sociales e institucionales frente a su rol en cada nivel educativo.

- Ambientes educativos: condiciones físicas, interpersonales y de seguridad de los espacios.

- Normas y pautas de convivencia: construcción de normas y reglas de convivencia en el entorno educativo.

- Presencia de las actividades rectoras de la infancia: la forma como viven las niñas y los niños el juego, las expresiones artísticas, la literatura y la exploración del medio en la educación inicial y los primeros años del sistema educativo.

- Relación con las familias y cuidadores: la concepción del rol de las familias en la educación de sus hijos e hijas.

- Evaluación y/o seguimiento al desarrollo: estrategias de como las maestras y maestros conciben, se aproximan y comprenden los retrocesos y avances en el desarrollo y aprendizaje de las niñas y niños.

- Conformación de grupos: proporción maestra-niño, el talento humano que los acompaña y las estrategias que se utilizan para organizar los niños alrededor del trabajo pedagógico. 
Es importante señalar que la armonía se evidencia en la efectiva articulación administrativa (asignación de cupo, matrícula) articulación pedagógica (rol maestro, rol del niño, estrategias pedagógicas) y articulación con la familia (acompañamientos). Tal como se describe en la tabla siguiente,

Tabla 8 Proceso a Implementar para garantizar el transito armónico

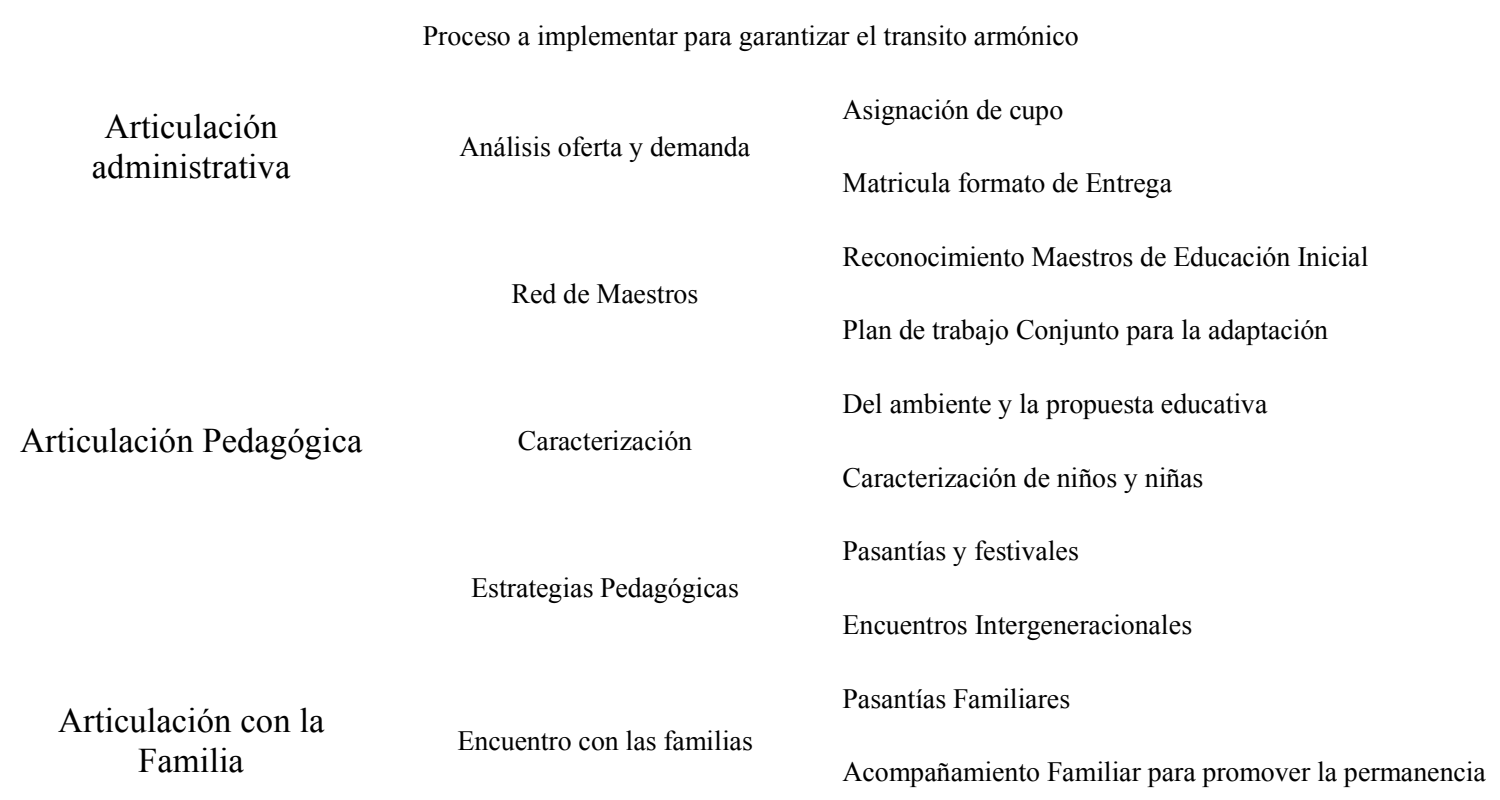

Fuente: Secretaria de Educación de Antioquia Circular 000228

Sin embargo, y para asegurar las transiciones armónicas, se ha construido el documento "Ruta Integral de Atenciones de la Política Nacional para la Atención Integral a la Primera Infancia De Cero a Siempre”. La ruta señala todo aquello que debe pasarle a los niños y niñas para que sus transiciones sean de calidad y aseguren su acceso y permanencia en el servicio educativo. En particular, se deben garantizar tres procesos: (1) ingreso oportuno y de calidad de las niñas y niños al entorno educativo, (2) procesos pedagógicos que promuevan la continuidad entre grados-niveles y (3) condiciones que aseguren su permanencia y el disfrute del entorno educativo. ${ }^{16}$

${ }^{16}$ El ingreso oportuno y de calidad de las niñas y niños se está centralizando en la articulación interinstitucional, en la entrega y recepción de los niños mediante el mecanismo de la asignación del cupo. Los procesos que 
Observamos que actualmente en Colombia las estrategias están más enfocadas a garantizar el componente armónico de la transición, dado que los factores presentes en una transición exitosa demandan acciones más centralizadas en la institucionalidad, requiere de mayor recursos porque lo que busca es garantizar una accesibilidad y permanencia efectiva en todo el proceso educativo; es decir una trayectoria teórica-lineal, centrada en una duración estándar que posibilite el ingreso y la continuidad entre los niveles educativos, en pocas palabras que los niños y niñas puedan contar con las mismas condiciones del nivel de Educación Inicial, (complemento nutricional, equipo interdisciplinario, infraestructura, ambientes protectores, dotación de material, formación docente, continuidad en la propuesta pedagógica y educativa, formación de las familias y accesos a servicios de salud, entre otras), en el nivel de educación formal. Es decir, un cumplimiento frente a los factores individuales y familiares, factores externos vinculados a las instituciones educativas y factores relacionados con la Política Educativa y de Primera Infancia.

Si bien se están implementando estrategias como la de "transición es una nota"17, los procesos de implementación solo están priorizados para algunos municipios y no presentan una cobertura del 100\%; lo que implica para las instituciones tanto del nivel de Educación Inicial como de Educación Formal, que no están priorizados bajo esta estrategia asumir los procesos de acompañamiento con la implementación de acciones desde la transición armónica centradas en el proceso de articulación inter-institucional desde lo administrativo, pedagógico y familiar.

promuevan la continuidad entre grados, para asegurar su permanencia, en la Institución en la que se realiza el trabajo de campo se está trabajando con los intercambios de experiencias entre maestras.

${ }^{17}$ A nivel Nacional se está implementando en algunas zonas del país la "Estrategia de transición es una nota" la cual busca para lograr el éxito la atención integral de los niños de 5 años inscritos actualmente en instituciones educativas oficiales. Se lleva a cabo en 15 entidades territoriales, busca garantizar, adicional a lo contemplado en la canasta educativa tradicional, los equipos interdisciplinarios, el porcentaje del requerimiento nutricional diario para completar entre el $40 \%$ y el $75 \%$ de los necesarios, y seguro estudiantil. Es ejecutado por las secretarías de educación, a través de convenios con ICBF, es una estrategia de acompañamiento pedagógico en el que los maestros cuentan con un tutor o mentor en el aula para planear, innovar y llevar a cabo experiencias pedagógicas de alta calidad; tienen como objetivo mejorar la calidad de la educación inicial mediante la garantía de: atención integral en el grado transición, el fortalecimiento pedagógico situado a maestros y maestras, y el acompañamiento a las transiciones de las niñas y los niños en el entorno educativo. Solo es implementado en algunos municipios del país. 
Ilustración 3 implicaciones de lo armonioso-exitoso en la transición

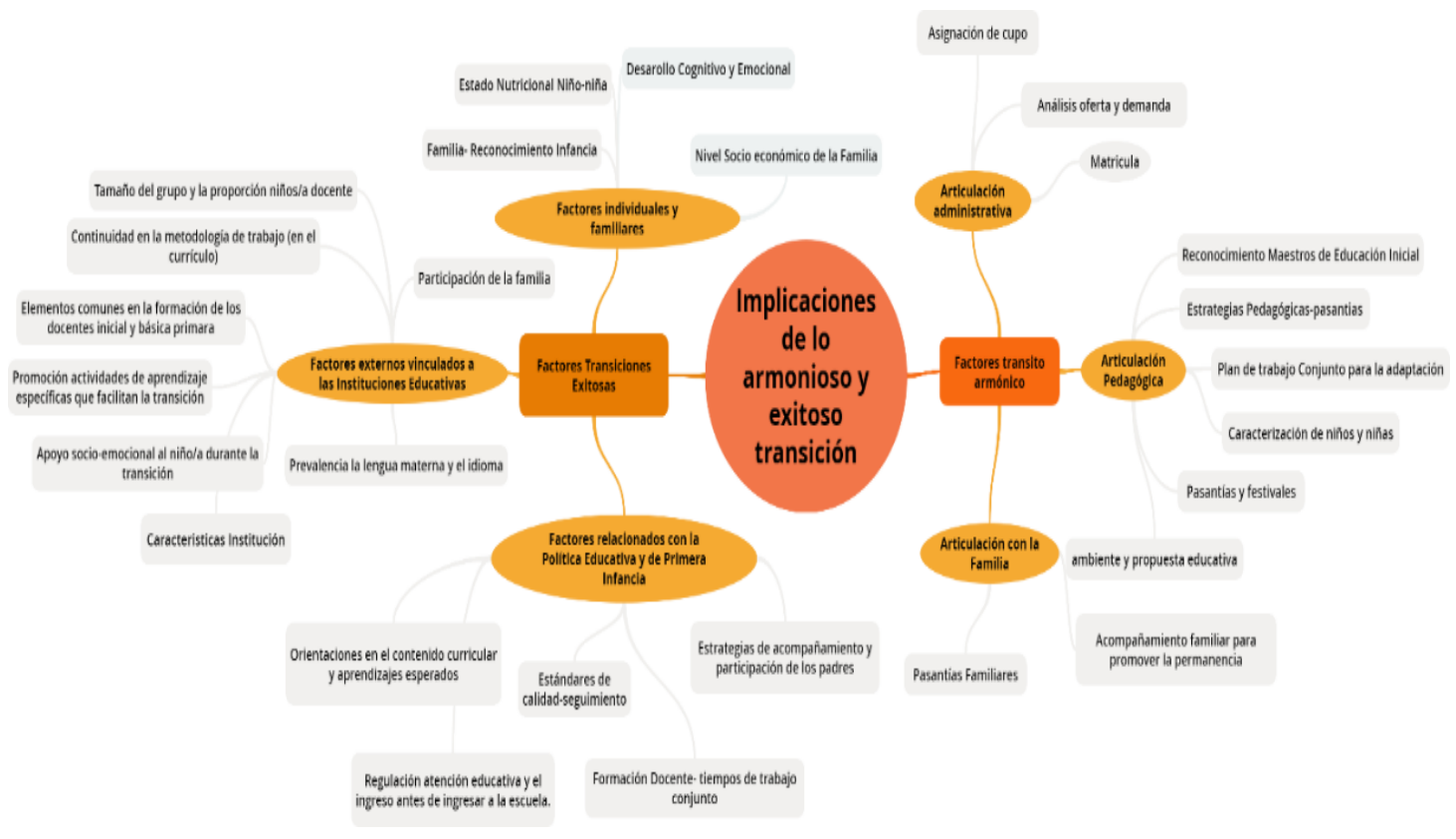

Fuente: Elaboración propia

Continuando con este análisis vemos que las implicaciones desde lo armonioso se centra en el sujeto y en la continuidad de las experiencias educativas, por ello se busca generar estrategias de articulación tanto administrativa, pedagógica y familiar; los ejercicios son más puntuales para ambos sistemas educativos en tanto se concentran en el logro efectivo de acciones direccionadas a (1) la asignación de cupos entre ambos escenarios centrado en el proceso de matrícula y en la garantía del derecho a la educación, (2) estrategias pedagógicas para la preparación de los niños y niñas desarrolladas por las maestras con estrategias como las pasantías o los rituales de aprestamiento para sensibilizar a los niños y niñas frente al cambio de modalidad, y (3) estrategias enfocadas en la preparación de las familias, empoderarlos de los procesos educativos de los niños y de la garantía de sus derechos. En definitiva, se busca proporcionar una experiencia positiva en los niños/niñas, para que el paso no sea brusco e impacte en su desarrollo infantil.

Aun cuando el Estado Colombiano, a través del MEN, elaboró una serie de orientaciones para que las instituciones educativas pusieran el foco más en lo armonioso que en lo exitoso de cara a garantizar el tránsito de las niñas y niños de la Educación Inicial a la 
Educación Básica Primaria se podría decir que prevalece el interés por garantizar el ingreso al sistema educativo, contribuir con la disminución de la deserción y la repitencia en ambos sistemas. Las acciones de acompañamiento del sistema de educación inicial y atención integral a la primera infancia se concentran en la experiencia del sujeto mientras que en el sistema de educación formal las acciones están más enfocadas en lograr la permanencia de los niños y niñas que transitan.

\subsection{A modo de cierre}

La representación social de infancia en el país data de la construcción de la Política Pública de Primera Infancia cuyo propósito principal es garantizar en los niños y las niñas el desarrollo pleno de sus dimensiones biológica, psicológica, cultural y social. Una concepción del niño/niña como actor protagonista y constructor de su desarrollo, sumado a la perspectiva de derechos y el enfoque de protección integral, son las orientaciones para la construcción de acciones técnicas, administrativas y pedagógicas en el territorio escolar.

La infancia se asume desde el reconocimiento de derechos en los ámbitos civil, político, económico, social, cultural, y se establece en el marco de la Educación Inicial. Así, la protección integral implica la concepción de los niños, las niñas como sujetos de derecho, seres activos que se desenvuelven en la vida social en permanente evolución, con una identidad específica que debe ser respetada y valorada.

De esta forma, las acciones desarrolladas y las articulaciones inter-institucionales a nivel nacional y regional comparten una forma de organización uniforme de contenidos colectivamente consensuados. En la mayoría de los documentos oficiales la transición es presentada como un proceso clave, una etapa del ciclo de vida que marca cambios y transformaciones importantes en la vida de los niños pues impacta en el desarrollo infantil; estos cambios están mediados por las múltiples experiencias que enfrentan los niños y niñas en los ambientes educativos, donde pueden experimentar situaciones de inestabilidad e incertidumbre que inciden directamente en sus procesos emocionales, cognitivos y sociales. Dichos cambios, además, están relacionados con los procesos de adaptación que deben asumir los niños/niñas cuando pasan a un nuevo entorno, sea el grado transición o la educación básica primaria. De esta forma, la transición se estructura desde los itinerarios de 
entrada y salida hacia instituciones educativas, atravesada por la tensión que provocan lógicas no necesariamente contrapuestas como son la atención puestas en las experiencias de las niñas y niños versus el interés por garantizar la cobertura, el acceso y permanencia en el sistema educativo.

Preexiste en los documentos una mirada en torno de la necesaria preparación para que el niño pueda enfrentarse a nuevos retos, tomar decisiones, participar con autonomía e independencia en los nuevos ambientes educativos. Es evidente, que la atención se centra en la institucionalidad, específicamente en el proceso de articulación inter-institucional más que en el sujeto y los factores sociales, personales, culturales e históricos y en el vínculo entre la sociedad/individuo, la acción/estructura/decisión y el condicionamiento social de la trayectoria.

En los documentos oficiales analizados en este capítulo existe una tensión con respecto a cuál es el grupo etario a que llamamos primera infancia. Mientras que en algunos textos la atención a la primera infancia es reglamentada como el primer nivel continuo de la educación hasta los seis (6) años, por ejemplo, la política pública de Cero a Siempre (1804/2016), en otros se comprende la etapa de la primera infancia hasta los ocho (8) años (acuerdo 56-Buen Comienzo). En efecto, estas diferencias marcan una acción en la cobertura, en la concepción de educación inicial/educación infantil y en la misma asignación de recursos que evidencia un sistema segmentado. Lo que amerita discusiones en el país frente a lo que se comprende por la educación de las infancias.

El análisis acerca de cómo el discurso gubernamental ha transitado de lo exitoso a lo armonioso nos ha permitido mostrar que lo exitoso de una transición está relacionado con el "resultado" institucional del pasaje de un entorno educativo a otro, con la efectiva garantía de que las condiciones que se ofrecen desde los factores internos individuales y familiares (estado nutricional, nivel de desarrollo cognitivo, social, emocional, salud, etc.), y externos vinculados a las Instituciones Educativas y a la Política Educativa Primera Infancia (proceso curricular, gestión administrativa y pedagógicas, estándares de calidad y seguimiento, formación docente, acompañamiento familiar, regulación de acceso y cobertura, infraestructura). 
En cambio, lo armonioso se centra en el sujeto y en la continuidad de las experiencias educativas, y por ello concentra su atención en las acciones institucionales que involucran la articulación administrativa, la articulación pedagógica y la articulación con la familia. Para que lo armónico se produzca se deben garantizar tres procesos a saber: (1) ingreso oportuno y de calidad de las niñas y niños al entorno educativo, logrado con la asignación de cupos, (2) procesos pedagógicos que promuevan la continuidad entre grados-niveles, mediado por las estrategias de pasantías, festivales, propuesta educativa y caracterización que realizan las agentes educativas y (3) finalmente con condiciones que aseguren su permanencia y el disfrute del entorno educativo, esto apoyado por el acompañamiento a las familias y la red de maestros.

Más allá de lo exitoso o armonioso, el proceso de transición educativa finalmente radica en un efectivo encuentro entre los niveles de educación inicial y atención integral y educación formal, en una reestructuración del sistema de educación en el que no se segmente la educación y atención integral a la primera infancia de la educación preescolar y la básica primaria. Nos referimos a un sistema que articule desde sus orientaciones pedagógicas, educativas, factores internos y externos, que posibiliten el diálogo igualitario y la construcción conjunta de oportunidades que favorezcan la continuidad en los procesos institucionales, pedagógicos y curriculares. Todo ello implica un trabajo de articulación no solo horizontal sino vertical en base a una conceptualización de infancia compartida entre las instituciones que forman parte de ambos niveles, cierta coherencia y continuidad en la organización pedagógica, en el currículo, la implementación de las actividades rectoras, el rol docente y el rol de la familia en el seguimiento, desarrollo y evaluación de los procesos. 


\section{TERCERA PARTE}

\section{ARTICULACIONES ENTRE LA EDUCACIÓN INFANTIL}

La infancia como institución - no los chicos, sino la infancia como representación, como teoría, como suposición- es producto de dos instituciones modernas y estatales destinadas a producir ciudadanos en tanto que sujetos de la conciencia: la escuela y la familia.

Ignacio Lewkowicz (2004)

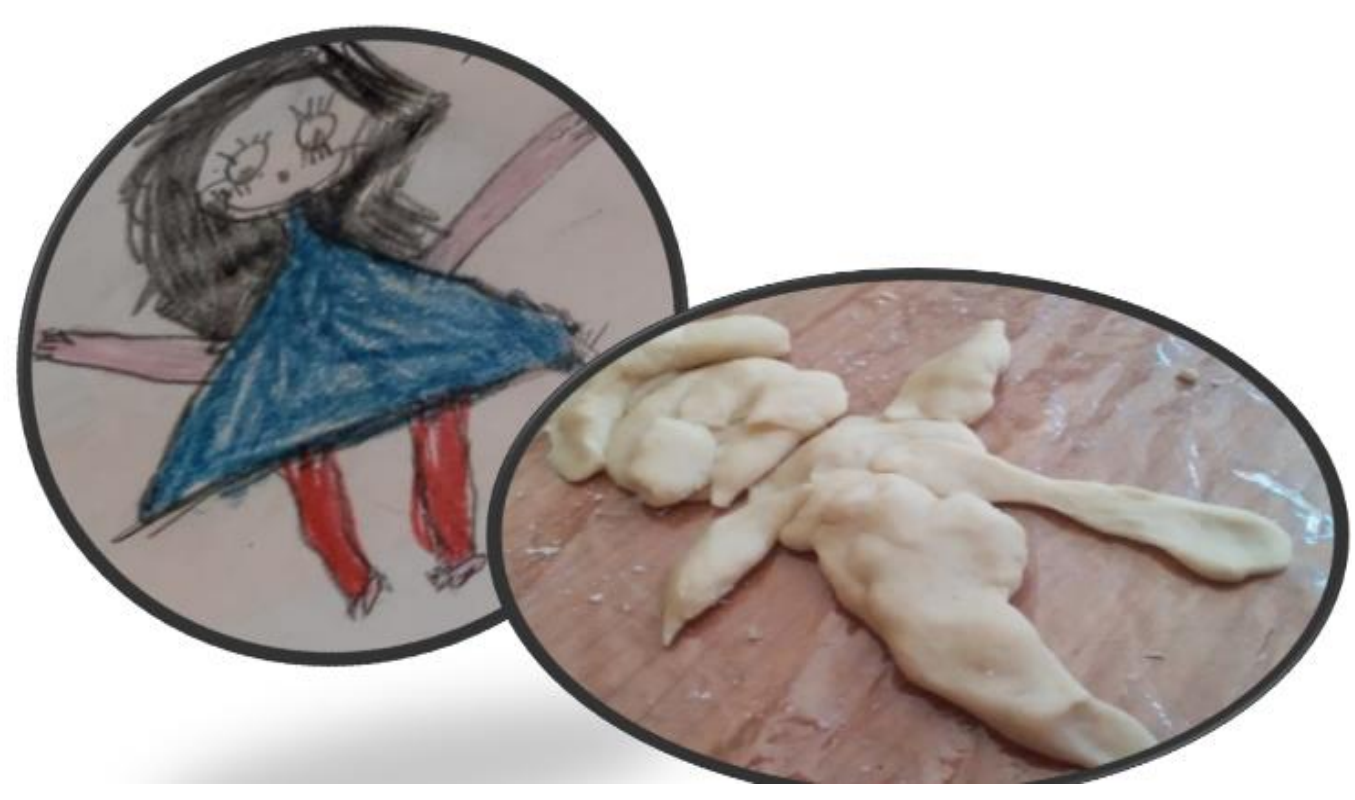

Ser niño/a- Representación N5-N9Transisicón 


\section{Capítulo IV}

\section{Articulaciones necesarias entre la Educación Inicial y \\ la Educación Formal}

\section{Introducción}

La articulación implica, desde la perspectiva de la Atención Integral a la Primera Infancia, propiciar el desarrollo de los niños y las niñas en una acción colectiva horizontal donde diversos actores, sectores e instituciones aúnan esfuerzos y recursos para alcanzar objetivos comunes en aras de generar transformaciones y nuevas oportunidades.

Sin embargo, es preciso decir que la articulación, tomando en cuenta la experiencia de las agentes educativas, maestras y directivos, está mediada por diferentes encuentros y desencuentros que permean los procesos de transición de los niños y niñas. La problemática de la continuidad y la comunicación en doble vía constituye un punto de análisis porque implica necesariamente la integración de ideas, la unificación de criterios y el desarrollo progresivo de estrategias para evitar que se produzcan cambios bruscos de una etapa a otra. No obstante, esta unificación no es efectiva por las diferencias observadas en nuestro trabajo de campo entre ambos sistemas.

El proceso de transición entre instituciones educativas representa un proceso de articulación horizontal en el que se desarrollan diversas acciones pedagógicas y administrativas para acompañar de manera oportuna y pertinente los procesos de paso que realizan los niños y las niñas inter e intra-institucionalmente. Las instituciones tanto del sistema de Educación Inicial como de Educación Formal dan lugar a un conjunto de estrategias para lograr que las familias, maestras y niños se reconozcan como partícipes de estos procesos.

Para orientar el proceso de transición y articulación en el municipio de Medellín la Secretaría de Educación ${ }^{18}$ define como acciones fundamentales la entrega y la recepción

\footnotetext{
18 Este apartado se construye tomando como referencia las entrevistas realizadas especialmente por las
} coordinadoras- Entrevista agente educativa coordinadora (15/12/2017) Entrevista coordinadora programa Buen 
pedagógica. La entrega representa el paso que dan la familia, el agente educativo y otras personas significativas para que los niños y las niñas sean recibidos en otros escenarios; la recepción se comprende como la acogida y recibimiento intencionados y afectuosa de los niños y las niñas por parte de las familias, adultos/as, agentes educativos y maestras. En este proceso es fundamental dar un lugar relevante a las articulaciones en tanto esta es importante en el éxito del proceso.

La articulación educativa implica procesos de comunicación, intercambio, formación, concertación, investigación e innovación entre los espacios de atención del Programa, las instituciones educativas, los jardines infantiles privados y los programas o entidades especializados (en el caso de los niños y las niñas con discapacidad), además de la participación activa y propositiva de las comunidades y las organizaciones sociales (Programa Buen Comienzo, 2019).

Para lograr una efectiva articulación que permita la conexión entre los dos escenarios y la acción conjunta para la entrega y la recepción de niñas y niños son fundamentales cuatro procesos: el primero centrado en la articulación administrativa especialmente en la cobertura y la asignación del cupo para la garantía del derecho a la educación, es decir, articulación horizontal entre la Educación Inicial Atención Integral a la Primera Infancia y el nivel de Educación Formal grado transición y primero; el segundo proceso se focaliza en la articulación pedagógica en el cual se establecen actividades como pasantías, festivales y encuentros intergeneracionales que posibilitan un acercamiento y reconocimiento del otro espacio; el tercer proceso se fundamenta en la articulación con las familias con las que se realizan estrategias para acompañar y orientar este proceso de cambio; el cuarto en la articulación curricular, es decir, en las formas de estructurar y organizar el currículo.

A continuación, explicaremos cada uno de estos procesos y en un último apartado intentaremos reflexionar en torno de las implicaciones que tendría formalizar lo informal, propio de la Educación Inicial, en una Escuela para la Niñez.

Comienzo (7/03/2018) entrevista coordinadora Institución (1/12/2017). La Secretaría de Educación es la entidad responsable de garantizar el derecho a la educación de los niños, niñas y jóvenes de la ciudad de Medellín, dirige, organizar y planifica el servicio educativo de conformidad con las disposiciones constitucionales, legales y los fines de la educación establecidos en las leyes que regulan el servicio público educativo, en condiciones de calidad, pertinencia, equidad, eficiencia, eficacia y efectividad tiene como gran reto fortalecer la calidad de la educación pública. 


\subsection{Transiciones entre las instituciones de Educación Infantil}

Caracterizando los procesos fundamentales para la entrega y la recepción de los niños y niñas entre los escenarios educativos encontramos que el primer proceso es la articulación administrativa. A través de este tipo de articulación se realiza una identificación de la población que va a transitar de las modalidades de Educación Inicial en correspondencia con los cupos ofertados por las instituciones de Educación Formal; dicha actividad se realiza mediante el análisis de cobertura y demanda efectuado por la Secretaría de Educación. De acuerdo a las coordinadoras el proceso de entrega de los niños y niñas que van a pasar a la escuela empieza en el mes de mayo, tiempo en el que se organiza una reunión con los padres de familia para informarles que al ser ese el último año de los niños y niñas en el jardín infantil de Buen Comienzo les van a dar la información de las instituciones educativas con las cuales se tiene convenio para realizar la articulación y garantizar el cupo.

Las recomendaciones para los padres de familia se centralizan en identificar cual es la institución que más responde a sus necesidades y se ajusta a los intereses de los niños/as. Para ello cuentan con una circular de la Secretaría de Educación con las opciones de las instituciones que forman parte de ese barrio, su función es elegir tres opciones para no quedar sin cupo. Así mismo les manifiestan que si se van a cambiar de barrio o sector de vivienda ellos mismo deben realizar el trámite porque la coordinadora solo ofrece cupos en el barrio en el que la familia reside.

La Secretaría de Educación se encarga de caracterizar a los niños y niñas que van a ingresar al preescolar y de acuerdo a las opciones que eligen las familias tramitar los cupos con las instituciones de Educación Formal. Para realizar la distribución de la matrícula se organiza un encuentro entre los rectores de las instituciones y las coordinadoras del programa Buen Comienzo en el que se asignan los cupos y se comparten los contactos para poder hacer posteriormente en el mes de octubre el proceso de matriculación.

Este proceso desde que lo asumió la secretaría de Educación es mucho más efectivo en octubre llega a los correos toda la información para las matrículas, las secretarias de la institución educativa son muy atentas y están pendientes del proceso y la garantía de los cupos (Agente Educativa Coordinadora, 15/12/2018). 
El segundo proceso es la articulación pedagógica que refiere a todas las acciones de preparación y acompañamiento -rituales- que realizan las agentes educativas para la entrega de los niños y niñas. Pasantías, festivales, encuentros inter-institucionales, dichas actividades deben estar programadas y coordinadas al momento que se hace el calendario escolar. Este es un proceso que se realiza durante todo el año pero se centraliza mucho más en los últimos tres meses. Su función es preparar a los niños y niñas para el cambio hacia el nuevo escenario escolar.

El tercer proceso es la articulación con las familias. Una vez se empieza el proceso de asignación de cupos se cita a las familias al Jardín Infantil de Calidad, se trabaja con ellos con la metodología de grupo focal y se les explica en que consiste este paso y la corresponsabilidad que deben asumir como padres de familia. Este encuentro se convierte en un momento de sensibilización y de preparación, se les entrega la orden de matrícula y se les anuncia que hasta este momento llega el acompañamiento del jardín infantil.

Este proceso es fundamental dado que no sólo los niños y niñas, las familias se deben preparar para este cambio pues las/los adultas/os acompañan el tránsito de sus hijas/os por el sistema en medio de motivaciones y angustias. Así, con diferentes talleres y estrategias como reuniones, pasantías, plegables se trabaja con ellos para sensibilizarlos frente a las nuevas rutinas y responsabilidades que deben asumir y se presenta el enfoque de derechos con el que se trabaja en las instituciones de ambos sistemas. El tránsito de la Educación Inicial hacia la Educación Formal requiere conocer los siguientes parámetros de organización del sistema:

- El tiempo: se les informa que ya no van a estar los niños 8 horas ya deben elegir en que jornada mañana o tarde puesto que solo son 4 horas que los niños y niñas permanecerán en la institución.

- La alimentación: ya no será del 75\% contaran con un restaurante que solo cubrirá una comida y un algo, siempre y cuando lo requieran.

- $\quad$ Responsabilidades económicas: en la escuela deben asumir la compra de cuadernos uniformes y materiales que requieran los niños a diferencia del jardín donde todo esto se suplía 
- El acompañamiento y la responsabilidad especialmente que deben tener para ir por los niños y niñas cuando terminan jornada, se les indica que en la escuela no los van a esperar hasta tres horas, en este espacio abren las puertas o se activan rutas de atención.

- Responsabilidad en el acompañamiento de las tareas y en los tiempos es decir que van a realizar con los niños y niñas en la otra jornada que no están escolarizados.

- $\quad$ Rutinas de trabajo se les explican las rutinas la importancia de llevar los niños bañados con el uniforme limpio, verificar que tenga todas sus pertenencias y por lo menos darles algo de comer.

Caracterizando este proceso se puede decir que los pasos que se realizan son los siguientes:

Tabla 9 Proceso de articulación entre los sistemas

-Inicia con una reunión a padres información sobre instituciones de núcleo

-Enviar circular a los padres de familia para que ellos elijan la institución educativa

-Enviar al programa de Buen Comienzo el formato con los niños que transitan

-Enviar a la Institución educativa el formato con los niños que pasan para la gestión de los cupos

-Buen Comienzo tramita con secretaria de educación los cupos

-secretaria de educación informa a cada núcleo sobre niños que transitan, cada núcleo informa a cada rector

-Reunión en el mes de Julio con jefes y rectores de núcleo, en la reunión se socializan los cupos a las coordinadoras del programa Buen Comienzo

-En septiembre y octubre empieza inicio de matrícula las Instituciones Educativas envían toda la información que se requiere para la matricula

-Citación a familias para grupo focal entrega orden de matrícula y preparación para el cambio

-Entrega de plegables con información frente al cambio

-Seguimiento proceso de matrícula

Comunicación con las secretarias de las Instituciones para ver cómo va el proceso por cada niño

Llamar a los padres de familia para verificar como van con el proceso de matricula

-Envió de información a secretaria de educación con los datos de donde quedaron los niños matriculados y garantizar porque si estén matriculados

-Llenar el aplicativo de transiciones, aunque este no tiene seguimiento.

Fuente: Elaboración propia 
En la escuela también se realizan actividades de sensibilización con los padres y madres una vez las niñas y niños ingresan al sistema de educación formal con el propósito de acordar formas de acompañar a sus hijas/os en la escuela, se realizan talleres educativos para orientarlos sobre prácticas de crianza, normatividad legal, casos específicos por los cuales se pueden sancionar a las familias, se les comparte y socializa el código de infancia y adolescencia. ${ }^{19}$ En este mismo orden se les habla sobre las responsabilidades del docente y el respeto que se debe tener hacia él, en tanto se han encontrado familias que vulneran los derechos de las mismas maestras. Asimismo, se presenta a las familias las diferentes actividades que realizan en la institución para favorecer los procesos de convivencia e inclusión, cómo se estructura la institución, cuáles son sus exigencias y cómo funcionan los dispositivos de acompañamiento con la presencia de psico-orientadores, maestra de apoyo y maestras.

Bueno nosotras inicial mente citamos a los padres de familia hacemos un proceso de inducción, entonces las familias llegan les contamos como es la dinámica de la institución, sus responsabilidades; hacemos dos o tres talleres sobre la responsabilidad familiar, en esos talleres trabajamos prácticas de crianza, manejo de la norma con responsabilidad y referente legal, entonces para que las familias también sepan que si dejan el niño/a acá después de cierta hora la policía de infancia y adolescencia se los va a llevar. Trabajamos en el respeto por el docente, o sea nosotros les decimos a los padres su hijo está llegando aquí nuevo pero su hijo no tiene corona y aquí hay unas normas y el docente tampoco tiene corona cierta, entonces vamos a respetarnos mutuamente, porque muchos papás tienen la visión de no valorar al maestro; se trabaja con las familias como un proceso de inclusión y también con las familias al finalizar el año se hace una evaluación de cómo nos fue (Coordinadora de Institución, 1/12/2017).

En este análisis es posible evidenciar que la articulación horizontal da cuenta de los procesos y las acciones que realizan las instituciones educativas para poder acompañar la entrega y recepción de los niños y niñas; las estrategias administrativas y pedagógicas dan cuenta de las acciones operativas que finalmente posibilitan el tránsito entre los escenarios; el acompañamiento a las familias se convierten en un factor fundamental para poder garantizar

${ }^{19}$ El código de infancia y adolescencia tiene por objeto establecer normas sustantivas y procesales para la protección integral de los niños, las niñas y los adolescentes, garantizar el ejercicio de sus derechos y libertades consagrados en los instrumentos internacionales de Derechos Humanos, en la Constitución Política y en las leyes, así como su restablecimiento. Dicha garantía y protección será obligación de la familia, la sociedad y el Estado. 
la cobertura y el acompañamiento de los niños y niñas para favorecer la permanencia y la adaptación. De acuerdo a lo establecido por la coordinadora administrativa del programa Buen Comienzo,

La preparación que se hace en el programa tanto a los padres de familia como a los niños y niñas se convierte en un proceso fundamental de la planeación y el direccionamiento estratégico, a las coordinadoras de los jardines se les da las orientaciones pertinentes para que puedan ayudar a las familias a encontrar la institución ideal para sus hijos y para que velen porque los niños/as queden matriculados en la institución. Nuestra responsabilidad es garantizar ese cupo y acompañarlos en todo el proceso (Coordinadora Administrativa, 7/03/2018).

Es importante señalar que la cobertura constituye un aspecto fundamental de esta articulación. Garantizar el acceso y la atención educativa es una de las mayores preocupaciones del Ministerio de Educación Nacional que, en los últimos años, ha promovido en las entidades territoriales la generación de acciones que permitan el acceso, la continuidad y permanencia de los niños y niñas mediante estrategias que se han centrado en la ampliación de cobertura y en la sensibilización de las familias, agentes educativos y maestras de preescolar sobre la importancia del proceso de transición de los niños/as al sistema educativo formal. El tema de la cobertura gracias a las acciones de articulación inter-institucional, intra-institucional, intersectorial en la Educación Inicial han permitido acciones colectivas donde los diferentes actores sociales, instituciones desde el ámbito público y privado han establecido consensos y acciones que han permitido en la ciudad el reconocimiento de las infancias, la protección y garantía de sus derechos.

Un estudio exploratorio elaborado por la Universidad de Antioquia y el Banco de la República durante el 2017-2018 evalúo los efectos del programa Buen Comienzo sobre la variable de Matrícula: "Inicio adecuado de la escolaridad (entrada a transición), continuidad escolar durante los primeros 5 grados, continuidad escolar hasta el bachillerato". El informe muestra que la cobertura del programa ha ido en aumento (6.792 participantes más entre 2015 y 2018), pasando de una cobertura de 75.858 niñas/niños en 2015 a 82.650 niños y niñas atendidos en 2018 gracias al convenio de articulación inter-institucional que permitió incluir la atención de todas las modalidades del ICBF. 
Si bien se ha aumentado la cobertura en la Educación Inicial programa Buen Comienzo es posible ver que en la Educación Formal la tasas de cobertura bruta de transición y media aún están por debajo del 100\%, se observa que la matrícula total en edad escolar para el año 2018 fue de 380.944 de los cuales el 78,6\% pertenece a instituciones educativas oficiales, el $5 \%$ a instituciones de cobertura contratada y el $16,5 \%$ a instituciones privadas; analizando el comportamiento de la deserción por grados, se observa que son los primeros grados de cada nivel los que mayores tasas de deserción presentan, es decir los grados $1^{\circ}, 6^{\circ}$ y 10 . Lo que especialmente en transición da cuenta de la urgencia de actualizar las cifras poblacionales y de hacer un análisis con respecto a la continuidad y trayectoria [ingreso y permanencia] de los niños-niñas que pasan de la inicial a la formal.

Este estudio es importante porque destaca que si bien se está cumpliendo a nivel institucional y de programa con los lineamientos generales de la Educación Inicial, aún hay procesos y acciones que se pueden realizar para mejorar la calidad y continuidad de la atención integral en el sistema formal. De esta forma resaltan la importancia de revisar el modelo y las actividades pedagógicas que se llevan a cabo con los niños/as más grandes, próximos a pasar a la educación regular, para facilitar ese tránsito, es indispensable continuar trabajando en la permanencia de las niñas y los niños en el programa, especialmente aquellos de estratos socioeconómicos más bajos, y sostener las líneas de formación de la Política Pública de Formación de Maestros (Alcaldía de Medellín, 2018).

\subsection{La articulación y las maestras}

Los mayores desencuentros en la articulación inter-institucional se establecen por el desconocimiento de las acciones que se realizan en cada nivel educativo. La estrategia principal consiste en garantizar entre ambos niveles el cupo para que todos los niños/as tengan un lugar asegurado en la institución de destino. Como lo refiere un directivo docente, "la articulación es más direccionada a los cupos, lo único que se hace es como la articulación de que los niños que estén allá tengan la posibilidad del cupo acá" (Directivo docente 1/12/2017). Así mismo otra docente refiere que también constituye un problema el poco reconocimiento de las acciones y estrategias implementadas en cada institución: "de pronto las dos entidades estamos haciendo bien nuestro trabajo, pero nos ha faltado comunicación como para saber, como vienen 
los niños, que estrategias podemos hacer para continuar con el proceso" (Docente de transición 12/11/2017).

La articulación es definida por las maestras como las acciones de engranaje y correlación de los procesos que tanto el recurso humano como las instituciones llevan a cabo en la formación del niño/a para el favorecimiento del tránsito entre ambos niveles educativos. Esta articulación se puede clasificar de la siguiente manera: inter-institucional, entre grados y curricular. En las voces de las maestras:

Sería el engranaje entre un proceso y otro, o entre un nivel y otro, tiene que ver con comunicación, con decirnos de pronto, hasta donde llega un proceso y done arrancaría el otro. A porque hay procesos desarticulados totalmente, porque pareciera que hubiera una línea, una ruptura donde termina el Buen Comienzo y el preescolar y donde empieza el primero, entonces la articulación sería ponernos de acuerdo, realmente conocer el proceso anterior y que ellos también conozcan el nuestro, y engranar actividades e ideas” (Maestra de Apoyo, 21/11/2017).

La articulación inter-institucional está constituida por una serie de acciones pautadas por la Secretaría de Educación para que las maestras compartan información sobre los procesos educativos de los niños y las niñas. Sin embargo, esta información resulta superficial en tanto los encuentros son dos veces al año y no permite un diálogo o empalme efectivo de cada uno de los procesos.

Ahora bien, hemos observado en el trabajo de campo que las responsabilidades frente a este proceso están designadas en su mayor parte por al nivel de educación inicial atención integral, en este caso al programa Buen Comienzo, quien asume toda la responsabilidad por este proceso de articulación inter-institucional. En su mayoría son las coordinadores y agentes psicosociales de los programas de Educación Inicial quienes deben garantizar los procesos de articulación entre ambos sistemas y entre instituciones aliadas. Son quienes aúnan esfuerzos para poder lograr acciones conjuntas. No obstante, comentan que se trata de actividades sin continuidad, y que es evidente el desconocimiento de quienes trabajan en la Educación Formal respecto de las orientaciones técnicas, administrativas y legislativas de la Educación Infantil lo que deja ver la falta de encuentros y diálogo entre ambos sistemas.

Expresiones como "no conocemos los nuevos lineamientos de la estrategia de Cero a Siempre ley 1804, nosotras trabajamos con los lineamientos del programa Buen Comienzo, no 
con de Cero a Siempre" (Agente Educativo coordinador 15/12/2017), "nosotras en preescolar trabajamos bajo las orientaciones de los lineamientos curriculares y los $\mathrm{DBA}^{20}$, yo sé que hay una política de infancia pero no la hemos abordado" (Docente de transición 11/10/2017), "creo que no nos hemos sentado entre los dos sistemas a dialogar con respecto a esta política, sabemos que existe y como coordinadores la tenemos presente, pero si se hace falta la discusión entre los dos sistemas" (Directivo Docente 1/12/2017). Lo anterior deja ver la falta de encuentros para debatir y discutir aspectos de la primera infancia y una segmentación entre el nivel de Educación Inicial y Educación Formal. Cada nivel conoce y respalda solamente sus estructuras internas de organización administrativa, pedagógica y curricular.

Otro tipo de articulación se da entre grados, es decir, entre el último nivel del sistema de atención integral, el grado transición y el grado primero. En esta articulación la falta de comunicación entre las agentes educativas y las maestras de preescolar y grado primero es el punto de discordia, la falta de tiempo y las diferencias en las estructuras institucionales que no posibilitan encuentros y reuniones se convierten en factores limitantes para planear, crear acciones conjuntas, pensar en estrategias, mecanismos de seguimiento y evaluación.

Yo pienso que falta la misma articulación entre nosotras cierto, entonces a veces es todo muy a la carrera con la premura de todo lo que hay que hacer a nivel institucional. Te cuento que en el diálogo que hacemos entre maestras, solo hay un intercambio de información informal, o sea, de buena disposición, pero de que haya una reunión formal donde nos sentemos y compartamos experiencias no (Docente de Primero, 25/10/2017).

La pasantía se constituye en la estrategia para favorecer esta articulación intrainstitucional en la que los niños/as hacen un reconocimiento del nuevo espacio. No obstante, el engranaje falla por la falta de comunicación entre las maestras y agentes educativas dado que este ritual se realiza una vez en el año y se centraliza en actividades de reconocimiento para que los niños/as puedan conocer su nueva escuela y se familiaricen con sus maestras.

En la pasantía vienen los papás y los niños/as. Los niños/as trabajan con unas profes y los papás con otras, las profes les cuentan a los papás cual es la dinámica, los niños/as hacen un recorrido por la institución, hacen unas actividades en el salón para también ir conociendo las dinámicas.

\footnotetext{
${ }^{20}$ Derechos Básicos de Aprendizaje.
} 
Pero una visita no es suficiente para la articulación, yo pensaría que se necesitaría como otro proceso para hacer la articulación, no solo una visita, si no cómo darle continuidad, una dos o varias en el sentido de que los niños/as vuelvan a conocer más el ambiente, para que las profes puedan identificarlo. Porque en ese momentico lo que las profes logran identificar es muy poquito. Lo que uno ve es que las agentes educativas entregan la documentación, matriculan los niños y niñas y ya se pierde el proceso; por eso pienso que la articulación se centra mucho en el cupo (Directivo Docente, 1/12/2017).

La mayoría de las estrategias realizadas entre ambos sistemas para engranar el proceso se pierden inmediatamente que los niños y niñas son entregados por el programa Buen Comienzo y recibidos en las Instituciones de Educación Formal. “Aquí, creamos estrategias para acompañar los pasos entre las salas, pero una vez salen de acá ya, se pierden el contacto por completo a no ser que ellos vengan y te saluden y te cuentan cómo están” (Agente educativo docente 11/12/2017). La pérdida de contacto con las niñas y los niños cuando se incorporan a la Educación Formal explica, en parte, las dificultades observadas en nuestro trabajo de campo por maestras, directivos y coordinadoras para sostener la propuesta de atención integral a la primera infancia sustentada por la política pública en Colombia.

Para el nivel de Educación Formal esta pérdida de contacto se ve reflejada además en el abandono, "es que ellas traen los niños y nunca vuelven a preguntar por ellos" (Docente de transición 10/10/2017). No obstante, las maestras de EIAIPI expresan que,

/.../ siempre entregamos los niños/as, y se pierde el contacto y se pierde ya todo el proceso, entonces no es que nosotros no queramos preguntar, sino que ya con el otro grupo no nos da el tiempo, pero yo pienso que, si estuviera planeado, si estuviera estructurado en un cronograma anual tal vez, si los contratos fueran más estables sería oportuno (Agente Educativo, 13/12/2018).

Cada nivel configura mecanismos de acompañamiento y de diálogo inter-institucional tanto internos como externos -por ejemplo, el programa Buen Comienzo utiliza el registro de experiencia, los informes de seguimiento, que son entregados a las escuelas para que puedan visualizar los procesos que se hacen con los niños/as-. También existen cuestionamientos para los dos sistemas pues no hay acompañamiento por parte de la Secretaría de Educación. 
/... yo insisto que ahí en la articulación, nos falta fortalecer más; lo hacemos muy en forma general, de pronto, cuando nos reunimos informalmente o cuando se reúne con el núcleo y preguntamos cómo van los niños de nosotros, como los ven ustedes, pero yo pienso que se puede fortalecer el seguimiento de estos egresados, que son egresado prácticamente (Agente Educativo Coordinador, 15/12/2017).

La articulación curricular es otro de los puntos críticos en el proceso de transición. Retomando la experiencia de las maestras y agentes entrevistadas es posible observar que las diferencias en los procesos académicos, y las exigencias en ambos sistemas, demarcan obstáculos para que existan continuidades en el proceso escolar; los aprendizajes se segmentan cada vez que los niños/as pasan de nivel y se da comienzo a una nueva construcción de saberes; la falta de continuidad representa un punto de quiebre en la necesaria progresión de los contenidos, las metodologías y prácticas maestras.

En Colombia, la principal preocupación está referida a la articulación intra-institucional sin atender los problemas que resultan de la falta de articulación respecto de lo pedagógico, curricular o metodológico. Esto sucede cuando los lineamientos técnicos especifican que es necesario garantizar un trabajo articulado e intersectorial desde la perspectiva de derechos y un enfoque de gestión basado en resultados (Ley 1804/2016) y promueve bajo los lineamientos de la Educación Inicial y Preescolar del año 2017 el conjunto de acciones intencionadas y efectivas encaminadas a asegurar que en cada uno de los entornos en los que transcurre la vida de las niñas y los niños existan las condiciones humanas, sociales y materiales para garantizar la promoción y potenciación de su desarrollo. Hemos podido recuperar en las entrevistas a maestras una preocupación centrada en el desarrollo curricular, así como una tensión entre lo que deben saber y aprender los niños y niñas y el espacio destinado al juego como estrategia pedagógica en la Educación Formal, todo lo cual genera diferencias claras si se compara la Educación Formal con la Educación Inicial.

En definitiva, las acciones en Colombia se están centrando, siguiendo la clasificación de Zabalza (2016), solamente en una articulación horizontal o continuidad horizontal, es decir, una "coordinación con otras agencias formativas del entorno: familia, instituciones de carácter social y cultural, otras escuelas, organismos y servicios municipales" (p.11), y no en una articulación vertical en la que se destaque la coherencia, secuencialidad y gradualidad que debe 
existir en el proceso de enseñanza y de aprendizaje, en definitiva, en la configuración de un currículo integrado.

La relación e interacción entre los niveles de la inicial -ultimo grado, nivel de preescolar y nivel de básica primaria-grado primero, la interconexión entre el Plan Operativo de Atención Integral (POAI), y el Proyecto Educativo Institucional (PEI) refleja encuentros y desencuentros que se cristalizan en puntos de quiebre o dicotomías pues reflejan las interrupciones con respecto a la continuidad, la identidad y autonomía de cada sistema, es decir la razón de ser, sus principios, objetivos de formación, estructura interna organizacional, metodologías y currículos.

\subsection{Dicotomía entre la Educación Inicial - Atención Integral a la Primera Infancia y la Educación Formal - Preescolar y Básica Primaria.}

Dicotomía entre la Educación Inicial Atención Integral a la Primera Infancia y la Educación Formal es una forma de nombrar los puntos críticos con los que un sujeto se encuentra en el tránsito que hace desde el punto de salida al punto de llegada. Los movimientos que el niño-niña realiza por los diferentes itinerarios están determinados por factores y variables que marcan las interrupciones y discontinuidades que afectan no solo la transición sino la trayectoria. En esta tesis los puntos críticos se ven altamente influenciados por las diferencias y los desencuentros presentados entre la Educación Inicial Atención Integral y la Educación Formal, por las coyunturas específicas en la escolarización y las situaciones que se ponen en juego por los factores internos y externos de las instituciones, lo que afectan los itinerarios de los sujetos.

El primer desencuentro se relaciona con la función educativa que cumple cada nivel de educación. Aspectos tales como la falta de información frente a los procesos institucionales, las dinámicas y la falta de comunicación y de reconocimiento de los dos escenarios como espacios de formación y socialización, connotan percepciones que evidencian desconocimiento. Las maestras de preescolar y primero reconocen el programa Buen Comienzo como una estrategia fundamental para el desarrollo integral de los niños y niñas, no obstante, manifiestan el poco conocimiento que tienen frente a las acciones que se realizan en todos sus componentes (familia y comunidad; pedagógico; salud y nutrición; talento humano; 
ambientes educativos y protectores; administrativo y de gestión). Este desconocimiento representa perspectivas e imaginarios que perfilan discursos e interpelan acciones que en el proceso educativo de enseñanza aprendizaje configuran disputas y una multiplicidad de significados y sentidos entre los escenarios.

/.../ no conozco nada de la estrategia, identifico que hay una entidad llamada Buen Comienzo que acoge a niños/as de ciertas edades, pequeñitos, algunas veces desde la secretaría nos llevaban a conocer estos lugares, las propuestas que ellos tenían, las manualidades, esa decoración que tenían, como pasaban los niños/as de un aula a otro, pero así por encimita (Docente de Primero, 10/10/2017).

/... / a veces uno trabaja como desde el imaginario que tiene de lo que hacen allá en Buen Comienzo, y de lo que uno logra escuchar que los niños y niñas te cuentan, pero en realidad no he tenido la posibilidad de verles una clase, de ver cómo está trabajando la profe, o sea trabajamos desde lo que nosotros pensamos y desde el supuesto, entonces así es más complejo (Docente de Preescolar, 11/10/2017).

El segundo desencuentro que nombran los protagonistas de esta investigación está directamente relacionado con las expectativas que se tienen en la Educación Formal frente a los aprendizajes y los saberes porque estos distan de la visión enmarcada en la Educación Inicial en el que se proponen experiencias enriquecedoras y el juego como eje trasversal para los desarrollos y aprendizajes. La representación frente a las metodologías, didácticas y formas de trabajo representan prácticas pedagógicas diversas y discursos que determinan actuaciones diferentes en los escenarios. Por ejemplo, una agente educativa del nivel de Educación Inicial refiere que las maestras de preescolar y de primero "se quejan mucho de que los niños aquí en Buen Comienzo solo vienen a jugar, entonces yo decía para mí, si la actividad rectora de la primera infancia es el juego, porque se quejan de que están jugando" (Agente Educativa docente, 12/12/2017).

El debate en torno de lo metodológico, por la forma de enseñanza y la búsqueda por la formación de un sujeto íntegro pone de manifiesto la presencia de diferentes miradas sobre uno y otro nivel. En la Educación Formal recuperamos un conjunto de estigmas y nominaciones discriminatorias cuando las maestras hacen mención a la Educación Inicial, y refieren a ella como un escenario que no enseña, pensado solo para la diversión y el juego, donde no se 
aprende contenidos ni se regulan los comportamientos de los niños y niñas para que puedan adquirir normas y hábitos. La EIAIPI es señalada como un escenario sin currículo, asistencialista, que no educa y que difiere desde los principios educativos y pedagógicos de la escuela que es el escenario para la formación y la adquisición de aprendizajes.

Los parámetros que se tienen para la Educación Inicial son muy positivos porque estimulan mucho el conocimiento no son de exigencia para el niño/a son más de espontaneidad más de exploración, cierto, pero no dialoga con lo proyectado por la escuela porque el choque que hay cuando ellos pasan al preescolar donde debe cambiar un poquito, pues se debe dar bases para la educación formada (Agente Educativa, 13/12/2017).

Ellas todavía tienen un rol muy asistencial, más que educativo, entonces ellas por ejemplo todavía apoyan darles la alimentación a los niños/as, hacen cambios de pañales (...) Cierto, muchas cosas que nosotras por norma no hacemos esas funciones, entonces hay cosas que ellas hacen que nosotras no podemos hacer (Grupo focal, 30/11/2017).

Estos desencuentros configuran una mirada específica respecto del sentido y la identidad de ambos escenarios. La tensión entre lo educativo y lo asistencial demarca para la Educación Formal la imposición de un régimen de trabajo estructurado con distribución de tareas, ritmos y tiempos de trabajo, mientas que para la Educación Inicial representa una práctica de cuidado, alimentación y juego.

Diker (2010) señala los debates que existen frente a la Educación Inicial respecto de su función asistencial vs su función pedagógica, refiriendo la identidad propia del nivel vs la "primarización" como etapa de preparación, el espacio del juego en la construcción del conocimiento vs la enseñanza de las disciplinas, y aclara que los debates respecto de la identidad del nivel inicial no han sido saldados. Es por eso que Diker reflexiona en términos de la nominación y las implicaciones que estas tienen frente a la concepción de educación e infancia.

/... / la Educación Inicial se concibe como una etapa con identidad propia, es decir, no se define en función de la preparación de los niños y niñas para la educación básica sino como la experiencia educativa más importante en la vida de las personas, a partir de la cual se propician nuevos aprendizajes a lo largo de todo el ciclo vital (Diker, 2010: 22). 
De esta forma el nivel inicial y el nivel formal se representan como espacios sociales donde el entrecruzamiento de las lógicas internas aparece de un modo absolutamente distintivo, tal como lo expone una docente del grado primero: "Buen Comienzo es un programa de aprender jugando cierto, la escuela no, la escuela se juega, pero se trabaja para el cumplimento de unos logros y estándares académicos" (Docente de Primero, 25/11/2017).

Con respecto a la tensión, puesta de manifiesto por las entrevistadas entre la función asistencial contrapuesta a la función educativa de la escuela, entendemos que detrás se encuentra un debate en torno del lugar de la enseñanza y el currículo. Mientras en la Educación Inicial los objetivos se centran en estimular el desarrollo cognitivo, emocional, social y cultural para el fortalecimiento de la autonomía, personalidad, integralidad y autoestima del sujeto a través del juego y de estrategias lúdico-recreativas, son objetivos de la Educación Formal propiciar una formación general mediante el acceso de manera crítica y creativa al conocimiento científico, tecnológico, artístico y humanístico (Ley 115/1994).

Si en la Educación Inicial se pone el acento en el cuidado, atención, asistencia, crianza, promoción, protección, prevención y juego, la Educación Formal supone una acción centrada principalmente en el proceso de transmisión de contenidos académicos. Por el contrario, en la Educación Inicial prevalece un trabajo experiencial con propuestas educativas que respetan las características, intereses y necesidades de los niños-niñas mediante el juego como medio para promover el desarrollo de sus capacidades y la construcción de saberes y aprendizajes, métodos y saberes que no son validados por la escuela.

Existe una diferencia curricular grandísima por lo que te digo, nosotras acá trabajamos a partir de la experiencia, de un modelo constructivista, el niño/a construye su aprendizaje, mientras que allá, es saque el cuaderno, mire la ficha, entonces hay si va hacer un choque bastante grande (Agente Educativa Docente, 12/12/2017).

/.../ hay un gran vacío a nivel curricular porque allá en la escuela manejan temas, acá no manejamos temas, aquí manejamos otra metodología a través del juego, trabajamos colores, figuras, los procesos de socialización del niño/a, el cuidado, la crianza, allá sería en la ficha solo en la ficha, en el cuaderno solo en el cuaderno, escriba el nombre y nosotras, esas áreas no las manejamos (Agente Educativo, 13/12/2017). 
Estos rasgos distintivos de cada escenario educativo contribuyen significativamente con otro de los puntos críticos -tercer desencuentro-, mencionados por las maestras, y es el rol que se le asigna al niño y niña como sujeto de aprendizaje, las formas de concebir las infancias se transforman y dan lugar a un perfil específico para cada escenario. Una docente de preescolar refiere lo siguiente,

Allá están trabajando con otro tipo de niño/a, el niño/a que ellas tienen no es el tipo de niño que viene aquí, porque en estas edades los cambios son, pero garrafales, el niño va volando en un proceso académico, entonces el niño/a que ellos tienen allá que juega se divierte y que salen en diciembre no se parecen en nada al niño/a que entra aquí en enero (Docente de Transición, 11/10/2017).

Ellos trabajan con esas edades para esas edades, con estrategia para esas edades y nosotras recibimos un niño mucho más grande, con otras habilidades que han adquirido que han ido desarrollando; todo hay que decirlo, me gusta mucho, porque no es ese niño/a tímido a nivel social, a nivel del lenguaje, los veo más avanzados, conocen muchas canciones, se saben rondas, veo que hay cosas muy fabulosas (Docente de Transición, 12/10/2017).

Estos testimonios confirman, por un lado, una representación de la Educación Formal como el proceso de escolarización que conduce a los niños progresivamente hacia el mundo de los conocimientos, al mundo de los adultos/as y de las reglas que conforman un ciudadano ético y responsable; por otro, a la Educación Inicial como el ámbito en la que los niños son sujetos libres, actores de su desarrollo, activos en permanente evolución, con una identidad específica, seres únicos con formas propias de aprender.

De este modo, la representación en torno de lo que el niño-niña es y debe ser con respecto a sus desarrollos demarca un perfil o ideal de sujeto para la institución de Educación Inicial y para la escuela de Educación Formal que es llamativamente diferente. En el nivel de Educación Inicial se espera un niño y niña que sea alegre, feliz, que logre en ese contexto de interacción ser autónomo y desarrollar su capacidad de agencia, un niño/a propositivo, líder, activo y que participe libremente; en cambio, el nivel de Educación Preescolar y la Básica Primaria (Educación Formal) espera recibir un sujeto que responda a las normas establecidas, atento, responsable y autónomo, con comportamientos adecuados y conductas que puedan ser 
moldeables y ajustadas a las reglas institucionales. Así lo expresa una de las maestras entrevistadas,

Es que los niños de Buen Comienzo no se sientan, no tienen normas, son muy libres, pero aquí se componen porque se componen, porque aquí les hablamos durito y les enseñamos a comportarse (Docente de Primero, 25/10/2017).

Además de la diferencia curricular, las entrevistadas mencionaron otras diferencias cuarto desencuentro- tales como el mobiliario, los materiales didácticos que se disponen para ambos niveles, entre otros. En la educación inicial resaltan la infraestructura de los Jardines de Calidad y los Centros de Desarrollo Infantil porque cuentan con dotación de materiales en todas las áreas para el desarrollo de las actividades, de manera que los niños y niñas pueden alcanzar experiencias significativas en espacios estructurados. Preescolar cuenta con una dotación de juegos y juguetes que están dentro del aula para acompañar las experiencias de los niños y niñas que, sin embargo, suele ser insuficiente. Por el contrario, en la Básica Primaria el material suele ser escaso y solo se ambienta con material reciclable o con materiales que las mismas maestras compran. Para el grado primero la dotación es mínima, los niños pasan de una organización del espacio que se corresponde con sus necesidades (sillas pequeñas, áreas de juego, juguetes), al grado primero donde deben acostumbrarse al pupitre, distribuidos en salones pequeños, no existen los juguetes, ya no son ubicados en el área cerca de los juegos o el parque, sino que se trasladan a un espacio compartido con los niños grandes de la primaria.

Bueno pues hemos visto dificultades con ellos en cuanto a que están por ejemplo acostumbrados a estar allá todo el día, acá por ejemplo, es menos tiempo, entonces estar allá todo el día, implica que las actividades tengan que ser más variadas, en términos de materiales pienso que ellos tienen muchos más materiales adaptados y muchas más cosas porque es un centro precisamente de primera infancia, entonces también notan el cambio cuando llegan se ve que extrañan los juguetes y sus espacios de juego (Docente de Preescolar, 10/10/2017).

Otro de los puntos críticos -quinto desencuentro- está relacionado con la estructura organizacional y administrativa de los dos escenarios, punto que no interfiere en la trayectoria del niño-niña pero sí en la del agente formador dado el rol que se le asigna al sujeto educador. La nominación de agentes educativos de la Educación Inicial versus las maestras de preescolar y primero demarca imaginarios que determinan acciones diferenciadoras en cuanto a la 
posición, estatus y las responsabilidades académicas. De este modo, el rol asignado al agente educativo es el de cuidado y protección de los niños y niñas, su papel se orienta a la promoción del desarrollo infantil y a velar por el bienestar de niñas y niños en correspondencia con la representación que el nivel sostiene de infancia. En cambio, en la Educación Formal (preescolar) se reconoce al docente como un profesional con dominio pedagógico en un campo del saber específico. En el documento guía evaluación de competencias del Ministerio de Educación Nacional, menciona que:

El maestro es una persona autónoma, dotada de habilidades específicas y especializadas, ligada a una base de conocimientos racionales procedentes de la ciencia y legitimados por la academia, y de conocimientos explícitos surgidos de distintas prácticas. Así pues, el maestro profesional es ante todo un profesional de la articulación del proceso de enseñanza - aprendizaje en situación; un profesional de la interacción de las significaciones compartidas (Altet, 2005: 38).

Estas representaciones comportan diferencias que jerarquizan la posición las/los maestras en ambos niveles. El imaginario de que las agentes educativas solo juegan, son maternales y protectoras, así como la referencia de que las maestras solo se preocupan por controlar y regular los cuerpos de los niños y niñas y trasmitir conocimiento son expresiones que enfrentan a estos dos niveles a una serie de desencuentros.

Las profes de la escuela piensan que nosotras las de Buen Comienzo, solo venimos es a jugar todo el tiempo, pero no es así, uno se piensa las actividades, el por qué, el para qué, aquí todas las actividades son intencionadas absolutamente todos los momentos hasta las que son complementarias, por ejemplo, el salir a la plazoleta tiene muchísimas cosas, su socialización, su exploración, o sea uno está ahí, todo el tiempo reforzando el porqué de las cosas (Agente Educativa, 14/12/2017).

La diferente caracterización de agente y docente repercute en lo que Southwell y Vassiliades (2014) llaman posición. Ellos establecen que la idea de posición docente procura dar cuenta de las paradojas, contradicciones y de la contingencia que regulan y organizan el trabajo de enseñar; los diversos modos en que las maestras recepcionan y resignifican las políticas públicas en educación, las estructuras organizacionales de las instituciones en las que trabajan, así como las concepciones respecto de dicho trabajo dan cuenta de la reproducción 
social y cultural que asumen frente a su perfil y formación profesional (Southwell y Vassiliades: 2014: 11-13).

El problema de la formación y profesionalización docente reaparece en cada una de las entrevistas realizadas. Los testimonios narran que las maestras del sistema de Educación Formal tienen más oportunidades para profesionalizarse a través de carreras de posgrado como Especializaciones, Maestrías y Doctorados, y esto es visto como una herramienta para ascender en el escalafón y un indicador de status y posición dentro del sistema, pero también responde a una necesidad particular de la escuela que estima que con un plantel docente formado elevará sus índices de calidad. En tanto, en la educación inicial y atención integral la formación se limita a cursos o diplomados, no existe apoyo para la formación continua de Maestrías o Doctorados dado que la forma de contratación de sus maestras no lo exige.

Las contrataciones para las agentes educativas no dependen del Ministerio de Educación sino que se reglamenta bajo las disposiciones de la estrategia de Cero a Siempre. Por su parte, las maestras de educación preescolar y básica primaria son empleadas oficiales de régimen especial que una vez que toman posesión del cargo quedan vinculadas/os a la administración por las normas previstas en el Decreto 2247/1997.

Aunque todas somos licenciadas si hay una diferencia en los títulos, de pronto algunas de ellas podrán tener hasta más estudios porque igual cuando uno está con el municipio le sale más barato la especialización y les toca estudiar un poco más para poder subir el escalafón, en cambio aquí no, solo realizamos diplomados y cursos, uno motiva a las muchachas, pero es que siempre sale costoso estudiar (Agente Educativa Coordinador, 15/12/2017).

Los tiempos de trabajo para las Agentes Educativas del sistema de Educación Inicial Atención Integral y las maestras de la Educación Formal (preescolar y grado primero) son diferentes: entre 4 y 6 horas en el sistema formal y 9 horas en la educación inicial. En este mismo sentido, se observan diferencias con respecto a la cantidad de estudiantes y el número de profesionales que acompañan los procesos desarrollados por los niños y niñas. Las agentes educativas de Buen Comienzo trabajan con grupos de hasta 25 niños y niñas, cuentan con auxiliares o madres comunitarias que están pendientes de todos los procesos, y un equipo interdisciplinario (nutricionista, psicóloga, enfermera, artista y otros agentes educativos) que 
acompañan y garantizan los derechos y el bienestar de los infantes. En la educación formal, en cambio, las maestras atienden entre 30 y 50 niños y niñas sin auxiliares ni apoyos.

Luego de haber presentado los puntos críticos entre ambos niveles es necesario resaltar que entre la Educación Inicial (Atención Integral a la Primera Infancia) y la Educación Formal (Educación Preescolar y Básica Primaria) se establecen unos puntos de encuentro que favorecen el proceso de articulación inter-institucional. Entre ellos el ideal de alcanzar una formación de los niños y niñas basada en experiencias y ambientes enriquecedores de aprendizaje. Otro punto de encuentro surge frente al empoderamiento, las maestras de ambos niveles coinciden que el reto está en delegar responsabilidad a las familias y empoderarlos del cuidado, la crianza y educación de los infantes. ${ }^{21}$

Las maestras de la escuela quieren que del cuidado se ocupe la familia pero dada la enorme importancia y el tiempo dedicado al tema cuidado en la Educación Inicial las familias reclaman el mismo trato para con sus niños/as en la escuela, y esto es ampliamente resistido por las maestras, quienes refieren que el modelo asistencial de los programas de atención integral en los aspectos como: la alimentación, el cuidado e higiene, son ejes centrales de las propuestas pedagógicas lo que difiere de la propuesta de la escuela donde enseñan. Para ellas este modelo asistencial se ha convertido en una barrera para que los padres asuman con corresponsabilidad sus obligaciones. Y es un debate con respecto a la función de la escuela; exponen que aunque "cuidar" "educar" y "enseñar" son conceptos que en la vida cotidiana estan totalmente relacionados se requiere de un análisis frente al rol de maestro.

Esto lo confirman las maestras del sistema de Educación Inicial quienes enuncian que, al atender las necesidades básicas de alimentación, salud y garantizar los derechos de los niños y niñas, de cierta forma ha quitado responsabilidad a las familias. Las agentes educativas maestras son quienes además se encargan de funciones propias de la madre o padre como controlar el registro de vacunas. Cabe señalar que muchas de las familias por las condiciones

\footnotetext{
${ }^{21}$ Al realizar la pregunta se observa que la mayoría de las docentes expresaban gestos de preocupación, desilusión y desesperanza, algunas culpan al sistema educativo por ser complaciente y asistencialista por qué en ocasiones asume la responsabilidad de hacer efectivo los derechos de los niños y niñas por ejemplo, estar pendiente de las vacunas, el derecho al nombre, el derecho al juego, la alimentación, según ellas algunas familias se sienten tranquilas porque saben que las docentes se harán cargo de esta responsabilidad.
} 
de contexto y la situación de pobreza, desplazamiento, violencia, desempleo requieren del programa pues es su única alternativa de supervivencia.

Buen Comienzo me parece un programa maravilloso, pero pienso que le ha quitado un poquito de responsabilidad a la familia, entonces la familia se ha tranquilizado de cierta manera porque como acá uno les da todo y todo se lo hacemos, entonces yo siento que la única como crítica al programa seria como vincular un poquito más a las familias en ese proceso de articulación, de transición porque en fin último es como esa familia la que tiene que asumir como esas responsabilidades (Agente Educativa Psicosocial, 14/12/2017).

Lo único es que de pronto me parece muy asistencial, entonces las familias se creen que vienen y dejan los niños acá y ya, y nosotras somos las encargadas de garantizar todos sus derechos, vea por ejemplo las vacunas, uno diciéndoles mamá, es importante para el niño/a, pero ellas dicen que no, que la estamos molestando. Pero le explicamos que no es que las queramos molestar si no por el bienestar del niño/a, crecimiento y desarrollo para que te enteres cómo va el proceso del niño/a, que etapas y que cosas tiene que hacer en el ciclo vital que está, o sea son muchas cosas que los papás, todavía necesitan que se eduquen. Acá, hay médico entonces por ejemplo hay jornadas de vacunación, entonces a las 10 comenzaron a vacunar unos niños que, aun así, tuvimos que llamar a las familias para que les trajeran el carnet (Agente Educativa Docente, 12/12/2017).

En la Educación Formal las maestras de preescolar-grado transición y de primero afirman que las familias abandonan a sus hijos en la escuela, mientras que en preescolar manifiestan una mayor preocupación por acompañarlos en la adaptación al nuevo ambiente y en los aprendizajes. Las maestras observan que cuando ingresan a grado primero los niños y niñas pasan a un segundo plano, es decir, de ser el centro de atención pasan a ser un sujeto con nuevas responsabilidades ${ }^{22}$, y las familias manifiestan preocupación por el rol docente delegando a la escuela toda la responsabilidad por la educación de sus hijos. “¡Es como si el Estado solo fuera el responsable de la formación y educación de los niños y niñas!" (Docente de apoyo, 21/11/2017).

\footnotetext{
22 Esta referencia hace alusión a que el niño debe crecer solo, hacer sus tareas, responsabilizarse de sus cosas porque los padres deben de trabajar, especialmente en el contexto de esta institución donde son de muy escasos recursos, los niños son cuidados por vecinas abuelos muy mayores o permanecen solos asumiendo la responsabilidad de la casa y su estudio.
} 
De esta forma las maestras entrevistadas identifican la presencia de modelos de familia frente a lo que la escuela exige y espera de ellas. Así, describen la presencia de familias que se caracterizan por su acompañamiento y compromiso ante las acciones de la escuela, familias que no pueden acompañar a sus hijos ni tener presencia en la escuela porque trabajan en jornadas completas generalmente en empleos informales y precarios pero respetan el trabajo que hace la escuela, y familias que asignan a la escuela toda la responsabilidad con respecto a la educación de sus hijos.

/.../ pienso que también estamos llegando a un estado, pues no sé si sea la palabra adecuada, como de alcaguetear, cierto, porque entonces las familias están entregando la responsabilidad al estado y nos encontramos en estos momentos, con chicos de primero de 6,7 años donde sus mamás dicen es que yo no puedo profe, es que yo no tengo tiempo para él, es que a mí no me queda fácil, es que él ya está muy grande (Docente de Primero, 25/10/2017).

Dado lo anterior, es importante señalar que se vuelve necesario un debate en torno de la función educativa de la Educación Infantil, tanto como acordar sus objetivos y el sentido asignado a términos como educación, escolarización, crianza, cuidado y asistencia. Jorge Larrosa (2000) afirma que "Educar es la forma en que el mundo recibe a los que nacen, responder es abrirse a la interpretación de una llamada y aceptar una responsabilidad." (p.12).

En este sentido, enseñar es una acción ineludible y específica que no puede reemplazarse por la acción de cuidar o asistir aunque éstas últimas constituyan dimensiones de la Educación Inicial. Para Rosa Violante (2009) “enseñar los diversos contenidos enriquece el universo cultural de los niños y su desarrollo personal y social, lo educativo incluye el tratamiento de lo asistencial porque forma parte de la respuesta educativa a las necesidades de los niños" (2009: 86).

Para Redondo (2017) resulta imperativo pensar nuevamente la participación de los diferentes actores, los nudos problemáticos y el falso dilema entre "el cuidar" y "el educar". Hoy sabemos que la escuela también cuida, protege, enseña y ayuda a cada familia a construir su futuro, por ello es urgente desde las construcciones culturales, políticas, sociales y económicas, poner en debate con los maestros y agentes educativos la mirada del paradigma asistencial versus el enfoque de derechos y las implicaciones del cuidado y sus interacciones con la educación y enseñanza. 
De esta forma, y teniendo presente que en el recorrido de estos capítulos se han nombrado constantemente las diferencias que preexisten en los procesos curriculares, metodológicos y académicos de los escenarios de Educación Inicial y Educación Formal, y que son varias las tensiones que se han caracterizado con respecto a la articulación curricular, la identidad de los escenarios, el niño y su relación con los saberes y aprendizajes, en el próximo apartado se describen la estructura organizacional de los contenidos, saberes y las implicaciones de tener una mirada vertical que dé continuidad al proceso de enseñanza.

\subsection{Estructura curricular de la Educación Infantil en Colombia}

En los apartados anteriores pudimos identificar que los esfuerzos por alcanzar la articulación entre las diferentes instituciones de atención a la infancia en el caso de Colombia se han centrado en un proceso horizontal que Zabalza (2016) denomina "continuidad horizontal". De este modo, se ha logrado una cierta coordinación entre las instituciones formativas del entorno como la familia, las instituciones de carácter social y cultural, otras escuelas y organismos. Si bien la articulación cuenta con procesos de acompañamiento desde la Secretaría de Educación y el MEN en la gestión administrativa y pedagógica, los actores que participan de esta investigación señalan que la responsabilidad por articular recae en coordinadores y directivos de las instituciones educativas cuando en verdad debería ser una lógica transversal a todo el sistema educativo.

La continuidad es indiscutiblemente el punto de quiebre en la articulación. La ausencia de conexión entre la organización institucional, curricular, las prácticas pedagógicas, los métodos y formas de enseñanza se convierten en ocasiones en un factor determinante de la repitencia y deserción escolar por la ausencia de un proyecto integrado curricularmente. Moya (2012) plantea que es necesaria la articulación porque observa que "muchos de los problemas de repitencia y deserción escolar, tienen como una de sus causas más significativas la ausencia de conexión entre las prácticas y modos de enseñar" (2012: 169). De acuerdo al informe de deserción y reprobación del municipio de Medellín se observa que para el año 2019 la matrícula en términos de deserción y reprobación es más alta para Preescolar-grado transición y Básica Primara como se muestra a continuación: 


\section{Deserción y reprobación - Medellín}

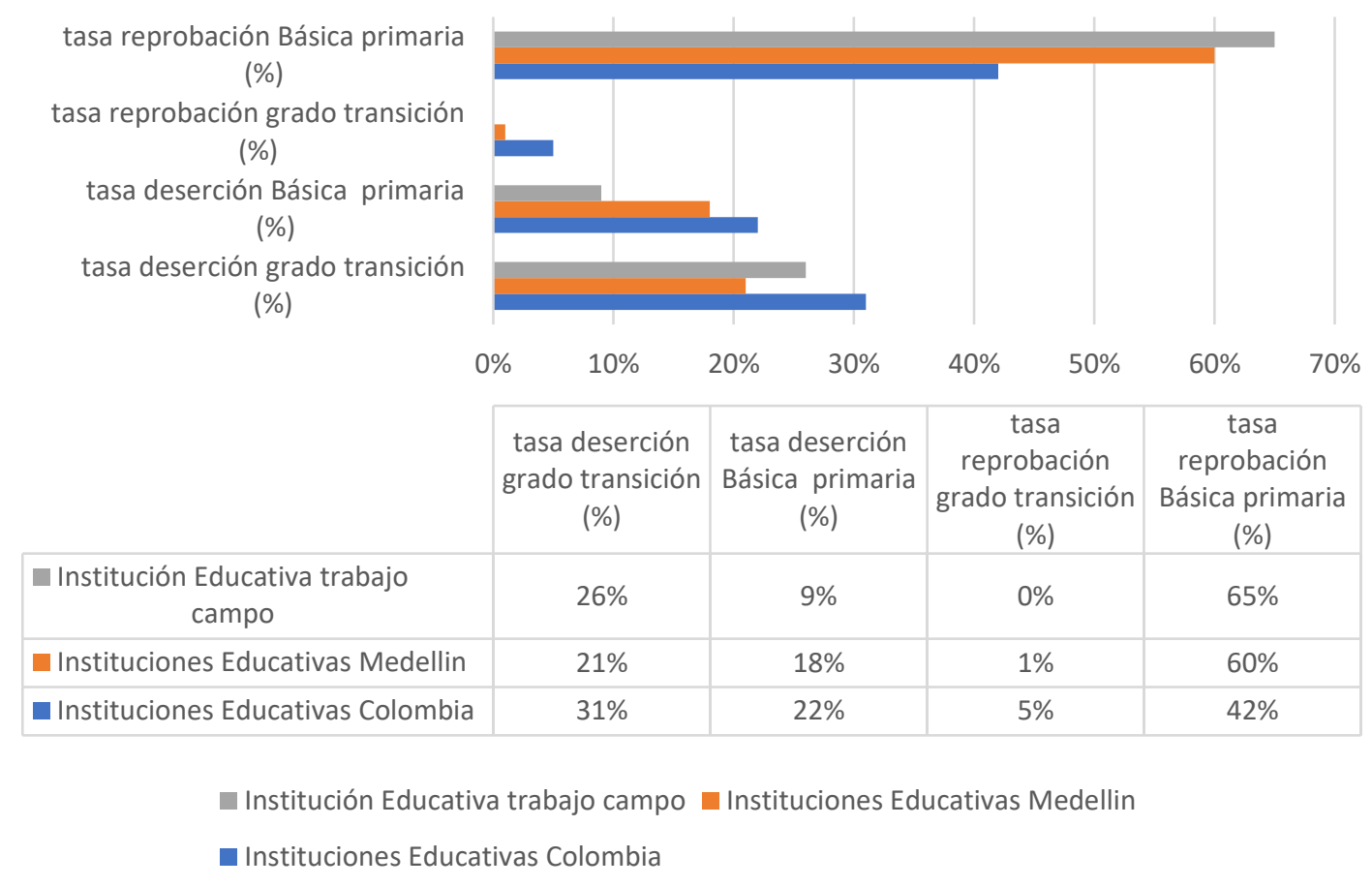

Fuente: Elaboración propia

Como se ve en la ilustración la tasa de deserción para preescolar-grado transición en Colombia es $31 \%$ y en la ciudad de Medellín 21\%, sin embargo, si se compara la tasa de deserción del grado transición con la Educación Primaria vemos que en Medellín el problema se concentra en preescolar-grado transición ( $22 \%$ Colombia y $18 \%$ Medellín). Es claro que esta deserción se ve anclada a múltiples factores que según el Ministerio de Educación se relacionan con situaciones individuales de los niños-niñas y sus familias, la situación socioeconómica y demográfica como resultado del desplazamiento por la violencia armada, la falta de acceso a oportunidades básicas (empleo, vivienda, alimentación). En el caso específico de la Educación Básica Primaria el Ministerio identifica cuatro aspectos que inciden en la deserción: los procesos académicos e institucionales, la falta de apoyo en los procesos de aprendizaje y áreas del conocimiento, el nivel educativo de los padres y la pobreza. Otro indicador preocupante es la tasa de reprobación en primaria que es de un $42 \%$ para Colombia y un $60 \%$ para Medellín, lo que evidencia que los niños y niñas no están alcanzando los logros 
y niveles de aprendizajes esperados para esa franja de edad lo que pone en cuestión que el Ministerio de Educación no identifique los factores internos del sistema.

Analizando el caso particular de la institución en la que se realiza el trabajo de campo se observa que la deserción para preescolar-grado transición es de un $26 \%$, siendo más representativa para el primer grado de la primaria donde las cifras representan un 35\%. En las voces de las maestras y coordinadoras se recupera la idea de que el ingreso, la permanencia y la graduación de los estudiantes se ve mediada por varios factores, entre ellos los conflictos y la violencia, la pobreza en la que viven los estudiantes sumada a la condición de desplazados, la precariedad de las familias que viven del trabajo informal. Además, la fluctuación porque las familias se cambian de barrio o mudan constantemente de sector. Indicadores que influyen en este índice de deserción. Por el contrario, ante la pregunta por los índices de reprobación las maestras entrevistadas afirman que esta problemática se relaciona también con los procesos académicos, organizativos, pedagógicos de las instituciones.

/.../ la falta de articulación y trabajo continuo entre los niveles, grados, modalidades, la falta de un currículo interdisciplinario y flexible, la falta de un acompañamiento y seguimiento oportuno a los desempeños de los niños-niñas, a sus logros y niveles de aprendizajes, además de los tipos de familia presentes en la escuela, las expectativas de aprendizaje de los maestros y las orientaciones técnicas, administrativas ministeriales con respecto a las pruebas inciden directamente en este proceso (Docente de Primero, 26/10/2017).

Rush y Vitale (1994) señalan que el logro escolar está estrechamente relacionado con características de la institución educativa a la cual ingresa el niño/a, como el tamaño de las clases, el nivel de formación de los maestras, la infraestructura, la disponibilidad de los recursos educativos y su estructura curricular, además de la importancia que otorgan a las variables individuales del niño/a como sus experiencias tempranas, su nivel de aprestamiento al ingresar al sistema de educación formal, su nivel de motivación, sus competencias sociales y sus habilidades cognitivas (1994: 325-333).

En los programas de Educación Inicial como Buen Comienzo no es posible hablar de contenidos temáticos. Esta educación no apunta hacia la enseñanza sino hacia el aprendizaje y el desarrollo integral, la exploración, el juego y la experimentación. 
Mientras la educación preescolar, básica y media organizan su propuesta a través de la enseñanza de temas y conceptos que se derivan de áreas específicas o para el desarrollo de competencias en matemáticas, ciencias naturales y sociales, entre otros, la Educación Inicial centra su propuesta en acoger, cuidar y potenciar el desarrollo de las niñas y los niños de primera infancia. Por lo tanto, se habla de un proceso de acompañamiento e impulso de los procesos de desarrollo integral y armónico, y no solo se enfatiza en su crecimiento cognitivo (Camargo Abello, 2014: 89).

Uno de los aspectos fundamentales que enuncian las maestras para favorecer la retención de los niños y niñas en el sistema radica en continuar con algunos de los procesos del sistema de la Educación Inicial en la Educación Formal. Como vemos, la implementación de articulaciones curriculares y metodológicas es una demanda que requiere mayor atención especialmente por los procesos cognitivos emocionales y sociales de los niños y niñas.

A pesar de que hay una articulación, yo pienso que en el preescolar y primaria debe de haber una continuidad curricular, pues o sea, es que llegan es a sentarse, llegan es a hacer planas, llegan es a coger un libro, entonces yo pienso que tienen que seguir esa etapa del juego, de buscar más estrategias para enseñarles a los niños y favorecer su aprendizaje y tránsitos individuales (Docente de Apoyo, 21/11/2017).

González, Duhalde, Borzone y Stapich (1996) afirman que se requiere programar la articulación entre el Jardín y la Educación Básica mediante una estructura en la que se conjuguen objetivos, contenidos, experiencias, materiales, en un intento por enmarcar los sentimientos, pensamientos y acciones de los actores involucrados. Para los actores de esta investigación la articulación curricular debe ser vista como un proceso de secuencialidad en la transición, es decir, de procesos ligados y estructurados del modo en que han sido elaborados los Derechos Básicos de Aprendizaje (DBA) ${ }^{23}$ orientaciones por MEN que muestran un punto

\footnotetext{
${ }^{23}$ Los Derechos Básicos de Aprendizaje (DBA): Son una selección de saberes claves que indican lo que los estudiantes deben aprender en cada grado escolar desde $0^{\circ}$ hasta $11^{\circ}$ para las áreas de lenguaje y matemáticas Dan cuenta del desarrollo progresivo de algunos conceptos a lo largo de los grados Presentan ejemplos para aclarar los enunciados. Estos ejemplos no se plantean como actividades que los docentes deban realizar en sus aulas de clase. Son referentes para la planeación de aula. De esta manera, las actividades en el aula pueden e idealmente pueden involucrar varios DBA de un grado, para que estos se alcancen gradualmente a lo largo del grado.
} 
de inicio y un punto de llegada respecto de los saberes y logros que deben alcanzar los niños y niñas desde el grado de transición hasta el quinto grado de la educación básica primaria.

/.../ conocer cuáles son los aprendizajes que adquieren en la Educación Inicial inclusive que ellas conozcan desde donde partimos nosotras y darle la secuencialidad a cada uno, pienso que desde ahí eso nos ayudaría, a estar más articuladas como institución (Agente Educativa Coordinadora, 15/12/2017).

Pensar la posibilidad de un proyecto curricular integrado es la propuesta y la demanda de una mayor articulación vertical que hacen las maestras para darle continuidad a una propuesta pedagógica de la que participan ambos niveles. Sáez (2015) señala que relacionar los distintos niveles dentro de un sistema escolar permite asegurar la continuidad pedagógica y la adecuada coordinación del proceso de transición entre instituciones educativas y niveles. Así mismo refiere que este tipo de articulación requiere de una secuencia lógica entre los lineamientos curriculares del Ministerio de Educación y la escuela para organizar el currículum coherentemente entre un nivel y otro (2015: 13-14).

De esta forma pensar en una articulación vertical que atraviese todo el sistema educativo es remitirse a una responsabilidad compartida de planeación, construcción y diálogo entre ambos sistemas frente a los procesos pedagógicos, curriculares y didácticos. Esto no significa perder la identidad sino por el contrario supone acompañar, establecer conexiones, coordinar esfuerzos, compartir ideas, establecer vínculos, aprovechar el capital de cada escenario y optimizar las condiciones propias para no centrar la mirada solo en los contenidos sino en los sujetos y sus características.

Las expectativas de aprendizaje de las maestras frente a los saberes que deben tener los niños demarcan diferencias conceptuales en cuanto a los contenidos y bases curriculares para cada área y grado. Lograr que los niños y niñas cumplan con las competencias de lectura, escritura, lógico matemática, inglés y un desempeño académico que responda a los estándares exigidos por el Ministerio de Educación en la básica primaria se convierte en una preocupación constante para las maestras, quienes cuestionan los saberes con los que llegan los niños y niñas del grado transición, así como la preparación que reciben en las instituciones de la Educación Inicial. La presión que sienten las maestras para responder a las exigencias del Ministerio de 
Educación respecto de cómo formar a los niños y niñas se debe al hecho de que se aplican en el país pruebas estandarizadas que miden y evalúan los saberes propios del grado y la edad.

/... / hay veces le echamos la culpa al docente del grado anterior y lo culpamos porque los niños y niñas no saben nada, pero no es el caso, porque como dicen las profes de transición ellas trabajan, las profes de segundo también mencionan que los niños/as llegan sin saberes y nosotras las de primero decimos, pero si lo trabajamos. Entonces uno se pone a analizar y, es más, sin la búsqueda de echar culpas, son como las familias, las familias que no estimulan, $o$ realmente el sistema que no permite la continuidad en los procesos y no apoyan (Docente de Primero, 26/10/2017).

Las pruebas estandarizadas operan como verdaderas tecnologías de control de la práctica las/los docentes y reactualizan el poder disciplinario sobre el trabajo docente. En particular, "la publicación de los resultados de las pruebas estandarizadas, la política de incentivos económicos para premiar al buen docente, la evaluación entendida como medición" (Seoane, 2019: 128-129). En nuestro campo hemos relevado el malestar docente respecto de cómo inciden las pruebas en los índices de deserción y repitencia. Sin embargo, faltan estudios sistemáticos en Colombia que permitan poner en relación los procesos de estandarización de la evaluación y del trabajo docente con los resultados de la enseñanza, para pensar formas de evaluar la educación que contemplen situacionalmente no sólo las condiciones de clase, género-sexual, étnicas, discapacidad, desplazamiento de los niños y niñas sino también de agentes educativas y maestras.

¿Qué deben saber los niños y niñas en la Educación Infantil? y ¿cuáles son las competencias con las que deben llegar a la Básica Primaria? son dos preguntas que las maestras, agentes educativas y coordinadoras se hacen constantemente frente al currículum escolar, las propuestas pedagógicas y el perfil de egreso de los niños y niñas. 
Tabla 10 Perfil y saberes de los niños y niñas en la Educación Infantil

\begin{tabular}{|c|c|c|c|c|}
\hline \multicolumn{3}{|c|}{ Perfil de los niños y niñas en la Educación Infantil } & \multicolumn{2}{|c|}{ Saberes } \\
\hline $\begin{array}{c}\text { Educación } \\
\text { Inicial }\end{array}$ & Grado Transición & $\begin{array}{c}\text { Grado } \\
\text { Primero }\end{array}$ & $\begin{array}{c}\text { Grado } \\
\text { Transición }\end{array}$ & Grado Primero \\
\hline $\begin{array}{l}\text { un ser sociable, } \\
\text { independiente, } \\
\text { participativo, } \\
\text { solidario, crítico, } \\
\text { observador, } \\
\text { respetuoso } \\
\text { creativo }\end{array}$ & $\begin{array}{l}\text { Un ser autonomo } \\
\text { con capacidad para } \\
\text { expresar } \\
\text { sentimientos } \\
\text { emociones y } \\
\text { pensamientos. } \\
\text { conocimiento del } \\
\text { propio cuerpo y de } \\
\text { sus posibilidades } \\
\text { de acción, así como } \\
\text { adquisición } \\
\text { de su identidad. }\end{array}$ & $\begin{array}{l}\text { Sujeto con } \\
\text { nociones } \\
\text { básicas de lecto } \\
\text { escritura para } \\
\text { que pueda } \\
\text { escribir y } \\
\text { expresar } \\
\text { información de } \\
\text { diferentes } \\
\text { maneras, } \\
\text { resolver } \\
\text { situaciones } \\
\text { problemas que } \\
\text { implique } \\
\text { operaciones } \\
\text { matemáticas }\end{array}$ & $\begin{array}{l}\text {-habilidades que } \\
\text { les permiten } \\
\text { prepararse para } \\
\text { aprender a leer y a } \\
\text { escribir. } \\
\text { Reconocer que las } \\
\text { palabras están } \\
\text { formadas por } \\
\text { sonidos (mediante } \\
\text { canciones, juegos } \\
\text { con el lenguaje y } \\
\text { poemas). } \\
\text { aprender que la } \\
\text { escritura tiene una } \\
\text { dirección, } \\
\text { interactúan con }\end{array}$ & $\begin{array}{l}\text { Pensamiento } \\
\text { aleatorio, } \\
\text { pensamiento } \\
\text { métrico y espacial, - } \\
\text { pensamiento } \\
\text { numérico } \\
\text { variacional } \\
\text { Comprensión: } \\
\text { reconocer textos. } \\
\text { Leer, conciencia } \\
\text { fonológica } \\
\text { escuchar } \\
\text { Producción: } \\
\text { escribir conocer el } \\
\text { alfabeto, hablar y }\end{array}$ \\
\hline $\begin{array}{lr}\text { con seguridad } \\
\text { para expresar su } \\
\text { opinión } & \text { y } \\
\text { confianza en } & \text { sí } \\
\text { mismo para } \\
\text { resolver } \\
\text { situaciones } \\
\text { problemáticas }\end{array}$ & $\begin{array}{l}\text { Sujeto respetuoso } \\
\text { de la norma, que } \\
\text { escuche preste } \\
\text { atención, tenga } \\
\text { respeto por la } \\
\text { palabra y por el } \\
\text { otro. }\end{array}$ & $\begin{array}{l}\text { Sujeto solidario } \\
\text { que sepa vivir } \\
\text { en comunidad y } \\
\text { acate las normas } \\
\text { de convivencia } \\
\text { sea respetuoso y } \\
\text { tolerante. }\end{array}$ & $\begin{array}{l}\text { encuentran en su } \\
\text { cotidianidad, } \\
\text {-identificar que la } \\
\text { escritura transmite } \\
\text { una intención } \\
\text { comunicativa en la } \\
\text { que plasman sus } \\
\text { interpretaciones }\end{array}$ & $\begin{array}{l}\text { vocabulario } \\
\text {-Entorno físico } \\
\text {-Entorno vivo }\end{array}$ \\
\hline $\begin{array}{l}\text { Con capacidad } \\
\text { para convivir } \\
\text { realizar } \\
\text { actividades } \\
\text { conjuntas y } \\
\text { colaborar con sus } \\
\text { pares }\end{array}$ & 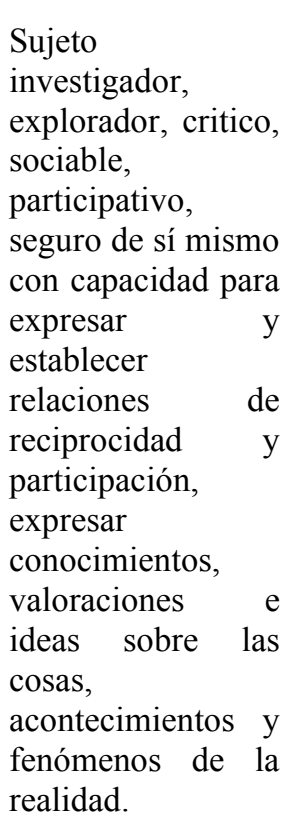 & & $\begin{array}{l}\text { de la realidad, y } \\
\text { realizan sus } \\
\text { propias } \\
\text { producciones } \\
\text { escritas } \\
\text {-clasificación de } \\
\text { objetos y la } \\
\text { descripción de sus } \\
\text { diferencias y } \\
\text { semejanzas } \\
\text { describir de forma } \\
\text { global figuras y } \\
\text { cuerpos } \\
\text { posiciones Las } \\
\text { relativas de los } \\
\text { objetos } \\
\text { (dentro/fuera, } \\
\text { lejos de/cerca de, } \\
\text { encima/debajo). } \\
\text { Establecer }\end{array}$ & \\
\hline
\end{tabular}




\begin{tabular}{|ll} 
Con nociones y & relaciones del \\
aprestamiento para & tipo: es más largo \\
la lectoescritura & que, es más \\
para las soluciones & pesado que, ocurre \\
de problemas que & antes o después \\
impliquen & \\
relaciones $\quad y$ & \\
operaciones & \\
matemáticas. &
\end{tabular}

Fuente: elaboración propia

Tal como el gráfico lo muestra, los saberes dan cuenta de la relación que se establece entre cada escenario educativo y el perfil de egreso que deben tener los niños y niñas para asumir un nuevo grado. Peralta (2006) considera que la articulación curricular constituye uno de los puentes esenciales de una acción educativa que, sin perder el capital de aprendizaje que ya han adquirido los niños, permita avanzar hacia una educación básica que no abandone el carácter lúdico de la Educación Inicial. Afirma que los aprendizajes deben ser concebidos como un "continuo progreso donde se construyen unos a partir de los anteriores, constituyendo una línea de trabajo permanente" (Peralta, 2006: 7).

Continuando con el análisis que se viene realizando en cuanto a la importancia de una articulación vertical es posible decir que en Colombia los niños y niñas transitan por un sistema educativo en el que la organización curricular y pedagógica es diferenciada, por ejemplo, se cuentan con diferentes documentos y orientaciones técnicas y administrativas para cada nivel, lo que implica para los niños y niñas asumir los aprendizajes de forma distinta. Como se ve en la siguiente gráfica. 
Ilustración 5 Estructura Curricular de la Educación Infantil

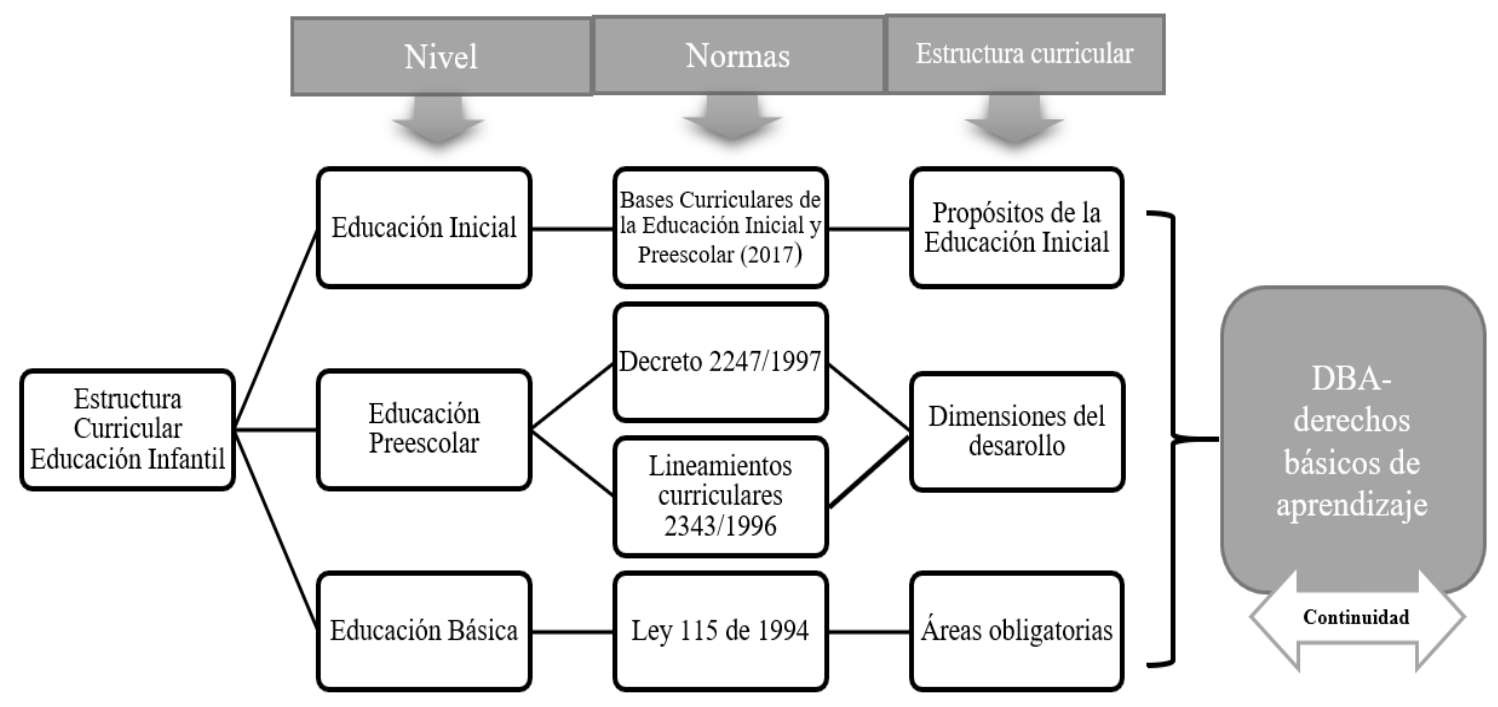

Fuente: elaboración propia

La Educación Inicial Atención Integral a la Primera Infancia cuenta con las Bases Curriculares de la Educación Inicial y Preescolar elaboradas recientemente (2017) para generar continuidad entre ambos sistemas. La propuesta está fundamentada desde un currículo basado en la experiencia. Tres propósitos son fundamentales en la estructura curricular de la Educación Inicial:

- Las niñas y los niños construyen su identidad en relación con los otros, se sienten queridos y valoran positivamente pertenecer a una familia, cultura y mundo.

- Las niñas y los niños son comunicadores activos de sus ideas, sentimientos y emociones, imaginan y expresan su realidad.

- Las niñas y los niños disfrutan aprender a explorar y se relacionan con el mundo para construirlo y comprenderlo.

En la Educación Preescolar se cuenta con los lineamientos curriculares 2343/1996 y el decreto 2247/97 aún vigentes y constituyen las orientaciones epistemológicas, pedagógicas que define el MEN para apoyar el proceso curricular. Se fundamenta en las actividades rectoras y en las dimensiones del desarrollo: 
- Dimensión afectiva: el mundo de los afectos, los sentimientos y las emociones se circunscribe a las relaciones que proporcionan bienestar y armonía para sí mismo y para los demás.

- Dimensión estética: a partir de actividades y acciones, el niño y la niña expresan ideas y opiniones acerca de sí mismos, de las demás personas y del entorno próximo.

- Dimensión corporal: el movimiento, la expresión corporal y gestual se convierten en fuentes de creación y comunicación del niño y la niña.

- Dimensión cognitiva: se refiere a los saberes y a la puesta en práctica de éstos en diversos contextos y con diferentes objetos.

- Dimensión ética: la formación ética y moral propende por el desarrollo de la autonomía y del actuar en coherencia con criterios propios.

- Dimensión comunicativa: se centra en la expresión de conocimientos e ideas sobre las cosas, los acontecimientos y los fenómenos de la realidad, y en el desarrollo de las habilidades comunicativas: hablar, leer, escribir y escuchar.

En la Educación Formal Básica Primaria la Ley 115 de 1994 en sus artículos 21 y 31 instituye el grupo de áreas obligatorias y fundamentales para el logro de los objetivos de enseñanza, y las áreas del conocimiento y de la formación que necesariamente se tendrán que ofrecer de acuerdo con el currículo. Para cada área se establecen unos estándares en los que se fijan las competencias en el currículo. El estándar sirve para identificar lo que se debe aprender de acuerdo con lo que está estandarizado y establece los niveles básicos de calidad que deben alcanzar los niños niñas y jóvenes. Las áreas obligatorias para la educación básica primaria son:

- Ciencias Naturales y Educación Ambiental

- Ciencias Sociales, Historia, Geografía, Constitución Política y Democracia

- Educación Artística y Cultural

- Educación Ética y Valores Humanos

- Educación Física, Recreación y Deportes

- Educación Religiosa

- Humanidades, Lengua Castellana e Idiomas Extranjeros 
- Matemáticas

- Tecnología e Informática

Retomando los conceptos propuestos por Peralta $(2006)^{24}$ continuidad, progresión y diferenciación es posible comprender que el Ministerio de Educación elabora los Derechos Básicos de Aprendizaje (DBA) como forma de estructurar los saberes que los niños y niñas deben alcanzar grado por grado; y como medio de continuidad entre la Educación Inicial y Básica primaria, sin embargo vemos que considerar las experiencias que han tenido los niños en los escenarios y mismo grados con respecto a los saberes, disponer de experiencias de aprendizajes lúdicas, materiales concretos, y la misma infraestructura es complejo por las mismas estructuras organizacionales, por los modelos pedagógicos, y estructuras curriculares; Para las maestras la progresión se vuelve más complejas en los niveles avanzados porque los contenidos a enseñar se organizan de forma distinta por áreas y responden a pruebas estandarizadas.

Así las maestras enuncian como punto de encuentro el desarrollo de experiencias y ambientes pedagógicos en los que está presente el juego, las expresiones artísticas, la exploración del medio y la literatura y relacionan el punto de desencuentro con la falta de conocimiento frente a las orientaciones normativas que rigen ambos sistemas.

Si me preguntas por lo curricular te confieso que no conozco mucho de los contenidos que se trabajan en el programa Buen Comienzo, ni de sus orientaciones, en preescolar trabajamos con los lineamientos curriculares, el juego y la lúdica, fortalecemos las dimensiones, pero ese documento del que me hablas el de bases curriculares aun no lo conocemos, estamos trabajando con los DBA de transición-interesante conocerlo (Docente de Transición, 12/10/2017).

Las orientaciones curriculares en Colombia constituyen referentes que apoyan y orientan el proceso de elaboración de los Proyectos Educativos Institucionales y sus correspondientes planes de estudio por ciclos, niveles y áreas. Analizando esta organización

\footnotetext{
${ }^{24}$ Para Peralta el desarrollo de los aprendizajes que se generan en la Educación Inicial debe tener articulación con la educación básica, lo que implica que si en el primer nivel se ha favorecido una base amplia de habilidades, actitudes y aprendizajes en diferentes áreas, debe velarse por su continuidad y/o progresión en el siguiente, de manera que no se pierdan ni los logros alcanzados, ni su enfoque activo, lúdico, y con sentidos para los niños y niñas (2006:13).
} 
para la Educación Infantil es posible mostrar que los aprendizajes se estructuran de forma diferente entre propósitos, dimensiones, áreas lo que no posibilita la progresión efectiva.

Pensar articuladamente es establecer conexiones entre la gestión institucional, la gestión pedagógica, la gestión administrativa; es coordinar esfuerzos para que los planes operativos de atención integral (POAI) y los proyectos educativos institucionales (PEI) compartan ideas, integren perspectivas epistemológicas y pedagógicas; es compartir ideas y experiencias significativas con los otros, construir acuerdos que posibiliten la continuidad, progresión y diferenciación entre los escenarios; es pensar en la formación del niño y la niña como sujeto singular dentro del proceso de enseñanza aprendizaje; es caracterizar su perfil y mediar para que la organización curricular no esté centrada en contenidos sino en las características del sujeto y en su contexto.

\subsection{Formalizar lo informal en una escuela para la niñez}

El análisis de las diferencias y las tensiones que se producen entre la Educación Inicial Atención Integral a la Primera Infancia y la Educación Formal grado preescolar y grado primero nos lleva a preguntarnos acerca de las implicancias que tendría formalizar lo informal -propio de la educación inicial- en una escuela para la niñez.

La necesidad de articular ambos niveles en Colombia se ha puesto de manifiesto a partir de las últimas movilizaciones y paros maestras quienes, desde la asociación Fecode ${ }^{25}$, radicaron un pliego de peticiones ante el Ministerio de Educación (MEN) que contempla 30 puntos divididos en siete ejes: política educativa, carrera docente, económico, bienestar, salud, prestacional e institucional. Dentro de estas peticiones uno de los puntos se relaciona con garantizar "el acceso universal al sistema educativo público de todos los niños y jóvenes desde los tres grados del preescolar hasta el grado once" (Fecode, 2015).

La situación que se expone de acuerdo con lo planteado por Fecode es que el Gobierno Nacional no incluyó la educación preescolar en el Plan Nacional de Desarrollo. Según la organización, el Ministerio "marchita la educación pública cuando desconoce y niega el

\footnotetext{
${ }^{25}$ La Federación Colombiana de Educadores (FECODE) es la federación sindical que agrupa los sindicatos departamentales y distritales de maestros y maestras de Colombia.
} 
preescolar de tres grados”. La formación de los niños, señalaron, la está asumiendo el Estado desde el grado transición (5 años), dejando los grados anteriores (parvulos, prejardin y jardin) a cargo del ICBF o en manos de programas tercerizados. En respuesta a esta petición, el Ministerio defendió el modelo actual que funciona con el Programa de Cero a Siempre (programa que vincula entidades públicas y privadas para la atención de niños) justificando que el país está mucho más allá del preescolar de tres grados porque suma dos años de escolaridad formal, y que gracias al programa de Cero a Siempre se garantizan 5 años de Educación Inicial con atención integral desde los cero años (Valenzuela, 3 de mayo 2015Noticia-Semana).

Bajo esta mirada se pone en duda la posibilidad de formalizar el nivel de educación inicial y preescolar en la educación formal y en concordancia con los procesos de articulación y continuidad que buscan mejorar las transiciones que los niños y niñas realizan, las voces de las maestras y agentes educativos dejan entrever angustias y reflexiones frente a lo que podría ser un espacio escolar con una estructura organizacional, administrativa, pedagógica y didáctica de "escuela" distinta a la actual.

El problema más relevante que preocupa a las maestras se relaciona con la infraestructura. Las maestras del grado prescolar y primero refieren que las estructuras de las instituciones educativas actualmente no cuentan con los espacios y las adecuaciones pertinentes que se requiere para atender con calidad a la primera infancia, dado que las condiciones y demandas de los niños y niñas más pequeños es compleja en tanto no se cuenta con el personal suficiente para acompañar cada uno de los procesos.

Pues uno se angustia de todas maneras porque son niños y niñas que requieren mucha, mucha dedicación, o sea mucho acompañamiento y yo pienso que de pronto la infraestructura no es pertinente, a mí me parece bien cómo opera ese sistema de Buen Comienzo allá los cuidan, pero acá no darían los espacios, o sea es pensar que en esas nuevas instituciones que se están haciendo se piensen en esto (Docente de Transición, 10/10/2017).

Otro de los puntos que ponen en consideración se relaciona con la asignación de recursos, factor fundamental para que una propuesta de esta magnitud logre ejecutarse y no sea un fracaso. Ante ello contraponen las dificultades que se presentan con respecto a la dotación y las diferencias con respecto al material didáctico que se brinda en la Educación Inicial, 
refutando así la idea de unificar los presupuestos, propuesta que no es viable teniendo presente los problemas identificados en el sistema de educación en Colombia con la experiencia de jornada única.

/.../ funcionaría si hay los recursos, porque si no los hay, ese programa vendría siendo un fracaso como el de la jornada del horario extendido, que no funcionó, para funcionar, tendrán que hacer el doble de las instituciones, aquí funcionan 3 jornadas y si quitamos la de la tarde para extender la de la mañana, entonces, que haríamos con la mitad de la población, es complejo (Docente de Primero, 25/10/2017).

Las mismas maestras y agentes educativas señalan que la propuesta de unificar recursos, metodologías, formas pedagógicas de trabajo implicaría una ruptura con las lógicas que regulan el trabajo en cada nivel porque la propuesta pedagógica, metodológica y didáctica debería ser el resultado de una construcción conjunta que amerita encuentros, debates relativos al desarrollo social, cognitivo, comunicativo de los niños y niñas. Una propuesta de reforma educativa como la que aquí se comenta implica un reto especialmente para las maestras de la Educación Formal y requeriría repensar el perfil profesional y la política de formación docente.

De igual forma ponen en consideración que el Programa Buen Comienzo se identifica como un espacio de protección, de cuidado en el que se trabaja por la garantía y el cumplimiento de los derechos de los niños y niñas, y que gracias a su organización administrativa favorece procesos socioculturales como se describe a continuación:

- Permite a las madres cabeza de familia, trabajar y obtener una sustentabilidad económica para garantizar el bienestar de sus hijos, en tanto cuentan con un espacio en el que sus hijos pueden gozar de una atención integral durante 8 horas.

- Se desarrolla un trabajo de movilización y sensibilización con la comunidad con respecto a la garantía y la protección de los niños y niñas, es decir, estos escenarios son centrales para la visibilización de la problemática de la niñez.

- Representa formación y empoderamiento en crianza, cuidado y educación para las familias; el desarrollo de los encuentros educativos y la forma como movilizan acciones con las familias es un ejemplo para la escuela que por sus estructuras organizacionales se centra más en la formación del niño y niña. 
- El componente de alimentación y su minuta, aunque en la escuela regular se cuenta con restaurante, no se cumple con el 70\% de alimentación que reciben los niños y niñas. El Ministerio de Educación tendría que darle continuidad a este componente.

- Evidencia la calidad de los procesos con respecto al desarrollo de los niños y niñas, los equipos interdisciplinarios son fundamentales para complementar todas las acciones implementadas.

Estamos ante un programa que piensa en las familias y en los niños-niñas. Formalizar lo informal propio de la Educación Inicial implica que la escuela asuma otra estructura organizativa y la propuesta de trabajo desde los componentes salud, nutrición, educación, protección de las infancias. En pocas palabras, supone continuar con la estructura del nivel de educación inicial atención integral en la educación formal lo que indiscutiblemente no solo requiere de mayores recursos sino de más profesionales y de un cambio en las metodologías y los currículos.

Para algunas maestras trasladar el nivel inicial y de atención integral a la educación formal es una utopía por el costo financiero que requiere, pero destacan que es una necesidad para garantizar la continuidad en los procesos educativos. La falta de continuidad entre ambos niveles conlleva la pérdida del reconocimiento de las infancias desde la gestación, la pérdida del juego como eje trasversal del aprendizaje y del desarrollo.

/.../ sería muy triste que se pierdan esos espacios tan bonitos que se han construído con tanto esfuerzo pensando en ellos/as, donde las familias también están vinculadas, como pasará a este espacio ya tan formal, pienso que se perdería pues como mucho la lúdica, como la capacidad expresiva que aquí se tendría que dar, si se da la situación de esa manera, sería triste quitar ese jardín o sea ese espacio para ellos/as (Maestra de Apoyo, 21/11/2017).

/... yo diría que se perdería un poco la calidad del proceso, cierto por qué, entonces todo lo que se vuelve público, es de todo el mundo, pero no es de nadie, cierto entonces mira que muchas veces uno va a instituciones y hay quejas de abandono y todo eso, yo pienso que estos centros perderían la calidad porque si no hay recursos para esa parte de educación entonces, si metemos más instituciones abrían más recursos? Me quedaría hay como la inquietud (Agente Educativa Docente, 12/12/2017). 
Como ya señalamos, pensar en formalizar la Educación Inicial Atención Integral a la Primera Infancia amerita un cambio de paradigma dado que ninguno de los escenarios está preparado para asumir las funciones administrativas, académicas, pedagógicas similares a las de Preescolar y Básica Primaria. Sin embargo, es preciso señalar que esta formalización está siendo contemplada para los grados de prejardín y jardín (3 y 4 años de edad) propuesto en el Decreto N²247/1997 del MEN, en el marco de los acuerdos que realizó el gobierno nacional representado por la Ministra de Educación Nacional y la Federación Colombiana de Trabajadores de la Educación-FECODE (2019), vinculado al plan previsto por el decreto $\mathrm{N}^{\circ} 160 / 2014$ para ampliar progresivamente la cobertura del nivel:

1. Grado transición: en el año 2021 , el $80 \%$ y el $100 \%$ al 2022

2. Grado jardín en el año 2022 , el $7,5 \%$ sobre la población en edad escolar y el $20 \%$ al año 2023

3. Grado pre jardín en el 2024 , el $7,5 \%$ sobre la población en edad escolar y el $10 \%$ en el año 2025

Dada la explícita intención del gobierno nacional por ampliar la cobertura con acciones concretas, no se observa aún una apuesta por la articulación de ambos sistemas en lo referido a la continuidad vertical y horizontal, lo que amerita un análisis y debate profundo respecto de la identidad, autonomía y función de la Educación Infantil en Colombia.

La identidad y autonomía de los escenarios educativos no pueden ser pensados como proceso separados sino como procesos de escolarización continuos. Como lo plantea Zabalza (2016), es necesario concebir la escolaridad como un "proceso global y continuado a lo largo del cual los sujetos van creciendo y educándose con un sentido unitario, con un currículo que supone un proyecto formativo integrado" (2016: 13). Es decir, pensar en la existencia de un espacio, como propone Narodowski (2009), desde las pedagogías democráticas, permite la funcionalidad del nivel inicial abierto a lo nuevo, sensible a la experimentación y curioso ante la posibilidad de buscar (y encontrar) nuevas formas de "ser escuela". Una escuela primaria que debería favorecerse "jardinizando" los primeros grados de la escuela primaria y no "primarizando" la sala de 5 (cinco) años (2009: 32). Por ello, en esta unificación el respeto por las metodologías, las articulaciones y acuerdos en cuanto a las dinámicas institucionales y el 
diálogo igualitario con el desarrollo de acciones conjuntas son fundamentales para la construcción de una escuela que no segmente, que sea una escuela pensada para la niñez.

\subsection{A modo de cierre}

Si educar es la forma en que el mundo recibe a los que nacen, se puede decir que las tensiones y puntos críticos anteriormente analizados con respecto al sentido e identidad de ambos escenarios, los procesos académicos, el rol del niño, la familia, el agente educativo, el lugar de la enseñanza, el currículo, los aprendizajes, el conocimiento, la profesionalización, ponen de manifiesto la segmentación y la dicotomía entre los objetivos planteados en ambos niveles.

Observamos que la articulación es definida por las maestras como las acciones de engranaje y correlación de los procesos que tanto el recurso humano como las instituciones llevan a cabo en la formación del niño para el favorecimiento del tránsito entre ambos sistemas. En sus voces correlacionar es saber cómo viene el niño-niña del otro sistema, es engranar una etapa, nivel, grado con el otro, depende de una efectiva comunicación en el que se reconozcan las funciones de cada nivel. Son tres procesos de articulación los que nombran: la primera la inter-institucional en la cual referencian a los procesos administrativos y pedagógicos que se deben realizar según los lineamientos del programa Buen Comienzo; la segunda es la que se da entre niveles y la tercera es la curricular en la relacionan actividades para favorecer la preparación de los niños.

Notamos que la articulación entre el nivel de educación inicial y educación formal representa un conjunto de puntos críticos-desencuentros- que repercuten en la trayectoria. El primero de ellos se relaciona con la falta de información frente a los procesos institucionales y las dinámicas propias de cada escenario. El segundo desencuentro se relaciona con las expectativas que se tienen en la educación formal frente a los aprendizajes y los saberes porque estos distan de la visión enmarcada en el sistema de educación inicial. El debate en torno a lo metodológico y la enseñanza pone de manifiesto la presencia de diferentes miradas sobre uno y otro nivel lo que muestra la tensión entre la función asistencial contrapuesta a la función educativa de la escuela. El tercer desencuentro refiere al rol que se le asigna al niño y niña 
como sujeto de aprendizaje, a las formas de concebir las infancias y al perfil específico que se define en cada escenario. El cuarto desencuentro se relaciona con el mobiliario, los materiales didácticos que se disponen para ambos sistemas. El quinto desencuentro está relacionado con la estructura organizacional y administrativa de los dos escenarios, punto que no interfiere en la trayectoria del niño-niña pero sí en la del agente formador.

Es indudable que en Colombia se ha puesto la atención en la articulación interinstitucional, horizontal, y siguen sin ser atendidos los problemas que resultan de la falta de articulación vertical respecto de lo pedagógico, curricular o metodológico. La continuidad es indiscutiblemente el punto de quiebre en la articulación vertical, por ello las maestras proponen pensar la posibilidad de un proyecto curricular integrado en el que puedan establecer vínculos y aprovechar el capital de cada escenario.

Los niños y niñas en el recorrido que hacen entre niveles y grados viven el proceso de articulación curricular de forma compleja debido a las diferencias entre las propuestas pedagógicas y curriculares de uno y otro nivel. En este sentido, si uno de los objetivos generales de ambos niveles remite a potenciar al máximo la capacidad del niño/a para participar y adquirir los elementos básicos que le permitan hacer frente a las dificultades con las que previsiblemente se topará en su camino, se evidencia la necesidad de superar la fragmentación de la AEIPI y su segmentación por rangos de edades y por modalidades. La educación en sí misma comprende la preparación para la vida y esto implica entender que es más que una escolarización oficial y engloba un amplio espectro de experiencias vitales y procesos de aprendizaje que permiten al niño/a, ya sea de manera individual o colectiva, desarrollar su personalidad, reconocerse como sujeto de derecho y llevar una vida plena en el seno de la sociedad.

Entendemos según estos hallazgos que la configuración de una escuela para la niñez que favorezca las trayectorias y las transiciones no solo debe contar con nuevas infraestructuras, con más recursos, con cambios en la modalidad de trabajo, sino sobre todo requiere del debate en torno de conceptos, lineamientos, fines y sentidos en los que exista un diálogo igualitario que no segmente y estigmatice los niveles, sino que produzca la identidad de un nuevo sistema sobre la base de colocar a las infancias como eje trasversal del proceso educativo y de reconocer a los niños y niñas como sujetos de derechos 
CUARTA PARTE

\section{CONFIGURACIÓN DE LAS TRAYECTORIAS Y TRANSICIONES EN}

\section{LAS VOCES DE LAS MAESTRAS Y AGENTES EDUCATIVOS}

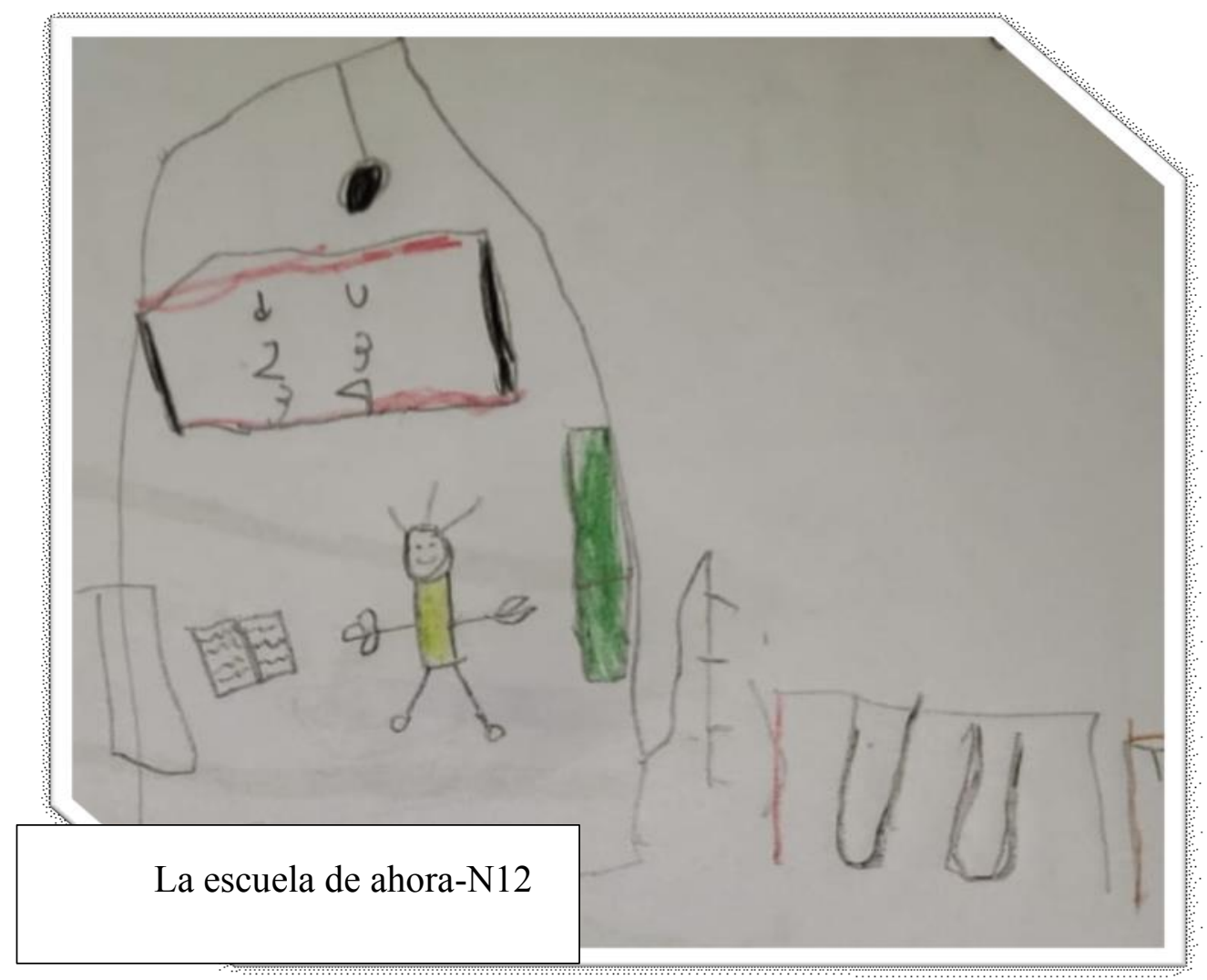

"si la escuela infantil (3-6 años) tiene que ser preparatoria y ser una continuidad con la después, te encuentras prisionero de modelos e itinerarios que terminan en un embudo, creo que el embudo es un objeto execrable. A los niños no les gusta. Para lo único que sirve es para apretar, estrangular hacer pasar lo que es grande por algo pequeño" Loris Malaguzzi, creador del currículo de Reggio Emilia (2001) 


\section{Capítulo V}

\section{Modos en que se configuran las trayectorias y transiciones de los niños y niñas}

\section{Introducción}

Los diferentes entornos institucionales en Colombia del sistema de Educación Inicial y Atención Integral a la primera Infancia y de Educación Formal configuran modos heterogéneos de educación escolarizada: "la expresión educación escolarizada hace referencia a la institución "escuela/jardín" y al rol que esta institución vino a desempeñar en las sociedades en un espacio social de relaciones, transmisión, reproducción social y cultural" (Peralta, 2018). En palabras de Mariano Narodowski (2009) hablar de "Nivel Inicial", "Jardín de Infantes", "Escuela Infantil", "Parvulario" o cualquier otra denominación es hablar de un espacio que es, ante todo, escolar; esto significa que en ese espacio se recibe y se trabaja con la infancia, se educa, se enseña y se protege (Narodowski, 2009: 31).

Por ello la escolarización se realiza a través de instituciones del sistema educativo formal (escuelas, jardines infantiles, etc.) que se articulan en diferentes componentes, grados y niveles para la obtención de determinados logros, los que se califican y certifican, y también involucra programas no formales y convencionales donde se presta atención integral a los niños y niñas.

/... / la "escolarización" es el procedimiento sistemático y sistémico que la sociedad construye para transmitir a las nuevas generaciones los aprendizajes básicos para socializarse y participar en su cultura. Visto de esta manera, algunos programas no-formales también vendrían a ser en cierta forma "escolarizados", e incluso a veces se desarrollan dentro de los locales "formales", como el jardín infantil o la escuela, y tributan a los currículos nacionales oficiales (Peralta, 2018: 19).

En este sentido, la escolarización en la que están inmersos los niños y las niñas se comprende desde los diferentes escenarios educativos formales o no formales. La Educación Inicial es la puerta de entrada al sistema educativo. Comprende un proceso que comienza en el 
vientre materno y, en razón de ello, en Medellín se reconoce a la familia y a la comunidad como el ámbito para este comienzo y se promueve el desarrollo armónico de la primera infancia a través de prácticas educativas oportunas y pertinentes. La Educación Inicial es parte del sistema educativo y hace posible la atención integral a la primera infancia, va más allá de preparar a los niños y las niñas para la escolaridad formal, se ocupa de ofrecer ambientes sociales, sanos, seguros, cálidos y enriquecidos; de acompañar oportuna y adecuadamente el crecimiento y el desarrollo infantil teniendo como ejes fundamentales el juego y la formación de la autonomía.

El Consejo Nacional de Política Económica y Social (CONPES 109/2007) como política pública nacional de Primera Infancia destaca la importancia de favorecer en este ciclo de la vida la promoción de competencias y habilidades que preparen a los niños y niñas para la nueva etapa escolar.

/.../ las competencias que los niños adquieren en este período son la base de los aprendizajes posteriores, puesto que los programas de atención educativa contribuyen a que se logre una mejor preparación para la educación básica; aumenta las probabilidades de ingreso oportuno al primer grado de primaria; fortalece los aprendizajes; reduce la repetición de cursos y la deserción temprana del sistema educativo; y aumenta la proporción de jóvenes que culminan exitosamente sus estudios (CONPES, 2007: 23).

Dicha preparación no se centra en una formación rígida estandarizada centrada en conceptos como está constituido en la ley 115/1994 que concierne a la preparación para la vida escolar y el ingreso a la educación básica; por el contrario, busca ser una etapa desligada del carácter formal de la educación básica, centrada en la promoción de desarrollo integral a través de experiencias de socialización pedagógicas y lúdicas en los niños y niñas.

Ahora bien, esta forma de concebir la Educación Inicial como un proceso de socialización y promoción de interacciones oportunas y pertinentes para el desarrollo integral en los niños y niñas se ve cuestionado por el sistema de Educación Formal, especialmente por la básica primaria, en tanto la "preparación" que ofrece en las voces de las maestras no responde al desarrollo de competencias que deben de tener los niños y niñas para ingresar al grado primero. Sumado a ello en la ley 1098/2006 por la cual se expide el Código de Infancia 
y Adolescencia, la primera infancia se define como la etapa comprendida entre los 0 y 6 años, es decir, dejando fuera de la Educación Inicial el ciclo vital de los 7 años.

Definir la Educación Inicial como un ciclo vital que abarca de 0 a 6 años de edad (ley 115/1994 y 1804/2016) difiere de la propuesta planteada por el Comité de los Derechos del Niño ${ }^{26}$ y la Observación General a OG N7 /2006 que extiende el concepto de primera infancia hasta los ocho años. Entonces se vuelve necesario analizar la atención educativa que se está ofreciendo al grupo poblacional de los niños y niñas entre los 0 y los 8 años de edad porque la segmentación por rangos de edades y grados evidencia que no hay claridad en las concepciones educativas acerca de la educación de la primera infancia. A su vez, existe una tensión entre la Educación Inicial y la Educación Formal entre el cuidado, la crianza y la formación que pone en tela de juicio la idea misma de sistema que se quiere ofrecer y por el que transitan los niños y niñas.

Según esta consideración en el desarrollo de este apartado se procederá a explicar, por un lado, los modos en que se configuran las trayectorias educativas de los niños y niñas de 0 a 8 años desde el momento que ingresan a la Educación Inicial (Programa Buen Comienzomodalidad institucional) y pasan Educación Formal (preescolar y básica primaria); por otro lado, se analiza cómo viven los niños y niñas el proceso de transición y como repercute en el ámbito personal de la trayectoria. Elegimos caracterizar cada una de las experiencias a las que se ven enfrentados los niños y niñas cuando pasan de un escenario a otro, y describir la forma como ellos/as asumen este tránsito para terminar un ciclo e iniciar una nueva etapa de escolarización. Se tendrán en cuenta las voces de los agentes educativos (agentes educativas del sistema de atención integral del programa Buen Comienzo, maestras del grado preescolar y del grado primero de la institución educativa oficial y coordinadores psicosociales de ambos sistemas) quienes participaron de entrevistas en profundidad.

Dado lo anterior, la organización del capítulo se estructura en cuatro apartados: el primero da cuenta de la forma como se configura o comprende en esta tesis la trayectoria en el

\footnotetext{
${ }^{26}$ El Comité de los Derechos del Niño es un organismo de las Naciones Unidas que tiene la función de examinar los progresos realizados en el cumplimiento de las obligaciones contraídas por los Estados Partes que han ratificado la Convención sobre los Derechos del Niño. (2001-2014)
} 
campo de la Educación Infantil; el segundo muestra los itinerarios que experimentan los niños y niñas entre el sistema de Educación Inicial-Atención Integral y la Educación Formal preescolar grado transición y básica primaria-, esto es, el ámbito socioeducativo de la trayectoria; el tercer apartado analiza la forma como son comprendidas las transiciones, teniendo en cuenta los cambios que experimentan los niños y niñas desde los factores biológicos, educativos, socioculturales; finalmente el cuarto apartado muestra como experimentan los niños y niñas el paso que dan de la educación inicial al preescolar y de preescolar a la educación básica primaria, evidencia los duelos y el proceso de adaptación que se requiere en el pasaje.

\subsection{Modos en que se configuran las trayectorias de los niños y niñas}

Los niños, niñas, familias recorren los sistemas educativos de Educación Inicial y Educación Formal de forma diversa pues su itinerario comienza no sólo cuando transita del hogar a la guardería o jardín, entre estas modalidades de atención integral, sino cuando cambia a la Educación Formal. Hay un universo de instituciones que influyen de manera directa sobre la forma en que se desarrolla la vida de los niños y niñas en el tránsito de un sistema a otro.

Para esta tesis se retoma el concepto de itinerario porque recupera la singularidad de los recorridos de los sujetos y las experiencias que viven en el ámbito institucional, familiar o social. Se trata de procesos singulares donde los individuos pese a tener las mismas experiencias obtienen resultados diferentes.

/.../ un itinerario es el conjunto de lugares vitales y experienciales por los que transita una persona en su secuencia de cambio. Es el encadenamiento, previsto, provocado, azaroso, de oportunidades educativas, sociales, por dónde transita la persona. Hablar de itinerarios es hablar de las vías de las transiciones (Artiaga, 2009: 42).

La trayectoria en el campo de la Educación Infantil para esta tesis doctoral se constituye en una dimensión ${ }^{27}$ de análisis, porque centra su atención en la interpretación de los fenómenos

${ }^{27}$ Se retoma el concepto de dimensión porque permite analizar cómo se ve un fenómeno social en un contexto determinado; la dimensión refiere a la longitud, a un espacio a un tiempo. En sociología, la dimensión se refiere a la ubicación espacial y el camino transitado por los fenómenos sociales en un tiempo y un espacio. Toboso, M., \& Valencia, G. (2008). Una representación discursiva del espacio-tiempo social. Estudios sociológicos, 119-137. 
sociales a lo largo del tiempo. La trayectoria las definimos como un camino de múltiples itinerarios por las que transitan las/los niños/niñas/familias/maestras a través del sistema educativo. Está compuesta por diferentes recorridos interseccionados por las experiencias que convergen en tres ámbitos fundamentales como son: el ámbito sociocultural, socioeducativo y personal, los cuales se articulan y entrelazan para determinar las posiciones de los sujetos en un campo educativo y explicar los tránsitos que experimentan. Las trayectorias se conciben como heterogéneas, singulares y discontinuas con transiciones simples o complejas.

En el capítulo II presentamos lo que aquí nombramos ámbitos que fueron hallazgos del trabajo de campo. Así, el ámbito sociocultural representa el contexto, la familia y refiere a la configuración institucional, sus estructuras internas y externas, el medio social y cultural con sus códigos y prácticas, la estructura política y cultural del momento. El ámbito socioeducativo se relaciona con lo escolar, con los dispositivos institucionales, representa la institución como escenario educativo con sus fines, objetivos, currículo, metodología, dinámica y estructura de oportunidades. El ámbito personal hace referencia a la relación individuo-sociedad partiendo del reconocimiento de la influencia del contexto sociocultural y las relaciones interpersonales en la construcción de identidad y en la configuración de la propia historia de vida. Tal como se explica en el siguiente gráfico: 
Ilustración 6 configuración de la trayectoria y transiciones educativas en el campo de la Educación Infantil

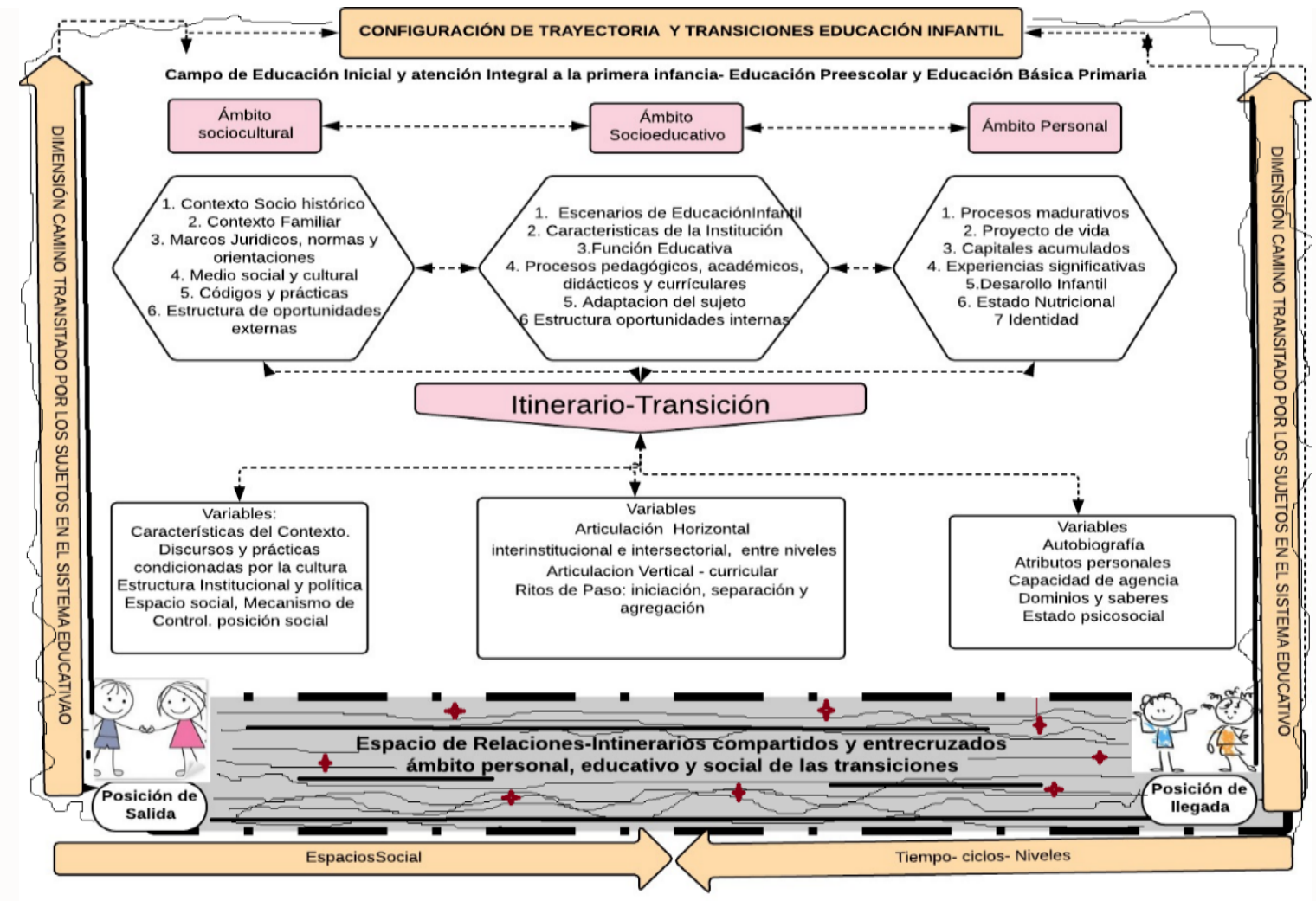

Fuente: Elaboración propia

Según las voces de las maestras en estos ámbitos se puede evidenciar un conjunto de variables que afectan los recorridos y las experiencias de los niños-niñas, de sus familias y de las maestras; por ejemplo en el ámbito sociocultural el hecho de que el niño y niña deba transitar simultáneamente por diferentes ambientes-familia, escuela y comunidad- produce experiencias diversas y heterogéneas vinculadas a las formas de acompañamiento que reciben de parte de los/las adultos/adultas. Por ello, las principales variables a analizar desde este punto de vista se concentran en los códigos culturales que se tejen en su contexto, es decir en el barrio en el que habitan, las situaciones sociales, económicas y culturales que atraviesan los niños y sus familias; factores también relacionados con la política educativa en cuanto a la regulación y normas educativas, los lineamientos técnicos y políticos, los estándares de calidad y seguimiento que establecen con respecto a la accesibilidad, reprobación y deserción en los escenarios educativos. El ámbito socioeducativo se concentra especialmente en la experiencia 
que tienen los niños y niñas en la escuela o jardín infantil. El análisis de los recorridos se centra en lo relacionado con los procesos académicos, pedagógicos, didácticos y curriculares; el apoyo socioemocional que se le brinda a los niños, niñas y familia, los procesos de articulación vertical-horizontal, los ritos de paso, el rol y la función docente. Finalmente en el ámbito personal se debe tener en consideración los atributos personales de los niños/as, el estado nutricional, su estado emocional, la capacidad de agencia, dominios y saberes, su desarrollo infantil, autoestima historia de vida. Según las maestras todas estas variables son determinantes para explicar cómo se vive el tránsito entre instituciones y escenarios educativos.

Para ellas en estos recorridos los niños-niñas y familias pueden experimentar puntos críticos, interrupciones, interacciones simples o complejas de acuerdo con las oportunidades, disposiciones de los sistemas educativos, capacidades institucionales, familiares e individuales. Por ello, la trayectoria se referencia como un proceso experiencial que va teniendo lugar en el tránsito entre instituciones y niveles de enseñanza, y esta condición permite realizar análisis comparados y evaluaciones acerca del modo en que incide el contexto, la historia personal, el desarrollo social y educativo del educando en el curso de vida, así como el papel que tienen diferentes actores (familia, niños-niñas, agentes educativos, maestras, directivos) que intervienen para acompañar, preparar y favorecer este momento clave de la vida.

Confirmamos con el trabajo de campo que los modos en que los niños y niñas experimentan sus itinerarios dependen de la experiencia que ellos y sus familias van teniendo en relación con las variables presentes en cada uno de los ámbitos tal como se explica en la ilustración \#4. Los puntos de partida no siempre son los mismos puntos de llegada, los recorridos son heterogéneos y singulares y dentro de ellos se establecen múltiples transiciones. Tal como expone Kaplan (2006), si bien es real que se pueden establecer tipos de itinerarios frecuentes e ideales, coincidentes con la estructura escolar (grados, ciclos, niveles), no es menos cierto que gran parte de los niños y jóvenes transitan su escolarización de modos heterogéneos, variables y contingentes en función de los condicionamientos sociales, como también de las subjetividades que se construyen en la escuela dado que juegan un papel crucial en la producción de tales itinerarios. 


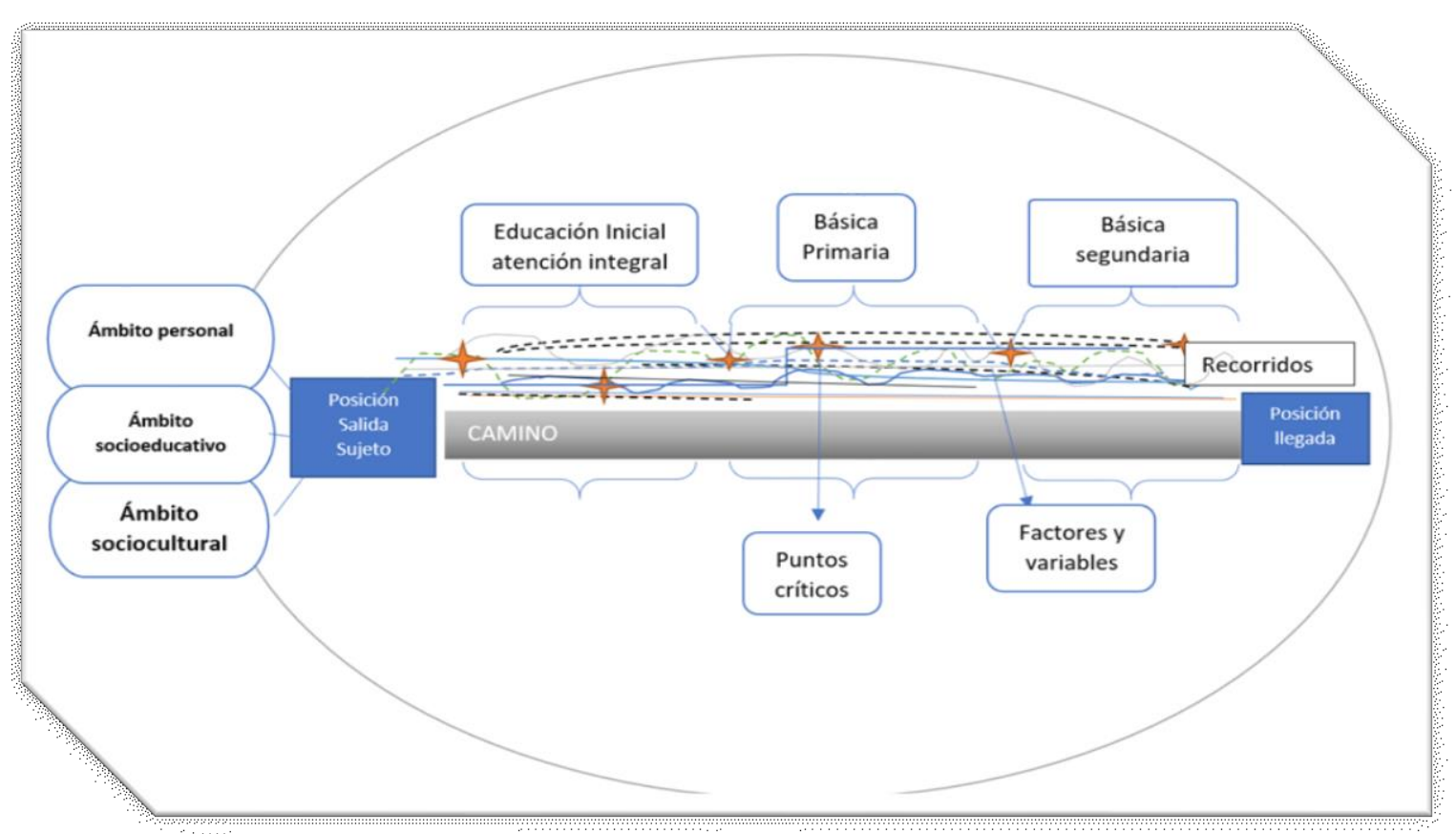

Fuente: Elaboración propia

En este sentido vemos que la trayectoria educativa nos muestra la forma en que el sujeto niño-niña experimenta la escolarización e institucionalización, da cuenta del modo en que efectivamente transita desde el inicio del recorrido por el espacio social y educativo. Para analizar una trayectoria se debe centrar la atención en la institucionalidad, en las estrategias puestas en juego por cada individuo, y en las disposiciones de los niveles educativo para objetivar los tramos y los itinerarios particulares de los sujetos. En los siguientes apartados se explica la forma como se comprende las trayectorias y transiciones en relación a los ámbitos (sociocultural-socioeducativo y personal) propuestos por las maestras y agentes educativas.

\subsection{Itinerarios que experimentan los niños y niñas entre el sistema de atención integral, el grado transición y la básica primaria}

Como señalamos en el apartado anterior, las trayectorias que realizan los niños y niñas están mediadas por las relaciones e intersecciones que se establecen en el ámbito sociocultural, es decir, los recorridos se encuentran mediados por los factores históricos del contexto y las 
dinámicas de funcionamiento de los escenarios que forman parte de la Educación Infantil. Sin embargo, al referirse a los modos en que los niños viven el pasaje entre cada nivel es necesario enfocar la atención en el ámbito socioeducativo y en las visiones de los actores entrevistados frente a los diferentes caminos que los niños, niñas exploran y los factores que en ellos intervienen.

Las maestras y directivas docentes, tanto de la institución educativa de Educación Formal ${ }^{28}$ como Jardín de calidad de Buen comienzo ${ }^{29}$, señalan que el proceso de trayectoria se configura en primera instancia como un recorrido que relacionan con los ciclos de edad, el contexto, las oportunidades y la política pública. Así, la trayectoria contiene todo lo que llevan los estudiantes desde pequeños, desde que inician hasta que terminan sus niveles de formación.

La trayectoria es el recorrido que pasan los niños/as desde que inician en lo transcurrido de su vida y los pasos o cambios, que viven en esa transición, este recorrido lo realiza en diferentes lugares y en diferentes aspectos de la educación, para pasar de un año a otro, o de una experiencia a otra en un transcurso de tiempo, mejor dicho, todo lo relacionado con la escuela; es lo más formal lo que está ya desde el magisterio, lo que diga pues como la parte más formal o de cartón, son esos tránsitos que dan de un ciclo a otro (Grupo Focal ${ }^{30}$, Maestras de Primero y Transición, 30/11/2017).

La trayectoria da cuenta de los cambios que se van teniendo lugar en la vida social y escolar del estudiante; es una herramienta clave en el análisis de las transiciones e itinerarios que realizan los niños, las niñas por ambos niveles. Estas experiencias son diferentes y se puede nominar como experiencias acumulativas y singulares determinantes en los momentos de

\footnotetext{
${ }^{28}$ Se realizaron 14 entrevistas en profundidad a docentes y agentes educativas de ambos sistemas. Para el sistema de educación formal se realizaron 8 encuentros de la siguiente forma: (3) entrevistas a docentes de Preescolar, (3) a docentes del grado primero, (1) a la coordinadora y (1) a la maestra de apoyo.

${ }^{29}$ En el sistema de atención integral se realizaron 6 entrevistas de la siguiente forma: (3) entrevistas a agente educativa docente, (1) entrevista a agente educativa educadora especial psicosocial, (1) entrevista a la coordinadora del Jardín Infantil, (1) entrevista a la coordinadora del componente de transiciones del programa Buen Comienzo.

${ }^{30}$ Para indagar en torno de las trayectorias infantiles y las transiciones de un sistema a otro, se realizaron dos grupos focales con las maestras del sistema de educación formal (en este grupo se complementaron algunas afirmaciones obtenidas en las entrevistas en profundidad).
} 
desarrollo en el curso de vida, en particular, la capacidad de agencia y la autonomía de los sujetos para lograr su proyecto de vida.

En estos 32 años de experiencia como profe de preescolar, veo que mucha gente de los que tuve hace años termino sus estudios como te lo decía ahora, pero también veo que muchos se quedaron en el camino, otros se desviaron, pero uno los ve como bueno, fallamos en esto, y entonces son lo que uno ya ubica que están haciendo nocturnas, pero esos son momentos que ellos pasan y que depende de las oportunidades que tienen y del contexto en el que se desenvuelven (Docente de Transición, 02 11/10/2017).

Las experiencias acumulativas dentro de la trayectoria dependen de dos procesos fundamentales: los ritos de paso y la articulación.

Los ritos de paso designan un conjunto especifico de actividades que simbolizan y marcan la transición de un estado de la vida a otro. Para Durkheim (1992) el rito es concebido como un recurso cohesionador y transmisor de valores sociales a través de un estado de efervescencia colectiva. Van Gennep (1988) establece que los ritos de paso tienen que ver con tránsitos en la vida de la persona; la función del ritual es la de permitir las transiciones entre territorios, tiempos o situaciones sociales en tanto los pasos van acompañados de actos especiales que constituyen aprendizajes.

La vida de todo individuo consiste en una sucesión de etapas cuyos finales y comienzos forman conjuntos del mismo orden, y a cada uno de estos conjuntos se vinculan ceremonias cuya finalidad es idéntica: hacer que el individuo pase de una situación determinada a otra situación igualmente determinada. Van Gennep (1988) clasifica los ritos de paso en ritos de iniciación, separación y agregación. Los ritos de iniciación son complejos porque su fase está pautada culturalmente por personajes, contenidos y rituales que son específicos mientras que el ritual de separación comprende la ruptura con la etapa anterior y el ritual de agregación tiene por efecto, según la expresión de los wayao del África Oriental, «introducir al niño en el mundo». En nuestra investigación vemos que para los niños y niñas estos ritos representan temores y tensiones dado que viven ritos de iniciación muy cortos centrados en una preparación para la escuela, y unos ritos de separación y agregación de forma simultánea donde se despiden de un escenario y son bienvenidos en otro, por lo que no hay tiempo de asimilar el cambio. 
En este orden, los ritos de paso constituyen para las entrevistadas un eje transversal en toda trayectoria, en tanto se convierten en el conjunto de estrategias y actividades que posibilitan acompañar los momentos especiales de la vida escolar de los niños y niñas. "Realizamos diferentes rituales para que haya como una adaptación, una familiarización con ese nuevo entorno escolar” (Grupo Focal, 30/11/2017).

En la Educación Inicial y Atención Integral (EIAI) los ritos de paso se establecen a partir de ritos de iniciación con actividades centralizadas en el aprestamiento; actividades lúdicas que movilizan en los niños y niñas conductas y comportamientos que deben adquirir y aprender para su adaptación a la nueva escuela y a las rutinas establecidas. Por ello, se trabaja la postura, el manejo del cuaderno, el espacio en la mesa de trabajo, los horarios del descanso y la ida al baño, el manejo de la cartuchera y algunas rutinas escolares. Se les prepara en la autonomía y la responsabilidad sobre sus pertenencias, en los tiempos de juego, en la regulación de la conducta para aprender a permanecer sentados y prestar atención por mayor tiempo, es decir, en un conjunto de acciones que están planeadas y organizadas de acuerdo con las necesidades de los grupos.

/.../ dentro de la planeación tenemos un momento que se llama transiciones y articulaciones; momento para trabajar la transición de ellos a la escuela con actividades muy de la cotidianidad, los preparamos para ese momento; entonces es jugar a la escuela, jugamos a la tiendita, jugamos al recreo. Veo que los niños y niñas están felices porque últimamente salimos al recreo cuando escuchan la campana, también tenemos momentos en los que nos sentamos hacer tareas, lo que hacemos es como para que ellos desarrollen autonomía, habilidades y sepan que van a enfrentar en la escuela. Ellos en este momento todavía lo visualizan como un juego y están felices porque están grandes y van para el preescolar (Agente Educativa Docente, 12/12/2017).

Asimismo se les prepara frente a las rutinas y momentos de la escuela distribuidos entre tiempo de ocio y tiempo de trabajo. El cambio metodológico y curricular entre ambos escenarios genera tensión y preocupación por parte de las agentes educativas quienes manifiestan que los niños y niñas no se adaptan fácilmente a las actividades propuestas en la escuela. Según expresan, es fundamental regular con los niños y niñas conductas, prepararlos para el cambio dado que deberán asumir nuevos roles, apropiarse de códigos, valores, saberes y prácticas, 
Entonces digamos que preparamos a los niños/as para ir a la institución regular cierto, entonces si las dos primeras actividades del día fueron de exploración: por ejemplo estar en la huerta, en el gusanito, en el deslizadero; esa hora la trabajamos en mesas para entonces estimular toda la parte de la atención, de la memoria, de la resección, mantenerse en la tarea porque una de las quejas principales de la escuela, "es que todo el día separa del puesto", " ellos piensan que esto es un buen comienzo y que todo el día van a jugar". Por ello le enseñamos a mantenerse en la tarea, trabajar con los colores, formas, tamaños, sin necesidad de que saquen las fichas, el cuaderno, cierto, entonces en esa hora, se trabaja todo ese tipo de actividades, además les enseñamos a esperar el turno, escuchar al otro, pedir la palabra, hacer la fila en la cafetería, en el restaurante, en el comedor, bueno en la parte alimentaria, mejor dicho todo el tiempo estamos en pro de una actividad para preparar al niño/a (Agente Educativa Docente, 11/12/2017).

Otro de los rituales que se realiza es la pasantía ${ }^{31}$, rito de agregación con el que se busca presentar a los niños, niñas y familias públicamente en la nueva institución para que reconozcan los espacios, los nuevos roles, para que sean reconocidos y aceptados por la comunidad como nuevos integrantes. La pasantía es el principal eje articulador entre los dos niveles, constituye una visita de intercambio que los niños-as y agentes educativos del programa Buen Comienzo hacen para reconocer las instalaciones de la escuela, sus espacios, maestras y rutinas.

Nosotras hacemos también esa articulación para visitar esas escuelas, entonces más o menos en octubre nosotras vamos y llevamos a los niños/as, ellos van allá y conocen a las profes y las profes les hacen todo el recorrido, les muestran los salones, les muestran el colegio, visitamos la escuela para que el niño/a se familiarice y conozca el nuevo espacio, ello para lograr una mejor adaptación en su proceso, pues se va haciendo a la idea del cambio (Agente Educativa Docente de transición 12/10/2017).

Como ritual de separación para ir preparando al niño y la niña para el cambio y el inicio del nuevo ciclo se apela a la imagen de niño grande, es decir, las maestras reiteran que el paso

\footnotetext{
${ }^{31}$ Las pasantías se encuentran estructuradas en los acuerdos municipales como una estrategia fundamental en la entrega y recepción de los niños y niñas. Estas pasantías deberán ser coordinadas en el momento en el que se hace la planeación del calendario escolar entre los socios operadores de Educación Inicial y los establecimientos educativos que reciben a los niños y niñas que pasan al grado transición.
} 
hacia una nueva escuela se debe a su ciclo de desarrollo, a su crecimiento, a la necesidad de adquirir nuevos saberes porque ya van a ser sujetos más grandes con responsabilidades. Una de las estrategias empleadas por las agentes educativas en este proceso es el trabajo de fortalecimiento de la atención con el propósito de preparar a los niños y niñas para que puedan estar atentos y permanecer por más tiempo en la tarea.

En el nivel de Educación Formal-Preescolar-grado transición la preparación se establece en términos de adaptación a través de un ritual de agregación en tanto se busca introducir al niño, niña en el nuevo ambiente escolar. Las maestras de preescolar refieren que inicialmente hacen una jornada escolar de dos horas con juegos para conocerse, a la semana siguiente se trabajan tres horas y la última semana se trabajan las cuatro horas de la jornada, donde las maestras proponen distintas actividades para que los niños y niñas se sientan acogidos y no abandonados.

/.../ para que los niños/as se sientan que no los dejaron aquí tirados, que los papás vienen muy rápido, entonces preparamos un ritual de actividades similares a las de Buen Comienzo por horarios y claro cuando llegamos a la tercera semana que es la jornada completa, los niños/as no extrañan tanto, ya han socializado mucho, ya tienen sus amigos, entonces el asunto es muy diferente (Docente de Transición 11/10/2017).

Asimismo, para ir introduciendo al niño y la niña al mundo de la primaria, se proponen actividades de escritura que son presentadas como propias de un/a niño/a grande.

/... que rico, miren allá vamos a aprender más cosas; miren como estamos de preparados, yo tengo en el salón el calendario con todos los meses del año, entonces todo el tiempo les vivo diciendo ya pasamos a este mes para pasar al otro año contamos cuántos meses faltan, y les reitero ya vamos para primero ya vamos hacer más grandes, porque ya van a pasar a los salones grande. Y esto se hace para ir introduciéndolos ya como a ese mundo de la primaria, o sea, ese mundo de primerito, donde tú vas a sentarte, donde tú vas a transcribir, vas a copiar y no puedes ser el mismo de antes (Docente de Transición, 10/10/2017).

Por su parte, en la básica primaria-grado primero las maestras establecen rituales de agregación centrados en la constitución de las normas. Al respecto, una de las maestras de primero refiere que, 
/.../ desde el principio se le dice aquí va a estar sentado, aquí no va a estar parado, y desde el principio yo me pongo seria con las normas claras, pero también voy a jugar, intento meter la escritura desde el principio, un proceso que es complicado el inicio, así mismo los preparo con rutinas para ir al baño, al descanso, realizar pausas activas, realizar el duelo por los juguetes, el manejo de los cuadernos porque ya no es uno, son diez cuadernos, se trabaja fundamentalmente la autonomía, independencia y empoderamiento (Docente de Primero, 25/10/2017).

El primer mes lo que hago por ejemplo es que yo más o menos a las 8 de la mañana llego y les digo, bueno vamos a soltar todo, vamos a ir en fila y nos vamos para el baño, entonces aquí se hacen las niñas, aquí los niños, y empezamos a entrar al baño, nos lavamos las manos y todo eso, mientras que ellos se acostumbran a que no es cuando ellos quieran, pues desafortunadamente no es así porque no puedo, porque los baños quedan en otros lugar y yo tengo que garantizar la seguridad de ese niño o esa niña y tampoco me puedo salir del salón para estarlos acompañando (Docente de Primero, 24/10/2017).

Entre ambos niveles educación Inicial y Formal, con el propósito de demarcar el cierre del ciclo y el inicio de un nuevo período, se realiza una fiesta de graduación, un rito de agregación y separación en donde se cierra un proceso generalmente relacionado con experiencias positivas, enriquecedoras, de aprendizajes y diversión, para abrir un nuevo inicio de aprendizajes, responsabilidades, obligaciones que implican una ruptura con la etapa anterior, en la que se adquiere un nuevo estatus, el sujeto alumna-alumno, e inicia un nuevo proceso de adaptación y preparación para la apropiación de capital cultural, la asunción de modelos éticos y la adquisición de nuevos aprendizajes que sumarán a su experiencia acumulada.

Continuando con este análisis y centrando la mirada en la trayectoria a partir de la incorporación del niño-niña a la educación formal, se observa que dentro de esta experiencia acumulativa y singular existe otro proceso que interfiere y es la articulación entre niveles, factor fundamental para favorecer los recorridos y movimientos de los sujetos por las instituciones educativas. El proceso de articulación es relevante porque garantiza la transición efectiva y armónica, promueve el conjunto de acciones intencionadas y efectivas encaminadas a asegurar condiciones favorables. Requiere de esfuerzos conjuntos para alcanzar objetivos comunes de acuerdo con lo establecido por los lineamientos políticos y las orientaciones técnicas 
La articulación implica que cada institución desde sus acciones administrativas y pedagógicas promueva interacciones, situaciones y condiciones en las que los niños, niñas y familias se preparan para enfrentar nuevos retos, conocer nuevas personas, espacios y entender el desarrollo y el aprendizaje. Estas acciones conjuntas representan distintos retos no solo para los niños y niñas sino para los actores como las familias, agentes educativas, por las mismas diferencias en la organización: pedagógica, las interacciones, el ambiente, el espacio, el tiempo, los contextos de aprendizaje y el aprendizaje entre escenarios educativos tal como se explico en el apartado anterior. La articulación según sus voces se representa como un punto crítico para la continuidad de los procesos educativos.

Digamos que estos dos sistemas no nos encontramos en la parte académica, en la forma de trabajar, porque digamos que en la institución queremos que aprendan letras, que aprendan números, pero también que jueguen, pero el juego pasa hacer un segundo plano y eso también nos pasa de transición a primero; en transición el juego es más activo. En primero cambia ya hay más tiempo de permanencia en una silla, ya no tiene la piscina de pelotas, ya no tiene los carritos, el tiempo de juego es únicamente el descanso o la clase de educación física y de pronto las pausas activas que el docente hace mientras esta en el aula, pero en transición no viven en pausas activas todo el día, viven jugando, entonces yo pienso que es eso; el hecho de pasar de la movilidad a cierta quietud es la que debe aprender el niño (Docente de Primero, 24/10/2017).

Sí me preguntas por los dos escenarios tendría que referir que son distintos; veo muy distinto por las mismas orientaciones políticas, ellas tienen demasiado trabajo. La función de Buen Comienzo se centraliza en el juego, en prácticas más asistenciales de cuidado, de ambientes enriquecedores, por ejemplo, la jornada de ellas es más extensa, mientras que aquí en transición los niños vienen solo 4 horas y se van para su casa, es muy diferente, debemos cumplir con un currículo, entonces es muy distinto, aquí preparamos al niño/a le enseñamos (...) aunque la dinámica del prescolar también contempla el juego, este, no es toda la jornada, o sea, hay un espacio de juego libre, hay un espacio de actividad grupal. Aunque me parece maravilloso el programa de buen comienzo, su infraestructura, el impacto con las familias (Docente de Transición, 10/10/2017).

Es de esta forma, que en este recorrido entre niveles educativos se va produciendo una trayectoria escolar que es atravesada por una serie de tensiones. Si bien cada nivel configura unos mecanismos de acompañamiento y de diálogo inter-institucional tanto internos como 
externos, las diferencias entre ambos suponen para los niños y niñas un conjunto de experiencias y acontecimientos que representan un proceso de adaptación y aceptación. Así, la transición se presenta como un proceso heterogéneo y diverso en relación con los ritos de paso (iniciación, separación, agregación), con las acciones de articulación que implementan las instituciones y por ello las transiciones que viven los niños y niñas se relacionan con experiencias que pueden ser estables, positivas o negativas tal como se explica en el apartado siguiente.

\subsection{Modo en los que se configuran las transiciones de los niños y las niñas}

Concibiendo que las transiciones representan distintos retos no solo para los niños y niñas sino para los actores como las familias, agentes educativas y maestras; y que, particularmente en el entorno educativo los cambios en la organización pedagógica, las interacciones, el ambiente, el espacio, el tiempo, los contextos de aprendizaje y el aprendizaje evidencian una relación de complejas interacciones por las diferencias en los objetivos y fines de cada escenario, en este apartado se analiza la forma como son configuradas las transiciones de los niños y niñas desde las voces de los actores, maestras, directivos, y agentes educativas quienes evidencian cada uno de los factores y variables que influyen en dicho recorrido.

Observamos que cada institución desde sus acciones administrativas y pedagógicas promueve interacciones, situaciones y condiciones en las que los niños, niñas y familias se preparan para enfrentar nuevos retos, conocer nuevas personas, espacios y entender el desarrollo y el aprendizaje. Cuando los niños y niñas ingresan a un nuevo entorno, el mundo representa un proceso de cambios, adaptaciones, preparaciones y adecuaciones. Para los actores que participaron de esta investigación las transiciones se estructuran en relación (1) con los cambios y situaciones que experimentan los niños y niñas en su curso de vida. Estos cambios mediados por factores biológicos en relación a sus desarrollos (cognitivo, comunicativo, corporal), (2) por factores educativos relacionados con los pasos de un escenario a otro y (3) por factores socioculturales en correspondencia con las condiciones del contexto y la familia. 
La transición tiene que ver con esos cambios biológicos que representan para el niño y niña experiencias nuevas de acuerdo a su nivel de desarrollo, por ejemplo, pasar de una edad a otra, de gatear a caminar, de balbucear a hablar, me entiendes es directamente relacionado con los desarrollos (Docente de Primero, 26/10/2017).

Transición pienso que es como un período de adaptación para el niño o el cambio de un momento a otro, de una fase evolutiva a otra, así lo comprendo (Docente de Transición, 12/10 2017).

Tanto las agentes educativas como las maestras consideran que los factores biológicos relacionados con el ciclo vital y el desarrollo infantil influyen en la transición educativa, para ellas los cambios representan experiencias nuevas que posibilitan múltiples aprendizajes vinculados a los niveles madurativos. Y confirman lo propuesto por autores como Moromizato (2013), Grantham-McGregor (2007) y Myers (1993) quienes indican que desde el campo de la psicología las transiciones están vinculadas a los niveles madurativos de los sujetos, al concepto de desarrollo y aprendizaje infantil, teniendo como referencia los aportes de Piaget en el campo cognitivo y los de Erickson desde lo psicoafectivo. Asimismo las maestras describen que las experiencias de los niños y niñas en sus recorridos también se relacionan con los ciclos vitales y la estimulación socioafectiva frente a su desarrollo. Artiaga (2009) caracteriza las transiciones desde categorías que no pueden ser consideradas separadamente y por ello las relaciona con algunos ciclos evolutivos, etapas del desarrollo o ciclos vitales socialmente construidos (2009:42).

Pues para mí la transición es más como el cambio, hay transiciones en la vida usted siempre está transitando de un momento de su vida a otro, de un ciclo de su vida a otro" (Docente de Transición, 11/10/2017).

De esta forma la transición para ellas es un proceso que ocurre en un momento del ciclo de vida del niño y niña y se relaciona con las experiencias individuales y colectivas en donde las familias, agentes educativos, maestras, comunidad intervienen para acompañar, preparar y favorecer este momento clave de la vida. Así lo expone la maestra de apoyo: 
para que el niño pueda tener una armoniosa transición nosotras acompañamos el proceso con actividades, articulaciones, es que los niños/as no solo vive una transición sino múltiples y para todas ellas hay que generar oportunidades y condiciones” (Maestra de Apoyo, 21/11/2017).

Asi observamos que las transiciones, tomando en cuenta sus narrativas, no solo representan un paso entre modalidades y niveles sino también se configuran como estados, situaciones, eventos que le pueden suceder a un sujeto en un contexto y pueden representar un acontecimiento importante en su vida.

Una transición representa cambios, los cuales se puede decir están sujetas a las experiencias del niño/a con su contexto. Entendiéndose que las transiciones y articulaciones no solamente son el paso a la educación o sea educación formal en este caso es una transición cuando yo vengo de mi casa al jardín, cuando estoy en la sala 5 y paso a la sala 6 , cuando a mí se me muere una mascota, cuando me falta mi papá, cuando va a nacer mi hermanito (Agente Educativa Docente, 11/12/2017).

Bajo esta visión las transiciones están mediadas por las relaciones e interacciones del sujeto con el contexto, las agentes educativas y maestras confirman lo planteado por Vogler, Crivello y Woodhead (2008) al afirmar que las transiciones están vinculadas con los cambios en las actividades cotidianas que viven los niños y niñas, en los roles y las relaciones que deben asumir ellos en los nuevos espacios; en la transformación con el uso del espacio físico y social que implica adaptarse a los discursos y prácticas institucionalizadas en los escenarios educativos. Como lo reitera Casal (1996) la transición es un sistema de dispositivos institucionales y procesos biográficos de socialización que de forma articulada intervienen en la vida de las personas.

Pues la transición es el paso, el cambio que sucede de preescolar a primaria o los que vienen de un jardín acá al colegio, bueno digamos la transición educativa o el tránsito educativo se entendería como ese paso que damos de un nivel a otro, donde se encuentra en juego las implicaciones de crecer de madurar, de experimentar algo nuevo (Docente de Transición 10/10/2018).

La transición es como lo que nosotros hacemos con las escuelas para que haya como una adaptación, como una familiarización con ese entorno escolar (Agente Educativa, 13/12/2017). 
Una transición representa diferentes experiencias, depende de cómo la asuma el niño/a yo tengo en el aula unos que se adaptaron muy bien ni siquiera preguntan por su profesora anterior, pero también otros que se nota que extrañan muchas cosas, les ha costado acostumbrarse a este entorno (Docente de Transición, 11/10/2017).

Asi mismo, ellas reiteran que las transiciones requieren de acompañamientos y acciones que favorezcan la adaptación y preparación del niño/a en esa situación particular de su ciclo de vida; en tanto para algunos niños y niñas representa un proceso crítico, como lo establece Sacristán, (1997) y Bennett, (2006). Pero con la particularidad de que lo crítico lo representan en los cambios y desafíos que deben enfrentar familias y niños en cuanto a:

1. Los ambientes de aprendizaje y las experiencias proporcionados en ellos, las oportunidades para adaptarse a nuevas rutinas, nuevos espacios y amigos

2. La interseccionalidad que presentan los niños y niñas por etnia, género, situación geográfica, situación socioeconómica, la discapacidad, el conflicto armado.

3. Los factores internos y externos vinculados a las instituciones

4. La formación docente y la actitud para asumir estos procesos.

5. La accesibilidad no solo a las instituciones sino a los aprendizajes porque las metodologías de trabajo son distintas.

En este orden, vemos que las transiciones como proceso institucionalizado y estructurado en los espacios escolares se convierten en una construcción social que evidencia la forma como cada escenario concibe las infancias. Las voces de las maestras, agentes educativas y lo descrito en las orientaciones políticas evidencian una conceptualización de las transiciones desde diversas visiones, por ello, en esta tesis se sustenta la necesidad de mirar de manera holística ${ }^{32}$ e integral el proceso de las transiciones educativas, en tanto, comprende los

\footnotetext{
${ }^{32} \mathrm{Se}$ asume desde una perspectiva holística, porque orienta una comprensión contextual de los procesos, permite entender los ámbitos desde el punto de vista de las múltiples interacciones, perspectivas, particularidades y procesos; la voz griega holos se expresa en castellano como prefijo, hol u holo, y significa entero, completo, "todo"; indica también íntegro y organizado, lo que permite deja ver las múltiples relaciones, dinámicas, sinergias y expresiones de un fenómeno, como lo expone Weil Pierre (1993).
} 
desarrollos de los niños y niñas, su singularidad y la relación con el contexto, familia y la institucionalidad que lo permea.

En el trabajo de campo se confirma que las transiciones como acontecimientos que se viven en la trayectoria se relacionan con múltiples experiencias, que en su conjunto, producen entre sí nuevas relaciones y dinámicas, cada hecho que viven los niños y niñas constituye un acontecimiento que produce nuevas situaciones, por ejemplo, terminar un ciclo e iniciar una nueva etapa de escolarización representa un desafío para ellos/as y sus familias porque como lo expone Frigerio (2006) el niño, niña y familia "debe transitar entre lo conocido y lo desconocido, entre lo familiar y el mundo y entre la extranjeridad y lo familiar" (p. 341).

También observamos que la llegada a la institución escuela supone para los niños y niñas una forma de ser extranjero, expone al sujeto a una situación nueva, un entorno diferente del suyo donde compartía unos espacios, rutinas, momentos, amigos, unas construcciones culturales, epistemológicas, para pasar a un espacio donde desconoce la mayoría de las cosas, sus amigos, profes, las reglas, rutinas, actividad escolar. El niño-niña se enfrenta a una nueva metodología, estilo de enseñanza, nuevos tiempos de trabajo, mecanismos institucionales que implican la asunción de nuevos retos, actividades y roles, los cuales marcan nuevos derechos obligaciones y a veces "implica nuevas facetas de identidad social tal como lo expone" (Elder, Kirkpatrick y Crosnoe, 2003 citado en Casal, 1996: 298).

Podemos decir que la situación de cambio entre escenarios, vista como un acontecimiento o proceso clave en la vida de los niños y niñas supone períodos de adaptación e interconexión entre situaciones sociales, familiares, culturales e individuales, los niños/as tienen claro el cambio, pero no saben si en ese nuevo entorno les va a ir bien, si serán aceptados, y si se van a adaptar fácilmente, lo que muestra lo planteado por Sacristán (1997) al definir el concepto de transiciones como los momentos de alumbramiento de nuevas realidades, etapas de crisis o de indefiniciones, en las que se sabe desde donde se sale, pero no se tiene claro adonde se va a llegar y en qué estado se quedará uno en la nueva situación.

Por ello, en esta tesis comprendemos la transición como un acontecimiento singular para los niños y niñas, cada uno lo vive y experimenta de forma distinta: para algunos representa un momento personal difícil porque se encuentra a la vez viviendo el duelo o la pérdida de todo lo que deja (juguetes, juegos, ambientes conocidos); para otros representa 
ansiedad por conocer algo nuevo; por último, hay quienes manifiestan preocupación por la llegada a un nuevo espacio y por no saber cómo serán recibidos, si serán incluidos y aceptados. Es decir, este cambio impacta de manera directa y particular en el desarrollo emocional de los niños-as, en su capacidad de adaptación y agenciamiento, en otras palabras, en el ámbito personal de la trayectoria. En el siguiente apartado intentaremos explicar cuáles son las implicaciones que tiene esta experiencia para los niños y niñas en lo que denominamos ámbito personal.

\subsection{Como viven los niños y niñas el proceso de transición en la Educación Infantil}

Según las voces de las maestras y agentes educativas el cambio entre escenarios es un proceso complejo y difícil que implica dos momentos, el primero se relaciona con la adaptación y el segundo con el duelo que se vive al dejar costumbres, rituales, espacios, amistades y apegos. Por ello y retomando estos planteamientos en este apartado se caracteriza la forma como los niños y niñas experimentan el pasaje que hacen desde la Educación Inicial al preescolar y del preescolar a la básica primaria.

Según las maestras y agentes educativas con respecto a la adaptación de los niños y niñas existen dos formas de entender el pasaje, en primera instancia; los niños y niñas viven una transición estable, ellos/as asumen con tranquilidad las nuevas experiencias porque se enfrentan a una cantidad de cosas que son nuevas, y se adaptan a todo lo que viene; los cambios son sinónimos de emoción, alegría y felicidad por enfrentar nuevas situaciones de aprendizaje y juego; las expectativas son altas frente a la nueva escuela; el hecho de representarse como niños y niñas más grandes, que ya crecieron, los motiva y engrandece de tal forma que se sienten tranquilos, confiados y seguros de poder compartir con otras maestras y un factor muy importante con sus hermanos mayores, familiares y amigos cercanos, lo que confirma lo expuesto por autores como (Anderson, Jacobs, Schramm y Splittgerber, 2000; Galton, Morrison y Pell, 2000; Salmela-Aro y Tynkkynen, 2010; Seidman, Allen, Aber, Mitchell y Feiman, 1994), quienes expresan que para la mayoría de los estudiantes las transiciones no suponen un problema relevante para sus trayectorias escolares. 
En segunda instancia, es compleja porque cuando pasan a la educación formal la tranquilidad, emoción y motivación que tenían, para algunos niños y niñas se convierte en pasaje de angustia, temor, incertidumbre, como sostiene Castro, Argos y Ezquerra (2015) y Abello (2008) estos problemas suceden por el miedo, la ansiedad e inseguridad que viven los niños y niñas frente a ese nuevo entorno y las metodologías propuestas. Asimismo ellas nombran que para otros niños/as representa problemas en tanto las condiciones de alimentación, de dotación en cuanto a uniformes, kit con materiales, el tiempo de permanencia que es de ( 8 horas), y el cual es distinto para la escuela (4 horas), hace que se presente deserción y abandono, pues muchas familias por su situación económica no pueden suplir ciertas necesidades, evidenciando lo que Fernández, Mena y Riviere (2010), Cobo (2010), Fernández (2011) sostienen cuando expresan que para algunos estudiantes las transiciones pueden suponer grandes problemas e influir notablemente en la configuración de trayectorias escolares cuyos principales puntos son el fracaso y abandono escolar.

\section{De la Educación Inicial al Preescolar}

Las maestras de preescolar que pudimos entrevistar comentan que los niños/as que vienen de Buen Comienzo cuando llegan a la institución son espontáneos, se les ve motivados y alegres, no llegan ni temerosos ni llorando, los niños y niñas llegan descrestados con el espacio, emocionados por tener una nueva experiencia, ven el preescolar como un espacio mágico en el que ya van a ser más grandes, van a aprender a leer, van a estrenar cuadernos, uniformes, van a tener otras oportunidades, sus expectativas evidencian una experiencia única que desean con felicidad. Sin embargo, una vez están en la "nueva escuela" esta adaptación es difícil primero porque extrañan algunos espacios, a sus maestras, sus juguetes, su libertad y segundo porque sus comportamientos y actuaciones no responden a las exigencias del nuevo entorno donde las normas son muy importantes y a ellos les cuesta seguir instrucciones.

Al principio ellos estaban descrestados con el espacio; la dificultad principal fue con respecto a la norma en muchos porque también hay otros que son muy juiciosos; igual aquí las normas son más estrictas, y es difícil porque en su escenario anterior gozaba de toda la libertad y protagonismo, acá es cumplir los compromisos y las normas que se establecen, por eso hay que enseñarles para que se adapten (Grupo focal, 30/11/2017). 
Esta situación se representa distinta con los niños y niñas que llegan de instituciones y guarderías privadas de quienes provienen de Buen Comienzo. Por ello refieren que para posibilitar una buena adaptación de los niños y niñas que vienen del Programa Buen Comienzo

y de instituciones privadas, guarderías y jardines ellas estructuran una agenda de trabajo en la que priorizan el juego, el trabajo desde las expresiones artísticas, flexibilizan los tiempos, y abordan la norma desde actividades divertidas como cuentos o representaciones sociodramáticas en las que le presentan a los niños y niñas, las reglas de aula, las normas de la institución, los comportamientos que se deben asumir en los espacios de juego y en los académicos, las normas de convivencia, es decir, los códigos socioculturales de ese espacio escolar, refieren además que este proceso de acompañamiento es bien asimilado por los niños y niñas dado que el grado transición presenta cierta continuidad con respecto a las metodologías empleadas en el programa Buen Comienzo.

\section{Del Preescolar a la Básica Primaria}

Las maestras de primero que se entrevistaron enuncian que cuando los niños y niñas llegan de transición lo primero que extrañan es la organización del espacio, al principio son muy observadores, algunos manifiestan preocupación por no ver los juguetes, por tener sillas y mesas distintas, otros preguntan frecuentemente por los cuentos, la ambientación de las paredes, extrañan sus espacios de juego en especial el parque que tienen frente a su salón, y las zonas verdes, otros incluso al principio del año lloran y enuncian la necesidad de regresarse para el grado transición o para la guardería como nominan el sistema de atención integral-Buen comienzo.

Para ellas la adaptación es compleja dado que el grado transición presenta cierta continuidad con respecto a las metodologías empleadas en el programa Buen Comienzo, pero dista de la metodología utilizada en el grado primero en el que los niños se ven enfrentados a otros retos con relación a la rutinas de trabajo, el manejo de cuadernos, los niños/as pasan de trabajar por proyectos pedagógicos a trabajar por áreas, es decir manejar 10 cuadernos distintos, las rutinas de trabajo cambian; ya tienen menos tiempo para el juego y deben permanecer sentados por más tiempo, los descansos son más cortos. 
Por eso desde sus propuestas uno de los aspectos que más se debe trabajar durante el proceso de adaptación es la norma y respeto por las reglas institucionales, en tanto a muchos niños les cuesta seguir instrucciones, permanecer en el puesto, o cumplir con las rutinas de trabajo. Esto se ve reflejado especialmente con los niños y niñas que aún no tienen la edad correspondiente para estar en primero, para ellos es más compleja la adaptación y en algunos casos representa deserción y repitencia, en tanto, para este grado las exigencias son más altas por el cumplimiento con el plan de estudio, con logros académicos por áreas y con las evaluaciones.

En este orden la adaptación tanto en el paso que se da entre la educación inicial al preescolar y de la educación preescolar a la básica primaria se presenta como un proceso de regulación, implica para los niños y niñas aceptar los nuevos códigos y estructuras institucionales, reacomodarse al ambiente escolar y tener la flexibilidad necesaria para incorporar nuevos hábitos. Esto representa un gran reto social, afectivo y psicológico para el niño, y un "equilibrio entre la asimilación del medio al individuo y la acomodación del individuo al medio (CECREAL, 1992: 3). Es la construcción de una nueva relación entre el espacio escolar, familiar, individual, tal como lo define Conde Martí (1982) “el camino o procedimiento que el niño/a va elaborando desde el punto de vista de los sentimientos de pérdida y ganancia hasta la aceptación interior de la separación” (p. 4).

Esta aceptación interior de la separación es lo que las maestras y agentes educativas denominan como los duelos que realizan los niños y niñas para poder acomodarse y aceptar las nuevas condiciones del espacio escolar en el que se desenvuelve. El duelo se refleja en las manifestaciones que ellos/as expresan cuando preguntan constantemente por sus juegos, se visualiza como una pérdida significativa que despierta diferentes sentimientos y emociones. Hay quienes se entristecen y recuerdan constantemente sus maestras, espacios; hay quienes ponen más énfasis en haber adquirido una nueva sensación de libertad, un nuevo estatus al ser niños/as más grandes.

De acuerdo a lo observado por ellas, para los niños y niñas aceptar el nuevo cambio supone admitir y prepararse para la nueva situación, y esto lo evidencian cuando son ellos mismos quienes nombran: “ cierto profe que aquí debemos portarnos bien, aquí aprendemos otras cosas divertidas", "esta escuela también es divertida” (Docente Transición, 11/10/2017) 
por ello, para ellos/as condicionar sus actitudes y comportamientos a las nuevas normas o estructuras internas del espacio en el que se habita supone poner en contraste los mecanismos del nuevo escenario con lo que se tenía, se dejó y se vivía; es decir con el recuerdo de todo lo bueno que proporcionó la experiencia pasada, para este caso lo que se vivió en el programa Buen Comienzo o en el grado de transición. Confirmando lo propuesto por Avellan (2000) cuando nombra que las pérdidas despiertan una serie de emociones y sentimientos.

/.../ algunas pérdidas las olvidaremos y las integraremos sin dolor ni sufrimiento, pero otras dejarán una huella que no se borrará en toda nuestra vida, pudiendo provocar, incluso, auténticas crisis existenciales. Es obvio que un mismo acontecimiento puede tener efectos distintos en las personas: para unas puede ser el hundimiento moral y para otras el logro de un nuevo modo de estar en el mundo (p.14).

Estas emociones son observadas por las maestras y agentes educativas cuando expresan que en el paso que hacen de la inicial a preescolar y de preescolar a la primaria los niños y niñas constantemente evocan recuerdos, comentarios y expresiones que muestran los desafíos que deben enfrentar para poder reacomodarse a la nueva situación; estos desafíos no solo se relacionan con aprender la norma sino, adaptarse a la estructura del salón, al trabajo por áreas académicas, a que ya no tiene material didáctico, al manejo del cuaderno, al restaurante, a la falta de acompañamiento de los padres, a las evaluaciones de período y el plan de estudio estructurado y homogeneizado, algunos niños/as extrañan mucho sus otros espacios, les cuesta adaptarse a las normas, a la adquisición de los nuevos aprendizajes. En este orden, a continuación, se caracteriza lo que más extrañan los niños y niñas, los duelos y los desafíos que viven:

Infraestructura Física: Los niños y niñas extrañan de las instalaciones los espacios de juego, ambientes de aprendizaje, restaurante y material didáctico, recuerdan con emoción el parque, las zonas de juego (los chorritos, deslizaderos, túneles, las zonas verdes). Las maestras de preescolar enuncian que en el descanso los niños y niñas:

/.../ vienen a visitarnos (grita): profe hola, profe cierto que usted era mi profe, si mi amor; como estas de linda, hay profe yo quisiera volver acá, todos dicen lo mismo (Docente de Transición, 10/10/2017). 
/.../ las agentes educativas también refieren que "los niños y niñas vienen y comentan que eso allá es muy maluco y hay otro que viene y se hace en la rejita, ellos extrañan mucho la alimentación y las instalaciones que son totalmente diferentes (Agente Educativa, 13/12/2017).

Equipo interdisciplinario: los niños y niñas extrañan las condiciones institucionales en las que son recibidos en tanto pasan de una educación acompañada por un equipo interdisciplinario (psicólogo, artista, docente, madre comunitaria, enfermera, entre otros) a un espacio con una docente con un grupo numeroso y con poco material didáctico, asimismo cuando pasan del grado transición a primero la diferencia se ve en cuanto la estructura del salón y el número de compañeros.

Ambientes de aprendizaje: Los niños y niñas extrañan la organización de los espacios dinámicos y abiertos a las posibilidades de múltiples actuaciones y experiencias, los espacios de construcción estimuladores y reflexivos propuestos en el Jardín Infantil Buen Comienzo y en el grado transición, recuerdan con agrado la estructura del aula. Cuando pasan a primero el orden de las sillas y la misma silla representa una dificultad en tanto en los primero días en primero "se columpian en la silla, ellos cuelgan la cabeza, se caen de la silla, una cantidad de cosas porque no están acostumbrados a manejar este tipo de sillas" (Docente de Primero, 25/11/2017).

Los juguetes y juegos: una de las angustias más grande de los niños y niñas especialmente cuando pasan al grado primero son los juguetes, sus preguntas más frecuentes al iniciar el año en primero se concentran en "¿profe es que aquí no hay juguetes, profe no vamos a ir a jugar, profe y el televisor, la grabadora y donde está el material" (Docente de Primero, 1/11/2017). Sus reclamos son por acompañar sus actividades con materiales y por tener tiempos de juego en la misma aula, en ocasiones el descanso no es suficiente. Esto implica para uno" ser más lúdico por no decir que soy muy payasa, yo soy muy lúdica para tratar de que ellos se adapten" (Docente de Primero, 24/10/2017). En el primer trimestre se les ayuda a elaborar el duelo por los juguetes, se les cambia por material concreto para motivarlos.

EI juego al aire libre, y las actividades rectoras: para los niños y niñas el juego es fundamental, en los primeros meses de adaptación desean salir a jugar, piden que las actividades sean dinámicas, como enuncia una de las maestras todo el tiempo quieren jugar y cantar, preguntan muchos por los juguetes y son felices cuando hacemos actividades al aire 
libre, cuando pintamos, o hacemos manualidades, es una forma de tenerlos concentrados en las mesas de trabajo.

Rutinas de trabajo: acomodarse y asimilar las nuevas rutinas y tiempos de trabajo es complejo para los niños y niñas, al principio en primero les cuesta permanecer en la silla, terminar las actividades, habituarse a la rutina de la ida al baño, les cuesta seguir instrucciones y habituarse a que ya no pueden estar jugando en los tiempos que ellos desean, uno de los aspectos más difíciles es el manejo de los cuadernos y el horario que es por áreas (ciencias, español, matemática), este cambio es traumático para ellos.

Al principio es muy complicado, por ejemplo con el uso de los cuadernos, ahí también las familias vienen con una cantidad de expectativas muy altas, cuando llegan a primero abren en cualquier parte en la dirección que sea, o sea, se desubican mucho con relación a los cuadernos, entonces ese primer momento cuando llegan a primero es casi que, saquen el cuaderno con estas y estas características y voy pasando por cada puesto diciéndoles en cuál es la hoja que van a escribir, debo trabajar eso de pasar hojita por hojita, pero es muy complejo, porque no todos lo cogen inmediatamente entonces, uno se va casi hasta medio año diciendo, o sea, a estas alturas hay unos que me dicen profe en cual hoja, y estamos en octubre (Docente de Primero, 26/10/2017).

A modo de cierre de este apartado es posible decir que los niños y niñas viven su proceso de transición desde tres fases: la primera de separación, la segunda de reacomodación y la tercera de aceptación. Estas tres fases son la clave para experimentar una transición compleja o una transición estable. En la separación vemos que los niños y niñas en el paso que hacen de la educación inicial al preescolar y de preescolar al grado primero deben de hacer un duelo en cuanto a los tiempos de juego, las formas de trabajo, los ambientes de aprendizaje, las condiciones institucionales como por ejemplo el equipo interdisciplinario y la alimentación, la separacion implica dejar el material didáctico, costumbres, amigos, profes, rutinas, juguetes, juegos, relaciones interpersonales entre otras.

La reacomodación implica la capacidad de asimilar los nuevos códigos y enfrentar los desafíos en cuanto a la infraestructura, las actividades rectoras, el currículo, el manejo de cuadernos, la apropiación de las reglas institucionales y de las normas de convivencia, las rutinas de trabajo, la estructura del aula, es decir las condiciones institucionales y 
metodológicas del espacio escolar. Esta fase requiere de apoyos y estrategias de acompañamiento por parte de las maestras para lograr la continuidad y progresión en los procesos. La aceptación se relaciona con la integración e implicación de los niños y niñas en el nuevo espacio o ambiente escolar, la capacidad de ellos para apropiar los códigos institucionales, asimilar los cambios curriculares, cuando se adaptan de tal forma que empiezan a valorar los procesos, permanecen en la silla, respetan los tiempos de juego, aprenden a utilizar los cuadernos, a ver su escuela linda, como un espacio de protección, disfrutan los tiempos de descanso y las zonas de esparcimiento de su nueva escuela.

\subsection{A modo de cierre}

En este capítulo fue posible explicar la forma en que se configura una trayectoria y las transiciones. De esta forma la trayectoria educativa se configura como una dimensión, un camino de múltiples itinerarios y experiencias que vive el sujeto desde que nace hasta que termina su nivel de formación; momentos del curso de vida en los que se adquiere experiencias, saberes, que le dan sentido y significado a los procesos educativos del sujeto.

En este estudio se observó que la trayectoria permite la interpretación de los fenómenos escolares. Está compuesta por diferentes caminos en los que se presentan un conjunto de factores y variables desde el ámbito sociocultural, socioeducativo y personal que afectan los recorridos y las experiencias de los niños-niñas, de sus familias y de las maestras. Las agentes educativas y maestras entrevistadas señalan que, no es solo el cambio de una institución a otra es considerar que en ese paso interfieren los códigos culturales, los condicionamientos institucionales, las características del contexto, las estructuras internas y externas de las instituciones, las regulaciones políticas, y siendo muy importante los atributos personales de los niños y niñas que están experimentando este cambio y de los maestros que lo acompañan

Las trayectorias educativas contemplan dos procesos que inciden directamente en la transición: ellos son los ritos de paso y la articulación. Para las maestras y agentes educativas los ritos de paso son el conjunto de estrategias y actividades que permiten acompañar el tránsito de los niños de la Educación Inicial a la Educación Formal; son factores determinantes que buscan preparar al niño, niña y la familia para que se adapte al nuevo ambiente. 
Observamos que las maestras en la Educación inicial realizan como rito de iniciación actividades centralizados en el aprestamiento; trabajan la postura, el manejo del cuaderno, el espacio en la mesa de trabajo, los horarios del descanso y la ida al baño, el manejo de la cartuchera, algunas rutinas escolares, entre otras, como rito de agregación se hace la pasantía que consiste en una visita a la institución de preescolar para que los niños y niñas conozcan el espacio y sus nuevas profesoras, como ritual de separación y para preparar al niño/a para el cambio y el inicio del nuevo ciclo se apela a la imagen de niño grande, desde el discurso se les motiva con que ya son grandes y niños fuertes.

En la Educación Formal - Preescolar (grado transición) las maestras como rito de iniciación hacen una flexibilización de los horarios, por ello sus jornadas de trabajo las realizan por horas, en ellas disponen mayor tiempo de actividades lúdicas y de juego; para ir introduciendo al niño y la niña al mundo de la primaria, se proponen actividades de escritura que son presentadas como propias de un/a niño/a grande. En la Educación Básica Primaria las maestras establecen rituales de agregación centrados en el trabajo frente a la norma, la apropiación de los códigos escolares, realizan ritos de agregación con actividades de aprestamiento en relación al manejo de los cuadernos, la permanencia en el puesto, el uso del escritorio. Entre ambos niveles, con el propósito de demarcar el cierre del ciclo y el inicio de un nuevo período, se realiza una fiesta de graduación, un rito de agregación y separación en donde se cierra los procesos.

En cuanto a la articulación las maestras la definen como un factor que favorece los recorridos y movimientos de los sujetos, garantiza el tránsito efectivo y armónico, siempre y cuando exista una comunicación efectiva entre las instituciones, requiere de acciones intencionadas con objetivos comunes; lo que implica para cada institución desde sus acciones administrativas y pedagógicas la promoción de interacciones, situaciones y condiciones en las que los niños, niñas y familias se preparen para enfrentar nuevos retos, conocer nuevas personas, espacios y entender el desarrollo y el aprendizaje.

Las transiciones se estructuran en relación a los cambios y situaciones que experimentan los niños-niñas y familias en su trayectoria educativa, para las maestras y agentes educativas se presenta como un proceso singular, un acontecimiento que vive cada niño/a en relación a las construcciones socioeducativas del espacio social y cultural en el que está 
inmerso; de acuerdo a lo observado el proceso de transición hacia la nueva situación o ambiente escolar implica para los niños y niñas dos procesos el primero de ellos es de adaptación y el segundo es el duelo, ambos se viven desde tres fases la primera de separación, la segunda de reacomodación y la tercera de aceptación. Estas tres fases son la clave para experimentar una transición compleja o una transición estable.

Así se observa que los niños y niñas que participaron de esta investigación por un lado viven un pasaje con una transición estable cuando pasan de la educación inicial al preescolar, hay expresiones de alegría y felicidad por enfrentar nuevas situaciones de aprendizaje y juego; las expectativas son altas frente a la nueva escuela; el hecho de representarse como niños y niñas más grandes, que ya crecieron, los motiva, pero esta al mismo tiempo, se convierte en una transición compleja para algunos niños/as porque cuando ya están en la escuela la tranquilidad se transforma en angustia, temor en cuanto hay una pérdida de sus rutinas de trabajo, sus juego y juguetes; lo mismo suele suceder en el paso de preescolar a primero los niños extrañan la organización del espacio, manifiestan preocupación por no ver los juguetes, algunos lloran; y es ahí donde las maestras observan que los niños y niñas realizan distintos duelos por la infraestructura física, los ambientes de aprendizaje, los juguetes y juegos, el juego al aire libre, las actividades rectoras, las rutinas de trabajo, las docentes, la alimentación etc. Lo que implica de actividades de acompañamiento. 


\section{Capítulo VI}

\section{Sentires de las maestras frente al proceso de trayectoria y transición}

\section{Introducción}

La transición educativa no solo representa un acontecimiento o proceso clave para los niños y niñas, también implica a las maestras y agentes educativas; son ellas quienes realizan un conjunto de acciones y estrategias para favorecer los procesos educativos de los niños y niñas. Si "preparar" en la Básica primaria refiere a un "conjunto predeterminado de habilidades físicas, sociales y cognitivas que los niños/as deben tener para cumplir con los requerimientos que exige la escuela" (Woodhead y Moss, 2007), en la Educación Inicial y Preescolar comprende acciones que propicien experiencias exitosas y positivas para que el niño y niña tenga la capacidad de adaptarse y de abrir nuevas oportunidades de aprendizaje que potencien su desarrollo y le permitan un "posterior éxito académico y social” (Dockett y Perry, 2005).

Esta diferencia frente al concepto de "preparación" genera angustia, temores, ansiedad y expectativa entre las agentes educativas y maestras, quienes se sienten evaluadas y juzgadas por las otras colegas desde el punto de vista de los saberes, el estilo de enseñanza, la organización del ambiente; así como los niños y niñas enfrentan desafíos en cuanto a "los contextos de aprendizaje y del aprendizaje mismo" (Fabian y Dunlop, 2006) las maestras enfrentan desafíos desde su rol profesional en relación a los acompañamientos pedagógicos y la articulación.

Por ello en este capítulo presentamos material relevado en relación con los sentidos y sentires que expresan las maestras del sistema de educación formal y agentes educativas del sistema de educación inicial frente a los temores y las angustias que les ocasiona este proceso de transición entre ambos sistemas. Asimismo se describen las acciones de acompañamiento a los niños-niñas y las propuestas, recomendaciones que dan para favorecer la articulación entre escenarios. 


\subsection{Sentires de las agentes educativas y maestras frente al proceso de transición.}

Para las agentes educativas directivos y maestras de la Educación Infantil el acompañamiento que hacen al proceso de transición de los niños y niñas no es solo una exigencia, es un reto con el cual buscan mediar las discontinuidades que se presentan en el sistema educativo; así como los niños lo viven, experimentan y sienten, ellas también desde su rol como acompañantes reflejan un conjunto de situaciones y temores que muestran la poca articulación que se vive entre los dos escenarios.

\section{Agentes educativas del sistema de Educación Inicial}

Observamos que para las agentes educativas y directivas del programa Buen Comienzo el pasaje que hacen los niños y niñas al nivel de preescolar es vivido con un sentimiento de angustia porque aunque ven que los niños están felices y motivados refieren que las diferencias por las metodologías, formas de trabajo, ambientación y espacios son un choque para ellos. A su vez, expresan que aun cuando los niños y niñas se sientan grandes, en el escenario de Educación Formal no gozarán de las mismas condiciones y esto porque en la educación inicial se les garantiza el 70\% de la alimentación, cuentan con un equipo interdisciplinario (psicólogo, artista, nutricionista, enfermera, educadora especial), pero no tienen un currículo establecido. Por ello plantean con preocupación la atención y el cuidado que los niños van a recibir.

Pienso que es un cambio de vida, ellos están felices porque se sienten grandes, pero cuando uno mira al otro lado de esa transición, uno dice hay Dios a este quien lo va a cuidar, a esta tal cosa, entonces uno empieza a sufrir y a cargarse de muchas cosas porque uno sabe que no van a tener la misma atención, que tienen acá (Agente Educativa Coordinadora, 15/12/2017).

Entonces si me da mucha nostalgia, ellos están felices y pensando en el uniforme, que no sé qué, y los cuadernos y mira, vamos a jugar, y ellos son loquitos por toda la institución cuando se hace la pasantía, pensando en cuando vamos a estar acá, yo pienso que ellos no dimensionan lo que se les viene (Agente Educativa Psicosocial, 14/12/2017).

Si bien resaltan que en el otro escenario de Educación formal existen condiciones para atender a los niños y niñas pues cuentan con profesionales calificados y para protegerlos en el marco de los derechos, afirman ser realistas y comprender que la función educativa se 
diferencia desde algunos aspectos relacionados con los procesos académicos y curriculares. Entre ellos destacan que desde el punto de vista de la infraestructura los espacios son diferentes, los niños-niñas ya no rotarán por los salones o aulas de exploración, no contarán con la presencia permanente de las auxiliares o madres comunitarias para acompañar las mediaciones pedagógicas, las rutinas cambian así como el tiempo de permanencia en la escuela dado que en Buen Comienzo los niños quedan durante 8 horas al cuidado de las agentes educativas.

Otro aspecto para destacar es la poca apertura que algunas veces sienten en la visita que hacen a las instituciones de preescolar (pasantía), estrategia que se realiza para que los niños y niñas reconozcan los ambientes educativos y a las maestras de preescolar.

Notamos que hay instituciones que nos reciben muy bien, acogen excelente a los niños-niñas y disponen de actividades entre las maestras de preescolar para darle la bienvenida, por ejemplo la institución de nuevo occidente, pero también nos encontramos con instituciones que no le dan la importancia a esta actividad de pasantía, se identifica resistencia, vemos maestras inquietas y angustiadas para facilitar un cupo especialmente cuando se trata de un niño o niña con discapacidad (Agente Educativa Docente, 11/12/2017).

Ante este estado de cosas ellas plantean la necesidad de preparar a los niños/as y darles algunas herramientas para que se puedan adaptar al otro escenario con mayor facilidad.

Yo en el fondo sospecho que más adelante, esa felicidad no va hacer tan felicidad, porque ellos pensarían desde su imaginario que va hacer igual que acá, que van a poder explorar espacios, que se van a encontrar una profe divertida, una profe que los escuche, una profe que los reconozca como sujetos, y no es por hablar mal de mis compañeras, de las profes de otras instituciones, pero cuando uno va, ellas, a veces son toscas con uno, uno las ve como tan serias, y como yo domino este espacio (Agente Educativa Docente, 12/12/2017).

\section{Maestras de Grado Transición y Primero}

Para las maestras del sistema de Educación Formal -grado transición y primero- los principales temores están asociados a las expectativas de aprendizaje que tienen sus colegas con relación a los saberes que los niños/as deben poseer. Las docentes de transición manifiestan preocupación por la valoración que la docente de primero realiza de las competencias que los 
niños y niñas deberían haber adquirido al momento de ingresar a ese nivel educativo en virtud de las diferencias en la metodología de enseñanza, por ejemplo, en grado transición trabajan por proyectos y en primero por áreas de conocimiento (matemática, español, ciencias). En este mismo sentido las maestras de preescolar sienten temor de que los niños y niñas se frustren y no sean capaces de superar los retos del grado primero especialmente en lo referente a lógico matemática y lectoescritura.

Nosotras las de preescolar tenemos una metodología basada en el juego, donde utilizamos mucho recurso de tipo concreto para los niños, para todo tipo de aprendizaje, me angustia pensar que van a pasar: a un aula donde ya no van a trabajar por equipos, si no que las sillas están en fila, me angustia pensar, que los niños y niñas ya no van a tener su baño, sino que tienen que esperar a salir al descanso o que suene el timbre de cambio de clase para ir. Ya su descanso no va a hacer solito, si no con todo el mundo y no es como en transición que la profe está aquí en el patio si no que se asignan unos puntos de acompañamiento a los maestras, pero los niños están libres por todos lados, tienen que empezar a ser muy autónomo para resolver sus problemas. En el descanso hay muchachos muy bruscos, muy agresivos y los niños muchas veces copian ese modelo, eso me preocupa, me angustia pensar que todo lo que hemos trabajado acá sea invalidado y esto en la experiencia que he tenido de otros grupos que han transitado (Docente de Transición, 10/10/2017).

Las docentes reconocen que para algunos niños y niñas este paso hacia la básica primaria es difícil y esto es confirmado por las maestras del grado primero quienes comentan que en este nivel es donde se presentan los cambios más bruscos, los niños y niñas se enfrentan a un aula distinta, unas rutinas diferentes, a otras formas de trabajo y relaciones interpersonales complejas, no obstante, las maestras de primero reconocen el trabajo que se realiza en preescolar, resaltan la labor y el acompañamiento que las maestras hacen para que los niños y niñas desarrollen las habilidades de lógico matemática, lectoescritura, conciencia fonológica, reconocimiento de vocales, abecedario, direccionalidad, lateralidad, coordinación, desarrollo motriz, entre otras, ejes fundamentales para el nivel de primero: "me parece que las profes hacen muy buen trabajo en preescolar" (Docente de Primero, 25/10/2017).

Las maestras de primero señalan que al igual que las de preescolar ellas sienten el mismo temor con sus niños de primero al pasar a segundo, reconocen que hay niños que transitan de un grado a otro sin mayores inconvenientes y tienen todas las bases para cumplir 
con los objetivos del grado segundo, mientras que otros no están preparados porque no cursaron previamente el preescolar y por factores que identifican y relacionan con el capital social y cultural de las familias.

/.../ no es el caso decir que los niños llegan mal preparados, porque como dicen las profes de preescolar ellas trabajan eso, o sea eso es una cadena, porque en segundo las profes mencionan, es que mira que estos niños llegaron sin las competencias. Y nosotras las de primero decimos pero si lo trabajamos; entonces uno se pone a analizar que los niños que a estas alturas no se saben las vocales así hayan trabajado en preescolar y en primero todo el año es porque en la casa no tienen el más mínimo acompañamiento (Docente de Primero, 24/10/2017).

A primero llegan muchos niños nuevos, por ejemplo, a mí me llegaron (2) que no eran de acá, de Medellín, una niña de Cartagena y un niño de Venezuela que no terminaron preescolar, llegaron atrasados, tengo otros que llegan de otras instituciones con diagnósticos de déficit de atención e hiperactividad, con ellos hay que hacer proceso de adaptación y es más lento el proceso de aprendizaje (Docente de Primero, 25/10/2017).

/... aquí falta mucho el acompañamiento porque la población es fluctuante, entonces este chico pudo estar o no escolarizado, a mí me han llegado niños de primero que ni siquiera habían hecho algo de primero y llegan en junio o julio, entonces son las condiciones del contexto las que exige también de estrategias para poder favorecer su aprendizaje y que pueda pasar a segundo con las competencias requeridas (Docente de Primero, 26/10/2018).

Otras de las angustias que manifiestan las maestras de primero se relaciona con la cantidad de estudiantes por aula, tener 50 niños y niñas en el salón de clase dificulta los acompañamientos que las maestras hacen de los procesos de aprendizaje especialmente porque sus aulas son heterogéneas, los niveles de aprendizaje de cada niño y niña son distintos, y aunque realizan múltiples estrategias para acompañar el proceso académico no son suficientes para lograr que todos vayan a un mismo ritmo. Además, no contar con material didáctico y concreto ni con personal de apoyo se vuelve más complejo sostener la tarea así como recuperar y valorar en su totalidad lo que los niños y niñas saben, ofrecer diferentes tipos de estímulos, formar grupos mixtos para favorecer la relación entre lo que ya saben o conocen y lo nuevo por aprender, proponer trabajos individualizados sin perder de vista la producción de un 
espacio colectivo de aprendizaje, entre otros. Es decir, planificar sus secciones de aprendizaje es todo un reto.

Una de las angustias que es compartida tanto por las agentes educativas de la educación inicial como para las del nivel de preescolar y básica primaria, es la atención educativa que se le brinda a los niños y niñas que presentan discapacidad o alertas en el desarrollo. Según ellas la transición para estos niños es más compleja.

A diferencia de otros países de la región donde los niños, niñas y jóvenes con discapacidad cuentan con una propuesta de escolarización diferenciada en escuelas de educación especial, en Colombia y a partir de la firma del decreto 1421 de 2017 se reglamenta en el marco de la educación inclusiva la atención educativa a la población con discapacidad. Por educación inclusiva el Estado colombiano entiende toda propuesta escolar a que los niños, niñas, adolescentes, jóvenes y adultos, según sus necesidades, intereses, posibilidades y expectativas, independientemente de su género, discapacidad, capacidad o talento excepcional, pertenencia étnica, posición política, ideología, visión del mundo, pertenencia a una comunidad o minoría lingüística, orientación sexual, credo religioso, lengua o cultura, asisten y participan de una educación en la que comparten con pares de su misma edad y reciben los apoyos que requieren para que su educación sea exitosa.

La educación inclusiva es un proceso permanente, cuyo objetivo es promover el desarrollo, el aprendizaje y la participación de todos y todas sin discriminación o exclusión alguna, garantizando los ajustes razonables requeridos en su proceso educativo, atendiendo sus particularidades y prestando especial énfasis a quienes por diferentes razones están excluidos o en riesgo de ser marginados del sistema educativo (MEN, 2016). Para lograr la inclusión de niños, niñas y jóvenes con discapacidad u otra condición en el sistema educativo el Estado garantiza la presencia en las escuelas de educación formal de maestras de apoyo que son educadoras especiales cuya función es acompañar a las maestras de grado regular.

En el caso del Programa Buen Comienzo los jardines infantiles cuentan con educadoras especiales que al igual que las maestras de apoyo realizan acompañamiento y seguimiento a la población, hacen foco en una serie de "alertas del desarrollo" que colocan el problema en el cuerpo individual y menos en la responsabilidad de las instituciones de garantizar la educación como derecho independientemente de las características de las niñas y niños, alertas de 
desarrollo se refieren a aquellas variaciones significativas en el proceso de desarrollo y aprendizaje de los niños y niñas. Las agentes educativas las reconocen a través de la observación y de un proceso de valoración y seguimiento al desarrollo. Estas nociones han sido fuertemente cuestionadas por los colectivos de Personas con Discapacidad (PCD) en su lucha por el reconocimiento de derechos y por el reclamo de políticas públicas desde los años sesenta el siglo XX cuestionando principalmente el modelo médico-rehabilitador y proponiendo en su lugar "un modelo social donde la persona con discapacidad posea el control y ejerza la responsabilidad sobre su vida reconociendo los apoyos necesarios para alcanzarla." (Martínez, 2015: 48)

En este momento, Colombia se encuentra frente al enorme desafío en términos de atención educativa a la diversidad e inclusión efectiva en el sistema educativo de Educación Infantil de resolver las desigualdades y las exclusiones educativas de ciertos grupos porque representan factores esenciales en la trayectoria de los estudiantes. Bourdieu planteaba que el "sistema escolar no es meritocrático ya que no reduce la desigualdad social entre los estudiantes, sino que la transforma en trayectorias escolares desiguales lo que evidencia para estudiantes en condiciones de vulnerabilidad menos éxito en su recorrido (citado por Breen y Goldthorpe, 2000).

La educación inclusiva en el país ha representado cambios en términos de actitudes, metodologías, currículos; ha estado puesta en debate en las últimas agendas educativas lo que ha contribuido en la construcción de políticas y normativas. Un ejemplo de ello son las orientaciones políticas creadas en los últimos años: la Ley $\mathrm{N}^{\circ} 1618 / 13$ por la cual se establecen las disposiciones para garantizar el pleno ejercicio de los derechos de las personas con discapacidad; el ya decreto ya citado $\mathrm{N}^{\circ} 1421 / 17$ por el cual se reglamenta la ruta, el esquema y las condiciones para la atención educativa a la población con discapacidad en los niveles de preescolar, básica y media, direccionado bajo los principios de dignidad, autonomía, la no discriminación, la participación, el respeto por la diferencia, la identidad y accesibilidad; dichas normas tienen como objeto favorecer las trayectorias educativas de las niñas, niños, adolescentes y jóvenes para su ingreso, permanencia, promoción y egreso en el sistema educativo. 
Asimismo se cuenta con las orientaciones técnicas, administrativas y pedagógicas que buscan, por un lado, generar procesos de transformación en las organizaciones escolares mediante el análisis y planeación de sus políticas, prácticas y culturas; por el otro, favorecer el reconocimiento de los derechos de las personas con discapacidad en el contexto amplio de la diversidad y la educación para todos, buscando evitar así prácticas de marginalización, segregación y exclusión (MEN, 2017). En el marco de la Ley $N^{\circ} 1804 / 16$ por la cual se establece la política de Estado para el desarrollo Integral de la Primera Infancia de Cero a Siempre se ha producido también otro documento con orientaciones para la transición educativa de los estudiantes con discapacidad y con capacidades o talentos excepcionales en la educación inicial, básica y media. Ciertamente estas normatividades han sido ejes transversales para que el sistema educativo asuma nuevas posturas desde sus procesos educativos; no obstante, de acuerdo con el estudio de la organización de la sociedad civil Niñez Ya "La niñez no da espera - Una mirada a su situación desde la sociedad civil” (2018).

/.../ los avances legislativos han sido insuficientes para lograr el principio de la protección integral y la transformación de las condiciones y la calidad de vida de los niñas, niños y adolescentes, con una visión de equidad, diversidad y con la participación activa de ellas y ellos en los diferentes espacios; este estudio resalta que niños y niñas de los quintiles más bajos de riqueza, con discapacidad, habitantes de zonas rurales y apartadas, indígenas y afrodescendientes siguen siendo excluidos de la implementación efectiva de las políticas públicas y sociales del país (...) así mismo reitera que la matrícula es aún menor en población de primera infancia con discapacidad, ya que se estima que la prevalencia de la discapacidad en esta etapa se ubica entre 1 y $2 \%$ (aproximadamente 57.000 niños y niñas) (2018: 14-48).

Volviendo sobre cómo viven las maestras la atención de niños con discapacidad en aulas superpobladas y con escases de recursos y materiales concretos, sobre el desafío de planificar diferentes secciones de aprendizaje atendiendo a las características de los niños, una docente de educación especial comparte su experiencia.

Yo soy docente de primero y además soy educadora especial aquí en la institución somos varias educadoras especiales, las compañeras nos dicen que, porque nos preocupamos si nosotras tenemos el saber, pero es complejo no es lo mismo el contexto de la educación especial donde se trabaja casi que individualizado porque voz elaboras un plan de intervención individual y elaboras unos objetivos solamente a ese estudiante, pero aquí son entre 45 y 50 niños con 
múltiples problemáticas. Si hacemos ajustes, pero es como en masa porque entonces llegan las evaluaciones de periodo, llegan las evaluaciones que son externas y todos se tienen que hacer de la misma forma, nosotras muchas veces hemos generado esa discusión, entonces para que exigimos un diagnóstico si los niños siguen teniendo las mismas formas de evaluación, la misma estructura curricular. Como institución se está trabajando para mejorar estos procesos. Por eso te digo es complejo y genera angustia (Docente de Primero, 24/10/2017).

Para ellas la transición para estos niños es más compleja de acuerdo a las siguientes variables:

1. El tipo de discapacidad o alerta en el desarrollo que tienen el niño o la niña

2. Los acompañamientos institucionales- apoyos

3. El acompañamiento familiar

4. El conocimiento por parte de las maestras y agentes educativos en relación al diagnóstico o desarrollos del niño-niña

5. Las condiciones culturales y sociales de los niños y niñas

6. La continuidad con los procesos académicos y escolares

En sus voces los niños y niñas que presentan alertas en el desarrollo o una discapacidad cognitiva, psicosocial, sistémica o múltiple se encuentran en desigualdad con respecto a los otros niños, porque se enfrentan a múltiples barreras no solo de tipo actitudinal, sino en los planes y programas de estudio, en las metodologías y métodos de enseñanza, deben enfrentar barreras sociales-prejuicios, barreras en la participación y los aprendizajes; si bien; resaltan que hay instituciones con toda la apertura frente al tema de diversidad, la falta de recursos o de experiencia en las instituciones genera retos para la institución que lo recibe.

Todos los que son "normales" ellos pasan y no hay ningún problema, pero los que tienen alertas, siempre existe un condicionamiento, nosotras tratamos de entregar todo súper bien, informar para que el otro sepa cómo le vamos a entregar al niño/a y como hemos trabajado con él, entonces, luchamos por conseguir un cupo. Pero uno si se queda pensando cuando en la otra escuela exigen que tiene que ir la mamá, hay que firmar un compromiso, lo extraño es que nosotras compartimos con ellos hace dos años y las mamás nuca tuvieron que venir (Agente Educativa Coordinadora, 15/12/2017). 
No es lo mismo entregar el proceso de los niños y niñas con alertas en el desarrollo o discapacidad a un niño regular, digamos que se encuentran en la otra institución aceptación y acogida pero también uno lee temores de quien los recibe, y estos por no comprender bien el diagnóstico, por no poder hacer el acompañamiento oportuno, no contar con los tiempos, las herramientas necesarias. Por ello uno cree que la transición de ellos es difícil, pues les toca enfrentarse y adaptarse a un proceso distinto a unas reglas diferentes, en ocasiones sortear dificultades por los procesos de evaluación y la misma estructura curricular que es tan diferente (Agente Educativa Docente, 12/12/2017).

Esta caracterización de lo "normal" denota una visión de un discurso hegemónico sustentado en una representación mental y simbólica, fruto de los estereotipos socialmente construidos frente a la categoría "normal" confirmando lo que establece (Foucault, 2009 [1978]) cuando refiere que la idea de lo "normal” estructuró prácticas y saberes encargados de normalizar a extensos grupos de sujetos que no cumplían las características deseables, "los discursos transferidos a las prácticas pedagógicas se tornaron en "discursos de y con poder" para construir y justificar los modos de clasificación en el espacio escolar (Foucault, 2001).

La Convención sobre los Derechos de las Personas con Discapacidad (CDPD) que entró en vigencia desde mayo de 2008 coloca como temas centrales los principios de la vida independiente y la promoción de la participación de las PCD en la vida comunitaria. Los derechos civiles, políticos, sociales, económicos, culturales y sexuales de las PCD fuerzan la sanción de leyes como también producen nuevas demandas hacia los Estados y, en particular, hacia los sistemas educativos. En el paradigma de la normalidad que atraviesa el proceso de construcción de los sistemas educativos modernos la autonomía y la independencia individual conforman un valor en sí, atributos necesarios para alcanzar la ciudadanía plena. (Martínez, 2015: 48-49)

Desde una epistemología descolonial, asumir al otro como alguien lejano es una construcción de la colonialidad y, en palabras de Escobar (2003), "el otro desde la perspectiva ética y epistemológica de la filosofía de la liberación: el otro como oprimido, como mujer, como racialmente marcado, como excluido, como pobre, como naturaleza" (p. 63). Este pensamiento aclara que la diferencia se ha construido a lo largo de la historia sobre el discurso segregador y no sobre el reconocimiento, la escuela se ha configurado en un discurso hegemónico y en unas prácticas homogeneizadoras, sin embargo es necesario resaltar que en 
los últimos años y gracias a los avances en el reconocimiento de la inclusión como un elemento clave para realizar el derecho a la educación para todas las personas, la escuela ha empezado a sumir el enfoque de derechos que propone que la discapacidad no es un atributo personal e individual, es una construcción social; porque es la sociedad la que impone obstáculos, estereotipos y dinámicas de exclusión.

Observamos que el pasaje de un modelo médico-rehabilitador, es decir, de aulas especializadas para las personas con discapacidad a un modelo social en el que todos y todas pueden participar en condiciones de equidad, el pasaje de una pedagogía centrada en el déficit y el diagnóstico a una pedagogía que se pregunta por las condiciones que deben generar las instituciones, el Estado, los docentes, la familia para promover los aprendizajes y la vida digna de los niños y niñas en el proceso de enseñanza aprendizaje, es lo que lleva a las maestras y agentes educativas de esta investigación a reflexionar y a manifestar sus angustias con respecto a: las implicaciones pedagógicas, accesibilidad-permanencia y la inclusión efectiva de los niños y niñas en el paso que dan entre el nivel de educación inicial al nivel de educación formal.

En las narraciones de las agentes educativas de la educación inicial es evidente la angustia que manifiestan con respecto a la participación efectiva de los niños y niñas. Su preocupación se centra en que ellos/as al ingresar a la institución de educación formal puedan incluirse aportar y aprender en el nuevo escenario escolar, refieren que la transición será compleja, llegar al nuevo escenario les implicara un proceso de adaptación y aceptación, un proceso de reconocimiento lo que genera para algunos niños y niñas manifestaciones de ansiedad, enojo, pánico y frustración. Esto es confirmado por las maestras de primero quienes refieren

Cuando los niños y niñas llegan se puede evidenciar interrupciones en los procesos y logros alcanzados, el proceso de adaptación es complejo vienen de un escenario distinto de juego y libertad, a una institución de normas, el niño empieza de cero a crear lazos de amistad, empatía, confianza, vínculos afectivos con sus pares y docentes, esto es complejo para ellos y depende de la actitud de la docente que lo recibe (Docente de Primero, 25/11/2017).

La otra angustia que manifiestan las maestras está centrada en las condiciones institucionales, en las acciones necesarias para el desarrollo y ejercicio de las capacidades individuales, de la comunicación colectiva y de la cooperación entre maestras; quizá esta es la 
que resaltan con mayor preocupación en el sistema de educación formal, de acuerdo con las maestras del grado primero los proyectos educativos institucionales (PEI) están en proceso de transformación hacia una educación inclusiva. Sin embargo, relacionan que aun la rigidez de los planes de estudio, las pruebas estandarizadas, los contenidos intocables y descontextualizados con algunas realidades de los niños; la mirada centrada en la disciplina; se convierten en limitantes para que los niños y niñas puedan participar plenamente, reconocen que tanto en el nivel de educación inicial como formal se hace necesario seguir reflexionando en relación al enfoque de derechos, la equidad, participación, los desarrollos y aprendizajes, la promoción-evaluación, los ajustes razonables y articulación entre los escenarios, exigen mayor formación y un diálogo conjunto entre la educación inicial y educación formal esto para favorecer la trayectoria.

Estas angustias que referencian las maestras con respecto a la atención educativa de los niños y niñas en cuanto a la accesibilidad y adaptabilidad de los centros educativos, los prejuicios, las barreras actitudinales, los derechos, las pruebas estandarizadas, la evaluación, el currículo entre otras refleja la realidad de una situación global que es compartida en America Latina y es validada con los resultados de la investigación "El derecho a la educación de las personas con discapacidad ¿Cómo estamos en América Latina y el Caribe?” realizado por la campaña Latinoamericana por el derecho a la educación (CLADE, 2020) en el que se presenta los resultados obtenidos en una consulta a organizaciones y comunidades educativas de la región con el propósito de indagar en qué medida los tratados internacionales se implementan a través de leyes, políticas y prácticas específicas en los países de América Latina y el Caribe. En el año 2017 se abrió la consulta ${ }^{33}$ dirigida a la comunidad educativa -estudiantes, docentes y familiares de personas con discapacidad- y a representantes de organizaciones de la sociedad civil y del campo académico, sobre siete categorías analíticas que se basan en los derechos consagrados por la CDPD.

El presente informe permite mostrar los problemas más acuciantes identificados por las personas consultadas para concretar los principios que sostienen los acuerdos internacionales

${ }^{33}$ De la consulta participaron 216 personas (comunidad educativa 148 respuestas; organizaciones y academia 68 respuestas) de 19 países: Argentina, Bolivia Brasil, Chile, Colombia, Costa Rica, Ecuador, El Salvador, España, Guatemala, Haití, Honduras, México, Nicaragua, Paraguay, Perú, República Dominicana, Uruguay y Venezuela. 
sobre los derechos de las personas con discapacidad, y para garantizarles el derecho a una vida independiente. Así, el estudio destaca como principales tendencias en América Latina y el Caribe:

1. Existencia de barreras actitudinales producto de la persistencia de estereotipos y prejuicios en lo referente a que los estudiantes son capaces de aprender, así como procesos de discriminación y promoción de culturas segregadoras que aparecen otra vez para explicar las barreras a la permanencia y flujo en la trayectoria educativa.

2. Inclusión efectiva de las y los estudiantes con discapacidad en los centros educativos y clases producto, en muchos casos, de la voluntad y de la decisión individual de docentes y gestores/as para adoptar prácticas pedagógicas diversas.

3. Presencia de un abordaje pedagógico homogéneo en el sistema educativo que no considera las distintas necesidades de las y los estudiantes, además de ausencia de metodologías y de estrategias diversificadas.

4. Adaptaciones curriculares que suelen significar en realidad la reducción de los contenidos y la simplificación de las evaluaciones.

5. Insuficiente formación de docentes, falta de apoyo familiar, ausencia de apoyos pedagógicos y de materiales en distintos formatos para asegurar esta atención educativa.

Lo que las maestras señalan y el informe viene a confirmar es que el contrato pedagógico reproduce la lógica de clasificación del contrato social por el cual los cuerpos que no son productivos se deshechan dado que este es el principal requisito del sistema de producción capitalista y de la dominación patriarcal. La escuela es parte de esa maquinaria moderna y lo que las maestras piensan responde a una socialización en la que las pautas de clasificación social se han ido incorporando y se han hecho cuerpo en la forma de disposiciones (Seoane, 2018).

En todo contrato pedagógico subyace una concepción de la igualdad que se sienta en la idea de que todos los seres humanos son idénticos y que la posibilidad de alcanzar los mismos derechos depende de que nos acerquemos a ese ideal. Dicho esto, es necesario identificar los mecanismos que hacen de la diferencia la razón de la opresión de determinados grupos y dentro 
del colectivo formado por personas con discapacidad las niñas, jóvenes y mujeres son las más oprimidas, discriminadas por un sistema de dominación patriarcal que encuentra en la escuela como institución y en la ciencia moderna la herramienta para justificar propuestas que segregan e infantilizan y atribuyen la discapacidad a la persona.

La igualdad no puede significar "mismidad" porque implica borrar las diferencias según clase social, género, sexualidad, etnicidad, discapacidad que caracterizan a niñas, niños y jóvenes, pero también invisibiliza los mecanismos por los cuales en la sociedad y en el sistema escolar se jerarquizan los sexos, se clasifica la población según un criterio de "normalidad" que es propio del proyecto moderno en que se fundó el sistema educativo. "La jerarquización y dicotomías presentes en el sistema escolar se basan en la diferencia sexual (...) La diferencia sexual en el campo educativo se asienta en una visión esencializada y biologicista de la feminidad y de la masculinidad" (Seoane, 2017: 31) Podemos hacer extensiva esta naturalización de la discapacidad como un atributo biológico de la persona en base a la cual se explican ciertas diferenciaciones jerárquicas que tienen lugar en las escuelas.

Por último, y en relación con el proceso de transición, observamos que las agentes educativas del sistema de educación inicial comparten con las maestras del nivel de educación formal un conjunto de preocupaciones que nacen de las características de cada uno de los escenarios educativos y de la falta de articulación inter-institucional e intra-institucional en la continuidad de los procesos. Por ello las maestras estructuran unas propuestas de acompañamiento para favorecer la adaptación de los niños y niñas al nuevo escenario, y elaboran un conjunto de recomendaciones que mejorarían el proceso de articulación interinstitucional y la transición educativa.

\subsection{Acompañamientos a los niños y niñas para favorecer su proceso de adaptación y transición por la Educación Infantil}

Los niños y niñas enfrentan diversos desafíos en su proceso de transición cuando pasan de una institución a otra o de un nivel a otro, lograr que asimilen las nuevas estructuras demanda de acciones puntuales que permitan transformar los hábitos y costumbres con las que los niños llegan; por ello las maestras en el sistema de educación formal desarrollan un conjunto de estrategias de acompañamiento para mediar los procesos de enseñanza y 
aprendizaje, favorecer la permanencia-retención en la escuela y lo más importante el proceso de adaptación y asimilación que ellos/as deben enfrentar en relación con los nuevos cambios y duelos.

La primera estrategia que realizan las maestras de preescolar y primero se enfoca en el trabajo sistémico y regular frente a los hábitos y las rutinas, con la idea de generar seguridad en los niños y niñas para que puedan alcanzar la autonomía y desarrollar las actividades que se les propone. Para mostrar que hay nuevos espacios, otros tiempos de trabajo, nuevos saberes, nuevas reglas, el dispositivo contempla la planificación y organización de los momentos de las clases con calendarios, el descanso como tiempo de juego y el orden en el aula.

Para moldear los hábitos y rutinas de los niños las maestras hacen foco en la norma y los comportamientos a través de la disciplina que requiere el nuevo escenario educativo. El conjunto de normas implícitas y explicitas que buscan regular la actividad y las interacciones de los niños y niñas, así como la disciplina entendida como una cierta manera de actuar en la escuela son para las maestras una forma de asegurar un trabajo conjunto, un ambiente de respeto, orden, autocontrol y de convivencia. Estas opiniones y sentires de maestras se basan en una representación de la escuela -compartida por agentes educativas de preescolar- como un espacio donde ya no se juega.

/.../ o sea desde el principio se les dicen las normas, desde el principio se le dice aquí va a estar sentado aquí no va a estar parado, ni jugando; y desde el principio nosotras nos ponemos serias estableciendo normas claras, intentamos enseñar la escritura desde el principio, porque es un proceso muy complicado para ellos, e intentamos que ellos interioricen las reglas para que puedan participar sin dificultad (Docente de Primero, 24/10/2017).

La necesidad de establecer normas claras y de mostrarle a los niños y niñas la importancia de ellas en la escuela para un adecuado proceso de enseñanza aprendizaje especialmente en la básica primaria- es una búsqueda constante y una estrategia que tienen las maestras de primero para tener control de su aula, su espacio académico y un ambiente que facilite las interacciones y el aprendizaje colaborativo.

Las maestras de primero refieren que en la básica primaria es donde más estrategias de acompañamiento deben realizar para favorecer el proceso de adaptación de los niños y niñas, y comentan que en las primeras semanas el primer proceso en el que deben trabajar es el 
reconocimiento del uso de varios cuadernos. El cuaderno se presenta como un instrumento en el que se irán estructurando los contenidos, las tareas y unidades didácticas, no obstante, las niñas y niños presentan serias dificultades para comprender que en grado primero cada área (ciencias, matemáticas, español, inglés) emplea un cuaderno distinto (total 10) a diferencia de preescolar en el que solo utilizaban un cuaderno.

Al principio es muy complicado cuando llegan a primero los niños abren en cualquier parte el cuaderno y allí escriben en la dirección que sea, a nosotras nos toca orientar el proceso paso a paso describiendo, saquen el cuaderno con estas y estas características yo voy pasando por cada puesto diciéndoles en cuál es la hoja que van a escribir a trabajar eso de pasar hojita por hojita es muy complejo porque no todos lo cogen inmediatamente entonces algunos se atrasan, otros sacan el cuaderno que no es y así no la pasamos (Docente de Primero, 25/10/2017).

Ante esta situación la estrategia que están implementando como colectivo docente es asociar las áreas de las asignaturas con un animal tal como lo explica la maestra de primero.

Mira el proceso más difícil para mí es el manejo del cuaderno, pero yo ya me acostumbré, que pasa que, por ejemplo, nosotras les marcamos los cuadernos, digo nosotras porque nosotras nos ponemos de acuerdo para hacer un mismo dibujo, entonces, vamos a sacar el cuaderno del oso que es el de ciencias naturales, vamos a sacar el cuaderno de la tortuga que es el de matematicas. No solamente le decimos el dibujo si no lo que significa, vamos a sacar el cuaderno del búho, de áreas integradas donde trabajamos todo, entonces ellos van haciendo una relación, y ya a lo último uno dice áreas integradas y ya lo sacan, es complejo porque, por ejemplo cuando llegan no saben manejar las hojas y escriben por todo el cuaderno y preguntan profe en dónde es que yo sigo, y ese proceso se les va hasta segundo para algunos niños y niñas (Docente de Primero, 26/10/2018).

Por ello y para garantizar esta asimilación y progresión de los aprendizajes dando continuidad a la forma de trabajar en ambos escenarios las maestras de primero implementan la estrategia del juego y el uso de material concreto para el proceso de enseñanza aprendizaje. Pensado el juego como estrategia de aprendizaje permite no solo la participación e implicación de los niños/as sino también posibilita que ellos permanezcan en las actividades por más tiempo; el juego es el vínculo que genera conexión con esa otra escuela o espacio de diversión, es el recuerdo, lo que motiva y permite la receptividad frente a las actividades que les propone 
la escuela. Para algunas maestras este es un eje transversal, no obstante, otras lo consideran una pérdida de tiempo pues sus principales fines se centran en moldear una norma y cumplir con el currículo.

El uso del material concreto en primero se convierte en una necesidad que urge repensar de carácter urgente en la básica primaria, las maestras relacionan que en primero los niveles de pensamiento de los niños niñas están muy enfocados en lo concreto, o sea, los niños todavía necesitan el material, las canicas, las semillitas, para contar, para sumar para restar, para iniciar como todos esos procesos de lectoescritura, matemáticas, el material concreto es otra conexión y vínculo que permite mayor resultado en el proceso de aprendizaje y contribuye a la continuidad y progresión de los aprendizajes.

No obstante, las maestras comentan que es escaso el material concreto con que cuentan en la educación primaria lo que deja al descubierto el cambio brusco en la metodología de enseñanza dado que los niños y niñas pasan de tener juegos, materiales didácticos, a no contar con ningún recurso dentro de las aulas. Coinciden en que los materiales son un recurso muy interesante para presentar retos a los niños y niñas, estimular el conocimiento, fomentar el interés por aprender y desarrollar sus capacidades.

Pues yo soy una defensora del juego y me encantaría que en primero siguieran jugando y en segundo siguieran jugando, pero es que todo está como estructurado de que los materiales concretos están en preescolar, los juguetes están en preescolar por eso cuando llegan a primero ya no hay material concreto, ni juguetes, entonces muchas veces uno trabaja con lo que uno elabora con lo que les pide a los niños que vayan trayendo, por eso digo que ahí como un abismo grandote; pienso que esa metodología del preescolar y buen comienzo debería continuar en la básica primaria (Docente de Primero, 24/10/2017).

Estas estrategias de acompañamiento a los procesos educativos de los niños y niñas favorecen no solo el proceso de adaptación sino posibilitan un espacio de interacciones armoniosas en el que los niños y niñas se van apropiando y reconociendo en el nuevo entorno escolar; acercan a los niños y niñas a una nueva estructura institucional y potencia su experiencia escolar. Para las maestras es la forma de generar confianza y que ellos reconozcan los nuevos códigos; de mediar el proceso para que no sea brusco pues utilizar el juego y el material concreto es la forma de posibilitar continuidad con la experiencia educativa pasada. 
Por ello reiteran la necesidad de darle continuidad a los procesos establecidos en el nivel inicial-preescolar y proponen un conjunto de alternativas.

\subsection{Recomendaciones de las maestras y agentes educativas para el proceso de articulación y transición por la Educación Infantil}

En el análisis que realizan las actoras de esta investigación frente a los itinerarios que experimentan los niños y niñas en cada una de sus transiciones realizan una serie de recomendaciones que se estructuran de la siguiente forma:

1. Articulación inter-institucional

2. Articulación pedagógica

3. Articulación curricular

4. Formación de maestros

5. Familia

Respecto de la articulación inter-institucional destacan la importancia de generar diálogos permanentes en los que se pueda centrar la atención no solo en la asignación de cupos sino en la transversalidad de los procesos pedagógicos y académicos, en la generación de espacios institucionales que posibiliten encuentros mensuales en los que se puedan debatir los lineamientos técnicos, administrativos y pedagógicos para generar y construir acciones conjuntas que favorezcan los procesos de transición que viven los niños, niñas y familia. Espacios para conocer las dinámicas institucionales y los objetos de formación, los fundamentos epistemológicos de los escenarios para la promoción de actividades, estrategias y mecanismos de articulación conjunta.

En cuanto a la articulación pedagógica tres son los objetos a contemplar. El primero es estructurar la Red de Maestras. Las docentes refieren que a nivel municipal existe una mesa de primera infancia liderada por la secretaría de educación y el programa Buen Comienzo $^{34}$ a la

\footnotetext{
${ }^{34}$ En esta red participan agentes educativos de las modalidad familiar e institucional, hogares infantiles, hogares comunitarios, maestros de transiciones, directivos y delegados de primera infancia de cada municipio. Se reunen para socializar la ruta de transición armónica de la educación inicial a la formal, mediante el concenso metodológico, pedagógico, operativo con el fin de establecer acuerdos.
} 
que solo asisten las maestras de preescolar y algunas coordinadoras del sistema de educación inicial atención integral. Por ello hacen hincapié en que sería de gran importancia contar con una mesa en la que participen también las maestras de la básica primaria, con encuentros que centren la discusión en los procesos de articulación y transición donde en conjunto se puedan planear las estrategias pedagógicas como los festivales, las pasantías, los encuentros intergeneracionales, un espacio donde socializar experiencias, investigaciones y proyectos significativos a fin de aportar a la construcción de condiciones y estrategias que favorezcan las transiciones armónicas en la primera infancia. Por el contrario, refieren a las limitaciones burocráticas que les impide participar en estos encuentros además de los escasos tiempos que les asignan especialmente a las maestras del nivel de educación inicial que deben estar todo el tiempo con los niños y niñas. La formación de una red de maestras haría posible contar con un espacio y mejorar la articulación pedagógica del sistema de educación infantil.

El segundo objetivo tiene que ver con las acciones que ellas realizan antes, durante y después para acompañar el proceso de transición de los niños y niñas, es decir, tiene que ver con las pasantías, los festivales de entrega pedagógica, los encuentros intergeneracionales con los niños-niñas y con las familias, establecen que es necesario que estas actividades se realicen durante todo el año y no se concentren solo en el último mes, además proponen que se pueda realizar con los niños de primero. Recomiendan que en el año se pueden hacer las siguientes actividades:

- Entre los grados de educación inicial, transición y primero utilizar el el cuaderno viajero: estrategia para contar historias, gustos, deseos, expectativas, temores de los niños y las niñas

- Realizar proyectos exploratorios conjuntos entre sistema de educación inicial, transición y primero.

- Realizar con los niños y niñas videos de experiencias: estrategia para que las maestras y los niños y niñas puedan presentarse y contar un poco sobre su vida y lo que representa el cambio para ellos. estrategia para que identifiquen los escenarios, las maestras y las metodologías

- Co-enseñanza entre los tres niveles: estrategia para que las maestras puedan hacer intercambios de grupos y compartir con los niños y niñas del otro nivel, planear una 
clase conjunta y puedan conocer las estructuras institucionales de los dos escenarios educativos

- Diseñar proyectos transversales: direccionar acciones para que los niños y niñas de los tres niveles puedan aportar en la construcción de un proyecto conjunto.

- Compartir fechas especiales como el día de la mujer, el día de los niños y niñas, juegos juguetes, semana de la convivencia.

Con respecto a estas experiencias las maestras recomiendan -tercer objetivo- realizar encuentros entre el nivel de Educación inicial y Formal en el que puedan socializar y mostrar las diferentes estrategias que se implementan a nivel institucional y, de esta forma, analizar, evaluar y hacer seguimiento a cada uno de los procesos de articulación vertical y horizontal.

En la articulación curricular las maestras nombran la necesidad de la planeación conjunta, de establecer en los encuentros de primera infancia (red de maestras de educación inicial), espacios para debatir los lineamientos y las bases curriculares de la Educación Inicial, espacios para construir propuestas que permitan la continuidad y establecer mecanismos de acción y seguimiento. Asimismo, en el trabajo con los grupos, pensar en estrategias que posibiliten la continuidad de las metodologías, poner en discusión las expectativas de las maestras frente a los saberes, los aprendizajes y el perfil de egreso que se requiere según el ciclo de edad de los niños y niñas.

En cuanto a la formación de maestras resaltan la necesidad de un encuentro o espacio de sensibilización en el que se pueda dignificar el rol del agente educativo y de las maestras, espacio para trabajar frente a los imaginarios y las representaciones sociales que existen frente a la Educación Inicial, la Educación Formal, el rol del educador en el marco de la Educación Infantil y el rol del niño y la niña como sujeto aprendiz en el escenario educativo. Generar un espacio para investigar y poner en discusión las diferencias, los encuentros y los desencuentros de los niveles, el proceso de articulación, la educación inclusiva, el enfoque de derecho, el currículo, los aprendizajes y desarrollos en los niños y niñas, la cobertura y la accesibilidad, el cuidado y la crianza.

Finalmente, respecto del trabajo con las familias proponen establecer mayores canales de comunicación y de trabajo articulado en donde ellos puedan asumir un rol más propositivo 
y corresponsable con los procesos educativos de los niños y niñas. Consideran que es necesario empoderar a las familias y trabajar en su capacidad de agencia para que puedan mediar y acompañar de manera pertinente las transiciones de los hijos. Establecer talleres entre las familias de los diferentes niveles para que puedan contar sus experiencias, así como ponerle palabra a las expectativas y los miedos frente al proceso de transición de un escenario educativo a otro.

\subsection{A modo de cierre}

Observamos que la transición no forma parte solo de la experiencia de los niños y niñas; toda transición requiere de un acompañamiento y de una preparación para que puedan adaptarse al nuevo escenario y son las maestras y agentes educativas quienes favorecen este proceso aún cuando las instituciones no cuentan con los recursos necesarios para facilitar a las niñas y niños dicho tránsito. No obstante, este cambio entre escenarios y niveles implica también para las maestras sentimientos de preocupación y temores reflejados específicamente en el proceso de "entrega" y "recepción". Los principales temores están asociados a (1) las expectativas de aprendizaje que tienen sus colegas con relación a los saberes que los niños/as deben llevar al grado primero, (2) temor de que los niños y niñas se frustren y no sean capaces de superar los retos del otro nivel y de adaptarse fácilmente, (3) angustia reflejada en la atención que se le brinda a los niños y niñas con discapacidad o alertas en el desarrollo en tanto las experiencias de transición son más complejas, no solo se ven expuestos a que los puedan aceptar e incluir, sino que su proceso de adaptación es más difícil.

Se recupera de las narraciones de las maestras la construcción de un discurso hegemónico sobre la discapacidad que responde más al modelo médico-rehabiltador que al modelo social de la discapacidad. Concebida como un atributo de los niños que deben adaptarse y no como una producción sociocultural, dar este debate incipiente en Colombia requiere de la puesta en marcha de procesos de formación en el que se pueda discutir en profundidad que entendemos por educación inclusiva en la educación inicial. Ser hospitalarios con todos y garantizar el acceso y tránsito por el sistema es un tema que urge analizar en la educación infantil, especialmente por las implicaciones que tiene con respecto al enfoque de derecho, las agendas mundiales, y más aún por los procesos de enseñanza aprendizaje. 
Observamos que actualmente la realidad educativa de los niños y niñas con discapacidad requiere su análisis en época, contextos y escenarios para comprender las situaciones de desigualdad que históricamente ha vivido esta población. Si se les niega la posibilidad de contar con experiencias significativas al interior del sistema educativo estamos ante un mecanismo sistemático de discriminación que perpetúa la segregación y la exclusión de los niños y niñas con discapacidad del derecho a tener igualdad de condiciones para recibir educación.

Para favorecer el proceso de transición educativa las agentes educativas y maestras recomiendan fortalecer los siguientes procesos a nivel institucional e inter-institucional: estructurar la red de maestras contar con una mesa en la que participen las maestras de la básica primaria en el que puedan analizar, evaluar y hacer seguimiento a cada uno de los procesos de articulación vertical y horizontal, pensar en estrategias que posibiliten la continuidad de las metodologías, poner en discusión las expectativas de los maestros frente a los saberes, los aprendizajes y el perfil de egreso que se requiere según el ciclo de edad de los niños y niñas y promover espacios de formación entre el sistema de Educación inicial y formal. 


\section{QUINTA PARTE}

\section{CONFIGURACIÓN DE LAS TRAYECTORIAS Y TRANSICIONES EN LAS VOCES DE LOS NIÑOS Y NIÑAS}

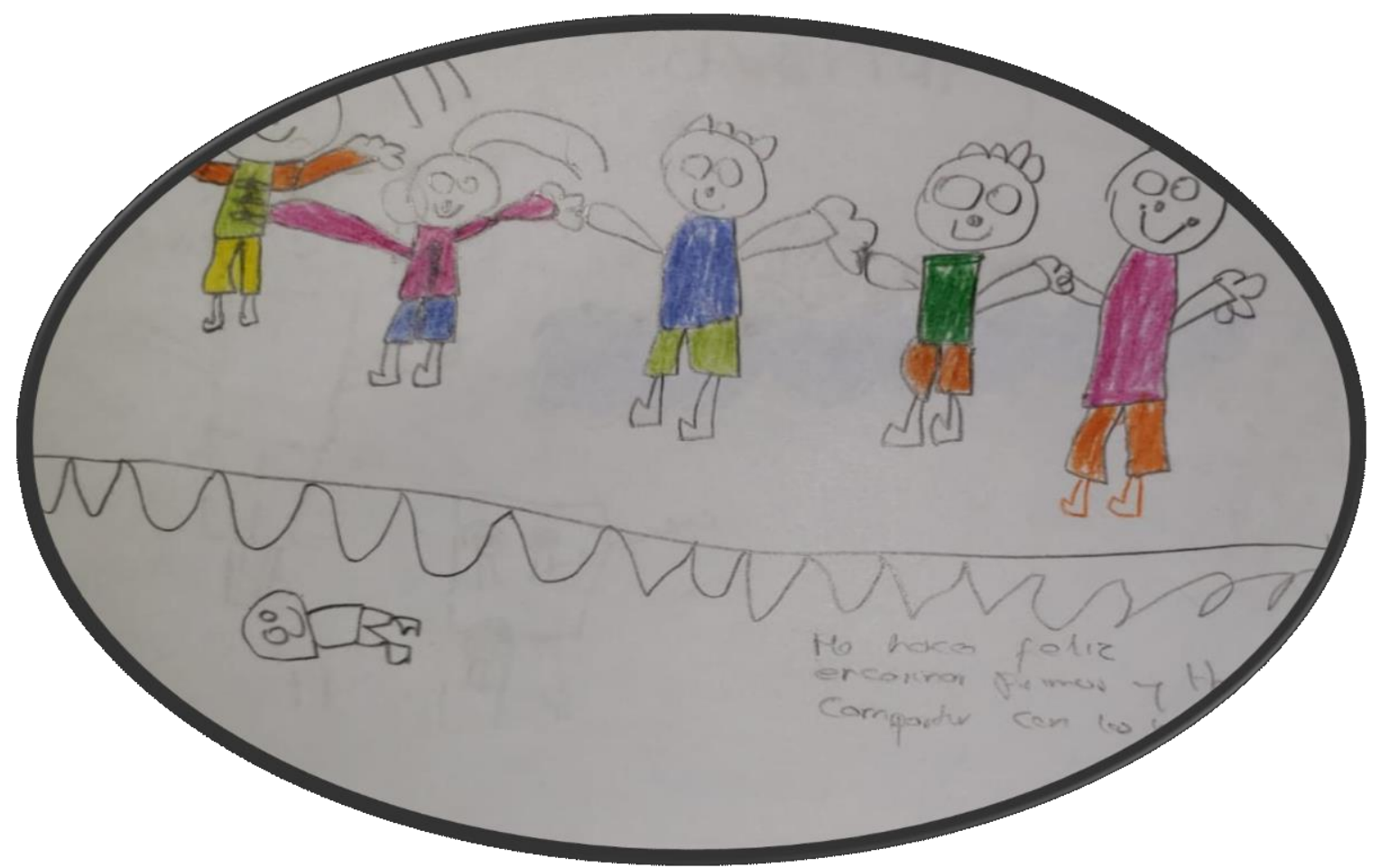

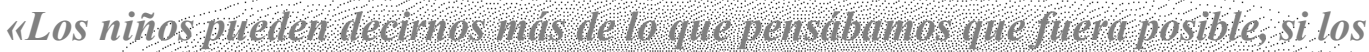
adultos estanos listos para poner de nuesrira parten. James Garbarino (2010) 


\section{Capítulo VII}

\section{Construcción de la transición de los niños y niñas entre la Educación Inicial, el Preescolar y la Educación Básica Primaria}

\section{Introducción}

Pensar en la construcción de este capítulo es remitirse a una experiencia significativa de aprendizaje de construcción colectiva y de agradecimiento a cada uno de los niños y niñas que participaron de este estudio quienes sin importar la lluvia, la madrugada, los tiempos de descanso y las fiestas escolares estaban atentos, siempre esperando mi llegada, animados y muy interesados por participar y formar parte de cada una de las actividades y talleres realizados; sus voces, narraciones y experiencias constituyen el eje central de esta tesis pues como lo plantean autores como Clark y Moss (2001), Lancaster y Broadbent (2003), Burke (2005), Macías (2016) afirma que "los niños son los expertos en sus vidas y son los principales conocedores de sus intereses y necesidades al constituirse en los auténticos protagonistas de su existencia" (p. 197).

La vinculación con los niños y niñas que protagonizaron esta investigación mayormente se dio desde sus espacios escolares en tanto sus maestras y directivos abrieron hospitalariamente sus aulas para que yo pudiera penetrar en la cotidianidad de la escuela y conocer sus experiencias escolares individuales, sus formas de pensar, sentir y percibirse en el campo educativo. La escuela impacta de formas diversas la subjetividad de los niños-niñas y por ello sus aportes, voces, son singulares y otorgan indicios acerca de los modos de transitar, vivir y significar la escolaridad.

En esta investigación se parte de la idea de que los niños-niñas "merecen ser estudiados por sí mismos y desde sus propias perspectivas, son actores y agentes sociales en la construcción de sus propias vidas" (James y Prout, 1990: 8-9). Considerarlos como sujetos activos en la investigación, es concebir que son constructores de su vida, es darles lugar, es reconocer en su experiencia una serie de significados compartidos que transcienden en la subjetividad y objetividad frente a la configuración de las infancias; es comprender la forma 
en que ellos elaboran y construyen sus ideas, nociones, sus propios conocimientos y opiniones respecto a su realidad o en este caso al fenómeno de las trayectorias y transiciones.

Estudiar a los niños/as como agentes sociales es comprenderlos como participantes activos de la sociedad, como coinvestigadores lo que supone, de acuerdo a Argos, Castro y Ezquerra (2009) entender y asumir la exigencia ética del reconocimiento del otro, prestar atención a la palabra de los niños/as, ayudarles en orden a fundamentar esa palabra y a liberarles de las imposiciones restrictivas de su significado. Clark y Moss (2001) establecen que los adultos/as tenemos una limitada comprensión de la vida y experiencia que afecta a los niños-as, por ello tal como lo plantea Punch (2002) el adulto debe acercarse con métodos y técnicas que favorezca la interacción para no reforzar la visión jerárquica entre adulto y niño, y que puede llevar al investigador a imponer sus percepciones, invalidando las intervenciones de los pequeños (p.321).

Gallacher y Gallagher (2008) señalan que la participación de los niños en la investigación educativa se convierte en un objetivo a lograr, a la vez que en un método a seguir. En este sentido, el método elegido para el trabajo con ellos se fundamentó desde lo propuesto por Alison Clark y Peter Moss (2001) en el método mosaico que combina técnicas visuales, orales y escritas que facilitan un mayor acercamiento a la perspectiva infantil. Es un multimétodo adaptable a diferentes ambientes y situaciones que posibilita la recuperación de las experiencias de los niños-as, respetando la voz como los silencios, a través de actividades prácticas y dinámicas, en un esfuerzo interpretativo por parte de los adultos/as. Se centra en las experiencias vividas por el niño que se convierte en el principal ejecutor del método y en el protagonista durante el proceso investigador.

En los 14 encuentros con los niños y niñas hemos privilegiado una comunicación bidireccional e igualitaria en la construcción conjunta de experiencias en las que se articularon formas creativas de expresar la vida y las experiencias biográficas; utilizamos técnicas participativas como el dibujo, la fotografía, los videos, los juegos de roles, las visitas guiadas, las líneas de tiempo, las entrevistas grupales, los diálogos individuales, los cuentos pictográficos, esenciales para recoger y comprender los múltiples lenguajes que los niños y niñas ponen en juego en cada actividad que realizan. 
En este ejercicio se reconocieron las individualidades, se respetaron los ritmos, se valoraron los conocimientos, las opiniones y sus puntos de vista sobre la escuela, el juego, la familia, y la comunidad; se construyeron acciones y visiones conjuntas frente al proceso de trayectoria y transición educativa. En el intercambio, sin duda, se le dio sentido a la Observación No 12 /2009 de comité de los Derechos del Niño de Naciones, porque todo el tiempo los niños y niñas fueron escuchados.

Para sistematizar la información generada a partir de las técnicas utilizadas se hizo uso del Atlas Ti porque permitió organizar la transcripción de los 14 encuentros, las fotografías y los dibujos en "documentos primarios" para luego proceder a la codificación abierta. En cada documento primario se realizó una codificación de segmentos significativos (citas), es decir, se señalaron los testimonios que contienen el fenómeno que se estudia y se les asignó códigos y memorandos que posteriormente representaron la emergencia de categorías y subcategorías.

A continuación, se procedió a la codificación axial, esto es, el proceso de identificación de relaciones entre las categorías obtenidas en la codificación abierta y sus subcategorías representado en esquemas explicativos, no jerárquicos, en función de las relaciones entre familias de códigos y anotaciones. Finalmente se realizó la codificación selectiva mediante la organización de familias que integran códigos y categorías conceptuales del fenómeno estudiado en la codificación abierta y axial y las cuales se relacionan a continuación.

Una vez estructurada la información se procede a la construcción de este apartado el cual se construye con material referido a las familias y el contexto; la dimensión de análisis es el ámbito personal en tanto recupera las impresiones, saberes y emociones de los niños-as, frente a su paso por la Educación Infantil.

En este capítulo se busca contextualizar la forma como son nombrados los niños y niñas dentro del contexto escolar conjugando sus voces con la de las maestras y agentes educativos, así como poner en discusión los factores sociales, familiares e individuales que interceden en las historias de vida de los niñas y niños y las concepciones que dibujan una imagen del cuerpo y suscriben una serie de características y atributos que delinean formas de clasificar y estructurar las infancias. En este recorrido veremos la forma como los niños y niñas construyen su trayectoria frente a ciertos hitos y momentos de cambio importantes para su vida; así entre chupar teta, gatear, caminar, jugar y hacer tareas; ellos narran sus experiencias describiendo 
sus pasajes por las instituciones: "programa Buen Comienzo" y la "Institución educativa Ciudadela Nuevo Occidente" en los cuales se dan unas formas de participación, pero también de debate respecto al papel de la Educación Infantil.

\subsection{Quienes somos y como nos configuramos en el paso por la escolarización}

Nuestro contexto-del campo a la urbanización

Narrar donde viven los sujetos de esta investigación es contar una historia de un barrio que desde el año 2002 proyectaba la construcción de uno de los megaproyectos de vivienda de interés social más grandes del país; la construcción de 23.000 unidades de vivienda con una tipología arquitectónica de torres-edificios, en su mayoría de 9 pisos y con área de 46 metros cuadrados. Pero su historia no inicia ahí, de acuerdo a lo escrito por Ceballos (2016), en este territorio a finales del siglo XX sólo 2 mil personas vivían en la vereda Pajarito del corregimiento de San Cristóbal- rodeados de montañas, con una temperatura fría y variedad de árboles, fauna y flora, los campesinos pobres cultivaban hortalizas en sus parcelas y trabajaban como jornaleros en las fincas vecinas de las familias pudientes.

En el año 2002 empiezan a circular rumores sobre un mega proyecto que traería desarrollo a la comunidad. En pocos años los habitantes de la vereda Pajarito y el corregimiento San Cristóbal se sorprendieron con la acelerada mutación del paisaje natural y de sus costumbres. Así, de habitar fincas y vivir en el campo pasaron a vivir en edificios y urbanizaciones en un territorio denominado Barrio Ciudadela Nuevo Occidente. En la actualidad el territorio está constituido aproximadamente por 100.00 personas que habitan 16.000 apartamentos- cuyos nombres rememoran las antiguas fincas de la vereda Pajarito como Las Flores, la Huerta, La Montaña y El Tirol; las quebradas El Chagualón, La Cascada, y Villa suramericana. La población está clasificada en estratos socioeconómicos ${ }^{35}$ según el

\footnotetext{
${ }^{35}$ El DANE realiza la estratificación socioeconómica que se ha utilizado en Colombia como herramienta de focalización del gasto, ésta clasifica los inmuebles residenciales con el fin de definir un sistema tarifario, por estratos, para el cobro de servicios públicos domiciliarios, con subsidios (estratos bajos) y contribuciones (estratos altos). Los estratos 1, 2 y 3 corresponden a sectores de bajos recursos que albergan a los usuarios con menores recursos, los cuales son beneficiarios de subsidios en los servicios públicos domiciliarios; los estratos 5 y 6 corresponden a estratos altos que albergan a los usuarios con mayores recursos económicos, los cuales deben pagar sobrecostos (contribución) sobre el valor de los servicios públicos domiciliarios.
} 
Departamento Administrativo Nacional de Estadística (DANE) a partir de una caracterización de los hogares y los servicios a los que acceden las familias.

Los niños y niñas de esta investigación habitan los apartamentos de La Montaña, El Tirol, El Chagualon, Las Flores (estratos 1 y 2) y Villa Suramericana (estrato 3) ${ }^{36}$. Todos están matriculados en la Institución Educativa Nuevo Occidente ${ }^{37}$, y asistieron al Jardín Infantil la Aurora-Programa Buen Comienzo. Ambas instituciones son reconocidas en el campo de la educación porque trabajan de forma articulada.

\section{Ilustración 8 Nuestro territorio}

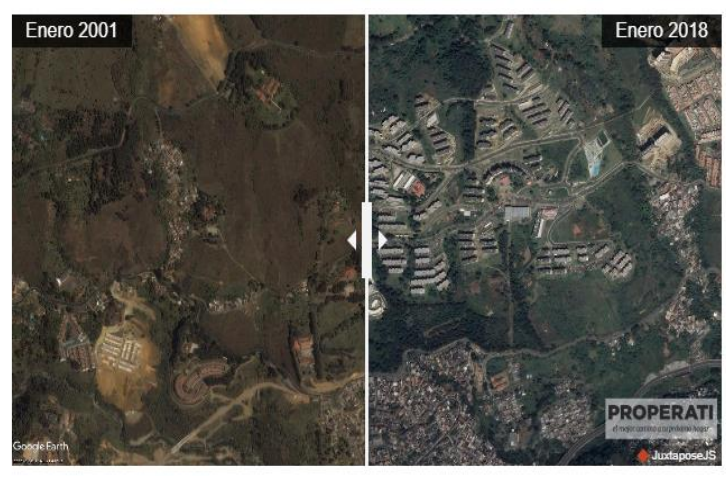

Fuente: Imágenes tomadas de Properati (noviembre 27, 2018)

\footnotetext{
${ }^{36}$ A diferencia de los apartamentos de La Montaña - El Tirol - El Chagualon y Las Flores que son estratos 1 y 2 en donde reubicaron familias desplazadas por la violencia y del sector de Moravia antiguo basurero de la ciudad, por los deslizamientos etc; las familias que habitan villa suramericana sustentan unas condiciones económicas más favorables- estrato 3-las viviendas fueron comprados por los propietarios con el beneficio de subsidio que les da el gobierno

${ }^{37}$ La Institución Educativa Ciudadela Nuevo Occidente se levantó en la que fue anteriormente la finca La Montaña. Creada para dar solución a la demanda educativa de las familias que llegaron a las diferentes urbanizaciones. En la actualidad los estudiantes que asisten a la Institución son, en su mayoría, habitantes de las urbanizaciones La Aurora, Las Flores, Cantares, Renaceres, La Montaña, Villa Suramericana, El Tirol, El Chagualón y Nazaret.
} 


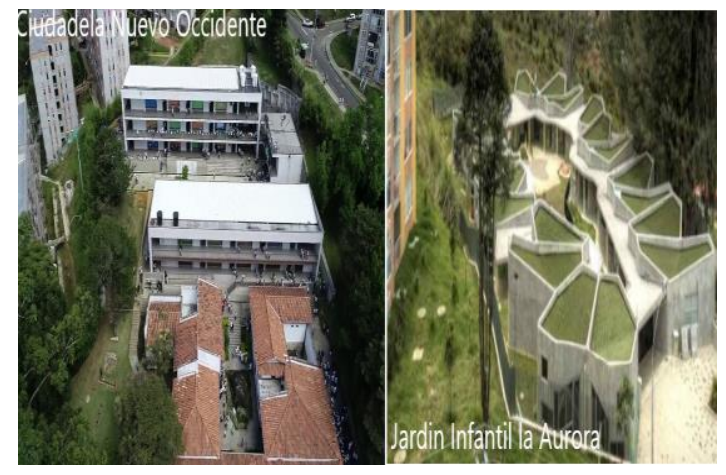

Fuente: Imágenes tomadas de Properati (noviembre 27, 2018)

Este megaproyecto de acuerdo a las voces de las maestras y agentes educativas se caracterizó como un sector de viviendas de interés social y de interés prioritario ${ }^{38}$ compuesto $^{2}$ por grupos poblacionales de estratos socioeconómicos bajos que fueron reubicados de barrios muy vulnerables de la ciudad como Moravia (antiguo basurero de la ciudad de Medellín), la Iguana (caracterizado geográficamente por desastres naturales, incendios), Santo Domingo y Popular (asentamientos de desplazados, barrios con problemáticas de tráfico de drogas, violencia y pobreza extrema), así como también desplazados provenientes de otras zonas del departamento que vivían en extrema pobreza.

El contexto (barrio) que habitan los niños y niñas tiene un alto porcentaje de población desplazada no solo por la violencia y el conflicto armado sino por los incendios y desastres naturales que han afectado a las familias y las han puesto en riesgo y vulneración; este desplazamiento para algunas familias ha significado una pérdida cultural pues se han desarraigado de sus lugares de origen dejando costumbres, estilos de vida y seres queridos. Según las maestras:

/... / llegar a este barrio ciudadela nuevo occidente les ha implicado a las familias dos procesos uno de resiliencia y otro de adaptación frente a nuevas problemáticas ejemplo el microtráfico,

\footnotetext{
${ }^{38}$ Vivienda de Interés Social (VIS). Es aquella que reúne los elementos que aseguran su habitabilidad, estándares de calidad en diseño urbanístico, arquitectónico y de construcción. Es un tipo de vivienda hecha para aquellas personas que devengan menos de cuatro (4) salarios mínimos mensuales legales vigentes o que están en situación vulnerable. Cada persona puede contar con un subsidio de vivienda otorgado por las cajas de compensación familiar y el Gobierno Nacional, es un proyecto que se encamina a garantizar el derecho a la vivienda de los hogares de menores ingresos, amparado por el concepto de lo que representa una vivienda digna.
} 
la intolerancia, la violencia, el consumo de sustancias psicoactivas; por ello una de las dificultades que más han tenido las familias es aprender a convivir en comunidad y aprender a compartir espacios colectivos en los edificios (Docente de Transición, 11/10/2017).

La situación económica es la que más afecta a este grupo de familias de los niños y niñas de esta investigación. Un porcentaje medio de la población se caracteriza por presentar pobreza extrema al ser desplazados por el conflicto armado y la violencia intraurbana dado que han perdido su sustento económico pues dependían de sus tierras, tiendas en las que trabajaban en los barrios que habitaban y otras formas de empleo. Según las maestras y agentes educativas entrevistadas la forma que tienen estas familias para cubrir las necesidades básicas es a través de empleos informales como las ventas ambulantes, el reciclaje, el comercio de traperas, escobas, el aseo en casas de familia y oficios varios. Otras familias reciben subsidios que otorga el gobierno y un último grupo, especialmente las personas que viven en el edificio villa suramericana son profesionales y técnicos que trabajan en empresas y presentan mejores condiciones de vida. De esta forma las familias se caracterizan por la preeminencia de una condición social de la población: ser desplazado, ser pobre y desempleado, víctima de conflicto armado, etc.

Para las agentes educativas y maestras los sectores de los que provienen los niños y niñas son marginados, violentos, peligrosos; en sus narraciones señalan que la vida de muchos de ellos/as está atravesada por la pobreza y la exclusión, en tanto sus familias no cuentan con ingresos económicos estables, la mayoría son desempleados y viven del reciclaje, hay muchas madres cabezas de familia que se rebuscan el día a día en casa haciendo aseo; otras familias que viven del trabajo informal; los niños y niñas presencian situaciones de violencia y tráfico de drogas; así la vulnerabilidad la definen por la falta de trabajo estable, por la precarización laboral, por las condiciones socioeducativas y psicológicas y por la ausencia de un tejido social que represente un sostén, confirmando lo expuesto por Redondo cuando especifica que "a los territorios de pobreza se les estigmatiza como territorios de peligros, de caos, de desorganización familiar y social-generando con esta argumentación nuevas formas implícitas de exclusión" (Redondo, 2004: 58-68).

Sin embargo, para los niños y niñas a diferencia de sus agentes educativas y maestras esta condición de pobreza y forma de vida en el barrio Nuevo Occidente no constituye un factor 
de discriminación ni exclusión. Si bien la caracterización del barrio que hacen las y los organos de gobierno (DANE) responde al tipo de vivienda que habitan, para las/los niñas/niños su barrio ofrece espacios de encuentro y convivencia, y que aún en esas condiciones económicas y sociales logran vivir de alguna forma ese período que llamamos infancia.

Vemos que el barrio es un espacio de proyección porque "se abre como un espacio cultural con marcas propias que los/as alumnos/as reconocen al caminar sorteando los obstáculos para llegar a destino, a buen puerto" (Redondo, 2016: 145). Es un espacio de interpelación pues cuentan con espacios lúdico-recreativos como son los parques recreativos al aire libre, las ludotekas, la uva (Unidades de vida articulada) que se caracterizan como zonas dinamizadoras de cultura, recreación y esparcimiento en lo que tienen extensas zonas verdes, piscinas, canchas, zona de juegos, programas culturales y recreativos para su esparcimiento y diversión, es decir espacios protectores para su desarrollo y crecimiento.

\section{Quienes son nuestras familias}

En cuento al contexto familiar los niños y niñas, desde sus discursos y dibujos, estructuran una tipificación de las familias caracterizándolas de la siguiente forma: un 22\% pertenecen a familias nucleares, es decir, sus hogares están conformados por la madre, el padre y los hermanos; un $22 \%$ forma parte de familias extensas conformado en su mayoría por la madre, el padre y otros integrantes de la familia como los tíos-as, abuelos, primos, sobrinos; un $28 \%$ son familias ensambladas, sus hogares están conformados por varias familias nucleares, es decir, familias separadas que conviven madre/padre con pareja más hijos de ambos; un $17 \%$ son familias monoparentales en especial la madre quien suele hacerse cargo de la crianza y un $6 \%$ son familias conformadas por abuelas que se hicieron cargo de la crianza de sus nietos y familias adoptivas que no tienen consanguineidad. 


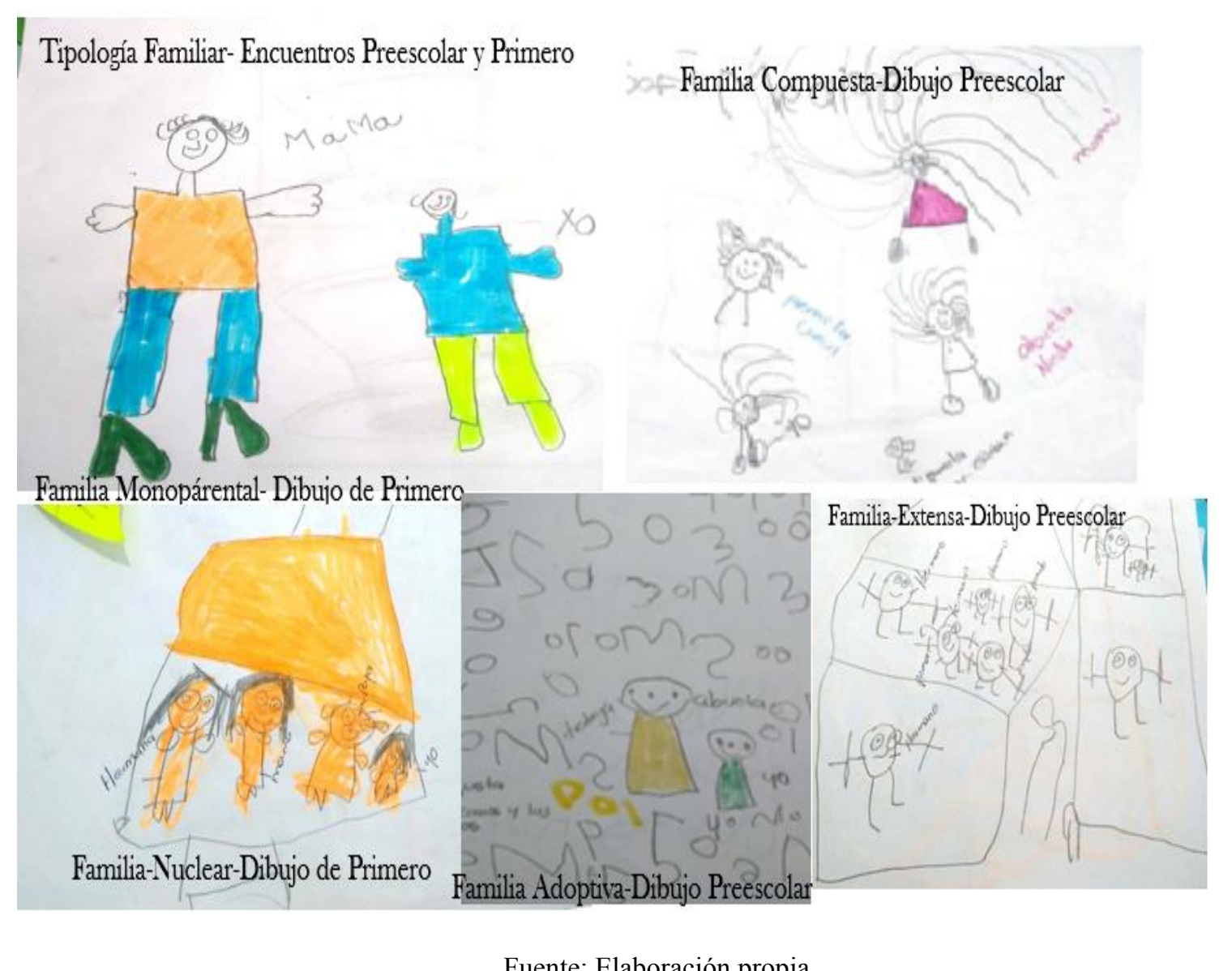

Fuente: Elaboración propia

Las maestras y agentes educativas utilizan criterios diferentes para caracterizar a las familias. Afirman que por las situaciones culturales y económicas las familias evidencian en los espacios escolares limitaciones respecto del acompañamientos de sus hijas/hijos. En este sentido, encuentran familias comprometidas con los procesos escolares de los niños-as, siempre atentas y dispuestas a mediar en diversas situaciones complejas que pudieran tener lugar en la escuela. No obstante, referencian que otras familias se caracterizan por estar ausentes en los procesos escolares debido a su situación económica y laboral (trabajan todo el día en pro del sustento económico), lo que implica dejar el cuidado de sus hijos en manos de otras personas. Asimismo identifican a otro grupo de familias compuestas por aquellas personas desplazadas y desempleadas que apenas logran adaptarse al contexto ciudad, al dispositivo escuela o jardín infantil, a vivir en un nuevo hogar cuyo espacio es pequeño, limitado lo que les implica la comprensión y adaptación a ciertas reglas y normas. 
Un asunto que reiteran las maestras y agentes educativas repetidamente y que influye además en los procesos de aprendizaje de los niños y niñas es el capital cultural asociado a la pobreza y al nivel de formación y educación de las familias. Bourdieu (1998) relaciona el capital cultural con aquellas representaciones, habilidades, actitudes, aptitudes que posee una persona y que, de algún modo, caracterizan su posición en la sociedad. Las maestras comentan que algunas familias presentan índices de analfabetismo alto, poseen un capital cultural que las ubica en posiciones inferiores comparado con las demás familias y esto es notorio en el acompañamiento que hacen a los niños y niñas especialmente en las tareas. Estas variables de pobreza, analfabetismo, desplazamiento, según las entrevistadas interfieren en la trayectoria escolar de los pequeños y se traducen en el aula en reiteradas inasistencias, problemas de conductas, situaciones emocionales, deserción que afectan la convivencia en el jardín infantil $y$ en la escuela.

Es necesario señalar que la desigualdad a la que refieren las maestras está presente en el sistema educativo pero también remite a un discurso hegemónico en las instituciones educativas sobre la pobreza, la marginalidad y la vulnerabilidad del alumnado que se ha convertido en eje estigmatizador para clasificar las familias y estigmatizar las infancias. Divisiones que naturalizan la desigualdad económica, cultural, social y justifican la aparición de problemáticas escolares sin que las instituciones y sus agentes se hagan cargo. Como establece de Sousa Santos (2014), un pensamiento abismal y posabismal que muestra dos universos, el universo de "este lado de la línea" (narraciones de las -agentes educativas) y el universo del "otro lado de la línea" (narraciones de los niños y niñas).

Percibimos que para las maestras y agentes educativos lo visible es que se trata de niños y niñas con necesidad de afecto, con falta de acompañamiento, niños y niñas en condición de vulnerabilidad por su situación cultural, social, económica y cognitiva, mientras que al otro lado de la línea para los niños y niñas no hay una estigmatización, hay opiniones, comprensiones, creencias frente a la realidad que viven y experimentan; más allá de la condición de vulnerabilidad las/los niñas/niños habitan un contexto cultural con condiciones e instituciones educativas que los acogen, los protege y les genera, las posibilidades de una vida digna, comparten con familias que independientemente de su estructura y situación los protege, de este modo "el otro lado de la línea comprende una vasta cantidad de experiencias 
desechadas, hechas invisibles tanto en las agencias como en los agentes" (de Sousa Santos, 2014: 34).

\subsection{Ser niño y niña en la Educación Infantil}

Ser niño-niña amerita un análisis con respecto a las posiciones y el lugar que se ocupa en el espacio familia, escuela y comunidad. Mayal (2002) advierte que los niños/as no son el simple "efecto" de prácticas de socialización y crianza, sino por el contrario, pueden ser considerados agentes sociales y la infancia no debe pensarse sólo en relación con ellos/ellas, sino que se produce en relación con las/los adultos/as/as. Ser niño/a entonces constituye una etapa de la vida que ha sido abordada desde múltiples disciplinas ${ }^{39}$ y enfoques. Sandra Carli (2005) plantea que la niñez es una categoría histórica, construida socialmente y por ello transformable y transformadora. Autores como James \& Prout (1990), Connolly (1998), Corsaro (2005), MacNaughton (2005) sostienen que los niños/as son agentes sociales que están también afectados por fuerzas políticas, económicas, sociales y culturales.

Para James y James $(2004,2008)$ los niños/as son sujetos y actores concretos, temporal y espacialmente localizados, que habitan, reproducen y transforman la infancia. En palabras de Schepper-Hughes y Sargent (1998) los niños/as han estado bajo una opresión de negación de permanente invisibilización y desconocimiento pues se han caracterizado bajo un prejuicio de inferioridad similar al que se tuvo antes con las mujeres y con los pueblos originarios. Por su parte, Gaitán (2006) señala que los niños/as han sido estudiados en una dimensión más instrumental, es decir, desde otros focos y por medio de otros informantes: padres y madres, docentes, pediatras y/o psicólogos. Según Diker (2009) al niño/a se le ha caracterizado como

\footnotetext{
39 En el relato histórico la connotación de niño-niña no siempre tuvo la significancia que se le asigna hoy, por ejemplo, el niño ha pasado de ser denominado como indefenso, dependiente y al mismo tiempo como estorbo (Jaramillo, 2007). El historiador francés Jean-Louis Flandrin refiere que el estudio de la infancia es una construcción de la modernidad en tanto "se convirtió en un objeto emblemático del siglo XX fijado por los saberes de distintas disciplinas, capturado por dispositivos institucionales, ¿proyectado hacia el futuro por las políticas de estado y transformado en metáfora de utopías sociales y pedagógicas” (Carli, 1999: 1). Por su parte Kohan (2004) sostiene que la infancia en la actualidad es concebida como condición de lo humano y su historicidad tiene una serie de consecuencias importantes. En primer lugar, ella ya no es concebida como debilidad, falta de desarrollo e incapacidad. Como hemos escrito ella es del orden de la irrupción, potencia y posibilidad. De una experiencia de la humanidad y la historia ya no como proceso lineal y cronológico, sino como devenir constante.
} 
un ser dependiente (del cuidado, la protección y la orientación de los adultos/as/as) e inocente, y la infancia como un tiempo de espera, de preparación para la vida adulta (p.20).

Todas estas concepciones dibujan una imagen del cuerpo, de la niñez, y suscriben una serie de características y atributos que delinean formas de clasificar y estructurar las infancias en la Educación. Como lo establece Gaitán (2006), los adultos/as atribuyen una serie de características a niños y niñas que habitualmente están connotados por aspectos e ideas proteccionistas, paternalistas y asistencialistas, venidos y heredados de un paradigma etnocéntrico y adultocéntrico (p.64). Así, en esta investigación, observamos que los niños y niñas son caracterizados por las maestras y agentes educativos de acuerdo a unos atributos que los posicionan en relación a sus situaciones socioculturales, socioafectivas y económicas, pero estas distan de la forma como configuran su propia infancia los niños y niñas.

\section{Voces de las maestras}

Para las maestras y agentes educativas, ante todo, los niños/as son la razón de ser, son el centro de todo lo que hacen y piensan desde los procesos pedagógicos, son el pilar y prioridad de las instituciones y por ello todo el tiempo se piensa en ellos/as, en que sean reconocidos, respetados, acompañados, en garantizar sus derechos; los niños/as son la alegría, el bullicio, la espontaneidad. Para las maestras satisfacer sus necesidades con amor, afecto y con una mirada integral constituye el eje para guiarlos; ellos/as requieren de protección, cuidados pues son los protagonistas del ejercicio docente. Al mismo tiempo comentan que son niños/as con muchas necesidades y carencias afectuosas, con temores, son infancias vulneradas tal como lo muestra el siguiente gráfico: 
Ilustración 11 características de los niños y niñas según las y agentes educativas

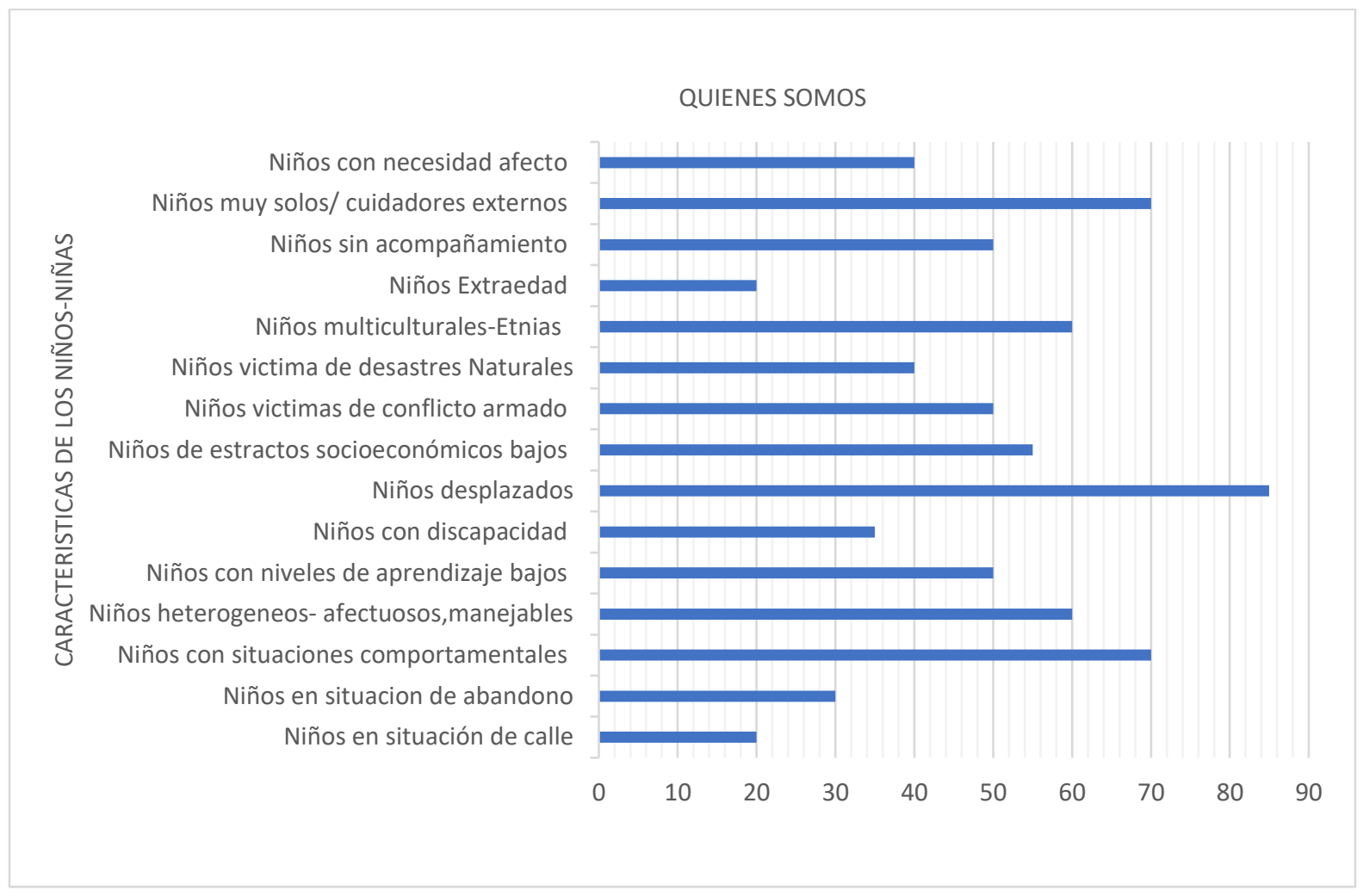

Fuente: Elaboración propia

En esta nominación los niños y niñas son caracterizados por sus diferencias culturales, sociales, económicas, de género, de edad, son reconocidos dentro de una infancia que se intersecciona por múltiples condiciones o factores; niños y niñas que atraviesan una situación de desplazamiento, de conflicto armado, o un alerta en su desarrollo, niños sin acompañamiento por parte de las familias, niños que son afectuosos siempre con una sonrisa o un abrazo indiferente de la situación social, cultural, psicológica que viven, niños y niñas que manifiestan en los espacios escolares conductas disruptivas producto de las violencias que viven, es decir, niños y niñas con historias de vida propias que evidencian dentro del contexto escolar la naturalidad de su infancia pero que a la vez son vulnerables. De esta forma recuperamos en la voz de las maestras una caracterización de las infancias "pobres y/o excluidas instaladas en la fragilidad social, en la vulnerabilidad como frontera o pasaje hacia la exclusión”, donde los niños y niñas son "sujetos sujetados a la privación” pero pueden ser también "sujetos deseantes de otros futuros" (Redondo, 2004: 127). 
Uno de los instrumentos más utilizados por las maestras y agentes educativas para describir estas características es el libro observador ${ }^{40}$, nominado así en la Educación formal y seguimiento al desarrollo en el sistema de Educación Inicial, un instrumento que le permite al docente escribir sobre las observaciones relativas a los desarrollos de los niños y niñas, sus capacidades, además observaciones referentes a los comportamientos que presentan en el ámbito escolar; se convierte en la hoja de vida de los estudiantes. En este dispositivo las maestras describen cada uno de los comportamientos de los niños/as; resume su historia de vida escolar. Dentro de este dispositivo la heterogeneidad representa la característica principal de sus aulas y así lo narra una de las maestras de transición.

Los niños y niñas son heterogéneos cada uno representa un mundo distinto; esta heterogeneidad se representa en las características individuales de los sujetos, en sus comportamientos y formas de relacionamiento, en sus formas de expresión e implicación en los procesos de enseñanza aprendizaje, niños y niñas que en sus procesos de aprendizaje demandan acompañamientos diferenciales ajustes distintos y ello en relación a sus capacidades, niveles cognitivos y de acompañamiento familiar (Docente de Transición, 10/10/2017).

Esta heterogeneidad representa además la forma de medir y clasificar al grupo de niños y niñas por parte de las maestras. En los libros observadores tanto de transición como primero se puede ver una clasificación de los comportamientos y rendimiento escolar por colores: verde son los niños y niñas que no presentan dificultades académicas ni comportamentales; amarillo aquellos que presentan algunas dificultades y rojo son los niños que tienen algunas situaciones complejas de comportamiento y disciplina. Se resaltan en los libros observadores historias de vida en las que por un lado prevalece la descripción detallada de cualidades, valores y las felicitaciones para aquellos niños y niñas que cumplen y responden a todas las exigencias de la escuela y, por otro lado, sobresalen los llamados de atención, de citación a las familias por conductas inadecuadas, por situaciones comportamentales o de aprendizaje. Algunas de las

\footnotetext{
${ }^{40}$ El libro observador es un instrumento cuya finalidad es el registro de información significativa en torno a los niños y niñas en las distintas situaciones que se dan en el ámbito escolar: los recreos, el aula, el comedor. Con este se pretende que el docente realice un acompañamiento en el proceso de convivencia estudiantil y se evidencia la historia escolar del estudiante en su cotidianidad, en el día a día de sus vivencias y en las relaciones con los diferentes miembros de la comunidad educativa (Nivela, 1997).
} 
anotaciones más recurrentes para la mitad de los niños y niñas que participaron de esta investigación son:

1. Falta acatamiento de la norma y el seguimiento de instrucciones

2. Presentan dificultades para tener una actitud de amabilidad respeto y tolerancia

3. Su comportamiento no es el apropiado en actividades académicas, culturales cívicas

4. No trata de solucionar conflictos a través del dialogo y la concertación

5. No avanza en sus niveles de desempeño-aprendizajes

Se evidencia para este grupo de niños y niñas que las anotaciones son negativas en su mayoria, lo que devela la mirada que la escuela tiene con respecto a la disciplina, la cultura y convivencia escolar; la preocupación por controlar los cuerpos en el aula de clase, por controlar las formas de actuar, por enseñar unas normas y comportamientos adecuados, por generar conciencia a partir de la reflexión y el diálogo frente a los actos y acciones impuestas, hace que se reproduzcan prácticas autoritarias que los niños y niñas desafían, pues en el nivel de educación inicial las sanciones son distintas, por ello se hace necesario repensar este dispositivo en la forma como se observan los desarrollos de los niños y niñas.

Se puede analizar que dentro de estas citaciones los acudientes papá-mamá pocas veces concurren a la escuela y asignan la responsabilidad a tías, abuelas, hermanas mayores, u otro actor diferente a la familia. Las maestras proponen un conjunto de estrategias para mediar el proceso académico, no obstante, en muchas de sus observaciones indican la falta de compromiso y desarrollo de las mismas por parte de las familias, así como también las múltiples dificultades que estas tienen que enfrentar para acompañar los procesos de sus hijos/as.

En este orden las situaciones sociales y culturales que viven las familias interceden en la falta de acompañamiento; en este contexto de pobreza, de acuerdo a las docentes, un 50\% de la población infantil que asiste a la escuela regular tiene que crecer solos o en manos de cuidadores distintos a la familia, son niños y niñas que deben aprender a responsabilizarse de su crianza, de sus compromisos escolares, son infancias que deben aprender a resolver conflictos, mediar situaciones y responder a las exigencias de su entorno escolar. 
Veo niños muy solos, entonces que el papá los abandono y quedaron solos con la mamá; la mamá permanece todo el día en el trabajo, entonces estos niños están en manos de cuidadores que muchas veces no es la misma familia si no el vecino o el otro amigo de este, veo que los papás están en función de sus trabajos para conseguir el sustento, y abandonan mucho estos niños, entonces realmente el 50\% son niños muy solos (Docente de Primero, 25/10/2017).

Todas las agentes educativas, maestras y coordinadoras reiteran constantemente la necesidad de acompañar con afecto, cariño, brindarles buen trato, buenos hábitos; sus metas se concentran en enseñar y brindar lo necesario a los niños-niñas y a las familias para que puedan aprender a defenderse en la vida; su objetivo es darles herramientas y oportunidades para que puedan salir de su condición de vulnerabilidad. Hay que decir que el trabajo en este contexto escolar en algunas ocasiones se vertebra alrededor de la función de "reemplazar" y de generar vínculos afectivos; se asumen por momentos funciones propias de la crianza y esto debido a las usencias observadas en sus contextos. Poner la mirada en la ternura, la disciplina, provoca el vínculo construido entre niño/a y docente y representan un capital pedagógico que le permite sostener una relación activa y crítica con su propia práctica pedagógica según las maestras. Sin duda, tal como lo refiere Redondo (2004), trabajar en escuelas populares conlleva casi sin excepción la consideración de una diversidad enorme de situaciones entre el desasosiego y la obstinación.

Llama la atención que para los niños y niñas la falta de acompañamiento de las/los adultas/adultos del hogar constituya también un reclamo de atención y mencionan así sus ausencias a la vez que las justifican. A continuación, transcribimos parte de los diálogos entre los niños-niñas (Encuentro 1, 19/09/2017).

- Mis papás no tienen casi tiempo para estar con uno, ellos tienen que trabajar (Niña 5 años de edadgrado transición).

- Mi mamá llega por la noche como a las 10, yo ya estoy dormido, aunque a veces espero que llegue, pero ya está cansada para jugar, por eso mire profe yo vivo en la torre (2) cuando llego a la casa mi madrina me cuida y me da la comida, yo almuerzo, juego y hago tareas solo (Niño de 7 años de edad-grado primero).

- Es que los adultos/as/as no tienen tiempo siempre mantienen trabajando por eso son aburridos (Niño de 5 años- grado transición). 
- Para mí no son aburridos los adultos/as/as, porque mi mamá no trabaja (Niña de 6 años de edadgrado primero).

- Toda mi familia trabaja y me dejan en mi casa solo y yo tengo que hacer las tareas solo, todas mis cosas solo, un primo hay veces me ayuda con las tareas (Niño 7 años de edad-grado primero).

- Los papás si pueden, es que los que tienen plata pueden jugar y comprar cosas para sus hijos (Niño de 7 años-grado primero).

- No porque no tienen tiempo, toda mi familia trabaja y me dejan en mi casa solo, y yo tengo que hacer las tareas solo, todas mis cosas solo, un primo hay veces me ayuda con las tareas (Niño de 7 años-grado primero).

A diferencia de las maestras quienes nominan con mayor frecuencia las ausencias de las familias en la escuela como abandono producto de falencias económicas que obligan a las madres y a los padres a trabajar jornadas completas, otros niños y niñas ponen en valor esa ausencia como la oportunidad para obtener responsabilidad, autonomía y crecimiento.

Es que nosotros tenemos que aprender a ser responsables, porque ya vamos creciendo hasta que ya estamos más grandes, ya somos hombres serios autónomos para asumir las consecuencias de lo que hacemos en la escuela, mi mamá refiere que debo aprender a resolver mis conflictos (...) sí profe porque ellos (madres-padres) no pueden estar para ayudarnos porque tienen que trabajar". (N15-niño 7 años grado primero y N14-niño de 7 años grado primero), cuando ya somos más grandes tenemos más responsabilidades como hacer las tareas, aprender a leer solas eso dice mamá (N9-Niña 7 años).

Observamos que los niños y niñas que hacen parte de esta investigación representan las distintas infancias, son sujetos que se configuran con él otro, son seres sociales en donde la condición de desplazamiento, de alerta en el desarrollo, de conflicto armado, de extra edad, de pobreza, solo muestra la intersección entre las múltiples situaciones culturales, cognitivas, de género, de edad, socioeconómicas y sociopolíticas que interpelan su vida y evidencia las múltiples identidades y pluralidades que presentan sus infancias y que en el recorrido que cada uno/a emprende en su vida escolar, evidencia una posición marcada por trayectorias heterogéneas. 
Desde esta perspectiva vemos que las aulas de las maestras se componen de niños y niñas con unas identidades únicas que se construyen de múltiples maneras. En palabras de Nicastro y Greco (2009) hablar de identidad en relación a las trayectorias educativas es hablar de la narración de una vida en singular y en un sentido común con otros a la vez. Identificamos en nuestro trabajo de campo que la identidad, para los niños y niñas en tanto vida narrada, inacabada, siempre está siendo, se va dando en el marco de situaciones, en relaciones con otros, con sus familias, maestras, pares, como efecto de miradas, expectativas y proyectos, por eso la identidad crea un conjunto de pensamientos que ellos/as narran frente a lo que son, lo que quieren ser, y como se proyectan en los escenarios escolares.

Esta noción de identidad está estrechamente relacionada con la categoría de interseccionalidad ya que los sujetos (niños/as) construyen su identidad en base a múltiples variables que derivan de las relaciones sociales que viven (Asociación para los Derechos de la Mujer y el Desarrollo-AWID, 2004:2). Hablar de identidad nos conduce a la noción de diferencia de Arendt (2001 apud Stormezan, 2016) para quien la singularidad será la diferencia constitutiva de cada individuo ya que no todas las identidades son iguales y esto lo vemos en las voces de los niños y niñas. Es por ello que se vuelve necesaria la narración de las historias de cada uno "porque es precisamente el discurso lo que hace del hombre un ser único" (Arendt, 2001:16). Así en medio de estas identidades e interseccionalidades que presentan los niños y las niñas las maestras y agentes educativas buscan formas para mediar y acompañar los procesos educativos y configurara en ellos la construcción de una infancia feliz y tranquila.

\section{Voces de los niños y niñas}

Para los niños y las niñas reconocerse a diferencia de sus maestras, agentes educativas es nombrarse dentro de un contexto en el que identifican sus desarrollos, cualidades, valores, su identidad; es nombrar que forman parte de un grupo social que condiciona y con el cual asumen responsabilidades, es identificarse con el juego con una etapa de crecimiento de la que nunca quisieran salir. Tal como lo narran a continuación:

- Para N15 ser niño significa ser parte de una familia (Niño-7 años).

- Para N14 ser niño es una cualidad y una diferencia, una cualidad porque uno niño tiene que ser buen estudiante gracioso o inteligente para que no lo regañen, y una diferencia porque una 
mujer tiene muchas cosas que el hombre no tiene, también la mujer tiene cosas diferentes (Niño- 7 años).

- $\quad$ Para N16 ser niño significa estar creciendo y madurando (Niño-7 años).

- Para N5 ser niño es ser escandaloso, divertido, es ser feliz, es jugar con los amigos (Niño5 años).

- Para N3 ser niña es muy divertido porque es una etapa de juego, deportes, por eso yo no quiero ser adulta (Niña-5 años).

- $\quad$ Para N8 ser niña es jugar es crecer con el otro, discutir, pelear, portarse bien y mal (Niña-5 años).

- Para N9 ser niña es respetar a los amigos no pegarles, es aprender hacer las tareas. (Niña-6 años).

Observamos que esta configuración discursiva evidencia, por un lado, que cambia la visión de sí en tanto niñas y niños a medida que crecen -en sus palabras supone pasar de "ser escandaloso a madurar"- y, por otro, el niño-niña se concibe en la relación con el otro/a, se identifica como un ser representado en un cuerpo de múltiples subjetividades; Carli, (2002) advierte que la infancia se relacionaría con dos modalidades: (1) el niño/a como cuerpo en crecimiento y (2) el niño/a como construcción de sujeto en la sociedad; ese cuerpo en crecimiento y en construcción está sometido a todos los elementos de los sistemas que operan en él: sus progenitores, el Estado, la iglesia, la escuela, y principalmente la familia. Para de la Rosa Reyes (2011) el niño, como cuerpo social, recibe y adquiere características asignadas por parte del mundo adulto. Adquiere una realidad y un saber cristalizado. Los niños/as introyectan la mayor parte de los conceptos o nociones que se les ofrecen como referentes de su identidad, especialmente los relativos a su pertenencia generacional (p.2).

El trabajo de campo nos muestra que esta introyección se evidencia en la apropiación de códigos, valores y significados que los niños y niñas nombran; las continuas interacciones sociales y culturales - familia, escuela y comunidad- genera una variedad de prácticas, experiencias y significados divergentes que interceden en la subjetividad de los niños/as y en sus formas de relacionarse con las/los otras/otros, así como también en la manera de comprender el contexto social y educativo que habita. Por ejemplo, los niños/as resignifican la 
forma en que sus agentes educativas y maestras caracterizan en definitiva al alumno/a de "ser un niño/a más grande".

Es que ustedes ya son niños/as grandes, por eso van a pasar a la otra escuela van a conocer nuevos amigos, van a aprender cosas nuevas" (agente educativa) "cuando estamos en octubre yo los preparo y les digo que ya son niños/as grandes y que por eso ya van a pasar al grado primero, que como son grandes se deben comportar bien, ser muy responsables y dar ejemplo a los de preescolar (Docente de Preescolar, 10/10/2017).

Cuando los niños y niñas vuelven sobre esta caracterización, se observa como incide la lógica escolar, lo que las maestras esperan de ellos/as en la construcción de una visión de sí que se aleja de la imagen asociada a la infancia que prevalece en la educación inicial:

- Ser una niña grande es cuando cumple años, los 5 los 9 y entonces es hacer tareas ya no se puede jugar (N8-niña de 5 años).

- Ser más grande es algo muy importante porque uno crece y así uno hace las tareas es más inteligente puede compartir con otros amigos, le dan regalos (N13-Niña de 7 años).

- Es que nosotros cuando pasamos al otro grado ya vamos creciendo hasta que ya estamos más grandes, cuando ya estamos adultos/as ya no jugamos, ya somos hombres serios, hacemos tareas y oficios por eso en el otro salón ya no podemos reclamar los juguetes, pero podemos hacer cosas de grandes como dice la profe (N16-niño de 7 años).

- En preescolar éramos más niños que ahora en primero, pero ya somos más grandes porque vamos para segundo hasta llegar a sexto (N14- niño 7 años).

Esta forma que tienen los niños y niñas para concebirse en el tránsito que hacen de un grado o escenario educativo a otro, evidencia que el niño-niña se piensa como un adulto en miniatura con una carga de responsabilidad, de ejemplo y de madurez que lo aleja de la imagen de niño/niña. Dicha nominación representa, por un lado, una sensación de orgullo en cuanto al crecimiento, la madurez; y por el otro, una perdida frente a lo que significa dejar de ser niñoniña en el paso del grado de transición al grado primero. Es notorio que a medida que crecen de los 6 años a los 7, la concepción de infancia se va transformando y se hace visible en una narración marcada por el sentido de pérdida: pérdida del tiempo, del juego, pérdida de los 
juguetes y regalos, pérdida de la infancia, del cuidado y atención de sus padres, de sus rutinas, rituales, del tiempo libre y el ocio, pérdida de sus espacios-nichos.

Algunos niños/as nombran el cambio entre escenarios educativos y niveles con orgullo porque cuentan con premios y reconocimiento de sus padres, mientras que otros lo manifiestan con nostalgia pues dejan un escenario en el que les brindaban comida, amor y juego, protección. Así las trayectorias educativas se construyen de formas distintas, pueden ser continuas o discontinuas confirmando lo propuesto por Bourdieu (2007) según las ventajas heredadas de cada uno, y sus ventajas merecidas (de negociación de beneficios materiales y simbólicos) (p.150).

De este modo, se observa la apropiación que hacen los niños/as de los discursos y valores que sostienen sus maestras. Como señalan Baquero y Narodowski (1994) no sólo se ponen en juego procesos de apropiación de la cultura por parte de los sujetos, sino también los modos a través de los cuales la cultura "se apropia del sujeto (p. 67). Para ellos/as dejar de ser niño/a y apropiar una nueva responsabilidad en un nuevo escenario es uno de los acontecimientos colectivos que experimentan en sus recorridos por el dispositivo escolar [trayectoria singular]; experiencia que es vivida y asumida de forma diferencial y que se condiciona por las oportunidades y los acompañamientos que como sujetos tienen en la trayectoria especialmente en los pasos entre niveles y escenarios educativos.

Así resulta que su infancia la configuran en el paso que hacen por las instituciones de educación inicial y educación formal, en ese transitar por los escenarios ellos/as describen un conjunto de sentimientos que le van dando sentido a su proceso de escolarización y a su niñez, vemos como identifican una etapa de felicidad, diversión, alegría, un tiempo de juego, de hacer amigos; de expresarse libremente, pero también una etapa en la que deben apropiar las lógicas superpuestas de la demanda escolar y es ahí donde nombran las pérdidas en cuanto al juego y los temores a crecer, a las nuevas responsabilidades de las tareas, de ser juiciosos y cumplir con las demandas escolares y exigencias de los padres de familia. Tal como se describe a continuación.

- Yo no quiero ser adulto porque ser niño es muy divertido, podemos jugar, hacer muchos deportes, en cambio ellos no son aburridos (N1-Niño 5 años). 
- Ser niño y niña es poder enojarse algunas veces yo me tengo que controlar cuando alguien me dice algo malo de mamá, yo hay mismo me pongo muy rabioso, también cuando me porto mal es porque molesto a los amiguitos, cuando nos portamos mal hay que pedir ayuda para controlarse (N6-Niño 6 años).

- Ser niña es muy divertido yo soy muy feliz puedo disfrutar con mis amigas, muy alegre, porque vamos a ganar el año y aprender a portarnos bien, a ser juiciosas (N9-Niña 6 años).

- Pero ser niño grande también es bueno, aunque más diferente, más tareas, pero no debemos asustarnos porque ser niño grade es ser fuerte y juicioso (N-12 Niño 7 años).

La forma como ellos/as se van reconociendo y van construyendo su identidad también se da en esas relaciones que establecen con los otros, en esos acontecimientos que experimentan de la mano de sus docentes, pares y familias. Bourdieu (1979) plantea que el paso de una trayectoria a otra depende a menudo de acontecimientos colectivos o individuales (p. 108) y por ello las experiencias e historia de vida de los niños y niñas son únicas notamos como expresan a través de sus dibujos los cambios en su infancia. Una niñez atravesada por la felicidad de compartir con amigos, de jugar, de estar siempre en espacios de diversión, con juguetes es la imagen que mejor representa la infancia que pierden al crecer. Los rostros que dibujan, feliz o serio, representan la madurez y seriedad que la educación formal demanda así como las nuevas responsabilidades que se deben asumir en la nueva escuela. 


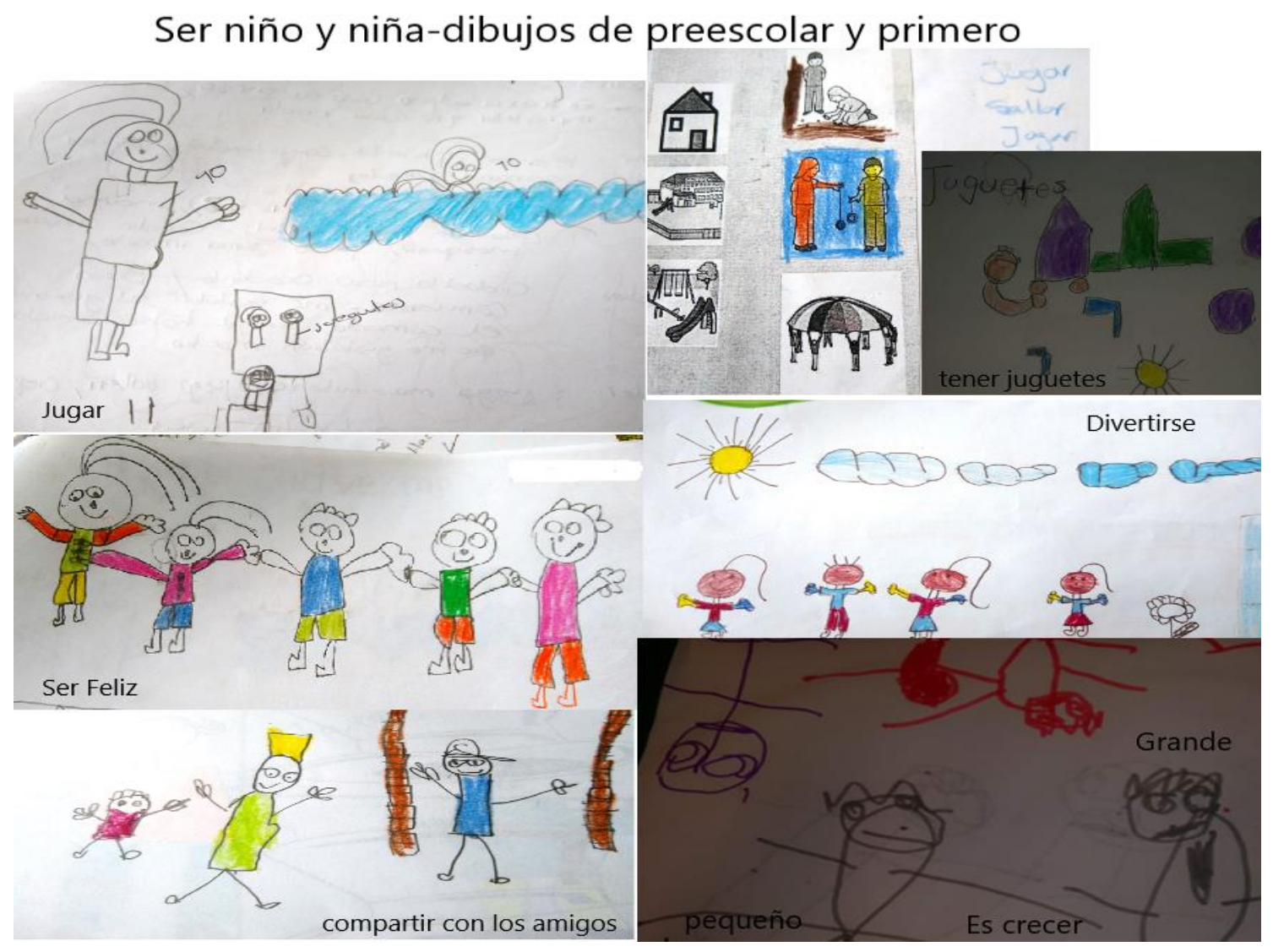

Fuente: Elaboración propia

En este orden entender la singularidad es evidenciar la pluralidad de la infancia e implica reconocer las múltiples miradas, voces, sentidos, sentires que construyen los niños y niñas en sus interacciones con el contexto en el que habitan, con su familia, con sus pares, con su escuela; los niños/as al igual que sus maestras realizan una construcción frente a lo que significa para ellos ser niño/a, construcción que dista de la percepción de sus maestras y agentes educativas quienes los clasifican además como una infancia vulnerable por sus diferencias culturales, sociales, comportamentales, una infancia cronológica que se debe abandonar para empezar correctamente una nueva etapa.

De esta forma es importante analizar el lugar que ocupan las concepciones referidas a la infancia y su relación con la educación y la escuela, se hace necesario abrir preguntas frente 
a su rol, posición, los modos de nombrarlos, pero también los modos de escucharlos. Redondo (2011) nombra que a los niños y niñas de hoy requiere pensarlos en una genealogía de herencias y legados que nos permite identificar una deuda; deuda con los que llegan, pero sobre todo deuda con los que aún no han llegado. Alojar a la niñez requiere de un enorme movimiento social que la reciba - en especial, a los más pequeños- en un presente que dialogue con el porvenir. La escuela debe pensar la infancia y en su modo de alojar la infancia como territorio: hacer escuela (Redondo, 2016: 382).

\subsection{Chupar teta, gatear, caminar, jugar y hacer tareas: experiencias significativas de los niños-niñas en sus trayectos de vida entre el hogar, la guardería y la escuela.}

Para los niños y niñas hablar de trayectorias es relatar sus experiencias de vida y sus recuerdos frente a las situaciones que han construido en la relación con la familia, la escuela, la comunidad; sus discursos entrelazan múltiples momentos, algunos compartidos, otros mediados por condiciones sociales, institucionales y estructurales que han permeado y delineado itinerarios diversos. En este encuentro se trabajó el taller de la línea del tiempo cuyo objetivo se centró en conocer cuáles son los momentos claves en la vida de los niños/as en el pasado, en el presente, y recoger no solo las características generales de la trayectoria de vida de los niños/as, sino también sus experiencias individuales en la transición. Algunas de las preguntas realizadas fueron: ¿Cómo fue cuando ustedes nacieron?, ¿Cómo fue el momento en el que ingresaron a la Educación Inicial-Buen Comienzo?, ¿Qué se acuerdan de la educación inicial?, entre otras.

El inicio de este encuentro ${ }^{41}$ empieza a las 8:30 de la mañana, dispuesto uno de los salones del grado primero y ambientado con los materiales que se iban a disponer: imágenes, fotos, colores, crayolas, tijeras, colbon, papel, música; los niños y niñas de transición empiezan a llegar, sus rostros dejan ver curiosidad por el cambio de espacio, pues en este día no se trabajaría en el salón de teatro o la biblioteca. Una de las primeras preguntas que hicieron fue, “¿Profe hoy vamos a estar en este salón? Este salón es de los niños/as grandes solo tiene sillas

${ }^{41}$ Este se realiza por separado con los niños y niñas de grado primero (3/10/2017) y con los de transición (5/10/2017). Con ellos se va construyendo la línea del tiempo que fue insumo para este análisis. Guardería es el nombre que los niños y niñas dan a las Instituciones de Educación Inicial- Programa Buen Comienzo. 
y ya, [con un suspiro agrega], profe ayer nos tomamos la foto de los grados" (N9-Niño 6 años), ante lo que N1 refiere que no quiere pasar a primero, "este salón es feo" (Niño 5 años); otra de las niñas refiere que esta bonito ante lo que en voz alta la mayoría responde no porque "no tiene juguetes"; "tampoco nuestros nombres", y "la pared esta fea mira, está sucia y con poca pintura", "las mesas están rayadas", no son parecidas a las de nosotros.

Después de este preámbulo que deja ver en sus expresiones de desilusión frente a la nueva escuela vemos en sus voces que la transición supone cambios y situaciones que experimentan en un momento determinado. Tal como se describe a continuación los niños y niñas de grado transición y grado primero priorizan ciertos hitos y momentos de cambio importantes del ciclo de su vida que fueron clasificados de la siguiente forma según sus palabras $^{42}$ : cuando éramos bebés y gateamos; cuando empezamos a caminar; cuando llegamos a la escuela y cuando somos niños y niñas más grandes.

\section{Cuando éramos bebés y gateamos}

En esta primera etapa los niños y niñas recuerdan y le dan vida a ese proceso de la gestación, al vínculo afectivo y emocional que se genera entre madre e hijo y refieren a características propias de la etapa frente a la crianza y el cuidado; la reconstrucción que hacen empieza desde el momento antes de nacer en el que evocan situaciones y sensaciones, y después de nacer en el que relacionan cambios importantes en sus vidas con la lactancia, con crecer y transitar del hogar a la guardería de Buen Comienzo.

Las voces de niños y niñas de Preescolar giran en torno de lo siguientes hitos:

- Cuando éramos bebés todos estábamos en la barriguita de la mamá, yo comía de la teta de mi mamá leche y andaba en la guardería, mamá me recogía en la noche (N1-Niño 5 años).

- Allí en la barriga teníamos un oxígeno para vivir y nos estábamos moviendo (N2-Niña 6 años).

- No podíamos movernos mucho porque se embaraza más grande y nos adelantábamos a nacer (N8Niña 6 años).

- N10 dice y la mamá come para uno poder comer, nos movíamos en la barriga de mamá, y andábamos en la guardería (Niña 5 años).

- En esa barriga yo dormía todo el día porque uno bebé duerme mucho, mi mamá me cantaba (N9Niño 6 años).

\footnotetext{
${ }^{42}$ Estas etapas son códigos in vivo que emergen de las voces de los mismos niños y niñas.
} 
- (muerto de risa) Cuando nacimos profe chupábamos teta de la mamá, y andábamos en la guardería de Buen comienzo, nosotros jugábamos en las colchonetas, dormíamos, allá jugábamos en los deslizaderos estando bebés, con los libros y nos llevaban a la ludoteka (N5-Niño 6 años).

- Es que cuando éramos bebés, si éramos chiquiticos, y mamábamos teta, nosotros llorábamos dormíamos, y gateábamos (N8-Niña 5 años).

- $\quad$ N3 era muy bueno ser bebé, dormíamos y gateábamos (Niña 5 años).

Las voces de niños y niñas de la Educación Básica Primaria -grado primero recuerdan:

- Cuando éramos bebés si éramos chiquiticos, y mamábamos teta, cuando yo nací yo me quedaba dormida, como acostadita todo el día, yo me movía mucho y una amiguita me tocaba; yo me alimentaba de mamá, pero ya ahí crecimos más y más hasta que nacimos, y después cuando uno aprende a caminar lo llevan a la guardería (N13-Niña 7 años).

- Cuando éramos bebés yo estuve en una barriguita, luego yo ya caminaba, miré yo estaba aprendiendo a caminar y cada momentico me caía, yo aprendí a caminar muy rápido, todos dicen eso; cuando ya caminé yo iba con mi mamá a todas partes y ella me llevaba de la mano a la guardería (N14-Niño 7 años).

- Cuando yo nací estaba llorando y ya más grande gateaba; yo dormía todo el día, me despertaba para comer, y cuando ya caminaba me llevaron a la guardería de Buen Comienzo y allí solo juagaba, jugaba, jugaba, y jugar y jugar, solo parábamos para la comida (N17-Niña 6 años).

- Yo estuve en una barriguita, y dormía todo el día, me despertaban para comer, me consentían (N15-Niño7 años).

Estos cambios o tránsitos de un estado a otro van configurando sus infancias, una manera de nominar los vínculos que empiezan a tejer con su familia y contexto, de representar los hitos en su desarrollo y de nombrar los recuerdos de una infancia vivida, es decir de una experiencia única, de lo que les "pasa”. Para Larrosa (2006) las experiencias son singulares y no pueden repetirse, cada quien tiene la propia, que la sufre y la padece. Estas experiencias de los niños y niñas no se reducen a "lo que pasa", a los sucesos y a los acontecimientos, sino a "lo que nos pasa"; es decir a la forma como la viven el momento narrado en la interacción con su familia. Por ello el nacimiento no es sino el principio de un proceso en el que el niño/a comienza a estar en el mundo y a ser uno de nosotros." El nacimiento constituye el comienzo 
de una cronología que el niño/a va a tener que recorrer en el camino de su desarrollo, de su maduración y de su progresiva individualización y socialización” (Larrosa, 2000: 6).

\section{Cuando empezamos a caminar}

De los vínculos que van tejiendo con los diferentes miembros de la familia, los niños y niñas destacan la relación que entablan con las madres sintetizada en la frase "chupar teta". Cuando narran el pasaje del hogar a la guardería aparece la mención a "cuando empezamos a caminar", y este desplazamiento habilita nuevos itinerarios y descubrimientos; el ingreso a la a guardería de Buen Comienzo ${ }^{43}$ o a una institución de Educación Inicial no interrumpe su visión sobre lo que implica ser niños/a, por el contrario, representa la verdadera naturaleza de ser niño/a como un sujeto alegre, sin normas, libres y auténticos, una experiencia particular cargada de juegos, aprendizajes e interacciones, en un espacio mágico de juego, diversión, exploración, reconocimiento y protección.

- Profe cuando estábamos más grandes que caminábamos fuimos a la guardería y nos divertíamos mucho, jugábamos en las colchonetas, dormíamos, jugábamos mucho (N17-Niña 7 años).

- En este espacio de Buen Comienzo solo era jugar, jugar, jugar y jugar, hasta que nos comíamos el desayuno y a jugar, jugar, muchas cosas (N14 niño 7 años).

- Profe es que nosotros estábamos en la misma guardería; y jugábamos en la guardería todo bueno; se acuerda cuando nos tirábamos por los deslizaderos, huy si dice (N13 niña 7 años).

- N12 dice yo estaba en otra guardería y era todo divertido todo el día jugábamos, y cuando cantábamos y jugábamos con el agua, esa era cual guardería N12 dice la de Buen comienzo profe, pero de ahí ya pasamos a otro colegio, pasamos aquí (Niño 7 años).

Pero este paso o momento de su vida está interseccionado por algunas situaciones particulares relacionados con los desplazamientos, violencia y pobreza que marcaron también el recorrido de algunos de los niños y niñas por el sistema escolar.

- Profe, pero yo no crecí aquí, ella bebé vivía conmigo, cierto; vivíamos en el chocó, allá estábamos con la tía, y mi papá; pero ellos ya no están con nosotros (N8-Niño 6 años).

\footnotetext{
43 Representar este momento para los niños y niñas fue de mucha emoción, risa, recordar cada una de las actividades que realizaban especialmente los niños/as de primero fue muy emocionante.
} 
- Yo los extraño, pero aquí también es bueno, mire allá jugábamos en el río, pero aquí llegamos a la guardería y nos daban comida (N9-Niña 6 años).

- Cuando era bebé vivía en enciso, pero nos vinimos para acá porque la casa estaba muy estrecha y no cabía ni el closet y ni la mesa, éramos muchos y la tierra nos caía encima, profe había deslizamientos, yo extraño ese lugar y mis amiguitos de la guardería de allá (N17-Niña 6 años).

De esta forma los niños/as relatan sus experiencias en cuanto a los desplazamientos, a las pérdidas de vínculos afectivos, amigos y familiares, al proceso de adaptación al nuevo barrio, pero también a la nueva institución de Educación Inicial. Esta escena permite pensar la infancia desde dos miradas, por un lado, desde una posición nostálgica donde los niños y niñas narran y describen lo que fueron, lo que tuvieron, y lo que son en un nuevo contexto, narran sus situaciones sociales de vulnerabilidad, y la implicación que tiene acomodarse, adecuarse a esta nueva situación; por otro lado, desde una posición en la que describen una infancia alegre que se transforma y que se narran como grandes por efecto de la escolarización en el paso hacia la escuela. Confirmando así que la trayectoria se compone de movimientos, hitos y situaciones que representan períodos de cambio importantes para cada sujeto.

\section{Cuando llegamos a la escuela}

Este es un momento importante para los niños y niñas porque configura el paso de la institución de Educación Inicial- programa Buen Comienzo a la institución de Educación formal- Institución educativa Ciudadela Nuevo Occidente. Este cambio se convierte en un período que configura el cierre de una etapa y el inicio de nuevos aprendizajes y experiencias, etapa que requiere de una adaptación e integración a las nuevas directrices institucionales, a la nueva infraestructura, a las nuevas, a los nuevos ritos institucionales. Transición educativa que hace sentir a niños y niñas la de que pierden la condición infantil atravesada por el juego.

- Cuando salimos de buen comienzo llegamos aquí cierto, mire deme permiso, buen comienzo queda cerca de la $\mathrm{UVA}^{44}$, entonces nosotros cuando salimos de Buen Comienzo, vea, termina el año, hacen fiesta, bailamos, y lo echan pa ca, a uno, aquí hacemos tareas personales ijummm!

\footnotetext{
${ }^{44}$ Unidades de Vida Articulada (UVA) son espacios multipropósito de calidad para la lúdica, la cultura, el deporte y el encuentro familiar, que contribuya al bienestar de la comunidad.
} 
y no podemos volver, vemos desde la rejita, yo hay veces voy y saludo a la profe (N8-Niña 6 años).

- Profe, pero aquí en Ciudadela también es bueno aprendemos otras cosas muy importantes hay juegos, pero no tantos, por eso vamos a la ludoteka un edificio con muchos juegos, que queda en la UVA...es una biblioteca con piscina, pero no nos dejan meter, y con muchos libros (N4niño 6 años).

- Yo quiero volver a vivir en la montaña (Buen comienzo) porque allí había muchos juguetes y carritos y aquí no, había unos triciclos en los que jugaba por todo el jardín, aquí no podemos jugar en todo momento (Niño 5 años).

En este sentido el análisis del pasaje del hogar a la guardería, y de la guardería a la escuela muestra la forma como los niños/as son producidos por una experiencia escolar, la institución como escenario escolar convencional o no convencional representa para ellos un lugar vital de experiencias, interacciones compartidas, de exploración y construcción de aprendizajes; es un espacio de encuentros y desencuentros, de interrupciones por las pérdidas ejemplo de sus juguetes como los armatodos, las cocinitas, los juegos de concentración de su infraestructura por los nichos exploratorios, pero también de aprendizajes; los niños y niñas viven interacciones simples o complejas, como resultado de una experiencia que tiene relación con ellos y después de la cual ya no son los mismos, evidentemente todos tienen sentires distintos frente a este cambio. "La experiencia suena, sobre todo, a vida, a una vida que no es otra cosa que su mismo vivir" (Larrosa, 2006: 110).

\section{Cuando somos niños y niñas más grandes}

Como última etapa surge en los relatos de niños y niñas la mención al cambio del grado transición a primero y posteriormente a grado segundo, es decir, el pasaje de la educación preescolar a la básica primaria. En esta etapa ellos asumen que son niños y niñas en crecimiento, más grandes, "ser niño-niña adulto" con responsabilidades; es un período para nombrar los duelos y las rupturas que se establecen entre una etapa y otra, y para nominar como viven esa transición; la escuela es un sitio donde van a hacerse adultos/as/as, los niños/as entran al mundo como expresión de lo nuevo y deben, cada vez más rápido, hacerse viejos: adecuarse, normalizarse, pensar seriamente. De esta forma pareciera que los niños y niñas en este cambio deben dejar su niñez (Skliar 2012: 78). 
- Profe yo me voy para primero en tres meses, es que ya nosotros somos unos niños adultos/as, porque nosotros ya vamos creciendo hasta que ya estamos más grandes, cuando ya estamos adultos/as ya no jugamos los niños grandes no juegan debemos hacer tareas (N6-niño 6 años grado transición).

- Ya estamos creciendo y no podemos tener miedo porque eso es crecer, crecer no significa que tengamos miedo, significa que ya estamos creciendo, y vamos a conocer nuevos salones, nuevos amigos, nuevas profesoras, y eso es crecer (N15-Niño 7 años grado primero).

- Es madurar y portarse bien, no ser indisciplinado porque si no se pierde el año, cuando ya somo grandes tenemos que aprender a controlar la ira, yo me quedo en el puesto juicioso, yo no me paro del puesto para hacer las tareas rápido, y para que no me regañen, en el otro grupo me regañaban mucho (N14-Niño 7 años grado primero).

- Ya somos más grandes vamos a cumplir años, es como los años que pasa la vida por ejemplo en segundo vamos a tener más años, y vamos a ser más grande, y eso es algo importante porque si uno hace las tareas y es más grande uno puede ser más inteligente; eso significa que uno se vuelva todo mayor (N17-Niña 6 años grado primero).

Vemos que estas expresiones se asocian a situaciones emocionales, el cambio hacia la nueva etapa o grado representa para ellos/as desafíos, retos, implica un análisis frente a lo que significa "crecer" y frente a su "infancia". Los duelos "profe ya me voy" confirman que en ese transitar ellos/as se enfrentan una pérdida frente a su propia infancia crecer no solo le implica tener mas años, madurar y portarse bien, aprender a controlar la ira, sino que les implica dejar el miedo, no sentir temor, porque hay nuevas experiencias de ser mas inteligente, de conocer nuevos amigos, profes. La pérdida del juego, el desarrollo de la autonomía, la autopercepción como sujetos escolarizados; y curiosamente la tarea como fundamento de su crecimiento, recupera la dinámica propia de sus vidas y las transiciones que experimentan entre la educación preescolar a la básica primaria, lo que evidencia un "cuestionamiento frente a los lugares escolares que acarrea el fenómeno de la escolarización" (Brailovsky, 2006:47). De esta forma encontramos que la trayectoria es un proceso en el que se ponen de manifiesto las múltiples transiciones, por ello las transiciones y las trayectorias deben ser vistas como conceptos relacionados (Crivello, 2009), pues son procesos que solo pueden ser entendidos en la relación entre sí y en su mutua interdependencia (Dávila y Ghiardo, 2005). 
Reconstruir la trayectoria de los niños y niñas a través de sus relatos es una manera de nombrar sus experiencias y configurar sus itinerarios, como nombra Bourdieu (1988) los sujetos van trazando itinerarios a veces más previsibles, a veces más aleatorios construyendo simultánea y pluralmente, en múltiples dimensiones: familiar, social, laboral, política, religiosa, cultural, de esta forma, observamos que aunque los niños/as viven una experiencia escolar similar porque están matriculados en una misma institución bajo unas mismas reglas, el recorrido de su trayectoria es distinto. Observamos que los niños/as viven modos de trayectorias lineales/continuas pues todos comparten la misma meta " ganar el año" y cumplir con la progresión lineal prevista por el sistema educativo, "trayectoria teórica"; sin embargo factores como la estructura institucional, la situación económica, el capital cultural, las características familiares, los vínculos afectivos, la situación de vulnerabilidad, las situaciones estructurales de desplazamiento, violencia y los atributos de cada sujeto, hacen que esta trayectoria sea heterogénea.

Profe vea a mí me van a cambiar de colegio, me van a pasar para donde mi hermanita para que ella ayude con las tareas, yo me porto bien y le obedezco a la profe para no perder, ese es el Colegio de Lusitania (N17-niña 6 años primero).

Las trayectorias también son singulares porque el niño/a como cuerpo social introyecta la mayor parte de los conceptos o nociones que se les ofrecen como referentes de su identidad. En el proceso de escolarización, vemos niños y niñas empoderadas con desempeños académicos en los que se evidencia un buen acompañamiento por parte de las familias, niños/as que se adaptan fácilmente que asumen, apropian y transforman ciertas situaciones de su vida; pero también vemos niños y niñas con inseguridad, con temor de enfrentar los cambios, niños/as que requieren de mucho acompañamiento.

Vea profe él no va a ganar el año, ni va a pasar a primero, porque él no sabe escribir el nombre, no sabe leer, este (señala otro de los niños y niñas) tampoco lo va a ganar por grosero, por jugar en el salón y por no hacer las tareas, eso dijo la profe (N5- 5 años transición).

Una novedad del encuentro con los niños y niñas de primero fue la llegada de una madre para acompañar a su hijo en clase. Con la maestra estableció un compromiso de que todos los días estaría presente en el salón, el niño participaría de las actividades hasta las 9:30 y la 
maestra le enviaría talleres para la casa, porque el niño no es capaz de concentrarse. "La madre tuvo que dejar de trabajar para acompañarlo, porque si no le negaban el cupo y en esta escuela le ponen muchas tareas" (Madre N16). En este sentido, estudiar la trayectoria implica analizar el lugar que adquiere la institución escolar con sus condicionantes, su estructura, sus objetivos, sus formas de regular de mediar y de transformar los espacios escolares. Nicastro y Greco (2009) resaltan la importancia de no centrar la mirada solo en el sujeto o en la organización escolar, por el contrario, refieren a la necesidad de mirar ambos a la vez, sin que cada uno de ellos pierda su singularidad, sus rasgos propios, sus dimensiones, su modo de presentación particular (2009: 57).

\subsection{La "escuela de antes" y "la escuela de ahora": reflexiones de los niños y niñas frente a su experiencia en la Educación Infantil}

En este apartado nos proponemos poner en contexto los debates respecto a la escuela infantil hoy en Colombia, así como mostrar las diferencias relevadas entre la atención y educación de los niños y niñas pequeños entre los 0 a los 6 años y los 7 a los 12 años según se pudo recoger de sus relatos orales y gráficos. La "escuela de antes" hace referencia a la experiencia que tuvieron los niños y niñas por el programa Buen Comienzo- Educación Inicial y la "escuela de ahora" indica las experiencias que viven en los grados de transición y primeroEducación preescolar y básica primaria.

Ilustración 13 Taller con los niños y niñas- Encuentro 3

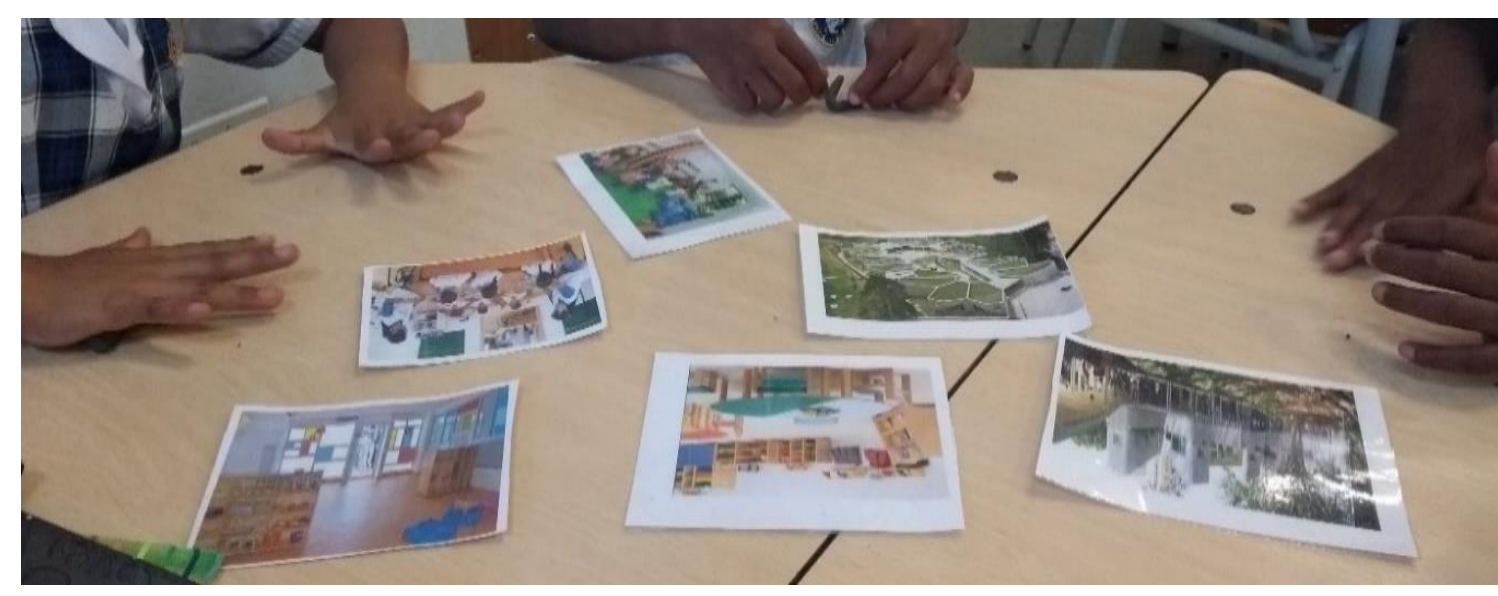

Fuente: Elaboración Propia 
El objetivo de este encuentro fue recoger las percepciones de los niños y niñas sobre su escolarización en el programa Buen Comienzo y en la institución educativa Ciudadela Nuevo Occidente. Se utilizó la estrategia de conversación, discusión de imágenes en este caso fotos de los dos escenarios educativos. Durante la conversación a los niños y niñas se les entrega plastilina para que ellos vayan moldeando sus historias. Al iniciar el taller se les mostró la foto de la fachada de la Institución Ciudadela Nuevo Occidente y con emoción todos, sin respetar el turno de la palabra, comenzaron a decir con orgullo en forma insistente que esa es su escuela y a describir cada uno de sus espacios (la cancha, los salones, hasta los mismos edificios que quedan cerca y en los cuales viven algunos de ellos/as), diferenciándola de la que nombran como la "escuela de ahora", la escuela en la que ahora estudiamos.

Después se les muestra la fotografía de la fachada de Buen Comienzo y las expresiones de los niños y niñas de preescolar son de asombro, algunos se quedan en silencio, otros emocionados empiezan a decir "yo estudiaba allí, ese era el colegio de la montaña, ese era el colegio de antes, mire aquí era donde jugábamos, esa era la escuela de cuando éramos pequeños" (N1); "nosotros estudiábamos allá, teníamos tres profesoras, una que ayudaba, una que lo hacía dormir y una que nos llevaba a comer" (N3), y de inmediato empiezan a referenciar sus anécdotas y recuerdos de los momentos de juego, de las actividades, de los juguetes.

Los niños y niñas de primero emocionados y con sonrisas empiezan a nombrar "me acuerdo de ahí es cuando nosotros íbamos ahí, y jugábamos, ese es el jardín que queda por la biblioteca, jugamos mucho en ese lugar, allá hacíamos actividades y jugábamos con los juguetes, títeres, bloques, libros para leer, muchas cosas" (N12); "era un lugar para divertirnos, no hacíamos tareas, se llama Buen comienzo", "pero esa es la escuela para los niños pequeños, era la escuela de antes"(N17); "esta es grande (muestran el colegio) la otra (Buen comienzo) es más pequeña, son diferentes porque hacemos distintas actividades, aquí en esta escuela hacemos evaluaciones que son actividades, hacemos muchas tareas" (N16).

Para los niños y niñas la "escuela de antes" versus la "escuela de ahora" representa un espacio escolar con un diseño estructural diferente en el que, por un lado, experimentan la alegría de una época de juego, diversión, libertad (Buen Comienzo) y por la otra se acercan a un escenario escolar de Educación Formal más estructurado, en el que apropian un mundo amplio y complejo de interacciones, normas y aprendizajes. Esa diferenciación se pone en 
evidencia cuando son los mismos niños/as quienes clasifican el escenario infantil o los tipos de escuelas como: (1) el espacio de juego versus el espacio de tareas y (2) El espacio de libertad versus el espacio de control, configurado en lo que ellos nominan la "escuela de antes" cuando era pequeño versus la "escuela de ahora" que soy grande.

Vemos que el espacio de juego versus espacio de tareas es la forma en que ellos/as expresan las diferencias entre etapas e instituciones y como caracterizan la transición que realizan entre un escenario y otro, y entre los mismos niveles o grados; por ejemplo, en el paso que hacen de los programas de Educación Inicial (Buen Comienzo) a la Educación Formal, y entre el tránsito del grado transición al grado primero. Sus relatos evidencian diferencias con respecto a las zonas de juegos, los juguetes, las metodologías de trabajo, los tiempos; al recordar su estadía en el escenario educativo Buen Comienzo sus rostros inmediatamente se transforman en alegría, sonrisas y suspiros. Sus cuerpos se predisponen para recordar, evocar momentos significativos y anécdotas con respecto a lo que hacían, los juegos, las actividades, sus docentes, para nombrar con agrado cada uno de los juguetes y los espacios de diversión, encuentro e interacción como las pijamadas o los juegos.

El lugar del juego:

- La otra escuela es un lugar para niños pequeños, era la de Buen Comienzo tenía muchos juguetes, allá, había chorritos, arma todos, cocinas, plastilina, pinturas, muñecas bebés, teteros, nos daban comida el desayuno, el almuerzo, la media mañana (N12-niño 7 años).

- Cuando íbamos allá pasamos a comer y después dormíamos, yo me acuerdo que dormía muy bueno con música, además comíamos sandwiches, arroz, carne, queso, pan, y huevo; jugábamos Golf, hacíamos bailes, nosotros éramos campesinos, también, indios, allá era cuando estábamos bebes cuando teníamos 4 años (N10-niña 5 años).

- Allá nosotros no hacíamos tareas, solo jugábamos y nos divertíamos, a mí me dio mucho miedo pasar a esta escuela, pero ya lo quiero mucho ya somos grande y estamos en este colegio (N17Niña 6 años).

- Yo extraño mucho la escuela de Buen Comienzo mi tita me llevaba, me gustaba mucho, tenía parque, fuentes y muchos juguetes, era una escuela para jugar (N1-Niño 5 años). El lugar de la disciplina:

- En esa escuela jugábamos, bailábamos, aquí en (ciudadela) escribimos lo que la profe nos dice por ejemplo la fecha y el nombre (N8-Niña 6 años). 
- Profe aquí cuando nos portamos mal nos ponen en esa pared que tiene ese semáforo, vea los que se portan bien y hacen las tareas están en verde, en amarillo son los que se portan más o menos, yo estoy ahí, me quedo atrasado; a veces no me controlo y grito; y en rojo Los que se portan muy mal como ella que le pega a todos los amigos (N5-Niño 6 años).

- $\quad$ No yo en la otra escuela no me portaba mal, allá era juiciosa (N9-Niño 6 años).

- Yo también era juiciosa porque allá nos estábamos divirtiendo (N5-niña 5 años).

La "escuela de antes" se configura como el escenario de protección, enfatiza la importancia del juego, destaca un escenario de diversión, que se extraña por su misma estructura organizativa, los niños y niñas se sienten feliz en este espacio y seguros; cuando realizan el paso a la Educación Formal "la escuela de ahora", es decir, el espacio de libertad versus el espacio de control, destacan la importancia de un escenario escolar que pone el acento en el contenido académico, la convivencia, la existencia de tareas, pero en el que también se sienten seguros y satisfechos; en la escuela de ahora los cuerpos se deben acomodar a unas nuevas reglas, en donde el juego deja de ser el centro de su formación y se pasa a un espacio más estructurado con horarios de trabajo más extensos; también se juega pero menos, porque se le da más prioridad a la lectura y escritura; allí los niños y niñas experimentan un conjunto de sentimientos por los momentos de cambio especialmente en el paso del grado de transición al grado primero, en el que además refieren a las expectativas que tienen por los nuevos aprendizajes.

\section{El lugar de los contenidos:}

- En preescolar nos ponen tareas y si uno sale al descanso jugamos en el salón, pero cuando ya pasemos a primero, ya no hay juguetes nos van a poner muchas tareas (N6 niño 5 años).

- En preescolar nos ponían hacer actividades todas buenas, nos ponían también a ejercitarnos todo el cuerpo, hacíamos clases de masajes y en primero no hacemos nada de eso, solo la profesora de educación física esa es la materia que más nos gusta (N12-niño 7años).

- Vea profe en primero nos ponen lectura y escritura, en preescolar nos ponían hacer tareas con plastilina, hacíamos manualidades, en cambio en primero tenemos colores y cuadernos para pintar, o lápiz para escribir, en preescolar solo teníamos un solo cuaderno, en primero tenemos muchos y en la guardería no teníamos que llevar ni un cuaderno (N13-niña 7 años). 
- En preescolar hacíamos actividades muy misteriosas, y que era misteriosas, como hacer unas cosas que no nos esperábamos, hacíamos muchos muñequitos, jugábamos con las motos deslizándonos por la barranca, los carritos y a veces los otros carros, pero en primero ya no nos dejan jugar allá, solamente es para preescolar, es que nosotros ya estamos más grandes, adultos/as ya no jugamos somos niños, pero grandes" (N14-Niño 7 años).

Los niños y niñas en sus discursos coinciden en evidenciar que la estructura curricular y pedagógica entre ambos escenarios es la que más cambia; el desarrollo de las actividades, el manejo de los cuadernos, la escritura y la pérdida de los juguetes, representan los retos que deben asumir. Arenas (2001) y Dunlop (2002) señalan lo oportuno de considerar las percepciones de los niños/as acerca de su transición o pasaje hacia la escuela primaria y, junto a Bennet (2006), coinciden al señalar que los niños/as emprenden el inicio de la escuela primaria con una actitud abierta al cambio, tienen una mirada positiva sobre el pasaje, con mucha información al respecto de todo lo que van a aprender y tal vez poca sobre el modo en que eso va a ocurrir.

Profe en primero no hay juguetes porque es que en primero los grandes no juegan, por eso no hay juguetes, uno tiene juguetes en un salón, pasa después para tercero cierto, y aquí no hay juguetes, aquí se hace tareas, porque ya somos grandes, profe ya el otro año vamos a ser niños más grandes porque vamos para segundo.... ique susto!, en primero solamente salimos al descanso y jugamos sin nada, aprendemos a ser tareas, unas que tienen que escribir mucho, hasta abajo, es que en preescolar no escribimos, solo pintamos con los colores, pasamos bueno (N15-niño 7 años).

De esta forma vemos que los niños y niñas tienen una mirada positiva frente al cambio de la Educación Inicial a la Educación Formal, sin embargo, es posible identificar que cada escenario escolar configura un modo de ser niño-niña, y los mismos niños/as lo identifican cuando nombran la escuela de "antes" y la de "ahora" y que no es más que el niño/a escolarizado. Graciela Frigerio (2007) refiere a la existencia del niño/a escolar y presenta a la escuela como una institución que al recibirlo "lo crea", crea un modo de "ser niño", en una asociación que vincula estrechamente niño a escolar, los niños escolares de acuerdo a su visión han sido estudiados, catalogados, etiquetados; en el escolar habita algo más que un alumno/a 
pues cobija bajo ese nombre muchas cosas (Frigerio, 2007: 332). En esta escolarización se presenta una interrupción de la niñez y la infancia (Skliar, 2012).

Vemos que esta configuración de niño y niña escolarizado se evidencia en sus dibujos en los que claramente muestran los cambios y las adaptaciones que deben asumir en el paso que realizan de una escuela a otra. En primera instancia en "la escuela de antes" dibujan espacios libres con juegos, parques, libros, comedor, se representan haciendo actividades lúdicas y las nombran de formas divertidas, representan el juego, el arte, la literatura. Mientras que la "escuela de ahora" la dibujan como un escenario encerrado, donde también hay juegos, pero fuera del espacio escolar; como algo representativo es el dibujo del tablero ${ }^{45} \mathrm{y}$ las letras para resignificar esta nueva responsabilidad, esta nueva asunción del currículo y de la institucionalidad. Bourdeau y Passeron (2008) nominan la escuela como un ámbito de interacción y relacionamiento entre niños y adultos/as/as, el lugar por excelencia donde se aprenden y se reproducen las normas, la disciplina y la doctrina de la institución.

\section{Ilustración 14 Dibujo de los niños y niñas Preescolar y Primero " La escuela de antes"}

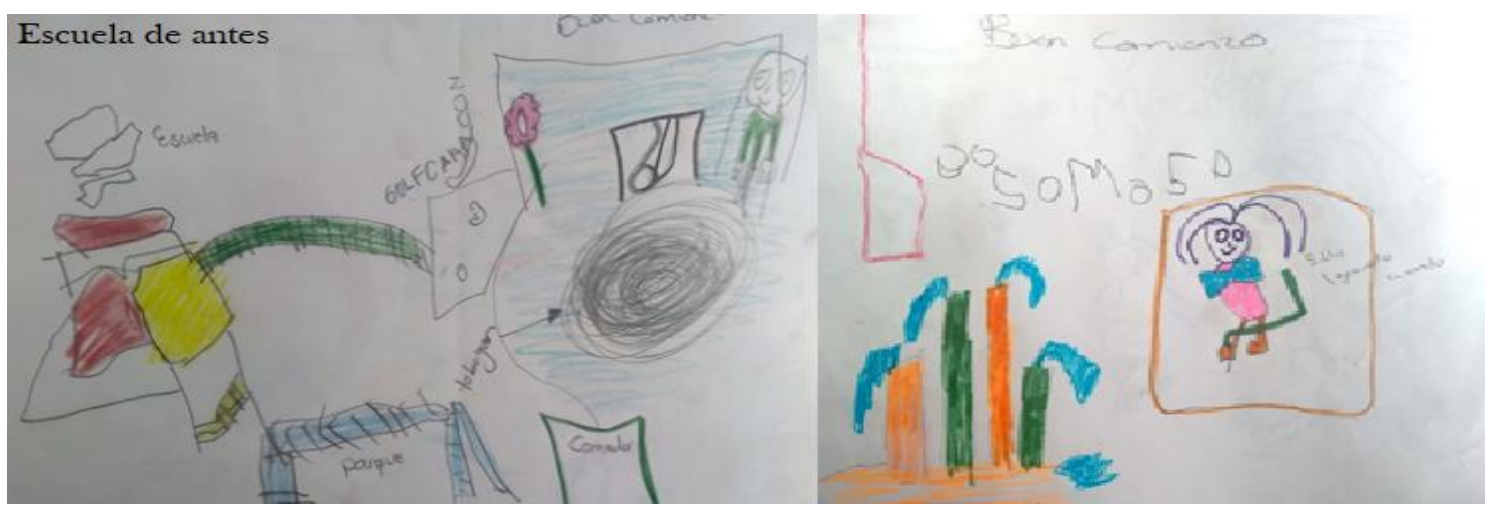

Fuente: Elaboración propia

\footnotetext{
${ }^{45}$ En Colombia en el sistema de Educación formal grados transición, básica primaria y básica segundaria, una de
} las herramientas de trabajo más utilizadas por los docentes es el tablero. 
Ilustración 15 "la escuela de ahora" niños preescolar-primero

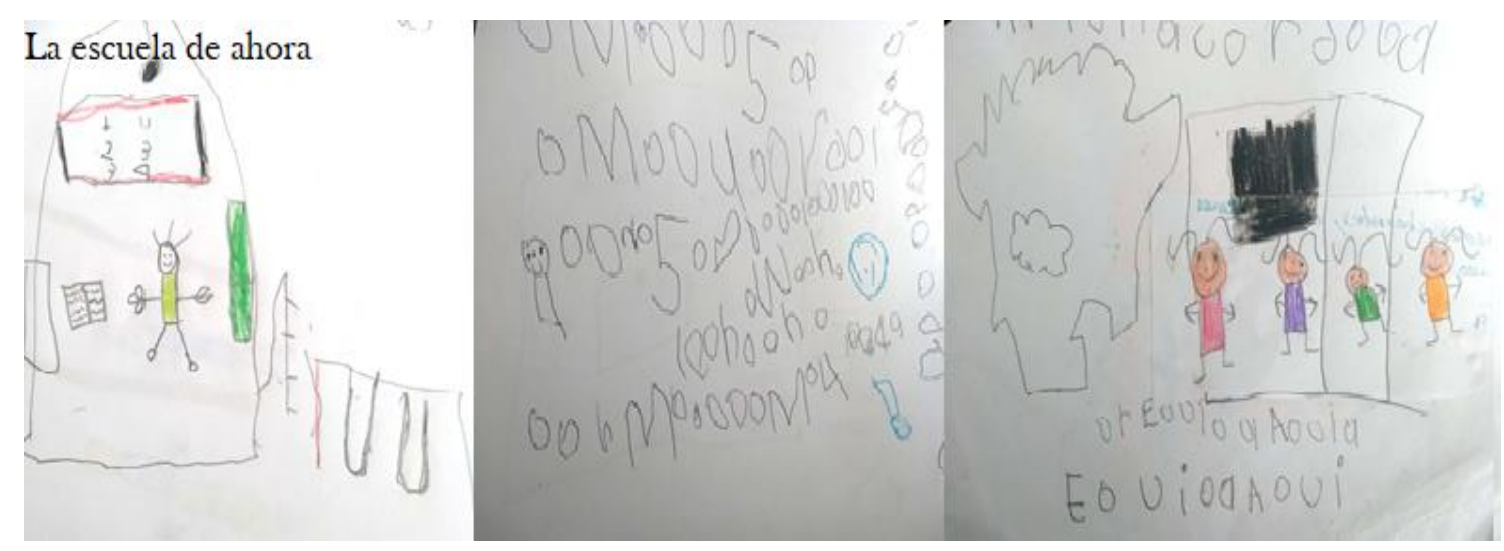

Fuente: Dibujo -Elaboración propia.

La imagen de infancia que supone la escuela de "ahora" y que los niños y niñas describen se evidencia desde una estructura centrada en la formación, un lugar de aprendizaje y transmisor de conocimientos, sus dibujos dejan ver que las dinámicas de trabajo en el aula se establecen en espacios separados de los juegos, visualizando una infancia homogeneizada presente en la forma como se dibujan ellos mismo. Kohan (2004) propone otra forma de concebir las infancias, el autor nos presenta una imagen que es disruptiva.

El infante, entonces es aquel que no habla todo, no piensa todo, no sabe todo, aquel que, como Heráclito, Sócrates, Rancière y Deleuze, no piensa lo que todo el mundo piensa, no sabe lo que todo el mundo sabe, no habla lo que todo el mundo habla. Aquel que no piensa lo que ya fue pensado..." Infancia es una apertura constante a pensar y repensar lo nuevo, lo inesperado, lo insólito. Es el mapa y territorio de una posible experiencia del pensamiento que puede transformar nuestra vida (Kohan, 2004: 275).

Notamos que esta imagen de infancia trae una serie de consecuencias políticas y pedagógicas en la institución escolar, porque la infancia es concebida de forma lineal, cumple la función de formar a los niños y niñas, de transmitir valores, de disciplinar social y políticamente a los sujetos, de prepararlos para el futuro, para el mundo adulto en un tiempo cronológicamente organizado por grados, niveles; se estructura en una línea continua que el niño/a debe atravesar paulatinamente; de ahí que en sus voces se escuche constantemente 
angustias, temores, se configure una transición compleja por las estructuras pedagógicas institucionales (Encuentro 2, grado primero, 4/10/2017):

- Esta escuela hay veces es difícil a veces lloro, muy duras las matemáticas, las sumas, todavía no se sumar, es que no entiendo y me quedo atrasado, por eso viene mi mamá a ayudarme (N16-Niño 7 años).

- Profe vea es que aquí dictan mucho y nos quedamos atrasados y borran el tablero, la profe nos regaña mucho porque nos distraemos o nos portamos mal, ijummm! yo ahí veces no le prestó atención a la profe y me toca pedir ayuda de mis amigos para desatrasarme, a veces son unas tareas demasiado duras (N14 Niño 7 años).

- Profe vea el no hace tareas, no sabe leer ni escribir, la profe siempre lo sienta adelante y hay que ayudarle, cierto el solo dibuja, la profe dice que tenemos que ayudarle mucho (N12-niño 7 años) .... es que a mí se me olvida lo que la profe enseña, yo trato y me concentro mirando bien al tablero, aunque no se escribir, no sé si pase a segundo, (rostro de tristeza) si es verdad contesta otro de los niños (N16).

Retomando el análisis hecho por los niños y niñas urge repensar la forma como se está concibiendo la relación entre infancia, niñez y escolarización. Pareciera que el escenario escolar fija la duración de la infancia con su currículo y propuesta de enseñanza, y esto lo mencionan los niños constantemente cuando hablan de sí como "niños/as grandes". Los niños y niñas quisieran una niñez que no fuera interrumpida, sin embargo, la escolarización especialmente en la básica primaria les implica dejar de ser niños/as porque hay que cumplir con la misión de la escuela. Kohan (2011) plantea la necesidad de pensar la infancia cuando se le da un tiempo, un instante, una duración (p. 102), y esto interpela los fines de la Educación Infantil.

En esta línea se puede ver también que preexiste en los discursos de los niños y niñas diferencias con respecto al género, la mirada que tienen las niñas es de ser buenas, inteligentes, juiciosas y la de los niños es de ser traviesos, desobedientes, pero a la vez ser hombres adultos fuertes, responsables, configurando un discurso hegemónico y patriarcal. Esta diferencia en las experiencias de niñas y niños hace que sea tan importante incorporar las cuestiones de género en el ámbito de la Educación Infantil. Así, observamos que los niños y niñas como consecuencia de la apropiación que hacen de los discursos instalados por sus maestras y 
agentes educativas en relación a "ser niños/as grandes" van apropiando una visión con respecto a los roles que nos recuerda la triple carga para las mujeres -trabajo, práctica doméstica y reproducción- como resultado de la división sexual del trabajo (Breilh, 1991). En este sentido, la asociamos con el rol que debe asumir el niño/niña en cuanto a la carga de las tareas escolares, el rol de ser sujeto maduro y responsable, ser un niño/niña adulta/o y autónomo en el nuevo escenario escolar.

Pensar de esta forma la escuela infantil como escenario escolar, es poner en cuestión la estructura institucional, los tiempos, sus espacios, sus currículos, es poner en consideración la configuración frente a las infancias, es visionar una escuela integral que no se segmente ni divida pues una educación infantil fraccionada influye en la deserción, la desmotivación y la interrupción de la trayectoria de los sujetos. Redondo (2016) sugiere que existen condiciones para que la escuela funcione con otros registros, bajo otros principios y criterios, otros modos de construcción pedagógica abierta y en movimiento. Para Frigerio (2007) sería posible educar y "hacer escuela", si se entiende por escuela no cualquier lugar sino un posible continente para que todos y cada uno encuentre modos de dar trámite cultural al enigma subjetivo. (p. 327)

En definitiva, y retomando nuestro trabajo de campo se trata de pensar una escuela que ha de ser ante todo un ecosistema que independientemente si se centra en un escenario convencional, formal o no convencional, propicie gran riqueza de experiencias, provocaciones, encuentros consigo mismo, con los otros, con el contexto, con las realidades, con las subjetividades, con otras formas de comportamientos, otras rutinas, estímulos y oportunidades. Una escuela que se caracterice por la riqueza de estimular las capacidades, las singularidades

y la sensibilidad intercultural; un espacio enriquecido capaz de mejorar las posibilidades de desarrollo y que varíe sus funciones dependiendo de las condiciones del contexto y la realidad de su grupo poblacional. No es pensar en una escuela única, por el contrario, escuela implica mediar un espacio entre lo cultural, lo político, lo social y lo particular.

\subsection{A modo de cierre}

En el paso que hacen los niños y niñas por la escolarización se observa que prevalece una estigmatización y caracterización de la infancia por parte de las maestras y agentes 
educativas asociada a sus diferencias culturales, sociales, económicas y cognitivas. Identificamos una mirada de las infancias pobres y/o excluidas instaladas en la fragilidad social, en la vulnerabilidad, de tal modo que los niños y niñas son sujetos caracterizados por su condición de discapacidad, alerta en el desarrollo, de desplazamiento, extra edad, abandono, por su situación económica, son actores afectados por las situaciones políticas, económicas, sociales y culturales, infancias que crecen solas, aprenden a responsabilizarse de su crianza como de sus compromisos escolares. En definitiva, una visión sobre la condición infantil de sus niños y niñas sostenida en la falta, la carencia, la pobreza sin poder rescatar otras características como los sentimientos de los niños y niñas, sus formas de pensar y concebirse en la infancia, de comprender los procesos de escolarización, de entender sus transiciones, es decir las voces del otro lado de la línea “de los mismos niños y niñas” quienes tienen una representación distinta de su infancia.

Para los niños y niñas "ser niño-a" a diferencia de sus maestras significa reconocerse dentro de un contexto en el que identifican sus desarrollos, cualidades, valores y su identidad; es estar creciendo y madurando, es una etapa para divertirse, para ser escandaloso, para ser feliz y crecer con el otro. Ser niño/a es pasar de ser escandaloso a madurar, es concebirse en relación con el otro, es transitar una infancia que se va transformando en el paso que hacen entre la educación inicial y la educación formal, porque viven experiencias de diversión y alegría, pero también de pérdida: pérdida del tiempo, del juego, pérdida de los juguetes y regalos, del cuidado y atención de sus padres, de sus rutinas, rituales, del tiempo libre y el ocio y esto porque se deben apropiar las lógicas de la demanda escolar, lo que genera temores a “crecer" y a las nuevas responsabilidades de las tareas, de ser juicioso y maduro.

Los niños y niñas configuran la trayectoria en relación a los recorridos, momentos y experiencias importantes que han construido con la familia, la escuela, la comunidad, en el paso que realizan entre la educación inicial programa Buen Comienzo y la educación formal ellos/as nominan la importancia de los vínculos que tejen con su familia, pares, la experiencia se construye con los otros; cuatro cambios significativos son los que demarcan su trayectoria: cuando éramos bebés y gateamos, cuando empezamos a caminar, cuando llegamos a la escuela y cuando somos niños y niñas más grandes. La primera representa una etapa del curso de vida en la que los niños le dan vida a ese proceso de la gestación, al vínculo afectivo y emocional que se genera entre madre e hijo y también esas características propias de la etapa frente a la 
crianza y el cuidado destacan la relación que entablan con las madres sintetizada en la frase "chupar teta".

La segunda etapa sintetiza las experiencias vividas en el paso que dan desde el hogar a la guardería narradas como un período mágico de juego, diversión, exploración, donde los niños-niñas se narran alegres, sin complicaciones, sin normas, libres. En cambio, la tercera etapa marcada por el ingreso a la escuela representa el cierre de un ciclo y el inicio de nuevos aprendizajes, experiencias y demandas que implican cambios en su forma de actuar y comportarse dentro y fuera de la escuela, relaciona las pérdidas ejemplo de sus juguetes como los armatodos, las cocinitas, los juegos de concentración de su infraestructura por los nichos exploratorios, pero también de aprendizajes. La cuarta etapa refiere a los duelos y las rupturas que se establecen entre una etapa u otra y que son recuperadas por los niños y niñas cuando narran la experiencia de transitar de la educación preescolar a la educación formal. Aquí los niños y niñas viven interacciones simples o complejas, como resultado de una experiencia que tiene relación con ellos y después de la cual ya no son los mismos, los duelos que nombran frente a sus ritos, juguetes, docentes, confirman que en ese transitar ellos/as se enfrentan una pérdida frente a su propia infancia.

De esta forma observamos que en su experiencia por el paso que hacen entre la Educación Inicial y Educación Formal la trayectoria representa períodos de cambio, duelos y rupturas. Los niños y niñas interactúan en un mismo escenario con metas compartidas pero sus trayectorias son heterogéneas. En algunos casos, las trayectorias son lineales y en otros, tal como venimos señalando, las diferencias en las dinámicas familiares y sociales producen trayectorias educativas otras, no ajustadas al patrón de escolarización, dado que cada niño-a representa una historia y sus experiencias son singulares porque el niño-niña como cuerpo social introyecta la mayor parte de los conceptos o nociones que se les ofrecen como referentes de su identidad; $y$, finalmente, son discontinuas porque depende de las condiciones y oportunidades que tiene cada sujeto.

Asimismo observamos que ellos tienen una caracterización para nombrar la escuela infantil, describiéndola como la "escuela de antes" versus la "escuela de ahora" para ellos/as representa un espacio escolar con un diseño estructural diferente en el que, por un lado, experimentan la alegría de una época de juego, diversión, libertad (Educación inicial ) y por la 
otra se acercan a un escenario escolar más estructurado (Educación Formal); "la escuela de antes" es el lugar del juego, de los juguetes, chorritos, arma todos, cocinas, plastilina, pinturas, el lugar para comer, para dormir, para jugar a ser campesinos, indios, para bailar es un escenario de protección, diversión, que se extraña por su misma estructura organizativa. la escuela de ahora es el lugar de la disciplina, destacan la importancia de un escenario escolar que pone el acento en el contenido académico, la convivencia, la existencia de tareas, el lugar de los contenidos: porque no hay juguetes, pero si tareas de lectura y escritura y por eso los cuerpos se deben acomodar a unas nuevas reglas, es una escuela que también protege y cuida.

En esta experiencia escolar los niños y niñas manifiestan diversas angustias, la más representativa es la pérdida frente a lo que significa dejar de ser niño-niña en el paso del grado de transición al grado primero, vemos una narración marcada por el sentido de pérdida: del juego, pérdida de los juguetes, de su propia infancia; ellos/as refleja un temor a crecer " yo no quiero ser adulto porque ser niño es muy divertido" pero también el temor a enfrentarse a un escenario escolar que es difícil porque: las matemáticas son duras, porque dictan mucho, porque se quedan atrasados y les borran el tablero, porque los regañan si se distraen; es decir una etapa de nuevas responsabilidades frente a las demandas escolares. Pareciera que el escenario escolar fija la duración de la infancia con su currículo y propuesta de enseñanza, pero los niños y niñas quisieran una niñez que no fuera interrumpida.

Dejar de ser niños/as porque hay que cumplir con la misión de la escuela es la insignia que nos muestran los niños y las niñas frente a su experiencia escolar en la Educación Infantil y esto nos pone a reflexionar a nosotros los maestros, frente a los discursos que instalamos y que ellos/as apropian, ejemplo la mirada que tienen las niñas de ser buenas, inteligentes, juiciosas y la de los niños de ser traviesos, desobedientes, pero a la vez ser hombres adultos fuertes, responsables; la visión con respecto a los roles que deben asumir cuando crecen especialmente con la carga de las tareas escolares, de ser sujeto maduro y responsable, ser un niño/niña adulta/o y autónomo en el nuevo escenario escolar, nos lleva a repensar las prácticas pedagógicas, el sentido de la Educación Infantil frente a la educación de las infancias, y a escuchar-privilegiar con más atención las voces de nuestros niños y niñas, hacer lecturas de lo que ellos/as sienten, desean, piensan, necesitan. Esa será la clave para lograr una verdadera educación democrática darle voz y voto a todos los niños y las niñas 


\title{
Capítulo VIII
}

\section{Experiencias y sentires de los niños y niñas frente a}

\author{
su proceso de transición
}

\section{Introducción}

Las percepciones, imágenes, valores, pensamientos, sentidos y símbolos que los niños y niñas construyen frente a la experiencia que implica transitar de un nivel a otro o entre escenarios educativos diferentes se convierten en ejes centrales de análisis para comprender como ellos/as configuran su participación, y la representación que tienen frente a las interacciones y relaciones que establecen con sus pares, docentes, familia y comunidad en los recorridos escolares. Corsaro y Rizzo (1988), Corsaro y Eder (1990) señalan que la infancia tiene su propia manera de ver, de pensar y de sentir, pudiéndose conceptualizar la cultura infantil de una manera amplia y penetrante. Por su parte Mayall (2000) pone el acento en la necesidad de otorgar especial importancia a las visiones de los niños/as dado que son actores en los mundos sociales en los que participan. Por esa razón la investigación debe enfocarse directamente sobre los niños y las niñas y sus condiciones de vida, actividades, relaciones, conocimiento y experiencias.

Varias son las investigaciones que resaltan la importancia de considerar la perspectiva infantil en la investigación educativa. Pascal y Bertram (2009) afirman que este proceso permite la generación de un diálogo sustentado en el respeto mutuo, la escucha activa, la participación, la negociación y, por lo tanto, la construcción de significados compartidos. En el mismo sentido, Argos y Ezquerra (2015) resaltan que este proceso amplía la mirada del investigador al incrementarse su conocimiento acerca de la realidad educativa que pretende estudiar, mientras que Gaitán (2006) refiere que tener la voz de los niños y niñas es de gran interés porque se comprende de primera mano sus propias valoraciones, necesidades, demandas y percepciones.

Para recoger la voz de los niños y niñas se requiere de su aceptación, esto es, respetar su deseo y decisión de participar en la investigación. Cocks (2006) enuncia tres momentos 
claves en el trabajo con los niños-as: el primero, centrado en la presentación de la información por parte del investigador; el segundo, tiene en consideración la comprensión que los niños y niñas hacen frente a la información suministrada, el alcance, los objetivos y su vinculación en el proceso; el tercero, referencia la emisión de la respuesta en la que los niños aceptan su participación. Al respecto Castro, Ezquerra, y Argos (2016) destacan la "importancia de la perspectiva ética de los propios niños en la investigación y la importancia de contar con él consentimiento informado de ellos/as por pequeños que sean" (p. 120).

En esta investigación se tomó en cuenta el consentimiento de los niños-niñas y su decisión de participar libre y autónomamente durante toda la investigación. Para ello se realizó un encuentro presencial en el que se les contó en qué consistía el estudio, cuáles eran sus objetivos y metodología, se contestaron todas sus dudas y se les proporcionó la información que pedían ${ }^{46}$. De este encuentro participaron las familias y maestras quienes apoyaron todo el proceso de la investigación, inclusive en el momento de cierre del proyecto en el que se socializaron los resultados.

Dado lo anterior y considerando la importancia de escuchar los sentidos y sentires de los niños y niñas frente a su experiencia de transición en cada uno de los niveles educativos, en el primer apartado del presente capítulo se analizan las implicaciones de los tres momentos que conforman toda transición (separación, reacomodación y aceptación), y se describen los acontecimientos, situaciones y experiencias que viven los/as participantes de esta investigación en el proceso de escolarización en la Educación Infantil. En el segundo apartado se estructuran los saberes que los niños y niñas dentro de su recorrido por los escenarios de Educación Infantil estructuran como importantes. Se analiza cómo interpretan las actividades que les proponen y agentes educativas y qué preguntas se hacen frente a las dinámicas curriculares. Finalmente, en el tercer apartado se analiza el valor que otorgan los niños y niñas a su experiencia escolar, los vínculos afectivos que tejen, el juego, las actividades rectoras, y el lugar de los espacios educativos y zonas de esparcimiento.

\footnotetext{
${ }^{46}$ En este encuentro se evidencia asombro y la inquietud constante por parte de los niños y niñas frente a lo que significa investigar en la escuela. Se evidenciaba en sus rostros emoción por iniciar este proceso, y en la madres y padres aprobación y satisfacción porque ven en esta investigación la oportunidad de comprender lo que sienten y piensan sus hijos frente al proceso de escolarización.
} 


\subsection{Sentidos y sentires de los niños y niñas frente a su proceso de transición (separación, reacomodación y aceptación)}

Describir los acontecimientos, situaciones y experiencias que viven los niños y niñas en el proceso de escolarización es construir artesanalmente la narración de una vida en singular, la sensibilidad frente a una transición mediada por expectativas, incertidumbres, temores, aceptaciones, imposiciones, propuestas, acompañamientos, vínculos, pérdidas, y adaptaciones; es observar las implicaciones que tiene en cada individuo una etapa importante en su trayectoria escolar en la que como sujeto debe tramitar situaciones particulares de separación, reacomodación y aceptación.

Separación es el primer momento importante que los niños y niñas nombran a partir del ritual de la graduación. Con sentimientos encontrados relatan este rito que significa despedirse de una etapa, un proceso y unas dinámicas: "nos tomamos la foto" sintetiza el momento exacto de la promoción a otro nivel educativo. El pasaje implica el cambio a un nuevo escenario, a un nuevo grupo en el que se entremezclan expectativas y temores. Las expectativas reflejan el deseo de conocer nuevos amigos, espacios educativos, docentes, compartir, interactuar, de sentirse más adulto. A continuación, presentamos aquellas expectativas y temores de niños y niñas que asisten a grado primero (Encuentro 5, 15/11/2017).

Expectativas de los niños y niñas

- Profe ayer nos tomamos la foto de los grados, sí y ¿para que esa foto?, pues para graduarnos (N9-niño 6 años).

- Yo si quiero pasar con los niños/as grandes porque vamos a hacer tareas como esas y muestra en el tablero el abecedario (N9-niña 6 años).

- Vamos a jugar en la cancha, nos vamos a portar bien, vamos a tener muchos amigos (N5 niño 6 años).

- Si la profesora nos dice que vamos a llevar cuadernos, nos vamos a sentar solitos en una silla por eso tenemos que cuidar nuestras pertenencias, también vamos a escribir más y aprender mucho los números del 1 al 100 (N7 niña 6 años). 
Los temores están referidos a la posibilidad de perder sus juegos, juguetes, amigos, profes, el susto de no ser aceptado y de no cumplir con las exigencias de ese nuevo espacio escolar.

\section{Temores de los niños y niñas}

- Yo no quiero pasar a primero me da susto yo no sé muchas cosas (N11-Niño 5 años).

- Profe yo tengo mucho miedo pasar a segundo porque todavía no se escribir, cuando llegué a primero también fue difícil (N16-Niño 7 años).

- a mí no me da susto, pero no sé (silencio) no sé si logro pasar el año, y ¿Por qué?, porque casi no hago las tareas, yo soy lento y me da dificultad, quien te ayuda en la casa con las tareas mi mamá, a veces mi hermano (N-12-Niño 7 años).

- $\quad$ yo sí hago las tareas, pero no se escribir bien (N17-niña 6 años).

- $\quad$ si yo pierdo el año, yo ya me voy para mi casa y ya voy a estudiar más, mi mamita dijo que no me va a pegar solo me va a enseñar más para que aprendas a ganar el año ( $\mathrm{N}-15$ niño 7 años).

- yo si voy a ganar el año porque la profe me dijo además en segundo vamos a tener otros amigos y profes (N13-niña 7 años).

En esta tesis pudimos corroborar que la transición como experiencia se enmarca en un fin y un inicio, un antes y un después y se ve atravesada por situaciones emocionales, apegos, costumbres, deseos y construcciones subjetivas. Para algunos niños/as representa un proceso difícil de adaptación por los múltiples cambios y dinámicas institucionales, representa un sentimiento de miedo por no creer que tienen las competencias ni los saberes suficientes para participar en el otro grado, la angustia se ve reflejada en los aprendizajes y en no saber escribir; el silencio es la forma de manifestar su preocupación pero a la vez el temor de enfrentarse a las nuevas configuraciones del aula o la institución, ven limitada su participación en este nuevo ambiente.

Para otros niños y niñas es sinónimo de timidez y tristeza por no querer dejar ese lugar en el que se sienten acogidos y apoyados, no querer dejar sus juegos mientras que otros simplemente reflejan tranquilidad ven el paso como una oportunidad para sentirse más grandes, tener nuevos amigos y docentes, ser mas independientes, y adquirir nuevos aprendizajes; la mirada hacia el otro escenario refleja un lugar de aprendizajes pero también deja ver un lugar 
hostil en el que deben aprender a cuidar sus pertenencias. Por todo esto la transición es una experiencia individual.

Dockett y Perry (2005) describen que el inicio de la escolarización es uno de los grandes retos a los que los niños/as se enfrentan. En las narraciones los niños y niñas manifiestan que quienes lograron generar empatía con los nuevos compañeros y maestras tuvieron un mejor proceso de adaptación y asimilación al nuevo escenario. En cambio, los que no lograron tener una red de apoyo presentaron mayores dificultades para aceptar y validar las nuevas experiencias. Estos obstáculos fueron relevados en el trabajo con niños y niñas que concurren al grado transición (Encuentro 5, 8/11/2017).

- Cuando empecé la escuela, fue muy triste porque extrañaba demasiado a mis papás, porque fue mi primer día de clase, porque los profesores eran muy diferentes, también uno se sentía mal cuando a uno lo regañaban, porque uno sentía que era la mejor estudiante allá, fue distinto a la guardería porque allá no había la presión por leer o escribir, aquí yo no me acordaba de nada, en cambio mis amigos sí (N13-Niña 7 años).

- Cuando llegué por primera vez a la escuela sentí un susto porque todo en mi nuevo colegio, en mi segundo nuevo colegio, era distinto, ya tenía que aprender mucho, y me dio susto, pero había una amiguita que se llama Mélani y me ayudo. Yo ya estoy muy feliz porque en la escuela ya vi muchos amiguitos entrando, muchas profesoras, y muchas cosas por descubrir y aprender en el colegio (N14-niño 7 años).

- Cuando empecé la escuela, bueno empecé sin amigos, pero ahora tengo muchos, cuando llegue no tenía a nadie y ya empecé a conocer niños, aquí fue distinto a la guardería, es que en la guardería de $\mathrm{BC}$ antes dormíamos, era lo único que hacíamos era dormir, pero en cambio acá ya estudiamos hacemos tareas, aprende uno a sumar, después a restar, los salones son diferentes, los de $\mathrm{BC}$ eran grandes aquí son chiquitos (N5-Niño 6 años).

Estas voces reafirman los postulados de Castro, Argos y Esquerra (2015) y Ames y Rojas (2011) quienes advierten que el proceso de transición es vivido de forma intensa por los pequeños quienes llegan a manifestar miedo, nerviosismo y ansiedad por el cambio a otro grado, los niños pierden interés por los estudios y por ello mantener los vínculos de amistad es un apoyo para poder afrontar positivamente este proceso. De esta forma analizar la importancia de las redes de apoyo y el establecimiento de vínculos afectivos es primordial en un proceso 
de transición en tanto garantiza la seguridad y confianza que necesitan los niños y niñas para asimilar los nuevos cambios y reacomodarse a las nuevas situaciones y experiencias del proceso escolar. La capacidad de aceptación es primordial en este proceso que se ve mediado, de acuerdo a las expresiones de los mismos niños y niñas, por cambios bruscos en cuanto a:

- La diferencia entre los salones de clase, especialmente en el cambio de transición a grado Primero-Escuela Básica

- La pérdida de los juguetes

- La metodología de trabajo

- Las tareas

- El uso de cuadernos

- El juego

- Los aprendizajes

- La escritura

Reacomodación es el segundo proceso e implica adaptarse a los nuevos códigos y prácticas institucionales apropiándose de normas de convivencia, de comportamientos esperados y formas de actuación propias de un dispositivo escolar disciplinar que regula el cuerpo, controla y moldea una forma de ser, propone ciertos aprendizajes y formas de evaluación que para algunos niños y niñas es compleja y genera sentimientos de temor, miedo y ansiedad, al tiempo que deben enfrentar desafíos desde el punto de vista de las relaciones sociales, los contextos de aprendizaje y el aprendizaje en sí mismo.

Los desafios desde el punto de vista de las relaciones sociales en la visión de los niños y niñas son: 
- Profe a mí también, a veces me porto bien y a veces mal, porque le pego a los amiguitos, pero yo me controlo la ira, yo hago mis tareas en silencio en este nuevo grupo pero profe vea los niños más inteligentes los pueden pasar para primero $3^{47}$, y los menos inteligentes los pasan para primero (2), y los más indisciplinados otra vez repiten primero, pero yo no voy a repetir yo soy inteligente y buen estudiante (N14- niño 7 años).

- yo siento miedo de pasar a primero, no me gusta porque los amiguitos me molestan, me siento triste cuando los/as compañeros no juegan conmigo y que las profes me regañen, me aburre hacer tareas, o que los amigos/as me aporreen, me gusta el salón de preescolar, pero los de primero no, porque yo no quiero estar en primero (N2-niña 6 años).

Los desafios desde el punto de vista del contexto de aprendizaje en la visión de los niños y niñas son:

- Es que a veces la escuela es difícil porque lo ponen a leer a uno, y a escribir, y yo se mas o menos, a mi da susto que de pronto me vaya mal en el otro grado (N9-Niña 6 años).

- Yo me siento feliz hago todas las tareas y la profe me pone caritas felices ya llevo siete, a veces me aburro aquí en la escuela a veces nos ponen a hacer unas tareas todas difíciles yo me quedo atrasado (N17-Niña 6 años).

- Profe a mí me aburre que la profe llene el tablero porque me cansa los dedos de escribir; esas tareas son muy largas (N15-Niño 7 años).

Zubizarreta, Muñoz y González (2017) clasifican las preocupaciones de los niños y niñas respecto de su transición de Inicial a Básica de la siguiente manera: (1) las relaciones sociales y afectivas, (2) la necesidad de asumir las normas y la conducta escolar, (3) la importancia de conocer los espacios, (4) las destrezas académicas y (5) la preocupación por el aprendizaje y su rol; preocupaciones que en relación con lo narrado por los niños/as de este estudio caracterizan los sentidos y sentires vividos en este cambio, evidenciando que en el proceso de reacomodación los aprendizajes, las tareas, el rendimiento escolar y el imaginario frente al estudiante ideal, inteligente y competente son los procesos que más implican acciones

\footnotetext{
${ }^{47}$ Primero (3) significa que de un mismo grado hay varios niveles en la institución. El caso particular de N14 es que hace una semana lo cambiaron de grupo, estaba en primero 1, y lo pasaron por dificultades comportamentales de acuerdo a su docente para primero 2. El niño hace una lectura diferente, afirma que el cambio de grado se debe a que la docente no lo quiere, que constantemente le llama la atención, y que fue ella quien lo cambio de grupo, según él, para el grupo de los menos inteligentes.
} 
de adaptación y que determinan en gran medida las discontinuidades o desencuentros entre los niveles.

En este sentido vemos que la carga que implica para ellos ser niños y niñas más grandes y juiciosos en el cambio entre niveles, especialmente del grado transición a la básica primaria, deja ver una preocupación constante por la tarea. El temor de los niños y niñas se concentra por un lado en el rendimiento académico, en que les "vaya bien" y, por el otro, en que sean aceptados y reconocidos por los compañeros y los/as maestras pues ingresan a una escuela que según sus narraciones es un lugar complejo por la asignación de las tareas y difícil porque es un escenario que categoriza y clasifica a los niños y niñas según sus saberes -“inteligencia”- y comportamientos. Ejemplo de ello es la visión que construyen de ese espacio sus actores y las recomendaciones que hacen los niños/as de grado primero a los que van a pasar de preescolar (Encuentro 5, grado primero 15/11/2017).

Investigador ¿Qué les recomiendan ustedes a los niños/as de preescolar que van para primero?

- que se manejen bien que no se vayan a manejar mal, que aprendan, que lean, que sumen, que resten, porque es muy difícil entrar en primero (N12 niño 7 años).

- aunque es muy difícil para los que se manejan mal, muy fácil para los que se manejan bien, porque los que se manejan mal, le pegan a los compañeros, gritan a la profe, le gritan a los compañeros, no hacen las tareas. Pero que no se asusten, que ya son niños grandes fuertes y juiciosos, que es muy divertido pa todos los niños, todos los primeros son divertidos" (N14niño 7 años).

La tarea indiscutiblemente es el eje de análisis en este proceso de transición porque constituye un condicionante para la participación, en tanto si cumplen con ella en los escenarios escolares van a poder pasar al otro grado o se van a sentir reconocidos. En las voces de las maestras la tarea permite desarrollar hábitos de trabajo, orden, responsabilidad, autonomía y capacidad esfuerzo. De acuerdo a lo establecido por Becerra (2010), "las tareas escolares, como parte del dispositivo pedagógico, representan una expresión en torno a la manera como se debe controlar al niño" (p. 52). Sin embargo, también hay que mencionar que no todos los niños y 
las niñas viven la transición de forma compleja, algunos se adaptan fácilmente a las nuevas estructuras institucionales, es decir, se apropian sin mayores inconvenientes del nuevo espacio.

Vemos que esta aceptación tercer proceso-esta mediada por su capacidad de implicación en las actividades y dinámicas propias del grado o nivel, en su forma particular de vivir el tránsito, de desenvolverse en el contexto, relacionarse y generar los vínculos afectivos con sus pares y docentes; de autopercibirse como el "niño grande" que impone la escuela, asumiendo nuevos rituales y acomodándose finalmente a las nuevas reglas institucionales.

- En esta escuela estoy muy feliz, muy amorosos, muy dedicados conmigo los profesores, la escuela, es muy grande, y bonita. Las profes son amigables conmigo súper amorosas, ellas quieren que nosotros aprendamos mucho, porque ellas no quieren que perdamos el año, porque ellas se quieren sentir muy orgullosas de nosotros, por eso no hay que sentir miedo porque eso es crecer, crecer no significa que tengamos miedo, significa que ya estamos creciendo, y vamos a conocer nuevos salones, nuevos amigos, nuevas profesoras, y eso es crecer (N15-niño 7 años).

- Aquí en esta escuela estoy con una profe que me escucha, y me pone hacer cosas importantes, al principio fue duro, pero ya mi profe me escucha, estoy feliz y tengo a mis amigos, el salón, aquí es muy bonito, limpio, me gusta cuando la profe me felicita y me dices cosas bonitas, me ayudan con las tareas (N7-Niña 6 años).

- Me encanta la escuela, es muy bonita, es grande, me gusta los profesores, y los espacios donde podemos jugar y ya. yo necesito mucha atención porque me distraigo y entonces en la escuela da miedo que lo regañen, pero me han tratado bien, y me aconsejan mucho (N2-niña 6 años).

Comprender por tanto que una transición educativa implica para los niños-niñas un proceso de separación, reacomodación y aceptación es clave para direccionar acciones y mecanismos que desde los procesos pedagógicos y administrativos puedan ayudar a mediar esta experiencia. Además, es clave para planificar la tarea que compromete también a las familias, para el fortalecimiento del desarrollo socioemocional y cognitivo de los niños y niñas, para la promoción de aprendizajes específicos que faciliten la transición y promuevan una trayectoria continua. 


\subsection{Qué se aprende y qué se debe saber en los recorridos escolares por la Educación Infantil.}

En este apartado se estructuran los saberes que los niños y niñas dentro de su recorrido por los escenarios escolares reconocen como importantes; se analiza cómo ellos interpretan las actividades que les proponen, qué cuestiones reconocen como aprendizajes, cuáles son sus opiniones con respecto a la propuesta de enseñanza propia de cada escenario y nivel. Recoger las percepciones de los niños y niñas sobre su proceso de aprendizaje y los saberes que se construyen en el escenario escolar es de suma importancia para analizar el sentido y lugar de los saberes en la Educación Infantil.

El lugar de los saberes en los escenarios escolares tanto de la Educación Inicial (atención integral a la primera infancia) como de la Educación Formal (grado transición y primero) es diferente como también los procesos de enseñanza-aprendizaje, los proyectos pedagógicos derivados de los currículos la formación ética, política y estética, así como la estructura curricular.

Encontramos que para los niños y niñas los saberes aprendidos en los escenarios escolares son distintos pues se estructuran en un grupo de conceptos que se transforman y se complejizan en la medida que avanzan en su trayectoria escolar. En este camino ellos/as experimentan desencuentros por los "saberes disciplinados" o institucionalizados ajustados a una convención institucional que en nuestro caso responde a tres escenarios: Educación Inicial Atención Integral, Educación Preescolar y Educación Primaria.

Se puede ver en este estudio que los saberes y aprendizajes de la Educación Inicial y Atención Integral se enmarcan en correspondencia con las actividades relacionadas con los juegos de roles, la exploración del medio, el arte, la literatura, el juego, la expresión corporal, artística y la representación gráfica; para los niños/as esta etapa de su vida está marcada por actividades divertidas y los principales aprendizajes son aprender a relacionarse con el otro, aprender a respetar, a compartir, hacer amigos, actuar con libertad, seguridad y autonomía. En este escenario de Educación Inicial el proceso de enseñanza aprendizaje se establece bajo una interacción mediada por la escucha, el interés del niño, su desarrollo infantil y por las relaciones de este con su contexto cultural familiar y social, mediante actividades que les permiten el disfrute, goce, alegría, diversión y creatividad. Los objetivos principales de la 
Educación Inicial se concentran en fortalecer en los niños y niñas la imaginación, la curiosidad, autoimagen y desarrollar habilidades cognitivas y sociales. En este sentido las principales actividades que nombran los niños-niñas y que según ellos dan cuenta de la promoción de experiencias significativas con sentido pedagógico en el sistema de Atención Integralprograma Buen Comienzo son:

- Actividades de roles: jugar hacer campesino, indios, a los héroes y oficios de los padres y animales entre otros.

- Actividades de movimiento: bailar, cantar, expresarse con el cuerpo

- Actividades de exploración: experimentar, interactuar con objetos del contexto y del medio natural y social

- Expresiones artísticas: danza, música, teatro

- Actividades literarias: lectura de cuentos, representación de obras

- Actividades de convivencia para el relacionamiento con el otro

- Actividades que involucran el juego y el trabajo

- Actividades con materiales concretos

Los saberes y aprendizajes de la Educación Formal-Preescolar según las voces de los niños y niñas se relacionan directamente con experiencias donde el juego, lo lúdico se convierte en el medio para aprender, compartir y descubrir saberes. Con expresiones artísticas como la pintura, el dibujo y la expresión grafico plástica; el preescolar es un espacio para preparar el cuerpo de manera tal que los niñas y niños puedan sostener la atención por más tiempo (permanecer sentados por tiempos prolongados), aprender a ir al baño en determinadas horas, hacer la fila para salir al descanso, utilizar los cuadernos, prepararse para el aprendizaje de las letras, la escritura, la lectura, las matemáticas y los números; un momento para aprender a regular los comportamientos, para obedecer, respetar las normas y reglas del juego; es un espacio donde se hacen actividades para aprender a controlar las emociones, la ira y no pelear con los compañeros, para hacer amigos y comprender las relaciones con los otros y otras. Qué se aprende en las voces de niños y niñas que asisten al grado transición (Encuentro 6, 22/11/2017).

- Aquí en preescolar aprendemos a pintar, colorear, leer, cortar (N11-niño 5 años). 
- En preescolar jugamos escondidijo, chucha cogida, jugamos en el parque, pintamos, jugamos a la rueda, y jugamos a la escuela; aprendemos a escribir, leer, trabajar, encajar, pintar y escribir (N1-Niño 5 años).

- Aprendemos a manejar las tijeras, a realizar tareas, a escribir el nombre, a hacer tareas personales y grupales a jugar en los descansos y en el parque con los primos, amigos, a utilizar materiales concretos para aprender a contar (N3-Niña 6 años).

- Se aprende a ver películas, a cuidar al agua, la tierra, realizar recetas y maquetas de los medios de comunicación o de la familia (N7-Niña 6 años).

- Un espacio donde las profes nos enseñan valores para ser mejores niños en primero (N6-niño 6 años).

- Preescolar es un grado para hacer actividades misteriosas, jugar con harina, investigar, actividades que nos preparan para el grado siguiente (N10-niña 6 años).

Ilustración 16-Dibujos de los niños/as de transición ¿que se aprende en preescolar?

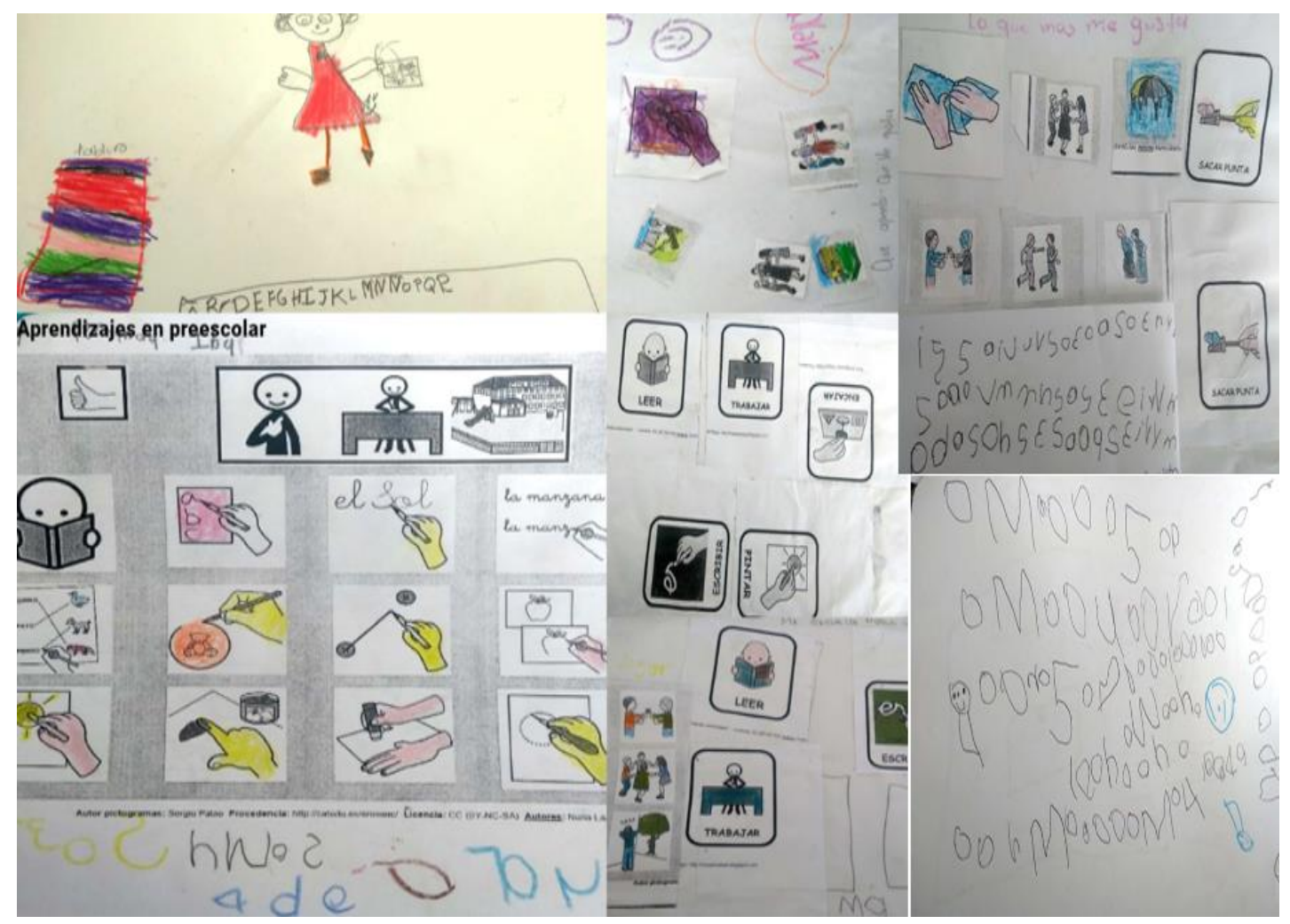

Fuente: -Elaboración propia 
La mediación en el proceso de enseñanza aprendizaje en este escenario parte de los proyectos de una interacción constante con la docente en la que se vincula la construcción de experiencias con los siguientes saberes:

- El aprendizaje de las letras, los números y la escritura

- El aprendizaje de las normas y los comportamientos

- El aprendizaje de las expresiones artísticas y la expresión literaria

- El aprendizaje por el cuidado de sí mismo del medio ambiente y del otro

- Relación con el mundo y desarrollo de la expresión y comunicación

- El juego

- La construcción de la identidad

Experiencias que se tornan complejas especialmente para los niños que presentan dificultades de aprendizaje o migran de otras regiones o países. Los códigos de la lectura, la escritura y las matemáticas es decir el aprendizaje de las letras y los números se torna complejo para ellos especialmente en el grado primero donde las exigencias son mayores y las pruebas evaluativas más difíciles.

Profe en primero no hay juguetes solamente salimos al descanso y jugamos, aprendemos a hacer tareas, unas que tienen que escribir mucho, a respetar a los amigos, no pegarles no morderlos, vamos a aprender a leer, porque todavía no sabemos y a escribir y sumar (N17niña 6 años).

En el grado primero tiene lugar la transformación de las actividades lúdicas y enmarcadas en el juego hacia la comprensión de un conjunto de áreas como son las ciencias sociales, naturales, artística, inglés, humanidades y lengua castellana, tecnología e informática, proyectos transversales entre otras. Todo ello implica una asimilación y acomodación frente a una estructura de saberes y conceptos que implican mayor exigencia académica. Para los niños y niñas esta organización curricular es compleja porque deben pasar de una estructura lúdica a una sistemática en la que se evalúa y se mide por competencias, lo que les demanda una exigencia mayor que también recae sobre el cuerpo. 
Esta regulación del cuerpo tiene por objeto el sostenimiento de la atención, los gestos corporales, la obediencia, él disciplinamiento porque se debe aprender a trabajar en silencio para respetar los espacios del otro/a, tener una buena postura corporal, aprender a realizar las tareas en orden, aprender normas de comportamiento, es decir, exige un estudiante más atento, maduro, disciplinado y ajustado al contexto institucional. Scharagrodsky (2007) afirma que "el cuerpo es un fenómeno social, cultural e histórico, siempre ha quedado prendido en el interior de poderes muy ceñidos que le han impuesto coacciones, interdicciones, autorizaciones y obligaciones permanentes” (p. 2). En la educación básica primaria de acuerdo a lo establecido por los niños y niñas la educación del cuerpo, que obedece, que responde al espacio a través de varios procedimientos, es el ideal de niño y niña; pues constantemente sus les están recordando la importancia de permanecer en silencio y sentados.

Para Chacón (2009), "la escuela es un espacio ecológico de cruce de culturas que provoca tensiones, aperturas, restricciones y contrastes en la construcción de significados" (p. 68). Los niños y niñas refieren al disciplinamiento del cuerpo que se logra a través del control de la actividad escolar mediante la vigilancia por parte de sus maestras, y la sanción normalizadora si no se cumple con las reglas establecidas en el aula. Para la escuela "la vigilancia y el control de los cuerpos infantiles es una de las funciones principales de las maestras; el espacio del cuerpo infantil es el de un sujeto dependiente, obediente y fundamentalmente dócil” (Scharagrodsky, 2007:5). Pérez Gómez (1998), la entiende la escuela "como una instancia de mediación cultural entre los significados, sentimientos y conductas de la comunidad" (p. 17)

El grado primero presenta muchas exigencias para los niños y las niñas porque realizan muchas tareas de matemáticas, inglés, de sociales con evaluaciones difíciles que miden sus aprendizajes. En sus palabras, aprender a concentrarse, a mirar bien el tablero y a no escuchar a nadie cuando están escribiendo. También es un espacio para aprender a escuchar a los/as maestras, para respetar a los compañeros, para ser más estudiosos, para aprender a comportase y seguir las instrucciones, reglas, las normas y la disciplina impuesta.

Aquí en primero aprendemos muchas cosas, sumas, restas, también nos enseñan aprender a leer, aprender a escribir, aprender a escuchar a las profes bien, a no pelear con los amiguitos, 
aprendemos a ser juiciosos aquí en primero no hay juguetes porque es que en primero los grandes no juegan (N12-niño 7 años).

Según los niños y niñas la enseñanza se traslada hacia un método tradicional en el que la lúdica y el juego son usados con menor frecuencia. Para muchos de los niños/as es "aburrida" reiterando la exigencia con respecto a las tareas, los dictados, y una preocupación enorme por el aprendizaje de la lectura y la escritura. Sus expresiones evidencian la ausencia de actividades divertidas, resaltan que la asignatura que más les gusta es educación física y artística porque se convierte en una conexión que les permite recordar su experiencia en preescolar gracias a la realización de algunas actividades de movimiento, pintura y uso de material concreto. Dado lo anterior vemos que en sus voces se configura el papel del cuerpo como un lugar en el que trascienden sentidos, sentires y códigos institucionales que dejan huellas y que marcan su trayecto de vida.

El análisis comparado de las narraciones de los niños/as respecto de lo que aprenden en cada escenario (Educación Inicial-Atención Integral, Educación Formal-Prescolar y Primaria) da cuenta de formas de estructuración del cuerpo infantil en un caso en base al juego y al movimiento y, en otro, la producción de un cuerpo escolarizado ajustado a los códigos institucionales. De este modo, las experiencias que promueven los escenarios escolares de la Educación infantil dejan huellas y dan lugar a una eventualidad que se encarna en el sujeto; vemos que el cuerpo es un lugar en el que se transcribe la obediencia, la rebeldía, la aceptación, la refutación o simplemente la identificación con unas prácticas o unos saberes impuestos, como territorio el cuerpo articula la subjetividad, sentidos y significados de lo otro y los otros, además expresa los conflictos y las tensiones que se viven en el recorrido de ese aprendizaje. Para Arcila (2015) el cuerpo,

/.../es portador de saberes, huellas y biografias, individualidad y sociabilidad; el territorio donde se articulan estéticas, sentidos y significados de los otros y lo otro, y es, por tanto, expresión y comunicación de la subjetividad humana, está en constante construccióndeconstrucción, aprendizaje, devenir y cambio, el cuerpo expresa los conflictos de las tensiones instituidas por la biopolítica: raza, clase, sexo, es el cuerpo el que metaforiza la forma de concebir personal y socialmente la relación entre lo singular, lo colectivo, el yo y lo otro. $(2015: 101)$ 
Así, el cuerpo sumergido en un escenario de Educación Infantil refleja los discursos estéticos, políticos, las prácticas, las nociones de un sistema escolar que institucionaliza saberes, contenidos, significados y subjetividades. Los itinerarios que realizan los niños y niñas en su transición entre escenarios educativos y grados escolares dan cuenta de las tensiones, subjetividades, encuentros y desencuentros frente al currículo, las metodologías, los saberes y aprendizajes escolares.

La concepción que ellos/as tienen frente a los saberes enseñados, hace alusión a unos planes de estudio y agrupamientos temáticos que son diferenciales para cada entorno; a un currículo que no parece dialogar o ser transversal y vertical frente a los procesos de la enseñanza y aprendizaje en la Educación Infantil.

1. Los desarrollos y aprendizajes de los niños y niñas tanto en la Educación Inicial como en la Educación Formal (preescolar y primero)

2. El lugar de las interacciones, de las actividades rectoras, el saber y la práctica pedagógica en ambos escenarios, es decir, del proceso de construcción curricular de la Educación Infantil

3. El reconocimiento del niño-niña como sujeto activo y protagonista del proceso de enseñanza aprendizaje y del maestro como actor que provoca y media experiencias significativas.

Desde este punto de vista la pregunta por el sentido de la Educación Infantil, su historia, su objetivación nos remite a seguir reflexionando, es decir, nos pone a pensar frente a los retos y desafíos que tenemos en correspondencia con el contexto de la Educación Inicial versus la Educación Formal. La forma de concebir las infancias, la manera compleja del contexto actual, los lineamientos y orientaciones tecnocráticas, la forma que se concibe la evaluación de los procesos infantiles, la estructura de los saberes, y más aún el perfil del ideal de niño o niña que queremos, deseamos y subjetivamos en nuestros escenarios educativos, requieren de un análisis sistemático. 


\section{3 ¿Y qué pasa con los vínculos afectivos y el juego en el paso entre niveles en la Educación Infantil?}

El valor que otorgan los niños y niñas a su experiencia escolar es de gran significado en la comprensión de las trayectorias. Su forma de concebir la escuela Inicial y Formal da cuenta de los sentidos que atribuyen a su experiencia, lo que les pasa, afecta y deja huella. Larrosa (1996) comprende la experiencia como aquello que nos pasa, nos afecta, atribuyéndole determinados sentidos y significados. La experiencia escolar de los niños/as se produce en relación con (1) los vínculos afectivos que tejen, (2) el juego y las actividades rectoras, (3) el lugar de los espacios educativos y zonas de esparcimiento.

Al preguntar cuáles son las interacciones más valoradas por su paso entre la Educación Inicial y la Educación Formal los niños/as mencionan dos aspectos fundamentales: el primero relacionado con el vínculo entre pares, la posibilidad de tener muchos amigos con quien compartir jugar y divertirse, y el segundo el vínculo con sus y agentes educativas. En esta relación el vínculo se establece como un sentimiento de amistad, afecto y reconocimiento del otro/a; es una forma de concebir su propia imagen, de identificar limitaciones o diferencias por los conflictos y enojos que mencionan cuando tienen peleas con los amigos/as. Frente a la pregunta ¿qué los hace feliz en la escuela? Los niño/as señalan a los amigos porque significan felicidad, apoyo, confianza y seguridad.

- Me hace feliz jugar con los amigos, tener muchos amigos, estar siempre con mis amiguitos, compartir en el descanso, me pone triste no tener amigos, pelear con ellos (N8-niña 6 años).

- también los amigos son todo para mí, con ellos aprendo, además jugamos y nos divertimos (N12-Niño 7 años).

- aquí me hace feliz estar con mi hermana me hace feliz jugar y jugar y jugar, que rico que la escuela solo fuera jugar y jugar y jugar (N7-Niña 6 años).

- Profe vea yo extraño mis compañeros de primero (1) para jugar con ellos, estar en el salón con ellos todos los días, pero la profe me paso para primero (3) porque no me aguantaba y aquí apenas estoy haciendo amigos, pero yo en el descanso juego con los de primero (1), me voy a portar muy bien para que me vuelvan a pasar de grupo, aunque la profe no me quiere (N14niño 7 años). 
Las relaciones que se tejen con el otro en la convivencia permiten interiorizar aptitudes, gustos y deseos compartidos, permite al niño-niña apropiarse de su espacio y entorno con mayor seguridad, autonomía e independencia. Por ejemplo, en la transición que se hizo entre Educación Inicial a preescolar y posterior a primero los niños que pasaron juntos asumieron el cambio con mayor tranquilidad, se adaptaron a las condiciones con más confianza y seguridad en sí mismo. Pinto (2012) afirma que las condiciones afectivas permiten al estudiante percibir con mayor confianza su posibilidad de protagonismo (p. 65).

Esta confianza se refleja en el conjunto de emociones que los niños y niñas comparten frente a este cambio, los estados de ánimo, los sentimientos que genera el cambiar de espacios locativos, ambientes de aprendizajes y docentes; se refleja también en la posibilidad de experimentar conductas de enojo y frustración cuando no se sienten valorados ni reconocidos en el nuevo ambiente escolar. Para Martínez (2000) las interacciones entre pares significativos posibilitan la construcción de identidad (su yo), su autoestima, su seguridad y la confianza en sí mismo y en el mundo que lo rodea (p. 55).

Continuando con este análisis otro de los aspectos fundamentales mencionado por ellos/as se relaciona directamente con el vínculo afectivo que generan con sus maestras o agentes educativas. Los niños y niñas asignan gran importancia a las profesoras ${ }^{48}$ que los acompañan en su trayectoria. La totalidad de sus respuestas evidencian una imagen elogiosa y positiva del agente mediador o provocador de las experiencias que los niños/as exploran y viven; sus maestras se posicionan en el lugar de saber, de cuidado, son protectoras exigentes, transmiten seguridad y afecto.

Se observa en esta investigación que la interacción entre maestras y niños/as está regulada por multiplicidad de procesos en los cuales las muestras de afectividad positiva hacia las acciones que realizan se convierten en ejes motivadores para asistir y participar de las actividades escolares, para lograr su adaptación y aprendizaje. Las buenas relaciones, la confianza y el apego que se crea entre ambos (maestra-niño/niña) se constituyen en las bases principales para la movilización de conductas, aprendizajes y actitudes. Sin embargo, los mismos niños señalan que, en ocasiones, las maestras asumen posiciones que podríamos

${ }^{48}$ El común denominador que utilizan los niños y niñas para nombrar a sus docentes es el de profesora. En Colombia no existe distinción entre maestra, docente o profesora en la Educación Básica a diferencia de la Educación Inicial Atención Integral donde se les reconoce como agentes educativas. 
tipificar de autoritarias. Las críticas están dirigidas a aquellas maestras o agentes educativas que proyectan una mirada negativa de sus conductas y aprendizajes, aquellas que no aprueban, no aceptan ni valoran las diferencias y que no ayudan al niño aprendiz para que cumpla con las expectativas que tiene la maestra.

- Me hace feliz el trato que me da la profesora que me ayuda con las tareas, en la guardería tenía una profesora distinta más seria no me trataban también como aquí, nos enseñaba diferente, por ejemplo aquí nos hacen traer cuadernos, en cambio allá nos guardaban los cuadernos y no teníamos que llevar maleta, y no copiábamos tanto, hacíamos más dibujos, no nos enseñaban casi, ahora copiamos mucho, jugamos, bailamos, en preescolar, aprendí que cuando alguien esté en problemas uno le tiene que ayudar y proteger al compañero (N8-niña 6 años).

- Aquí en primero me gusta cuando la profesora nos enseña en el tablero y no borra, o cuando nos pone a participar, por eso me hace feliz ver que todos están contentos y que tengo una profesora que me escucha, me entiende y me hace sentir importante, por eso sueño con tener una escuela donde tenga muchas profes como la mía, le recomiendo que todos los días siga así, que me mire, y haga actividades buenas de participación (N15 niño 7 años).

- Yo extraño mucho mi otra escuela, la escuela es mala porque las profes me regañan, me siento triste cuando los compañeros no juegan conmigo, por eso me enojo y ahí veces quiero irme para la casa, me gustaba mucho el salón de preescolar la profesora era muy amorosa, y las de primero no, por eso yo quiero estar en preescolar (N12-Niño 7 años).

Esta forma de analizar los diferentes perfiles de las agentes educativas/maestras es también la manera de describir uno de los puntos críticos a los cuales se ven enfrentados algunos niños- niñas en su recorrido escolar, y que es la falta de empatía entre docenteestudiante. Cárdenas (2010) y Jaude (2003) afirman que la interacción del profesor con sus alumnos conlleva procesos afectivos, y éstos a su vez producen la generación de un determinado clima social en el aula, el cual puede ser propicio para el aprendizaje o interferir con el mismo; los autores sostienen que en la interrelación con el niño el educador muestra muchas conductas emocionales que serán aprendidas por estos, induce emociones e influye en la manera de afrontarlas. Por ello es de gran importancia la relación maestro-niño/niña en las trayectorias. 
Al indagar acerca de los sentidos atribuidos al juego como actividad rectora de la primera infancia se observa que los niños y niñas lo valoran con alta significancia en la transición que realizan entre escenarios educativos. El juego es el eje trasversal de su proceso de desarrollo, es una actividad fundamental del proceso de socialización a través de la cual se insertan al mundo y contexto que los rodea; se constituye en una oportunidad "para reír, compartir, ser feliz, pensar, comunicar, tomar decisiones, resolver problemas, participar, mostrar sus capacidades y ante todo es la esencia de ser niño-niña" (N15-Niño 7 años). No obstante, es una actividad que pierde su esencia especialmente cuando se pasa a la básica primaria pues se convierte en un dispositivo de control con el que se condicionan las actividades y los aprendizajes; el juego pierde su esencia en términos de libertad, placer, curiosidad, creatividad, imaginación y experimentación, y esto se evidencia cuando el juego es un premio que se establece solo cuando terminan una acción o actividad.

Según los niños y niñas el pasaje a la básica primaria marca un quiebre respecto del juego y de las actividades rectoras como el arte, la música, la literatura. Estos principios rectores de la Educación Inicial se restringen y prácticamente se abandonan en la Educación Formal debido a la preparación de los niños/as para las pruebas estandarizadas del Estado en las que se priorizan contenidos curriculares; los tiempos de juego se limitan, para algunas maestras de primaria el juego empieza a ser visto, como lo establece Pescetti (2013), como una «pérdida de tiempo» en situaciones en las que hay que «ganar tiempo» aprendiendo «cosas útiles», y va desapareciendo de la escuela a medida que se asciende en el nivel educativo. Sin embargo, un modo que tienen las instituciones de la Educación Formal de dar continuidad a los principios que rigen la Educación Inicial es por vía de la promoción de áreas como la educación física y la educación artística, y también a través del desarrollo de actividades transversales a todas las áreas. En palabras de los niños y niñas estas son experiencias de trabajo que tienen menor frecuencia y presencia especialmente en la básica primaria.

- Profe vea en primero nos evalúan si uno no pasa ese examen pierde el año, es muy difícil, toca estudiar mucho, mi mamá siempre me insiste en que haga las tareas estudie, pero cuando yo hago la prueba la pierdo (N14-Niño 7 años).

- a mí me va muy bien es que profe él no estudia ni pone cuidado (N13 Niña 7 años).

- profe yo no sé sumar y en eso hay que sumar por eso siempre las pierdo, ya llevo como dos periodos perdidos; hay veces es muy difícil yo no entiendo las preguntas” (N12-Niño 7 años). 
Para los niños/as en la primaria existe un enfoque más hacia el potenciamiento de habilidades lingüísticas, numéricas, en el marco de la lectura, escritura y las matemáticas, se resignifica otro tipo de construcción de saberes que centralizan actividades más rutinarias. Es un momento oportuno para dejar ir la etapa de exploración y asumir con madurez las responsabilidades de ser un niño-niña más adulto.

En la primaria los saberes son estructurados y corresponden al logro de unas competencias y metas que se miden a partir de las evaluaciones; notamos que la escuela como escenario formal condiciona el aprendizaje y produce infancia(s). Finocchio (2010) y Tonucci (2008) plantean que el saber debe resultar de las experiencias de vida de los niños, niñas y jóvenes y que éste puede o no entablar un diálogo con los contenidos escolares seleccionados previamente. En este sentido, y como resultado del trabajo de campo, entendemos que en necesario contemplar la escuela desde su estructura física como un espacio de saber.

Tonucci (2008) refuerza la idea de que las escuelas deben seguir siendo bellas donde los niños y niñas puedan pasear, jugar; deben concebirse como espacios con patios enormes donde los maestros no llenen de contenidos, sino que escuchen y propongan métodos interesantes para discutir el conocimiento que los niños traen de sus casas; es precisamente esta mirada de una escuela bella la que los niños y niñas desde sus narraciones tratan de rescatar y resignificar en la experiencia escolar. Por ejemplo, en el taller de toma de fotografía y expresión artísticas los niños/as dan significado a los lugares que más les gusta y se divierten en la escuela. Tal como se evidencia en las siguientes imágenes. 
Ilustración 17-Fotografías y dibujos de los lugares más significativos de la escuela- preescolar y primero

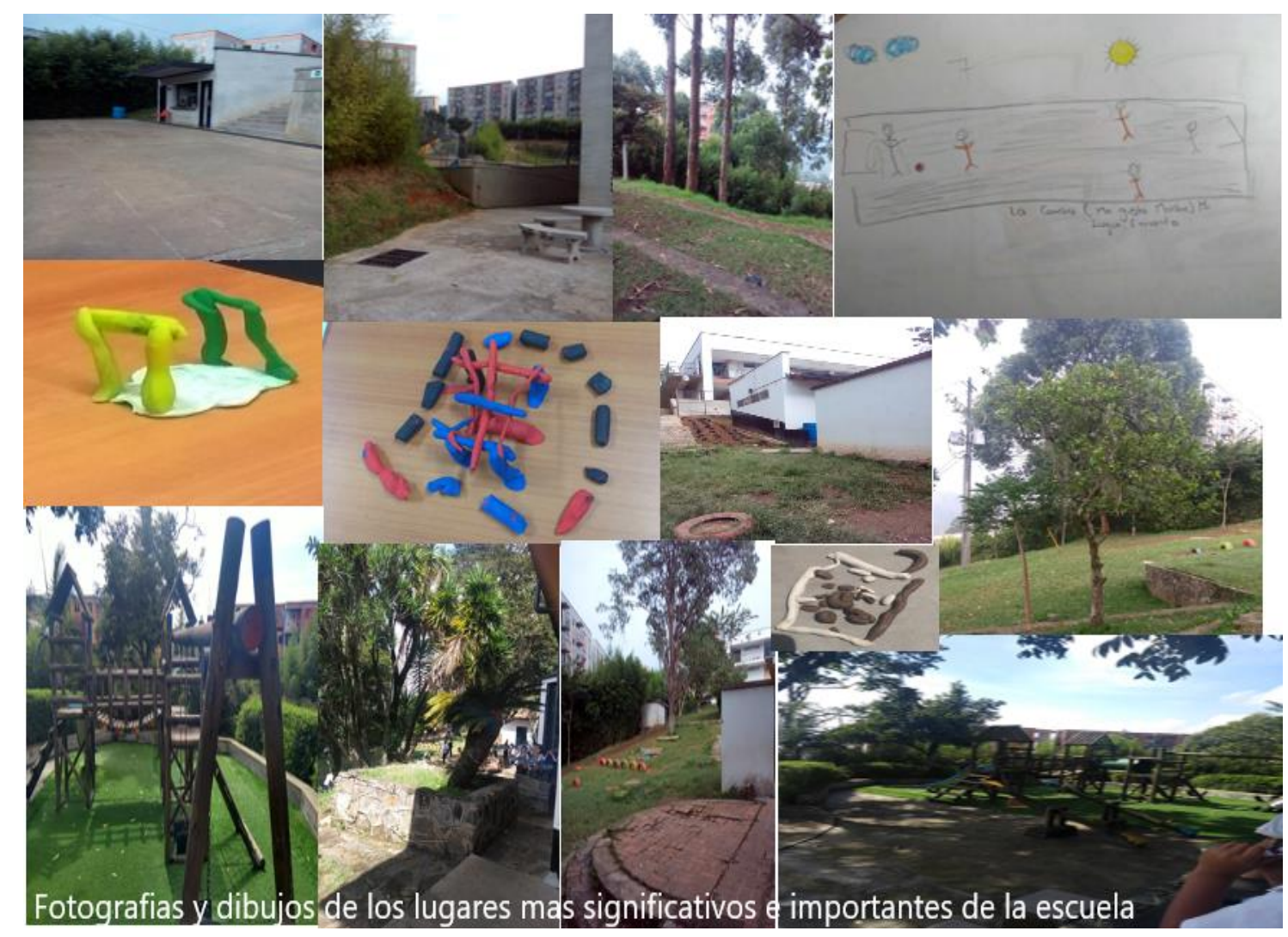

Fuente: - Elaboración propia

Estos espacios educativos están cargados de sentimientos porque representan y los conecta con la primera infancia. El valor que los niños y niñas asignan a los parques, las bibliotecas con sus nichos, las zonas verdes, las canchas, los espacios al aire libre en la escuela primaria representa la forma de mostrar cómo se adaptan en un nuevo escenario educativo que cuenta con otras formas organizativas estructural y físicamente. De esta misma forma los niños y niñas visitan su jardín infantil y toman fotografías de los espacios que más recuerdan y en los cuales disfrutaban y pasaban momentos mágicos donde "aprendían a ser felices". 
Ilustración 18-Fotografías y dibujos de los lugares más significativos del Jardín Infantil Buen Comienzo

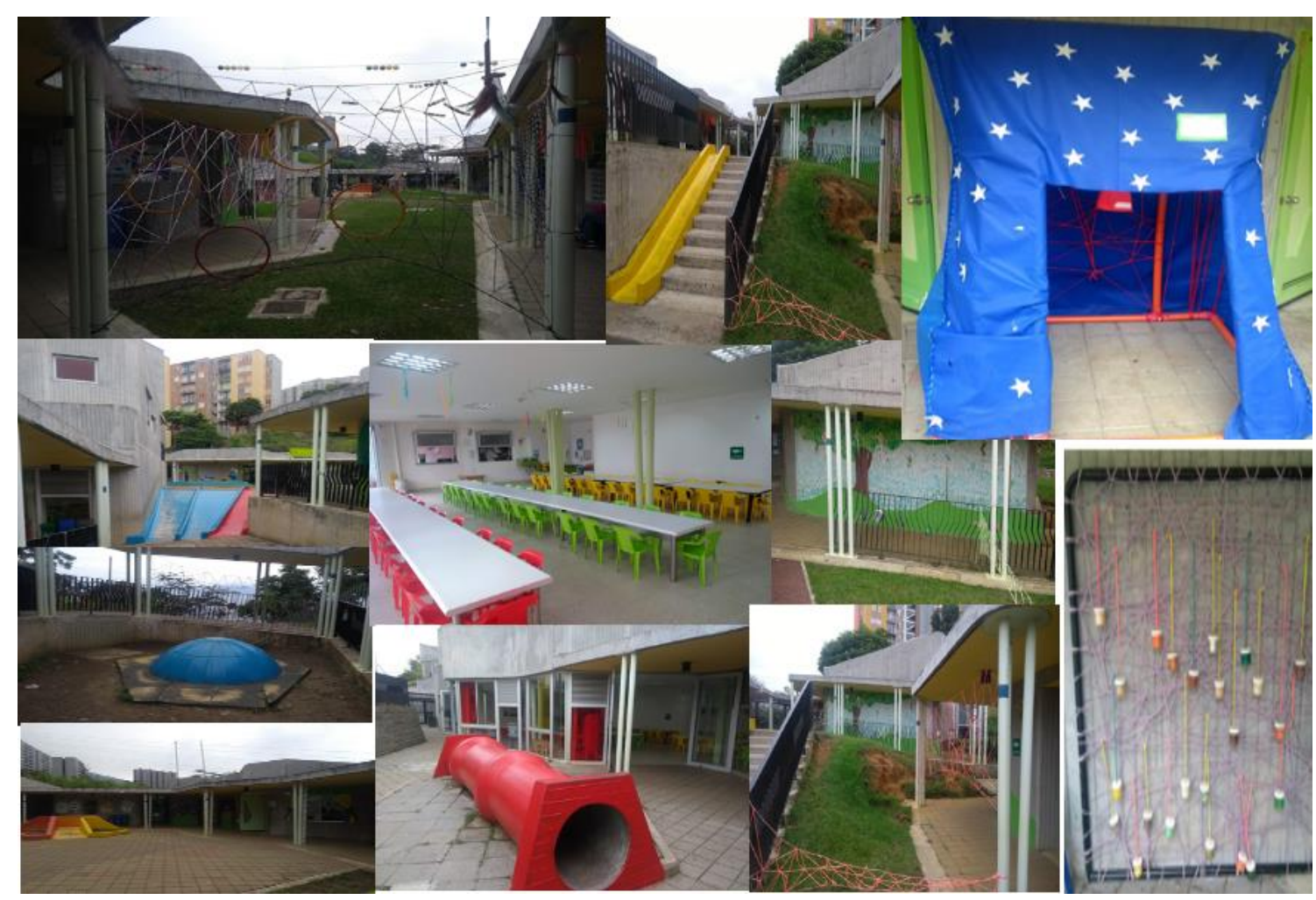

Fuente: Elaboración Propia

Sus narraciones dejan ver claramente que extrañan los ambientes de aprendizaje y espacios lúdico-recreativos diseñados en la educación inicial, y que estos retratos presentan una conexión con lo vivido en esa etapa de juego, diversión, exploración, investigación. Asimismo, se convierten en una forma de reclamar a la escuela primaria el derecho a transitar y disfrutar por esos espacios educativos como los parques o simplemente algunas zonas verdes, que no se conviertan en un privilegio para los más chicos sino en un espacio compartido entre todos. Así lo expresan,

- Cómo te sueñas la escuela, esta escuela me gustaría que fuera con paredes de colores, muchos espacios para disfrutar, pero mire profe ya en primero no podemos jugar en el parque de 
transición es para los más chicos, y porque no los dejan utilizar este parque con columpios porque ya somos niños grandes ya no somos pequeños (N14-niño 7 años).

- Somos grandes y no podemos montar aquí ya tenemos 6 años, si podemos jugar pero en otros espacios (N17-niña 6 años).

- Aunque en el salón no se puede solo es para estudiar, pero eso es injusto yo todavía quiero montar en las llantas de preescolar (N13-Niño 7 años).

- Aunque nosotros tenemos derecho a la cancha y la zona de la huerta y ellos no (N15-Niño 7 años).

Observamos en el llamado que hacen los niños y niñas frente al juego y las zonas de esparcimiento, nuevamente la necesidad de repensar en la educación infantil la concepción de infancias de juego y aprendizaje. Ellos/as son claros al afirmar que el juego es esencial para su bienestar, porque promueve su creatividad, la imaginación y la confianza en sí mismo; el juego contribuye en sus aprendizajes, en la construcción de saberes, se convierte en una forma natural de su vida cotidiana, tiene un valor intrínseco, por el disfrute y el placer que causan; es un elemento central en su desarrollo y en los vínculos que construye con la familia, los pares y con los/as maestros; y es por ello que se hace necesario analizar el lugar que tiene el juego en la Educación Inicial y el que debería tener en la Educación Básica Primaria.

Vemos que es importante que las instituciones garanticen el derecho al juego pensando en los gustos, necesidades emocionales, sueños y preferencias de los niños y niñas, pues estos movilizan sus aprendizajes y sentimientos en cada escenario escolar. Se debe pensar en las infancias, romper la aparente oposición entre juego y trabajo, pensar de forma distinta las situaciones educativas en la básica primaria mediante una variedad de propuestas que incluyan el juego, el fortalecimiento de los vínculos y el aprovechamiento de los espacios educativos.

\subsection{A modo de cierre}

En los capítulos anteriores se logró comprender la configuración de las experiencias que viven los niños y niñas en su proceso de transición entre grados, niveles y escenarios educativos. Al mismo tiempo, hemos podido observar que los niños viven su proceso de transición de acuerdo a tres momentos: la separación, la reacomodación y la aceptación. La 
separación significa despedirse de una etapa, un proceso educativo y de una institución que desarrolla dinámicas que le son propias. Este momento incluye las expectativas que reflejan el deseo de conocer nuevos amigos, espacios, docentes, de compartir, interactuar y sentirse más adulto. Los temores se concentran en la posibilidad de perder sus juegos, juguetes, amigos, profes, el miedo de no ser aceptado y de no cumplir con las exigencias de ese nuevo espacio escolar.

La reacomodación implica la adaptación a los nuevos códigos y prácticas institucionales, a dejar el juego y los juguetes; pone a los niños y niñas en posición de tener que comprender la metodología de trabajo y las nuevas responsabilidades. Finalmente, la aceptación involucra la asimilación frente a las nuevas experiencias mediada por la capacidad de implicación que tiene los niños y niñas en las actividades y dinámicas propias del grado o nivel. Por ello, observamos que la transición genera sentimientos de temor, susto y ansiedad en tanto para ajustarse a ese nuevo entorno los niños-as deben enfrentar desafíos desde el punto de vista de las relaciones sociales, los contextos de aprendizaje y el aprendizaje en sí mismo.

Los niños en sus transiciones otorgan diferentes sentidos a los acontecimientos que viven y experimentan. El primer acontecimiento se relaciona con el vínculo afectivo entre maestras y pares; el vínculo se establece como un sentimiento de amistad, afecto y reconocimiento del otro, es una forma de concebir su propia imagen, se puede ver que las relaciones que ellos/as tejen con el otro, y lo otro en las interacciones les permite interiorizar aptitudes, gustos y deseos compartidos, apropiarse de su espacio-entorno con mayor seguridad, autonomía e independencia. El segundo acontecimiento al que le otorgan gran relevancia en el proceso de transición es al juego, eje trasversal de su proceso de desarrollo. Según ellos se constituye en una oportunidad para reír, compartir, ser feliz, no obstante, es una actividad que pierde su esencia especialmente cuando se pasa a la Básica primaria pues pasa a establecerse como un dispositivo controlador. El juego así pierde su esencia en términos de libertad, placer, curiosidad y experimentación, en sus voces hacen el llamado a recuperar el juego como una actividad esencial de su vida cotidiana, como un elemento transversal su proceso de desarrollo.

Se pudo observar que en las transiciones que los niños y las niñas realizan entre escenarios educativos y grados escolares preexisten ciertas tensiones referidas a: (1) los desarrollos y aprendizajes, (2) el lugar de las interacciones, (3) el juego y las actividades 
rectoras, (4) los saberes. Vemos que en las experiencias de los niños y niñas entre escenarios los principios rectores de la Educación Inicial como el arte, la música, la literatura, la exploración del medio, en la Educación Formal (básica primaria) se usan con menos frecuencia, las actividades son más rutinarias y se concentran en el desarrollo de habilidades lingüísticas y numéricas, mediante métodos más tradicionales.

En este sentido los resultados de nuestra investigación evidencian la necesidad de pensar una escuela que ha de ser ante todo un ecosistema hospitalario que independientemente si se centra en un escenario convencional, formal o no convencional, dé continuidad a los procesos implementados en la Educación Inicial. Nos referimos, por ejemplo, a las metodologías implementadas, el juego como actividad rectora, de modo tal de generar un espacio que propicie gran riqueza de experiencias, provocaciones, encuentros consigo mismo, con los otros, con el contexto.

Vemos la necesidad de que nosotros/as los/as maestras, agentes educativas y actores que trabajan con la primera infancia tanto de la inicial como de preescolar y la básica primaria reflexionemos frente al lugar que le estamos dando a los saberes y aprendizajes, el lugar de las interacciones, de las actividades rectoras, la práctica pedagógica, los contenidos académicos, es decir, reflexionar en torno de la construcción curricular de los escenarios convencionales y no convencionales de la Educación Infantil.

Se hace necesario que reflexionemos en torno de quienes son nuestras infancias, sus familias, y cuál es el contexto que habitan, pensar en la enorme carga de tareas y roles que les estamos asignando a los niños y niñas ejemplo -el rol de ser niño más "grande" el rol de ser niño/a juicioso", el rol de ser un niño atento y respetuoso de la norma, reflexionar en la asignación de roles diferenciados tanto para las niñas como para los niños-; en la organización de los espacios educativos y las limitaciones que generamos para que ellos/as puedan participar en la primaria, así como la preparación del cuerpo para regular los comportamientos y responder a las pruebas estandarizadas. Debemos pensar en la formación de los/as maestros y en los retos que tenemos para evitar la confrontación entre la educación inicial vs. Educación formal y lograr un sistema integrado.

Finalmente queremos remarcar que investigar con los niños/as y no para los niños y niñas se constituye en una fuente esencial para conocer su realidad y consolidar procesos 
investigativos; cada niño y niña de acuerdo a su historia de vida, aporta información necesaria que da fundamento a un fenómeno estudiado; sus experiencias y vivencias se configuran en datos relevantes que constituyen ejes trasversales a considerar en cualquier propuesta pedagógica, educativa y en las construcciones curriculares; las voces de los niños y niñas son vitales para transformar el sistema de Educación Infantil, sus llamados de atención frente al juego, la infancia, los saberes y la enseñanza, nos muestran la necesidad de que la educación infantil sea respetuosa de la infancia y de los derechos de los niños y niñas. 


\section{SEXTA PARTE}

\section{AL FINAL DE LA EXPERIENCIA}

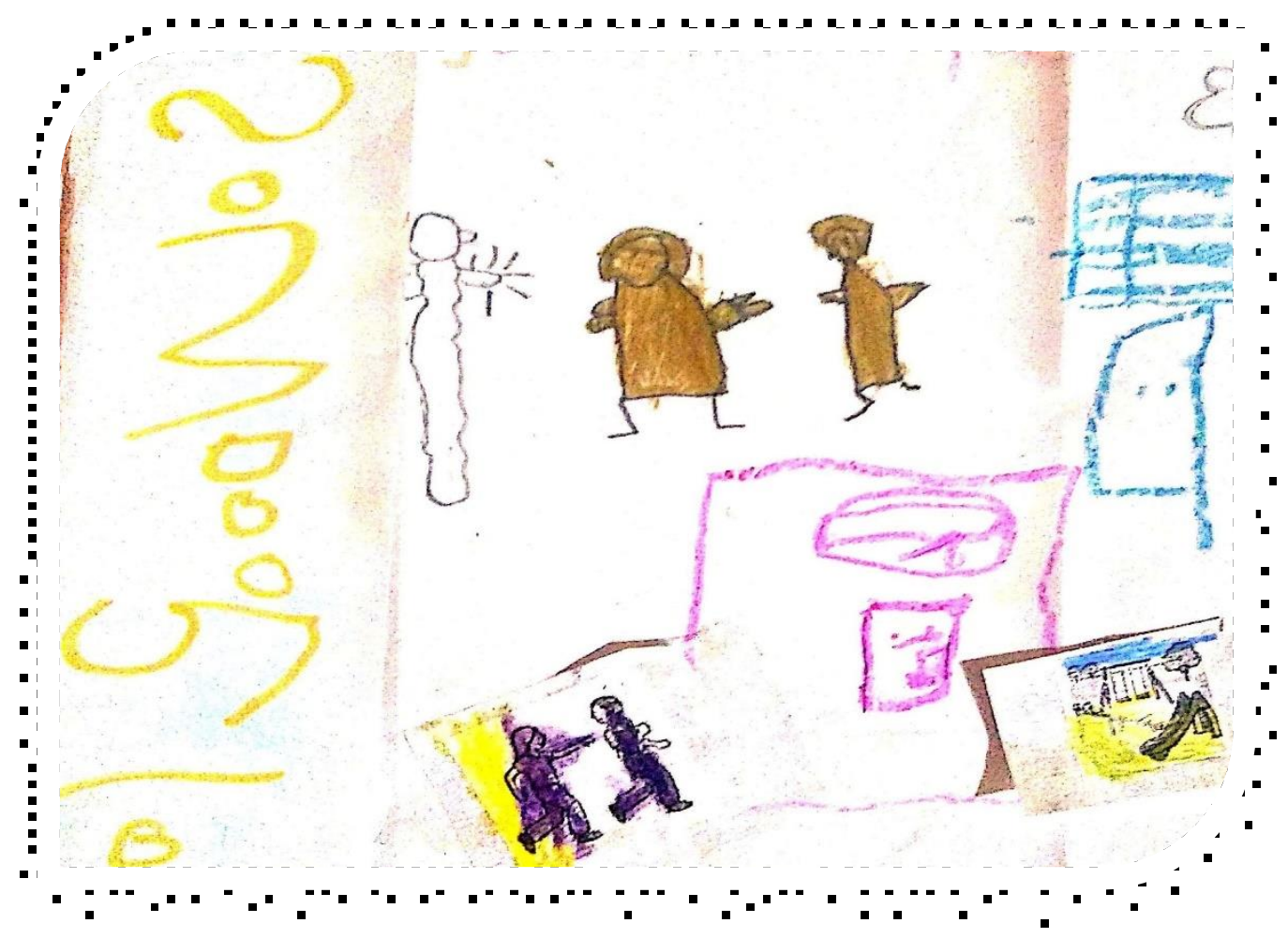

“La escuela debe ser un lugar bello,

donde se pueda respirar cultura,

haya música, arte, sea agradable y cómoda"

(Tonucci, 2008) 


\section{Reflexiones y Consideraciones Finales}

Después de este ir y venir entre las voces de las maestras agentes educativas y voces de nuestros niños y niñas confirmamos en nuestro trabajo de campo que los recorridos que ellos/as realizan por el sistema de Educación Infantil están estrechamente relacionados, por un lado, con las oportunidades que ofrecen las diferentes instituciones de Educación infantil por las que se desplazan los sujetos y, por el otro, con los recursos económicos, culturales y simbólicos que ellos y sus familias tienen para afrontar los acontecimientos que viven en ese espacio social.

Desde múltiples disciplinas sociales, posturas y perspectivas políticas-sociales que abarcan realidades, significados y usos diferentes es necesario conceptualizar las trayectorias educativas. Desde la perspectiva del curso de vida la trayectoria se comprende como una línea de vida o carrera, a lo largo de toda la vida que puede variar y cambiar en dirección, grado y proporción. Fue caracterizado en un primer momento como una perspectiva, luego como paradigma y en los últimos años como teoría encontrando su máximo desarrollo en el campo de la psicología, la sociología y, en los últimos años, como enfoque teórico metodológico porque abarca una variedad de ámbitos o dominios (trabajo, escuela, familia, comunidad, entre otros).

En el campo de la psicología del desarrollo el curso de vida se lee a partir del ciclo de vida, supone una secuencia basada en la edad y en eventos producidos socialmente sobre un tiempo y espacio situado históricamente. En el campo de la sociología abarca el desarrollo individual en contextos sociales, culturales e históricos cambiantes; los individuos generalmente resuelven sus cursos de vida y trayectorias en relación a los trayectos institucionalizados y los patrones normativos (políticas); el trayecto de vida es un conjunto de procesos que transcurren desde el nacimiento hasta la muerte y son configurados por fuerzas históricas que están usualmente estructurados por las instituciones sociales. Desde un enfoque teórico-metodológico el curso de vida constituye una plataforma necesaria para el estudio de los nexos que existen entre las vidas individuales y el cambio social, y para la comprensión de la biografía individual del sujeto no en forma aislada sino determinada por el contexto y el tiempo en el que se desarrolla. Hay que decir que como enfoque teórico-metodológico el curso 
de vida aporta tres conceptos básicos a partir de los cuales es posible estudiar los recorridos que el sujeto realiza. El primero es la trayectoria entendida como línea de vida o carrera, un camino a lo largo de toda la vida que puede variar y cambiar en dirección, grado y proporción; abarca una variedad de ámbitos o dominios interdependientes (trabajo, escuela, familia, entre otros). El segundo es transiciones y refiere a los cambios de estado, posición o situación de un individuo en un momento determinado durante la trayectoria. El tercero es turning point o punto de inflexión y hace referencia a los momentos de cambio especialmente significativos que provocan fuertes modificaciones en la vida de la persona.

El curso de vida comprende el desarrollo humano como un proceso que abarca del nacimiento a la muerte. Tener una perspectiva a largo plazo es necesaria para estudiar las vidas y la incidencia de los acontecimientos y eventos que experimentan los sujetos dado que este curso de vida se ve afectado por proceso políticos, sociales, económico, culturales, socioafectivos, etc. Sin embargo, existe una red de relaciones compartidas razón por la cual se debe analizar la interdependencia de las diversas trayectorias de un mismo individuo respecto de otros individuos y grupos (por ejemplo, las relaciones de familia, los vínculos en el trabajo, el grupo de vecinos, maestros, estudiantes). Es en la relación entre lo individual y lo estructural que los sujetos construyen su propio curso de vida haciendo elecciones y llevando a cabo actividades y acciones que permiten la construcción de su autobiografía. Las personas pueden moldear sus vidas, pero lo hacen dentro de límites socialmente estructurados.

En Colombia el curso de vida es un enfoque reciente que emerge especialmente para interpelar a las políticas dirigidas a la infancia y a la adolescencia que inicialmente se asentaban en una concepción del ciclo vital enmarcada en las consideraciones biológicas y psicológicas que ordenan el desarrollo del individuo por etapas (embarazo, niñez, adolescencia), reconociendo que las experiencias se acumulan a lo largo de la vida dando lugar a la primera infancia (0-5 años), la infancia (6 - 11 años), la adolescencia (12-18 años). Desde esta concepción del ciclo vital las políticas de atención a la infancia y a la adolescencia se proponen el desarrollo de intervenciones y acciones a temprana edad para minimizar las vulnerabilidades futuras. Actualmente dicha concepción está transitando hacia una perspectiva orientada bajo la corriente sociológica y el enfoque teórico-metodológico del curso de vida, es decir, constituye una ampliación del enfoque de desarrollo humano y una perspectiva que permite reconocer en los distintos momentos de vida trayectorias, transiciones, ventanas de 
oportunidad y efectos acumulativos que inciden en la vida cotidiana de los sujetos. Este cambio en las formas de concebir la infancia y la adolescencia requiere del análisis de los diferentes momentos de la vida para comprender no solo lo que sucede en las distintas edades y etapas, sino también identificar la manera en que las experiencias vividas en cada etapa se relacionan con los contextos sociales, históricos, políticos y culturales donde se inscribe cada vida en virtud de una serie de variables tales como clase social, género, sexualidad, etnicidad, discapacidad, entre otras.

En Colombia, especialmente en el campo de la Educación Infantil, se hace referencia específicamente a las transiciones entre escenarios o ámbitos educativos y no se tiene en cuenta que forman parte de una trayectoria. Para comprender los efectos que puede tener este enfoque en las acciones políticas del país se hace necesario caracterizar y definir la categoría trayectoria. La preeminencia en la educación infantil de la categoría transición desligada de la trayectoria podría explicar la ausencia de estudios e investigaciones, en particular en Colombia, que pongan el acento en el análisis de los procesos sociales, históricos y culturales en los que están inmersos los niños, niñas y familias y en los que se va escribiendo una trayectoria educativa.

En el campo de la educación y en relación con los estudios de trayectorias se identifican dos perspectivas diferentes pero complementarias para comprender los recorridos seguidos por los sujetos, por un lado, estudios que centran la mirada en los procesos de escolarización institucional y, por el otro, trabajos orientados al análisis de procesos socioeducativos.

Desde el análisis de los procesos de escolarización la trayectoria da cuenta de los modos en que efectivamente los sujetos transitan por el sistema educativo, sintetiza los itinerarios que los agentes van delineando a lo largo de su vida, es decir, los caminos que recorren las/los niños/niñas a través del sistema educativo; refiere no solamente a los itinerarios de entrada y salida hacia instituciones educativas y entre ellas, sino que constituyen campos de experiencia interceptados por un marco de complejas interacciones que producen trayectorias teóricas y trayectorias reales. La trayectoria teórica estipula el ingreso de los sujetos al sistema escolar, establece la organización del sistema por niveles, la gradualidad del currículo y la anualización de los grados. La trayectoria real refiere a aquello que efectivamente le acontece al sujeto en su paso por la escuela, y la relación entre lo real y lo ideal deja ver marcadas diferencias en correspondencia con los procesos que tienen lugar en los escenarios de la 
educación infantil. Las trayectorias escolares de muchos de los niños/as que asisten a las instituciones que conforman en Colombia la educación infantil están desacopladas respecto de los recorridos esperados por el sistema educativo.

En tanto proceso socioeducativo la trayectoria se relaciona con los espacios sociales, estructurados en campos como la educación infantil en los que encontramos jerarquizaciones y reglas de juego que le son propias. En este campo se ponen en juego un sinnúmero de factores (históricos, jurídicos, institucionales, familiares, culturales, personales) que producen cambios significativos en las experiencias de vida del sujeto y las posiciones que ocupan en dichas estructuras sociales. La trayectoria socioeducativa no se puede analizar sin la comprensión del espacio social porque vemos que, aunque la posición inicial de los sujetos en el sistema educativo puede ser compartida por los miembros del grupo social eso no implica que todos los sujetos alcancen el mismo punto de llegada; por ello la trayectoria educativa depende a menudo de acontecimientos colectivos y está estrechamente ligada con la experiencia de los sujetos en sus transiciones.

Existen diferentes tipos de transiciones: transiciones de carácter social-cultural se relacionan con el contexto, con el proceso de cambio y posicionamiento, rol o situación que experimenta el individuo, y hacen referencia a los momentos significativos que explora el sujeto con la familia, con los miembros de la comunidad, en función de características históricas y culturales propias del contexto que habitan los niños. Para estudiar las transiciones de este carácter se asume un enfoque sociológico dado que, desde el punto de vista social, el sujeto en su trayecto de vida explora un proceso de cambios heterogéneos que implican adecuación y redistribución de roles en tanto es miembro de un grupo (familia, escuela, comunidad).

Las transiciones de carácter educativo se corresponden con los pasos que viven los sujetos desde un ambiente familiar-social a una institución educativa, programas no convencionales, guarderías, jardines, modalidades y niveles educativos donde tienen lugar ritos de paso o pasaje. El enfoque para estudiarlas es el ecológico porque permite analizar las experiencias e interacciones de los niños/niñas con sus compañeros, maestros y cuidadores en los entornos cotidianos de la escuela o la guardería. Las transiciones de carácter individual se relacionan con el sujeto, su vida individual, sus cambios físicos biológicos, atributos 
personales, autoestima, motivaciones, y el enfoque para estudiar estas transiciones es desde una perspectiva psicológica.

De acuerdo a los hallazgos del trabajo de campo la trayectoria se configura para las maestras como un recorrido que se relaciona con la edad, el contexto, las oportunidades y la política pública. Así, la trayectoria contiene todo lo que llevan los estudiantes desde pequeños, desde que inician su paso por la escolaridad hasta que terminan sus niveles de formación. Para las maestras la trayectoria se concibe como un camino de múltiples itinerarios por las que transitan las/los niños/niñas/familias/maestras a través del sistema educativo, por tanto no solo refiere a los recorridos personales del niño-niña sino que interpela a la institución por la que transita, es decir, refiere no solamente a los itinerarios de entrada y salida hacia instituciones educativas y entre ellas, sino que constituyen campos de experiencia interceptados por un marco de complejas interacciones que se dan en las transiciones entre las instituciones que forman parte de la Educación Infantil.

Para comprender las transiciones de los niños y niñas de nuestro estudio y producto de los análisis teóricos realizados y los primeros hallazgos del trabajo de campo hemos caracterizado las transiciones clasificándolas a partir de considerar los ámbitos de inscripción y que denominamos ámbito sociocultural, ámbito socioeducativo y ámbito personal. El ámbito sociocultural representa el contexto, la familia y refiere a la configuración institucional, sus estructuras internas y externas con códigos y prácticas. El ámbito socioeducativo representa la institución como escenario educativo con sus fines, objetivos, currículo, metodología, dinámica y estructura de oportunidades. El ámbito personal referencia la relación individuosociedad y tiene en consideración los atributos personales de los niños/as, el estado nutricional, su estado emocional, la capacidad de agencia, dominios y saberes.

Encontramos que en estos ámbitos se puede evidenciar un conjunto de variables que afectan los recorridos y las experiencias de los niños-niñas, de sus familias y de las maestrasagentes educativas y esto porque observamos que en la entrada y salida hacia instituciones educativas y entre ellas se pueden experimentar y se recuperan de las entrevistas a docentes puntos críticos, interrupciones, interacciones simples o complejas de acuerdo con las oportunidades, disposiciones de los niveles educativos, capacidades institucionales. La trayectoria permite dar cuenta de las posiciones que logra ocupar el sujeto en el campo 
educativo para futuras inserciones y la transición da cuenta de los procesos de adaptación que viven los niños y niñas frente a los cambios y acontecimientos vividos entre escenarios educativos. Por eso en esta investigación la trayectoria es presentada como el horizonte en el que se inscriben las diferentes transiciones que realizan los niños de este estudio de una etapa a otra, de unas instituciones educativas a otras dentro de la Educación Infantil.

En el siguiente gráfico explicamos el trabajo de campo y los hallazgos encontrados en la triangulación que se realizó de cada uno de los instrumentos aplicados y que dan lugar a la organización de la tesis en apartados en los que buscamos explicar los modos en que las trayectorias y las transiciones que realizan los niños y niñas por la Educación Infantil se configuran a partir de considerar lo que denominamos ámbitos sociocultural, socioeducativo y personal.

Ilustración 19-Trabajo de Campo

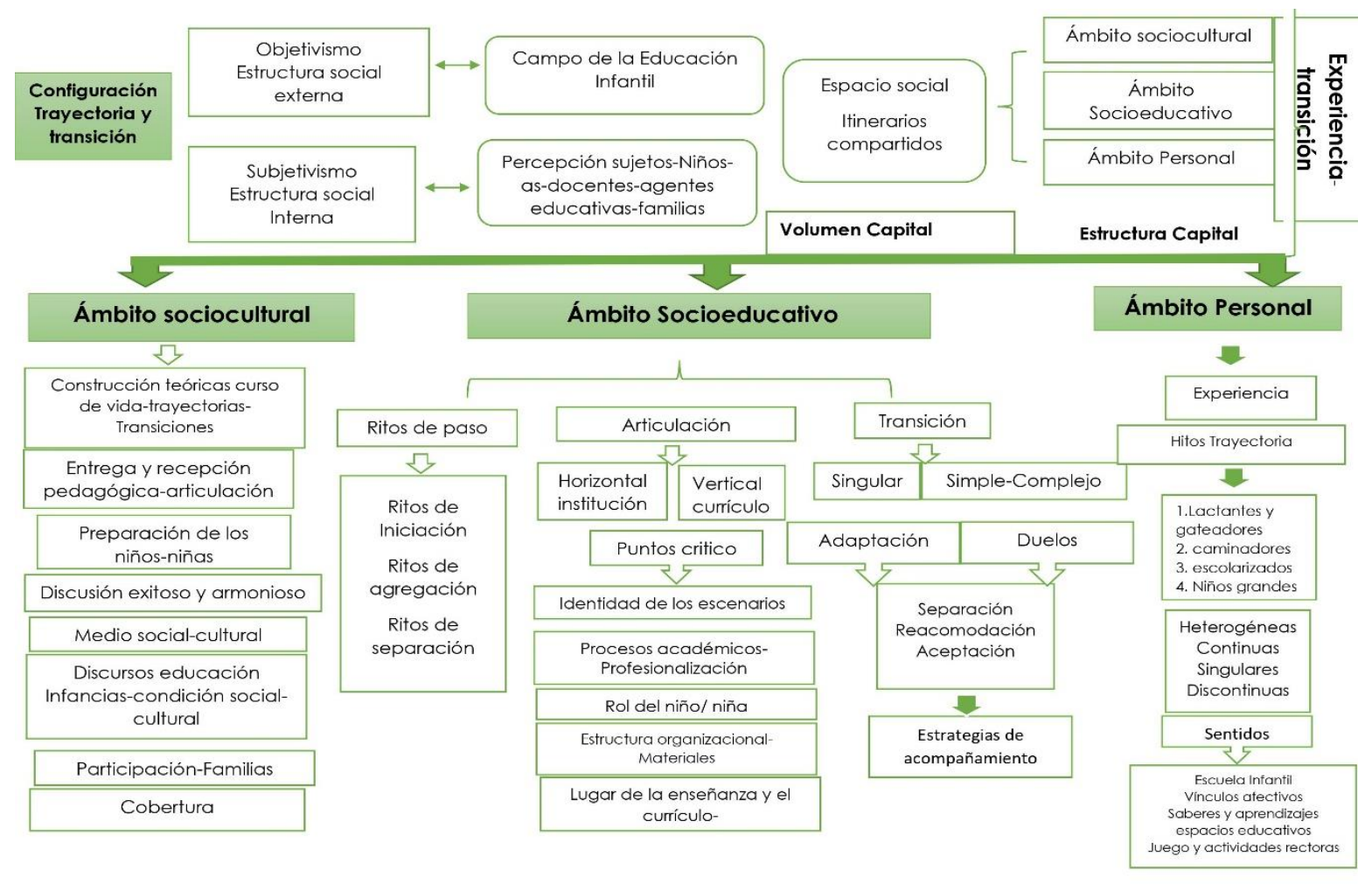

Elaboración propia 
En esta investigación observamos que el hecho de que el niño y niña deba transitar simultáneamente por diferentes ambientes -familiar, escolar y comunitario- produce experiencias diversas y heterogéneas vinculadas a las formas de acompañamiento que reciben de parte de los/las adultos/adultas. De esta forma observamos que tanto la caracterización de las familias, las maestras como de las infancias se establece bajo un pensamiento abismal y posabismal (Santos, 2014) que muestra dos universos, el universo de "este lado de la línea" (narraciones de las maestras-agentes educativas) y el universo del "otro lado de la línea" (narraciones de los niños y niñas). En este ámbito sociocultural observamos que la relación que los niños y niñas construyen es con su medio social y cultural -el barrio- y sus recorridos por el sistema escolar están atravesados por una serie de prácticas y dinámicas de funcionamiento de las instituciones educativas inscriptas en dicho territorio. Vivir en un barrio, y no en otro, es un indicador de los capitales sociales, económicos y culturales que poseen las familias de los niños y niñas de este estudio. Las maestras y agentes educativas observan que la desigual posesión de dichos capitales constituye uno de los factores que incide de manera directa en los recorridos de los niños y niñas y que se refleja en las entradas y salidas entre escenarios educativos, en los acompañamientos por parte de las familias, en los apoyos institucionales, en las concepciones que se construyen por parte de sus maestras y agentes educativas frente a la infancia, la educación, la familia, el cuidado, entre otras.

De las entrevistas observamos que las maestras hacen una caracterización de las familias otorgando preeminencia a la condición social de la población: ser desplazado, ser pobre y desempleado, víctima de conflicto armado, ser analfabeta, entre otros. En los barrios donde viven los niños y niñas hay un alto porcentaje de población desplazada no solo por la violencia y el conflicto armado sino por los incendios y desastres naturales que han afectado a las familias y las han puesto en riesgo y vulneración. Las narraciones de las maestras evidencian la desigualdad de origen, pero también responden a un discurso que se ha vuelto hegemónico en las instituciones educativas y que es utilizado de manera estigmatizante para clasificar los tipos de familias y sus acompañamientos a las transiciones y trayectorias de los niños.

Otro eje que toman las maestras para caracterizar a las familias está relacionado con el tipo de participación que tienen las madres y los padres en el acompañamiento que realizan a sus niños y niñas durante el proceso escolar. La posibilidad de que las familias acompañen a 
sus hijos en los puntos críticos que se producen en el tránsito de un escenario educativo a otro se vuelve difícil cuando la pobreza y el desplazamiento caracterizan sus vidas, dependiendo del nivel educativo alcanzado. Sin embargo, las mismas maestras reconocen que la relación entre capital cultural y acompañamiento escolar no es lineal dado que identifican a un grupo de familias sin escolarización, con un capital menor comparado con el resto de las familias de sus alumnos, que se destacan por realizar un seguimiento sostenido de las transiciones desde el hogar como por la presencia que tienen en las instituciones educativas. Otras familias se caracterizan por su vulnerabilidad, son aquellas que aún se están adaptando al contexto ciudad y a la escuela por ser desplazadas de la ruralidad, mientras que otras familias presentan serias dificultades económicas que afectan el acompañamiento que la escuela espera de ellas. Estas variables indiscutiblemente interfieren en la trayectoria escolar de los pequeños y es evidenciado por las maestras en los procesos académicos de los niños y niñas en las reiteradas inasistencias y en cambios en los comportamientos, en la convivencia escolar, en los aprendizajes escolares.

La realidad del contexto social y cultural que viven las familias y los niños-niñas deja ver la construcción de códigos y prácticas que las maestras y agentes educativas construyen en los escenarios de la educación inicial y de la educación formal, por ejemplo, ellas respaldan la idea de que el ingreso, la permanencia y la graduación de los estudiantes se ve mediada por varios factores como la violencia y la pobreza que trae aparejada la condición de desplazados. Esto hace que exista una alta fluctuación de las familias porque se cambian de barrio o mudan constantemente de sector y es un indicador a considerar porque influye en los altos índices de deserción que tiene la institución educativa de educación formal, en particular en el tránsito del grado transición al grado primero de la Educación Básica Primaria.

En este camino de indagación encontramos que el ámbito socioeducativo representa la experiencia que tienen los niños y niñas entre el sistema de educación inicial y el sistema de educación formal con respecto a los procesos institucionales, las metodologías, las dinámicas organizacionales propias de cada escenario, la estructura curricular, la articulación. Los recorridos que los niños y niñas hacen entre el nivel de educación inicial y el nivel de educación formal dan cuenta de las diferentes experiencias para cada niño y niña dependiendo de dos procesos fundamentales sostenidos por las maestras y las agentes educativas como son los ritos de paso y la articulación. 
Los ritos de paso se enmarcan en el proceso pedagógico y se comprenden como el conjunto de estrategias y actividades que permiten acompañar el tránsito de los niños/as de la Educación Inicial a la Educación Formal, son factores determinantes que buscan preparar al niño, niña y familia para el nuevo estado o ambiente de manera que pueda adaptarse y afrontar con seguridad y autonomía ese cambio significativo en su vida. Cada escenario de educación establece un conjunto de ritos y acciones de articulación para favorecer los procesos de transición. Observamos que las agentes educativas del nivel de educación inicial realizan ritos de iniciación con actividades centralizadas en el aprestamiento: actividades lúdicas que movilizan en los niños conductas y comportamientos que deben adquirir y aprender para su adaptación en la nueva escuela; trabajan la postura, el manejo del cuaderno, el espacio en la mesa de trabajo, los horarios del descanso y la ida al baño, además de algunas rutinas escolares y momentos de la escuela. Otro de los ritos que realizan es el de agregación con el cual buscan presentar a los niños y niñas públicamente en la nueva institución a través de pasantía como estrategia fundamental en la entrega y recepción de la educación inicial a la educación formal.

En el sistema de Educación Formal el Preescolar (grado transición) trabaja en la adaptación a través de un ritual de agregación para introducir al niño y niña en el nuevo ambiente escolar entre las que destacan actividades de escritura. En la Educación Básica Primaria (grado primero) las maestras proponen rituales de agregación centrados en la constitución de las normas. Finalmente ambos niveles, Educación Inicial-Programa Buen Comienzo de la ciudad de Medellín y la Educación Formal (Preescolar y Básica Primaria) realizan ritos de separación en donde se cierra un proceso, una experiencia del ciclo vital, un itinerario de experiencias positivas y enriquecedoras de aprendizajes y se abre una etapa donde los niños/as adquieren un nuevo estatus y en el que las maestras trabajan en el fortalecimiento de la atención a la primer infancia y en la adaptación a los nuevos escenarios educativos.

La articulación es importante en el proceso pedagógico dado que en el sistema educativo se realiza entre niveles y grados en lo que hace a la gestión institucional, la gestión pedagógica y la gestión administrativa. Son tres los procesos de articulación que destacan las maestras en este ámbito: la primera la inter-institucional en la cual referencian a los procesos administrativos y pedagógicos que se deben realizar según los lineamientos del programa Buen Comienzo y la Secretaría de Educación de Medellín; la segunda es la que se da entre grados y la tercera es la articulación curricular. La articulación es definida por las maestras como las 
acciones de engranaje y correlación de los procesos que las instituciones llevan a cabo en la formación del niño para el favorecimiento del tránsito entre ambos sistemas, en la forma de una articulación horizontal- inter-institucional e intersectorial- y vertical de cara a lo curricular. Ambos tipos de articulación suponen una continuidad, una construcción conjunta para el seguimiento y evaluación del proceso que no siempre ocurre.

Las agentes educativas y maestras reconocen que se producen encuentros y desencuentros en lo que respecta a los dos tipos de articulación (horizontal y vertical). Dos son los puntos de encuentro en los que coinciden las agentes educativas y maestras consultadas: por un lado, comparten el ideal de alcanzar una formación de los niños y niñas basada en experiencias y ambientes enriquecedores de aprendizaje; por otro, el reto de ayudar a empoderar a las familias respecto del cuidado, la crianza y educación de los niños. Esto se asienta en el mayor peso puesto en la educación inicial al tema del cuidado que lleva a las familias a reclamar en la escuela de la educación formal la misma atención para con sus hijos e hijas, y frente a estas demandas las maestras oponen resistencia.

Cuando las maestras de las escuelas de Medellín refieren a los desencuentros plantean con preocupación que se vuelven puntos críticos en las transiciones que deben hacer los niños entre niveles educativos o grados. Los puntos críticos que destacan son:

- Sentido e identidad de ambos escenarios: la tensión es entre lo educativo y lo asistencial

- Los procesos pedagógicos, el lugar de la enseñanza y el currículo

- $\quad$ El rol de niño y la niña como sujeto aprendiz-la comprensión frente a la infancia

- La estructura organizacional y administrativa, específicamente en el rol y las funciones de las agentes educativas versus las maestras de preescolar y primaria

- La profesionalización y el perfil de las maestras y agentes educativas

- $\quad$ El mobiliario y los materiales didácticos que se disponen para ambos niveles educativos El mayor desencuentro según las maestras resulta de la falta de atención política a la articulación vertical, esto es, a lo pedagógico, curricular y metodológico. Según ellas, la articulación curricular debe ser vista como un proceso de secuencialidad en la transición, sin embargo, señalan que el recorrido que hacen los niños y niñas entre niveles y grados se vive de forma compleja porque no hay progresión y secuencialidad en la estructura curricular entre los contenidos, saberes y aprendizajes establecidos entre la Educación inicial Programa Buen 
Comienzo, Educación Formal -grado transición y grado primero-. En este estudio pudimos corroborar que los niños-niñas transitan por propuestas curriculares donde la organización curricular y pedagógica, la organización de los contenidos, las metodologías y formas de organización de los ambientes, la estructura de los aprendizajes se establece de forma diferente lo que no posibilita la progresión efectiva entre ambos escenarios porque no se ha podido avanzar en la configuración de un currículo integrado.

Los principales temores que expresan las maestras consultadas están asociados a (1) las expectativas de aprendizaje que tienen sus colegas de educación inicial (agentes educativas) con relación a los saberes que los niños/as deben llevar al grado primero, (2) temor de que los niños y niñas se frustren y no sean capaces de superar los retos del otro nivel y de adaptarse fácilmente, y (3) angustia reflejada en la atención que se le brinda a los niños y niñas con discapacidad o alertas en el desarrollo.

Los puntos de desencuentro son experimentados por los niños y niñas cuando recorren los niveles de educación inicial y formal, la llegada a un nuevo escenario escolar supone una forma de ser extranjero por lo que los niños y niñas deben adaptarse a un entorno diferente del suyo. En el trabajo de campo se logró comprobar que viven su proceso de transición educativa de forma singular, sus experiencias son únicas. Según las voces de las maestras y agentes educativas el cambio entre escenarios para algunos niños es simple -asumen con tranquilidad las nuevas experiencias, con emoción, alegría y felicidad de enfrentar nuevas situaciones de aprendizaje y juego; y para otros complejo las tensiones que genera el cambio y por el desafío frente a lo nuevo -en el paso de una institución a otra extrañan a sus maestras, sus juguetes, las metodologías y rutinas de trabajo, la organización del espacio, los niños-niñas evocan recuerdos, realizan comentarios y expresiones que muestran los desafíos que deben enfrentar para poder reacomodarse a la nueva situación.

Este pasaje entre la educación inicial al nivel de educación formal grado transición y primero implica para los niños y niñas un proceso de separación del Programa Buen Comienzo-Educación Inicial que conlleva duelos ante la pérdida de la infraestructura física, los ambientes de aprendizaje, los juguetes y juegos, el juego al aire libre, las actividades rectoras, las rutinas de trabajo, las docentes, la alimentación; de reacomodación al nuevo escenario escolar que implica adaptarse a los nuevos códigos y prácticas institucionales, 
abandonar los juguetes y dejar de contar con espacios dedicados al juego, comprender otra metodología de trabajo y asumir responsabilidades ligadas al estudio; finalmente la aceptación, refiere a la capacidad de apropiación frente al nuevo espacio escolar mediada por su capacidad de implicación en las actividades y dinámicas propias del grado o nivel, por su forma particular de vivir el tránsito, de desenvolverse en el contexto, relacionarse y generar los vínculos afectivos con sus pares y maestras.

La preocupación por la atención educativa que se le brinda a los niños y niñas que presentan discapacidad o alertas en el desarrollo se asienta en su experiencia docente. Las maestras observan que para estos niños y niñas la transición es compleja porque se enfrentan a propuestas curriculares poco flexibles, planes de estudio estandarizados, a contenidos intocables además de las barreras no solo de tipo actitudinal sino pedagógicas, curriculares y sociales tales como prejuicios respecto de la sociabilidad de los niños y niñas con discapacidad en la escuela y sobre su capacidad para alcanzar las metas de aprendizaje.

Después de haber centrado el análisis en la institucionalidad y en las voces de las maestras nos propusimos comprender la forma en que los mismos niños y niñas conciben su experiencia y trayectoria escolar. Este ámbito hace referencia a la relación individuo-sociedad en la construcción de la identidad de cada niño-niña y en la configuración de la propia historia de vida. Los niños y niñas que formaron parte de esta investigación representan las distintas infancias, son sujetos sociales que se configuran con el/la/los/las otro/s otra/s y para quienes la condición de desplazados/das, las alertas en el desarrollo, el conflicto armado, la pobreza se interseccionan con edad, sexo, género, discapacidad para producir una experiencia singular que incide en su trayectoria y transiciones educativas.

En este estudio observamos que los niños y niñas configuran la infancia y una forma de concebirse en tanto tal en la transición que hacen de un grado o escenario educativo a otro y producen una serie de sentimientos que dan sentido a su proceso de escolarización. Logran expresar utilizando para ello diferentes lenguajes los cambios que observan en su condición infantil a medida que avanzan de un nivel a otro del sistema educativo. A diferencia de las maestras que construyen una representación de infancia vulnerada para ellos/as ser niño o niña es reconocerse dentro de un contexto en el que identifican sus desarrollos, cualidades, valores, su identidad; representa un conjunto de sentires porque es una etapa para divertirse, para ser 
"escandaloso", para ser feliz y crecer con el/la otro/a. Pero también es pasar de ser escandaloso a "madurar", es transitar una infancia que se va transformando porque viven experiencias de diversión y alegría y también de pérdida: pérdida del tiempo, del juego, pérdida de los juguetes y regalos, del cuidado de los adultos (agentes educativas) en la trayectoria escolar.

Los niños y niñas en este pasaje de la infancia configuran su trayectoria educativa a partir de experiencias, hitos y situaciones que representan períodos de cambio importantes para cada sujeto; la trayectoria educativs se hace y se construye con otros, cada trayectoria es un recorrido situado, particular y construida por el sujeto; es una experiencia única que se da en 4 momentos (1) cuando éramos bebés y gateamos, (2) cuando empezamos a caminar, (3) cuando llegamos a la escuela y (4) cuando somos niños y niñas más grandes. En el primer momento los niños/as dan vida al proceso de la gestación, al vínculo afectivo y emocional que se genera entre madre e hijo, frente a la crianza y el cuidado. Aquí sitúan los vínculos y tejidos con sus familias, en particular con la madre ("chupar teta"), y el pasaje del hogar a la guardería del Programa Buen Comienzo.

Caminar marca el comienzo de otra etapa de crecimiento y relatan las experiencias vividas en el paso que dan desde el hogar a la guardería, un período representado íntegramente por el juego. Sin embargo, es una etapa que exige también que los niños se adapten al nuevo escenario escolar. Esto explica que hayamos podido identificar en sus relatos la presencia de una mirada nostálgica sobre la infancia, de una infancia alegre que se va perdiendo producto de las dificultades sociales, económicas que les ha tocado atravesar junto a sus familias y por efecto de la experiencia de la escolarización en el tránsito hacia la escuela.

La llegada a la escuela configura el paso de la institución de Educación Inicial a la institución de Educación formal (grado transición y primero); implica el cierre de una etapa pero a su vez el inicio de una experiencia basada en nuevos aprendizajes, relaciones, amigos, maestras; requiere de parte de los niños y niñas adaptación e integración a las nuevas directrices institucionales. Por último, la referencia a "niños y niñas más grandes", implica el cambio de la educación preescolar a la básica primaria. En esta etapa se autoperciben todavía como niños y niñas asumiendo una serie de responsabilidades impuestas por la escuela. Lo que para los niños y niñas significa pérdida, para la escuela es madurez y autonomía. Sin embargo, se percibe durante el trabajo de campo inquietud por responder a la imagen de "niño/a adulto/a" 
que esperan la institución escolar porque sería una señal de que la adaptación se ha logrado y los niños se convierten en un sujeto escolarizado.

Vemos en el trabajo de campo que ellos/as en sus transiciones otorgan diferentes sentidos a los acontecimientos que viven y experimentan en la experiencia escolar. El primer acontecimiento se relaciona con el vínculo afectivo entre maestras y pares, el segundo con el lugar de los saberes y aprendizajes, el tercero con el juego y el cuarto con los espacios educativos. El análisis del material relevado nos permite inferir que para los/as niños/as el lugar de los saberes es de transformación y cambio. Los saberes en la Educación Inicial y Atención Integral se corresponden con las actividades de juegos de roles, exploración del medio, el arte, la literatura, la expresión corporal, artística y la representación gráfica. En la Educación Preescolar el juego sigue siendo el medio para aprender, compartir y descubrir saberes, con expresiones artísticas como la pintura, el dibujo y la expresión plástica, pero sobresale una preocupación entre las maestras por la forma en que el preescolar prepara a los niños y niños en su paso hacia la educación primaria por lo que consideran son otros puntos críticos.

El primero es que los saberes tienen un enfoque más hacia el potenciamiento de habilidades lingüísticas, numéricas, en el marco de la lectura, escritura y las matemáticas, es decir, se resignifica otro tipo de construcción de saberes que centralizan actividades más rutinarias que en ocasiones se vuelve compleja de asimilar lo que influye en los procesos de deserción, desmotivación o discontinuidad en las trayectorias escolares especialmente para los niños y niñas que tienen alertas en el desarrollo, discapacidad o una situación cultural específica. El segundo es que los saberes son estructurados y corresponden al logro de unas competencias y metas que se miden a partir de las evaluaciones estandarizadas; el tercero es que el escenario educativo cuenta con otras formas organizativas y estructurales físicamente, y el cuarto es que la enseñanza se traslada hacia un método tradicional en el que la lúdica y el juego son usados con menor frecuencia. Podríamos señalar que en la educación básica primaria se pierden el juego y las actividades rectoras como el arte, la música, la literatura y se incrementa el control sobre las actividades y los aprendizajes para el cumplimiento de un currículum académico.

Los espacios educativos es otro de los aspectos a los cuales niños y niñas dan sentido: el parque, la biblioteca, la cancha, los corredores, las zonas verdes, los salones o salas de 
desarrollo, la tienda, la zona de juegos infantiles, el restaurante entre otros, son ambientes con los que establecen una conexión que le da identidad a su infancia; en sus narraciones dejan ver que en el paso que realizan de la educación inicial a la educación formal ellos extrañan los espacios de aprendizaje y lúdico recreativos diseñados en la Educación Inicial. Su reclamo hacia la escuela primaria es que se los deje disfrutar de los espacios dispuestos para los más pequeños porque, en su visión, siguen siendo niños y niñas. Aman, valoran la escuela infantil porque la consideran el escenario más importante para socializarse, para tejer los vínculos con sus pares, maestras, padres, para aprender. Es por eso por lo que demandan a la escuela que garantice el derecho al juego y rompa con la aparente oposición entre juego y trabajo, porque quieren una niñez que no sea interrumpida por el proceso de escolarización.

Dado lo anterior y después de narrar las experiencias de los niños y niñas, de las maestras y agentes educativas frente a la trayectoria y transición escolar en el campo de la Educación Infantil es importante decir que la reflexión que se debe hacer desde el universo de “este lado de la línea" (narraciones de las maestras-agentes educativas, directivos), es volver a la infancia, esa que se pierde o se guarda cuando se crece, cuando se asume las múltiples responsabilidades de un mundo adulto que parece absorber cada momento, cada tiempo, que te envuelve en la rutina, en el trabajo, en las formas de ser de otros o de reproducir una vida asignada desde muy temprana edad. Volver a recordar la infancia, a dejar el miedo, a soñar sin limitaciones, a despertar la curiosidad, la imaginación, y capturar con los niños y niñas en el lente de la vida lo que nos ocurre, nos afecta, cada momento del proceso pedagógico, ocurrencia, pensamiento, idea, sonrisa, se convierte en la posibilidad para nosotros/as las maestras de aprender a ser otra vez niños y niñas.

Y es que este aprendizaje de ser otra vez "niños y niñas" para nosotros los maestros/as es necesario. Pareciera que en el escenario escolar estamos fijando el período de la infancia, imponiéndole a los niños y niñas unos modos de ser sujetos escolarizados, forjando un currículo que limita su niñez y asignando una carga con respecto a los roles que les encomendamos de ser niños y niñas maduros, responsables, autónomos, adultos. La preocupación por cumplir con unos estándares, una preparación para la vida adulta, un disciplinamiento que refleja conductas autoritarias que se justifican, argumentan y sostienen bajo las lógicas escolares, nos está limitando de ver y escuchar lo que reclaman los niños y niñas, sus juegos, sus espacios, sus formas de aprender. Los niños y niñas quisieran una niñez 
que no fuera interrumpida, sin embargo, nuestra posición respecto de la infancia, su educación, la misión de la escuela, las representaciones de género que no cuestionamos - niñas buenas, inteligentes y juiciosas; niños traviesos, desobedientes, fuertes y responsables- configuran un discurso hegemónico y una matriz de formación que atraviesa los procesos escolares y la forma como estamos comprendiendo las infancias.

Nos preguntamos ¿Qué significa la escolarización cuando los niños y niñas reclaman seguir siendo tratados como "niños-niñas"; cuando reclaman por espacios educativos pensados para ellos/ellas, por sus tiempos y sus juegos? Quizá la respuesta la hayan dado los niños de nuestro estudio cuando expresaron que su deseo es tener "escuela con muros de colores", una escuela que transite al ritmo de los niños y niñas y no una escuela que fuerce la adaptación de los niños y niñas a sus normas, códigos, estructuras y propuestas; una escuela que no reproduzca un estigma de vulneración ni marginación, que contemple el universo del "otro lado de la línea" (narraciones de los niños y niñas) y que ofrezca múltiples alternativas donde la niñez sea una experiencia compartida y prolongada entre maestras-niños y niñas. Con esto no se pretende decir que se infantilice la infancia ni la escuela infantil, sino que se posibilite un espacio de colores en el que se dé la posibilidad de construir una trayectoria escolar, un espacio donde tengan lugar las preguntas y las propuestas de los niños.

Lo que se pretende es que pongamos la mirada en la reflexión con respecto a la escuela infantil, los niños y niñas reclaman una educación en la que puedan compartir, interactuar y generar vínculos con sus padres, pares, maestras, con su contexto, su mundo, para ellos/as la escuela es el espacio para la vida en común, para compartir, para aprender a vivir juntos, para soñar, reir, jugar, conocer el mundo; la escuela infantil se convierte en el escenario donde pueden mostrar su condición humana, donde pueden ser escuchados y ser reconocidos. De ahí el llamado a un diálogo igualitario que no segmente y estigmatice los sistemas de educación inicial y educación formal, sino que promueva oportunidades que favorezcan la continuidad en los procesos institucionales, pedagógicos y curriculares. Todo ello implica un trabajo de articulación no solo horizontal sino vertical, una educación hospitalaria pensada para todos y todas.

\section{Lineas abiertas}


En Colombia las orientaciones políticas y normativas dirigidas a la atención de la primera infancia constituyen uno de los puntos de debate público. Observamos gracias al análisis documental que la atención educativa de las infancias se concentra en la institucionalidad, específicamente en el proceso de articulación inter-institucional, poniendo de manifiesto estrategias y condiciones que buscan la ampliación de la cobertura, la disminución de la desigualdad, la detección de los problemas que se presentan en los momentos de salida y pasaje de una institución a otra. La apuesta se concentra en asegurar el acceso, permanencia con estrategias como la entrega y la recepción, los intercambios pedagógicos, los encuentros con familia. Sin embargo, según lo relevado en nuestro campo al estar la mirada centrada en los itinerarios de entrada y salida hacia instituciones y en la necesaria preparación para que el niño/a pueda enfrentarse a nuevos retos se deja de lado la articulación vertical, es decir, la coherencia y continuidad entre las propuestas educativas, la organización pedagógica, y esto genera puntos críticos en las trayectorias de los niños y niñas en su paso por la educación infantil. Esto explica que el discurso gubernamental ha dejado de referir a transiciones exitosas para poner el acento en las condiciones necesarias para garantizar transiciones armoniosas como resultado de una mejor articulación horizontal, inter-institucional. Las maestras entrevistadas señalan que este cambio en la forma de concebir las transiciones educativas esconde la desigualdad en lo que respecta a la infraestructura, equipo interdisciplinario, dotación de materiales, ambientes pedagógicos, formación docente, propuesta curricular, presupuesto entre ambos.

Los marcos políticos que regulan las transiciones en Colombia son claros con respecto a las orientaciones administrativas, técnicas y pedagógicas. La revisión documental enmarca avances significativos especialmente en los últimos cuatro años desde el 2016 frente al proceso de transición y articulación entre ambos sistemas. La apropiación de las políticas por parte de los entes territoriales, las secretarías de educación y los actores de las instituciones educativas requieren de un mayor debate a escala nacional si se comprende que el proceso de transición educativa finalmente radica en un efectivo encuentro entre los niveles de educación inicial y educación formal, lo que indiscutiblemente muestra la necesidad de un trabajo de articulación no solo horizontal sino vertical.

El mayor avance observado en el país es el reconocimiento de los niños y niñas como sujetos de derecho, la concepción de niño y niña presente en los documentos oficiales vigentes 
responde a una perspectiva de derechos humanos que asume una perspectiva holística de los derechos y el desarrollo infantil, implicando la coparticipación en su propio desarrollo, reconociendo las características y capacidades de niños y niñas como sujetos contextuados. Esta noción de niño y niña ha conducido al desarrollo de acciones, estrategias y orientaciones que buscan aumentar las tasas de cobertura, disminuir las desigualdades, detectar y dar respuesta a las condiciones de las salidas, ausencias y transiciones de los niños y niñas de los programas de Primera Infancia.

Cabe destacar que las acciones de articulación inter-institucional intra-institucional, intersectorial en la Educación Inicial han permitido acciones colectivas para ampliar los niveles de cobertura donde los diferentes actores sociales, instituciones desde el ámbito público y privado han establecido consensos y acciones que han permitido en la ciudad el reconocimiento de las infancias, la protección y garantía de sus derechos, sin embargo la continuidad de las acciones entre los escenarios de inicial y formal es indiscutiblemente el punto de quiebre en la articulación. La ausencia de conexión entre la organización institucional, curricular, las prácticas pedagógicas, los métodos y formas de enseñanza, en definitiva, la ausencia de un proyecto integrado curricularmente se convierte en un factor determinante de la repitencia y deserción escolar. El reto mayor definir una estructura articulada de la Educación Infantil en la que se conjuguen objetivos, contenidos, experiencias, materiales.

Finalmente podemos decir que los resultados obtenidos en esta investigación nos mostraron la forma como se configuran las transiciones y trayectorias en la educación infantil tanto en las voces de las maestras como en las de los niños y niñas. Hemos podido identificar los esfuerzos que se vienen realizando en la Educación Infantil desde el Programa Buen Comienzo-Atención Integral a la Primera Infancia, las escuelas de la Educación Formal (Preescolar y Básica Primaria) junto a la Secretaría de Educación para acompañar los procesos educativos de los niños y niñas. Pero también este estudio nos señala los caminos que se deben seguir indagando y explorando con respecto a la trayectoria y transición.

La presente tesis es una aproximación a un campo de estudio menos explorado en Colombia como es el estudio de las transiciones de los niños y las niñas por la Educación Infantil. Hemos querido mostrar el pasaje de niños y niñas que asisten a instituciones educativas de la ciudad de Medellín desde el Programa Buen Comienzo hacia la Educación 
Formal (Preescolar y Educación Básica Primaria), y observar los modos en que van configurando la trayectoria educativa. Recuperar las voces de los niños y niñas ha sido el mayor desafío metodológico al que nos enfrentamos y por ello resulta necesario producir nuevas estrategias de indagación que recuperen esos otros lenguajes con los que logran comunicar lo que sienten y piensan sobre la familia, la escuela, el juego, las maestras, los amigos. También hemos querido relevar las visiones de maestras y agentes educativos respecto de cómo se preparan los niños y niñas en cada escenario educativo para enfrentar los requerimientos y expectativas del escenario que los recibe, identificando a su vez los puntos críticos de un sistema que se presenta desarticulado inter-institucionalmente entre niveles y grados educativos (articulación horizontal) y entre las definiciones de política pública, los lineamientos pedagógicos y las prácticas docentes (articulación vertical). Creemos que hacen falta otros estudios e investigaciones no solo para identificar los puntos críticos que se producen en la transición de niños y niñas entre instituciones de la Educación Infantil en Colombia sino para relevar las voces de niños y niñas que nos ayuden a pensar de qué modo la escolarización no se asienta en la negación del derecho a vivir 


\section{Lista de referencias}

Abello, R. (2008). Transiciones al inicio de la escolaridad: una experiencia de construcción de sentido. (Informe de Tesis Doctoral). Doctorado en ciencias sociales niñez y juventud CINDE - Universidad de Manizales. Recuperado http://biblioteca.clacso.edu.ar/Colombia/alianza-cinde-umz/20091210024743/tesisabello-correa.pdf

Abrego, P., y Brammer, L. (1992). Counseling adults in midlife career transitions. Adult career development: Concepts, issues, and practices, 234-254.

Alcaldía de Bogotá (2018). Documento de Orientaciones recorrido para acompañar las transiciones efectivas y armónicas de los niños y las niñas en el entorno educativo. Recuperado de https://www.icbf.gov.co/sites/default/files/procesos/orientaciones para acompanar la s transiciones efectivas y armonicas.pdf

Alcaldía de Medellín (2011). [anexo 5 diciembre 2011]. Política de atención integral a la primera infancia del municipio de Medellín. Lineamientos educativos para el desarrollo integral de la primera infancia del municipio Medellín

(2018). diagnóstico del sector educativo. Secretaría de Educación de Medellín

Alvarado, S. V., y Suárez, M. C. (2010) Transiciones educativas en primera infancia, una mirada desde las políticas públicas en Colombia: avances y desafíos. Recuperado de https://web.oas.org/childhood/ES/Lists/Temas $\% 20 \% 20$ Proyectos $\% 20 \% 20$ Actividad $\%$ 20\%20Documento/Attachments/635/Colombia3,\%202007.pdf

Álvarez González, M., y Fita, E. (2005). La intervención orientadora en la transición Bachillerato-Universidad. Revista Bordón, 57 (1), 5-26.

Alwin, DF (2012). Integrando Conceptos del Curso de Variedades de Vida. Las Revistas de Gerontología Serie B: Ciencias Psicológicas y Ciencias Sociales ,67B (2), 206-220. http://doi.org/10.1093/geronb/gbr146

Ames, Patricia; Rojas, Vanessa (2011). Cambios y oportunidades: La transición de la escuela primaria a la secundaria en el Perú/ Lima. Grade: Niños del Milenio, 2011. 61 p. Documento de Trabajo, 63.

Anderson, L., Jacobs, J., Schramm, S. y Splittgerber, F. (2000). School transitions: beginning of the end or a new beginning? International Journal of Educational Research, 33, 325 339.

Antúnez, 1. (Coords.) La transición entre etapas (pp. 13-22). Barcelona: Graó.

Arcila, J. (2015). Corporeidad, arte y escuela. Magazín aula urbana, (97), 3-4.

Arenas, P. (2001). Percepción de estudiantes de educación parvularia y educación general básica de la universidad de los lagos, sobre la problemática de articulación entre ambos niveles. 
Argos, Castro, y Ezquerra, M. (2009). Repensando la práctica pedagógica de nuestras escuelas: algunos vectores potencialmente revitalizadores. En J. Hernández, s. Molina, \& m. Inda (eds.), la escuela hoy. La teoría de la educación en el proceso colectivo de construcción del conocimiento (pp. 161-171). Oviedo: universidad de oviedo.

Arnold, C., Barlett, K., Gowvani, S., \& Merali, R. (2006). Is everybody ready? Readiness, transition and continuity: lessons, reflections and moving forward. Unesco Background paper prepared for the Education for All Global Monitoring Report 2007 Strong Foundations: Early Childhood Care and Education.

Artiaga, J. F. (2009). Transicions, itineraris i processos. Educació social. Revista d'intervenció sòcioeducativa, (42), 15-26.

Altet, M. (2005). La Formación Profesional del Maestro. Estrategias y competencias. México, D.F: Fondo de Cultura Económica.

Avellan, C. P. (2000). Pérdidas y duelos: reflexiones y herramientas para identificarlos y afrontarlos.

Baquero y Narodowski. (1994). Existe la infancia, en revista del instituto de investigaciones en ciencias de la educación de la universidad de Buenos Aires.

Barrera Morales (SF) Qué es la holística. Recuperado de http://www.telurium.net/PDF/holistica.pdf

Becerra, A. J. (2010). El devenir de las tareas escolares y la emergencia de la infancia contemporánea: Una arqueología histórica en Colombia entre 1968 y 2006. Pedagogía y saberes, (33), 51-61.

Breilh, Jaime. "La triple carga; trabajo, práctica doméstica y procreación: deterioro prematuro de la mujer en el neoliberalismo." CEAS, 1991.

Bennett, John (2006). Entrevista publicada en la Revista Espacios para la Infancia, Número 26, Fundación Bernard van Leer - Holanda

Bennett, John. (2006). Debemos aprender a ver las transiciones en las vidas de los niños de una forma mucho más positiva, en: "van leer, fundación. "el continuum desde el hogar a la escuela", en: "las transiciones en los primeros años: una oportunidad para el aprendizaje”. Espacios para la infancia, noviembre 2006, número 26, p. 148 opus cit. Pág. 2

Blanco, M., y Pacheco, E. (2003). Trabajo y familia desde el enfoque del curso de vida: dos subcohortes de mujeres mexicanas. en Revista Papeles de Población, Nueva Época, año 9, núm. 38, Centro de Investigación y Estudios Avanzados de la Población, Universidad Autónoma. MéxicoD.F

Bourdieu, P. (1977). Razones Prácticas. Barcelona: Anagrama, 1997. (1979). La distinción. Criterio y bases sociales del gusto (3a. ed.). Madrid: Taurus (1980). El sentido práctico. Ed. Buenos Aires: Siglo XXI-2007

(1988). Espacio social y poder simbólico, en: Bourdieu, Pierre, Cosas dichas, Buenos Aires, Gedisa, pp. 127-142 
(1989). La ilusión biográfica. Historia y fuente oral. $\mathrm{N}^{\circ} 2$. Barcelona, universidad de Barcelona y archivo histórico de la ciudad.

(1991) El sentido práctico. Madrid: Taurus.

(1997) "Espacio social y espacio simbólico", en Razones prácticas. Sobre la teoría de la acción, Anagrama, Barcelona, pp. 11-26.

(1999). El conocimiento por cuerpos, en Meditaciones pascalianas, Barcelona, Anagrama, 1999, pp. 169-214.

(2000), El sociólogo y las transformaciones recientes de la economía en la sociedad, Libros del Rojas, Universidad de Buenos Aires. (2000), Cosas dichas, Barcelona, Gedisa.

(2007). Intelectuales, politica y poder. Argentina: ediciones Eudeba.

Bourdieu, P. y Passeron, J.C. (2008). La reproducción. Elementos para una Teoría del sistema de enseñanza. Madrid, España: editorial popular.

Bourdieu, P. (2001). Poder, derecho y clases sociales (Vol. 2). Bilbao: Desclée de Brouwer.

Breen, R.; Goldthorpe, J. H. (2000): «Explaining Educational Differentials», en J. H.

Goldthorpe (dir.), On Sociology, Oxford, Oxford University Press

Brailovsky, D. (2006). Revoluciones silenciosas. El jardín de infantes y el homeschooling como tentativas de reinvención de lo escolar. EnM. Narodowski \& D. Brailovsky (comps.) Dolor de Escuela, (pp. 131-152). Buenos Aires: Prometeo Libros.

Briscioli, Bárbara. (2013). Tendencias y puntos críticos en las trayectorias escolares de estudiantes de Escuelas de Reingreso de la Ciudad de Buenos Aires. Una indagación sobre las condiciones de escolarización en la construcción de las trayectorias escolares (Tesis de Doctorado). Universidad Nacional de Entre Ríos, Paraná, Argentina.

Bronfenbrenner, U. (1977). Toward an experimental ecology of human development. American Psychologist, 32, 513-531

(1979) The Ecology of Human Development. Cambridge, Massachusetts: Harvard University

(1987). Ecología del desarrollo humano. Barcelona: Paidós

Burke, c. (2005). "Play in focus": children researching their own spaces and places for place. Children, youth, environments, 15(1):27-53.

Camargo Abello, M. (2014). Sentido de la educación inicial, documento 20 serie de orientaciones pedagógicas para la educación inicial en el marco de la atención integral. Recuperado http://www.deceroasiempre.gov.co/Prensa/CDocumentacionDocs/Documento-N20sentido-educacion-inicial.pdf

Cárdenas, H. (2010). Actitudes afectivas hacia niños y niñas con necesidades educativas especiales. Revista pensamiento actual, 4(5), pp. 4-12.

Carli, S. (2002). "Niñez, pedagogía y política: transformaciones de los discursos acerca de la infancia en la historia de la educación argentina entre 1880 y 1955”. Miño y Dávila. 
(2005). Infancia, cultura y educación en las décadas del 80 y 90 en argentina. Buenos Aires: universidad de San Andrés.

(2011). El campo de estudios sobre la infancia en las fronteras de las disciplinas. Notas para su caracterización e hipótesis sobre sus desafíos. Infancias: Políticas y Saberes en Argentina y Brasil. Buenos Aires: Teseo.

(S, F). La infancia como construcción social. Recuperado de http://blogs.unlp.edu.ar/pec/files/2016/04/Carli-La-infancia-como-construcci\%C3\%B3n$\underline{\text { social.pdf }}$

Casal, J. (1996). Modos emergentes de transición a la vida adulta en el umbral del siglo XXI: Aproximación sucesiva, precariedad y desestructuración. Revista Española de Investigaciones Sociológicas, 75 (96), 295-318.

Castillo, P. (2011). Desigualdad social y espacio en la infancia. Trayectorias espaciales observadas en el juego infantil en niños de diferentes posiciones sociales. Revista de Psicología, 20(1), ág-7.

Castro, A., Argos, J., y Ezquerra, P. (2015). La mirada infantil sobre el proceso de transición escolar desde la etapa de educación infantil a la de educación primaria. Perfiles educativos, 37(148), 34-49.

(2016). Procesos de escucha y participación de los niños en el marco de la educación infantil: Una revisión de la investigación. Educación XX1, 19(2), 105-126.

CLADE (2020). El derecho a la educación de las personas con discapacidad ¿Cómo estamos en América Latina y el Caribe?. Recuperado de https://redclade.org/wpcontent/uploads/CLADE_InformeDiscapacidad.pdf

Ceballos C. (2016). ¿Los macroproyectos de vivienda masiva solucionan los problemas de habitabilidad?: un acercamiento a la experiencia de Medellín con Ciudadela Nuevo Occidente.

CECREALC. (1992). Un enfoque actual de la adaptación del niño al centro infantil.

(M. E. Villegas., Ed.)

Cerda, H. (1996). Educación preescolar: historia, legislación, currículo y realidad socioeconómica. Cooperativa Editorial Magisterio.

Cerletti, L. (2016). Enfoque etnográfico y formación docente: aportes para el trabajo de enseñanza. Pro-Posições, 24(2), 81-93

Chacón Reynosa, k. (2009). El cuerpo infantil en la comunicación escolar: un análisis desde la sociología del cuerpo. (monografía). Tomado de: http://eprints.ucm.es/11087/Children's Bureau.

Christian Lalive d'Epinay (Lalive dÊEpinay, Bickel, Cavalli y Spini, 2005) citado en Lombardo, E., \& Krzemien, D. (2008). La Psicología del curso de vida en el marco de la Psicología del Desarrollo. Revista argentina de sociología, 6(10), 111-120. Compes 2009

Clark, A. y Moss, P. (2001). Listening to young children. The mosaic approach. Londres: National Childern's Bureau and Rowntree Foundation 
(2006). Listening to young children. The mosaic approach. Londres: National.

Cocks, a. (2006). The ethical maze. Finding an inclusive path towards gaining children's agreement to research participation. Childhood, vol 13(2):247-266.

Concejo de Medellín (2011) [Acuerdo 58 de diciembre 2011]. Política Pública de Atención Integral a la Primera Infancia. Buen Comienzo Alcaldía de Medellín. https://medellin.edu.co/buen-comienzo/politica/497-acuerdo-058-de-2011/file

(2015) [Acuerdo 54-14 diciembre 2015] Por medio del cual se redefine la regulación municipal sobre la Política Pública de Primera Infancia y el Programa Buen Comienzo. Recuperado https://medellin.edu.co/buen-comienzo/politica/496-acuerdo-054-de2015/file

Poch, C. (2013). Pérdidas y duelos. Reflexiones y herramientas para identificarlos y afrontarlos.

Conde M. (1982). El periodo de adaptación en la escuela Infantil. Cuadernos de pedagogía, ${ }^{\circ}$ 89. Mayo. Barcelona

Cobo, E. R. (2010). El abandono temprano de la educación y la formación en España. Revista de educación, (1), 31-62.

Congreso de la República de Colombia. (1991) [Ley 12 de 1991 enero 22]: Por medio de la cual se aprueba la Convención sobre los Derechos Del Niño adoptada por la Asamblea General de las Naciones Unidas el 20 de noviembre de 1989. Bogotá

(2006) [Ley 1098 noviembre 8 de 2006]: Por la cual se expide el Código de la Infancia y la Adolescencia. Bogotá, D.C

(2016) [Ley 1804 de 2016 (agosto 2]: Por la cual se establece la política de Estado para el Desarrollo Integral de la Primera Infancia de Cero a Siempre y se dictan otras disposiciones. Bogotá D.C.

[Decreto $\mathrm{N}^{\circ} 2247$ de 1997], Normas relativas a la prestación del servicio educativo del nivel preescolar Congreso de la República de Colombia [Ley N 115 de 1994]. Articulo xx Ley General de Educación Santa Fe de Bogotá, Colombia.

[Ley N ${ }^{a} 115$ de 1994]. Articulo 15 Ley General de Educación Santa Fe de Bogotá, Colombia. (2006). Ley 1098 de 2006. Código de la Infancia y la Adolescencia.

Connolly, p. (1998). Racism, gender identities and young children. London: routledge.

Córmack, L. y Dulkenberg, E. (2009). Las Transiciones en la Primera Infancia: una Mirada Internacional. Organización de los Estados Americanos, Oficina de Educación y Cultura, y Junta Nacional de Jardines Infantiles (JUNJI) de Chile. Recuperado en, http://portal.oas.org/LinkClick.aspx?fileticket=qrqhTMKY4EU\%3D\&tabid=1318

Corsaro, W. A. y Eder, D. (1990). Children's Peer Cultures. Annual Review of Sociology, 16, 197-220. Indiana: Indiana University.

Corsaro, W. A. y Rizzo, T. A. (1988). Discussione and Friendship. Socialization Processes in the Peer Culture of Italian Nursery. School Children, 53(6), 879-894. 
Corsaro, w.a. (2005). The sociology of childhood. Thousand oaks, ca: pine forge press.

Creswell, J. W. (2007). Qualitative inquiry and research design: Choosing among five approaches (2nd ed.). Sage Publications, Inc.

Crivello, gina (2009) becoming somebody: youth transitions through education and migration -evidence from young lives. Working paper $n^{\circ} 43$ (documento de trabajo $n^{\circ} 43$ ), oxford: younglives

Cubero, C. Abarca, A.; Nieto, M. (1996). Percepción y manejo de la disciplina en el aula. San José, Costa Rica: IIMEC.

Dávila, O y Felipe G. (2005). "trayectorias, transiciones y condiciones juveniles en chile". Nueva sociedad 200:114-126

De la rosa reyes, M. (2011) las representaciones sociales de niñas y niños sobre su experiencia de vida como infantes. Ponencia, IX congreso nacional de educación educativa, sujetos de la educación, 16, 1-9.

Departamento Nacional de Planeación (2017) Balance de resultados 2016. Plan Nacional de Desarrollo 2014-2018: "Todos por un nuevo país. Recuperado de https://colaboracion.dnp.gov.co/CDT/Sinergia/Documentos/Balance_de_Resultados 2016.pdf

Diker, G. (2009). ¿Qué hay de nuevo en las nuevas infancias? Universidad Nacional de General Sarmiento

(2010). Organización y perspectivas de la Educación Inicial en Iberoamérica: "Principales tendencias"; OEI y "Atención y Educación de la Primera Infancia". Informe regional. América Latina y El Caribe. UNESCO. 2010

DINIECE-Unicef, (2004). Las dificultades en las trayectorias escolares de los alumnos. Un estudio en escuelas de nuestro país. Ministerio de Educación, Ciencia y Tecnología de Argentina y Dirección Nacional de Información y Evaluación de la Calidad Educativa

Dockett, S. and B. Perry (2005). 'Researching with children: insights form the Starting School Research Project' Early Childhood Development and Care 175:6, 507-521.Educación (Madrid) número extraordinario, 31-62.

Dockett, S. y Perry, B (2001). Starting School: effective transitions. Early childhooh research $y$ practice, 3(2) 118

Documento Conpes Social (2007). Política pública Nacional de Primera Infancia "Colombia por la Primera Infancia”. Departamento Nacional de planeación. N 109. Recuperado de https://www.mineducacion.gov.co/1759/articles177832 archivo_pdf_Conpes 109.pdf

Dunlop (2002). Transitions in the early years. Debating continuity and progression for children in early education. Londres y nueva york: routledge falmer.

Durkheim, E. (1987), La división social del trabajo. Madrid, Akal. - (1992), Las formas elementales de la vida religiosa. Madrid, Aka Frabboni, F. (1984) La educación del niño de cero a seis años. Cincel. Madrid, España. 
E., Salas, G., \& Vigorito, A. (2018). Desarrollo en la infancia y trayectorias educativas de los adolescentes. Un estudio con base en datos de panel para Uruguay. El trimestre económico, 85(337), 81-113.

Élder GH. (1974). Hijos de la gran depresión: cambio social en la experiencia de la vida. Chicago, IL: Prensa de la Universidad de Chicago.

(1985), "Perspectives on the life course", en Glen Elder (ed.), Life Course Dynamics. Trajectories and Transitions, 1968-1980, Ithaca (Nueva York): Cornell University Press. (1991), "Lives and social change", en Walter Heinz (ed.), Theoretical Advances in Life Course Research. Status Passages and the Life Course, vol. I, Weinheim: Deutscher StudienVerlag.

(1994) Time, human agency, and social change: Perspectives on the life course. Social Psychology Quarterly 57 (1): 4-15

(1997) El curso de la vida y el desarrollo humano. En: Lerner RM, editor. Manual de psicología infantil, vol. 1: Modelos teóricos del desarrollo humano. Nueva York: John Wiley; 1997b. pp. 939-991.

(1998). The Life Course as Developmental Theory, Child Development 69, pp. 1-12.

(1999). El curso de la vida y el envejecimiento: algunas reflexiones. 1999, 10 de Agosto Distinguished Scholar Lecture, Section on Ageing and Life Course, Annual Meetings of the American Sociological Association

Elder, Glen y Monica Kirkpatrick (2002), "The Life Course and Aging: Challenges, Lessons, and New Directions", en Richard Settersten (ed.), Invitation to the Life Course: Toward New Understandings of Later Life, Nueva York: Baywood.

Elder, G. Kirkpatrick Johnson, M. Crosnoe, R. (2003) "The emergence and development of life course theory". En J. T. Mortimer, M. J. Shanahan (Eds.) Handbook of the life course. Nueva York: Kluwer. Pp. 3-19

Élder GH, Jr, Johnson MK, Crosnoe R. (2003). El surgimiento y desarrollo de la teoría del curso de la vida. En: Mortimer JT, Shanahan MJ, editores. Manual del curso de la vida. Nueva York: Kluwer Academic / Plenum; 2003. pp. 3-19.

Elder GH, Jr., Shanahan MJ (2006). El curso de la vida y el desarrollo humano. En: Damon W, Lerner RM, editores. Manual de psicología infantil. Vol. 1. Modelos teóricos del desarrollo humano. $6^{\mathrm{a}}$ ed. Nueva York: John Wiley \& Sons; 2006. pp. 665-715.

Elder, Glen, Monica Kirkpatrick y Robert Crosnoe (2006), "The emergence and development of life course theory", en Jeylan T. Mortimer y Michael J. Shanahan (eds.), Handbook of the Life Course, Nueva York: Springer

Elder, Glen y Janet Giele (eds.) (2009), The Craft of Life Course Research, Nueva York: The Guilford Press.

Estrategia de atención integral a la primera infancia de cero a siempre, (2015). Informe de balance octubre de 2014 - junio de 2015, Ministerio de Educación Nacional recuperado http://www.deceroasiempre.gov.co/Prensa/CDocumentacionDocs/Informe-EstrategiaCero-a-Siempre-balance-oct2014-jun2015.pdf 
Escobar, Arturo,2003, Mundos y conocimientos de otro modo. El programa de investigación de modernidad/colonialidad latinoamericano. Tabula rasa, 2003, no 1, p. 51-86.

Fabian, H. y Dunlop, A.-W. (eds.) (2002) Transitions in the Early Years. Debating Continuity and Progression for Children in Early Education. Londres y Nueva York: Routledge Falmer.

Failache, E., Salas, G., \& Vigorito, A. (2018). Desarrollo en la infancia y trayectorias educativas de los adolescentes. Un estudio con base en datos de panel para Uruguay. $E l$ trimestre económico, 85(337), 81-113.

Fernández, M. (2011). Del desapego al desenganche y de éste al fracaso escolar. Propuesta Educativa, 35, 85-94.

(2013) Notas sobre educación popular y primera infancia. En educación popular en la historia reciente en argentina y américa latina Aportes para balance y prospectiva, Buenos Aires APPEAL (pp126127), Recuperado de http://cidac.filo.uba.ar/sites/cidac.filo.uba.ar/files/revistas/adjuntos/UNIDAD $\% 2014 \%$ 20-\%20Educaci\%C3\%B3n\%20Popular.pdf

Fernández, F. (2002). El análisis de contenido como ayuda metodológica para la investigación. Revista de Ciencias Sociales, 2(96).

FECODE (2019) Acta de acuerdo colectivo, mesa nacional de negociaciones pliego de solicitudes 2019-Gobierno Nacional y FECODE. Recuperado de https://www.fecode.edu.co/images/acta_acuerdo2019/Acta_de_Acuerdos_Final_2019 .pdf

Fernández, M., Mena, L. y Riviere, J. (2010). Fracaso y abandono escolar en España. Colección Estudios Sociales No 29. Barcelona: Obra Social Fundación "La Caixa".

Figuera, P., Dorio, I., y Forner, A. (2003). Las competencias académicas previas y el apoyo familiar en la transición a la Universidad. Revista de Investigación Educativa, 21 (2), 349-369.

Finocchio, s. (2010). Una cartografía de saberes escolares en movimiento para américa latina. Revista propuesta educativa, 34. Buenos aires: flacso. Foucault, m. (1987). La arqueología del saber. (12a . Ed.). México: siglo xxi editores. Foucault, m. (2002). Hermenéutica del sujeto. Buenos aires: fondo de cultura económica

Frassa, Juliana y Muñiz Terra, Leticia. (agosto, 2004). Trayectorias laborales: origen y desarrollo de un concepto teórico-metodológico. Ponencia presentada en las Cuartas Jornadas de Etnografía y Métodos Cualitativos, Instituto de Desarrollo Económico y Social, Buenos Aires, Argentina

Frigerio, G. (2006) "Infancias (apuntes sobre los sujetos)". En: Terigi, F. (comp.) Diez miradas sobre la escuela primaria. Buenos Aires, siglo XXI eds Frigerio, G. y Diker, G., Educar: saberes alterados. Buenos Aires, Del estante

(2007). Argumentos para ampliar lo impensable. En las formas de lo escolar. Editorial, Buenos Aires. Compilado por Ricardo Baquero, Gabriela Diker y Graciela Frigerio.

Foucault, M. (2009 [1979]). Vigilar y castigar. Nacimiento de la prisión. Madrid: Siglo XXI. 
(2009 [1978]). Historia de la sexualidad I. La voluntad del saber. Madrid: Siglo XXI. Goffman, E. (2001 [1963]). Estigma. La identidad deteriorada. Buenos Aires: Amorrortu

Gairín, J. (2005). El reto de la transición entre etapas educativas. Aula de innovación educativa, $142,12-17$.

Gaitán. L. (2006)" La nueva sociología de la infancia. Aportaciones de una mirada distinta. Política y Sociedad", (43) Núm. 1: 9-26. Madrid, España. Recuperado de: http://revistas.ucm.es/index.php/POSO/article/view/POSO0606130009A/22625

Gajardo, A. (2010). Importancia dada por las educadoras de párvulos y profesoras y profesores al trabajo de articulación curricular entre niveles. Horizontes educacionales. 2(15), 2331. Recuperado de $\mathrm{http}: / / \mathrm{www}$. redalyc.org/articulo.oa? $\mathrm{id}=97917578002$

Gallacher, Lesley-Anne y Michael Gallagher (2008), "methodological immaturity in childhood research? Thinking through participatory methods", childhood, vol. 15, núm. 4, pp. 499-516

Galton, M., Morrison, I. y Pell, T. (2000) Transfer and transition in English schools: reviewing the evidence. International Journal of Educational Research, 33, 341-363.

Gastrón L, Oddone MJ. (2008). Reflexiones en torno al tiempo y el paradigma del curso de la vida. Perspectivas en Psicología. 2008;5(2):1-9.

George, Linda (2006), "Life Course Research", en Jeylan T. Mortimer y Michael J. Shanahan (eds.), Handbook of the Life Course, Nueva York: Springer

Gimeno Sacristán, J. (1996). La transición a la educación secundaria. Madrid: Ediciones Morata

(2007). La diversidad de la vida escolar y las transiciones. (1998) Kikiriki. Cooperación educativa, (48), 16-20

Giroux, Henry (2003), pedagogía y política de la esperanza, Buenos Aires, amorrortu. Greco, s. N. M. B., \& Nicastro, s. (2009). Entre trayectorias. Escenas y pensamientos en espacios

Glaser, B. y Strauss, A. (1967). The discovery of grounded theory: strategies for qualitative research, New York: Aldine de Gruyter. investigación. La búsqueda de significados. Buenos Aires: Paidós

Gómez, C. G. (2004). Entre el estudio y el trabajo: la situación y las búsquedas de los estudiantes de la UNAM que trabajan. Universidad Nacional Autónoma de México, Centro Regional de Investigaciones Multidisciplinarias.

Gonzalez Cuberes, y Duhalde. (1996) Articulación Entre El Jardin y La E.G.B: La Alfabetización Expandida (Spanish Edition) Aique, Buenos Aires

González, G. D. G., Sánchez, B. Y. L., \& Araque, C. S. (2013). Procesos transicionales en niños y niñas indígenas de primera infancia, del Distrito Capital a su ingreso a la escuela pública. Revista ALETHEIA, 5(1), 16-33. 
Grantham-Mcgregor, S., Cheung, Y., Cueto, S., Glewwe, P., Richter, L., Strupp, B., y otros. (2007). Child development in developing countries 1: Developmental potential in the first 5 years for children in developing countries. Lancet, Vol. 369, 60-70.

Graó. Gobtlb I. y B. Wheaton. (1997). Stress and Adversity over the Life Course. Trajectories and Turning Points. Nueva York: Cambridge University Press. Citado en https://revistas.unal.edu.co/index.php/recs/article/view/31341/39585

Greco, M. (2015). Trayectorias educativas: el trabajo de los equipos de orientación escolar, desde la psicología educacional contemporánea. Anuario de Investigaciones, XXII, 153-159. http://www.redalyc.org/pdf/3691/369147944014.pdf

Guba, E., (2008) [1989] Criterios de credibilidad en la investigación naturalista En: Gimeno J., Pérez A. La enseñanza: su teoría y su práctica. Madrid: Akal.

Guber, R. (2004). El salvaje metropolitano: reconstrucción del conocimiento social en el trabajo de campo. Buenos Aires: Paidós.

Gustavo Mariluz (2013). El curso de la vida. Una mirada desde la Filosofía Fenomenológica y la Sociología del envejecimiento. X Jornadas de Sociología. Facultad de Ciencias Sociales, Morata.

Hockey, J. (2002) The importance of being intuitive: Arnold Van Gennep's The Rites of Passage. Mortality 7 (2): 210-217. Investigación Educativa, 21 (2), 349-369.

Hirst, M. Jervis,N., Visagie, K., Sojo, V y Cavanagh, S. (2011). Transition to primary school: a reviex of the literatura. Canberra: conmonwealth of Australia.

Instituto Colombiano de Bienestar Familiar-ICBF. (2013). Protocolo para la transición de los niños y niñas desde las modalidades de educación inicial del ICBF al sistema de educación formal (grado de transición).

(2014). Guía Orientadora $N^{\circ} 8$ "Guía para la transición de los niños y las niñas desde los Programas de atención a la Primera Infancia del ICBF al sistema de educación formal (Grado de Transición)".

(2016). Lineamientos para la inclusión de la primera infancia, la infancia y la adolescencia en los planes territoriales de desarrollo. Documento preparado por el equipo técnico del Comité Ejecutivo del Sistema Nacional de Bienestar Familiar. Recuperado de https://intranet.meta.gov.co/secciones_archivos/281-26847.pdf

(2017) Guía Orientadora para el tránsito de los niños y niñas desde los Programas de atención a la Primera Infancia del ICBF al Sistema de Educación Formal. Recuperado de

https://www.icbf.gov.co/sites/default/files/procesos/g13._pp_guia_orientadora_de tra nsito de ninas y ninosdesde_los_programas_de_atencion_a_la_primera_infancia_d el icbf_sistema_educativo.pdf

James, A. y James, A. L. (2004). Constructing childhood. Theory, policy and social practice. Nueva york: palgrave macmillan. (2008). Key concepts in childhood studies. Londres: sage 
James, A.; Prout, A. (eds.) (1990). Constructing and reconstructing childhood: contemporary issues in the sociological study of childhood. Basingstoke: falmer press

Jaude, G. (2003). Transformaciones familiares en chile: riesgo creciente para el desarrollo emocional, psicosocial y la educación de los hijos. Revista estudios pedagógicos, 29, pp. 1-11.

Kagan, S y Neuman, M (1998) Lessons from three decades of transiction research. The Elementary School Journal, 98(4) 365-379. http://dx.doi.org/10.1086/461902.

Kaplan (2006). La Inclusión como Posibilidad. Módulo editado por el Ministerio de Educación Ciencia y Tecnología de la República Argentina. Recuperado de http://www.bnm.me.gov.ar/giga1/documentos/EL005386.pdf

Kaplan, C. y Fainsod, P. (2001). Pobreza urbana, diversidad cultural y escuela media. Notas sobre las trayectorias escolares de las adolescentes embarazadas. Revista del IICE. Vol. 10, Año $\mathrm{N}^{\circ}$ 18. Buenos Aires, Miño y Dávila/Facultad de Filosofía y Letras-UBA. Agosto de 2001.

Kohan, W. (2004). Infancia. Entre educación y filosofía. Barcelona-España, Edición Lartes. (2011). Filosofía y educación. La infancia y la política como pretexto. alcaldía de Caracas: Fondo Editorial Fundarte

Ladd, G.W. (2005). Transition entre la maison à la maternelle/aptitudes nécessaires à l'entrée à l'école: une conséquence du développement précoce de l'enfant).Centre d'excellence pour le développement des jeunes enfants Encyclopédie sur le développement des jeunes enfants ii Synthèse sur la transition vers l'école http://www.enfantencyclopedie.com/pages/PDF/LaddFRxp-Original.pdf

Lancaster, y Broadbent, (2003). Listening to young children. Maidenhead: open university press.

Larrosa, J. (1996). Narrativa, identidad y desidentificación. . La experiencia de la lectura. Barcelona: Laertes, 461-484. (2000). Pedagogía profana: estudios sobre lenguaje, subjetividad, formación. Noveduc libros.

Legarralde, M. R., Cotignola, M. L., \& Margueliche, J. C. R. (2017). Trayectorias estudiantiles y saberes maestras en las carreras de grado de la Facultad de Humanidades y Ciencias de La Educación (2014-2016). In X JIDEEP-Jornadas de Investigación, Docencia, Extensión y Ejercicio Profesional (La Plata, 2017).

León, Z. (2011). La transición entre la Educación Inicial y la Escuela primaria en Venezuela. Revista de investigación, 35(72), 189-203.

Lineamientos para la inclusión de la primera infancia, la infancia y la adolescencia en los planes territoriales de desarrollo. (2016). Documento preparado por el equipo técnico del Comité Ejecutivo del Sistema Nacional de Bienestar Familiar, recuperado de http://www.suin-snbf.gov.co/SUIN/FileDocumentos/PlanDesarrollo/Lineamientos.pdf

Lombardo, E., \& Krzemien, D. (2008). La Psicología del curso de vida en el marco de la Psicología del Desarrollo. Revista argentina de sociología, 6(10), 111-120. 
Machado, C. (2012). Proceso de articulación entre el nivel de preescolar y el primer grado de educación básica (Tesis Doctoral). Universidad Nacional Abierta, Caracas Venezuela.

Macías, h. F. (2016). Niños de preescolar participando en la investigación educativa mediante el enfoque mosaico. Revista ibero-americana de educação, 71, 197-216.

Macnaughton, g. (2005). Doing foucault in early childhood studies: applying post-structural ideas. London: routledge.

Martínez, g. (2000). Desarrollo emocional del niño. En psiquiatría y psicología de la infancia y adolescencia. (p. 55). Madrid: editorial medical Panamericana

Martínez, Ma. Elena (2015). Personas con Discapacidad, vida independiente y educación inclusiva. Discapacidad, Justicia y Estado No5. Disponible en: http://www.saij.gob.ar/maria-elena-martinez-personas-discapacidad-vidaindependiente-educacion-inclusiva-dacf150104-2015-01/123456789-0abc-defg401051 fcanirtcod

Mayall, B. (2000). Conversations with children: working with generational issues. En p. Christensen, \& a. James, advocating for children: international perspectives on children's rights (págs. 120-135). London: falmer (2002). Towards a sociology for childhood. Buckingham: open university Press.

Maykut \& Morehouse, (1999) Investigación cualitativa una guía práctica y filosófica. España: Hurtado p. 127.

Mayol Lassalle (2015). El derecho a la educación en la Primera Infancia OMEP Región América Latina Asamblea Anual - mayo 2015/ Patricia Ramírez Otálvaro Ed.; Medellín: Editorial Publicar-T. Tecnológico de Antioquia, 2016. 292 p.

Medina, J. (2006). Propuesta para fomentar eficazmente desde la gerencia escolar el proceso de articulación del nivel de educación inicial con la primera etapa de educación básica en la Parroquia la Sabanita de Ciudad Bolivar, Estado de Bolivar (Tesis de maestría). Recuperado de https://postgradoeducacionudobolivar.files.wordpress.com/2008/06/juana-medina-demontes.pdf

Ministerio de Educación Nacional (1997) [Decreto 2247 septiembre 1997: por el cual se establecen normas relativas a la prestación del servicio educativo del nivel preescolar y se dictan otras disposiciones. Recuperado de https://www.mineducacion.gov.co/1621/articles-104840 archivo pdf.pdf

(1998) Lineamientos Curriculares de la Educación Preescolar. Recuperado de https://www.mineducacion.gov.co/1621/articles-89869 archivo_pdf10.pdf

(2007). Viceministerio de la educación Preescolar, Básica y media. (2007) Informe sobre el estado de la situación nacional de la atención del niño menor de 0 a 4 años. Política Educativa Para la Primera Infancia. Bogotá. Ministerio de Educación Nacional. (2008). Plan Sectorial Revolución Educativa (2006-2010). Documento No 8 recuperado de https:/www.mineducacion.gov.co/1759/articles$\underline{152036 \text { archivo_pdf.pdf }}$ 
(2015). "OECD-Colombia education and skills accession policy review: Country background report”, Ministerio de Educación Nacional, Bogotá.

(2016). Revisión de políticas nacionales de educación la educación en Colombia. Recuperado de https:/www.mineducacion.gov.co/1759/articles356787 recurso $1 . p d f$

(2016). Lineamiento ¡Todos Listos!!! Para Acompañar las transiciones de las niñas y los niños en el entorno Educativo. Recuperado de http://aprende.colombiaaprende.edu.co/sites/default/files/naspublic/Orientaciones To dos\%20listos_Educaci\%C3\%B3n\%20Inicial.pdf

(2016). Ruta del proceso de transición armónica de los niños y niñas al Sistema de Educación Formal: Grado Transición. Recuperado de https://aprende.colombiaaprende.edu.co/ckfinder/userfiles/files/Ruta $\% 20$ proceso $\% 20 \mathrm{t}$ ransici\%C3\%B3n\%20arm\%C3\%B3nica\%20GT.pdf

(2017). Orientaciones para la transición educativa de los estudiantes con discapacidad y con capacidades o talentos excepcionales en la Educación Inicial Básica y Media Ministerio. Recuperado de https:/Www.mineducacion.gov.co/1759/articles$\underline{360294 \text { foto portada.pdf }}$

(2017). orientaciones para la transición educativa de los estudiantes con discapacidad y con capacidades o talentos excepcionales en la educación inicial, básica y media. Bogotá. Recuperado de https:/Www.mineducacion.gov.co/1759/articles360294 foto_portada.pdf

(2017). Derechos Básicos de aprendizaje Transición. Recuperado de https://aprende.colombiaaprende.edu.co/ckfinder/userfiles/files/DBA\%20Transici\%C 3\%B3n.pdf

(2017). Bases Curriculares de la Educación Inicial y Preescolar. Referentes técnicos para la educación inicial en el marco de la atención integral

Ministerio de Educación del Gobierno de la Ciudad Autónoma de Buenos Aires (2016) Articulación entre el nivel inicial y el nivel primario. - Ciudad Autónoma de Buenos Aires

Moromizato Izu, R. (2013). Transiciones educativas en comunidades indígenas de la Amazonía peruana: Del hogar a los programas educativos.

Moya, Y. (2012). ¿Qué se entiende por articulación al interior del sistema educativo? In sujetos y experiencias: Primer encuentro de Intercambio Pedagógico. Universidad Nacional Rio Negro Argentina: Editorial REUN.

Myers, R. (1993). Los doce que sobreviven. Fortalecimiento de los Programas de desarrollo para la primera infancia en el Tercer Mundo. Bogotá: Coedición con UNICEF- OPS Peñas C, (2016) comparación entre los derechos básicos de aprendizaje (DBA) y otras normas técnicas curriculares. Recuperado de https://santillanaplus.com.co/pdf/comparacion-entre-los-dba-las-normas-tecnicascurriculares.pdf 
Narodowski, M. (2009). Jardinizar la educación: nuevas prácticas, nuevas utopías. Mercedes Mayol Lasalle. (Editorial Puerto Creativo) Grandes temas para los más pequeños, 3133.

Nicastro, S. y Greco, M. B. (2009) Entre trayectorias. Escenas y pensamientos en espacios de formación. Rosario: Editorial Homo Sapiens.

Niñez Ya (2018) La niñez no da espera. Una mirada a su situación desde la sociedad civilBogotá. Recuperado de https://fundacionexe.org.co/wpcontent/uploads/2018/02/Ni\%C3\%B1ezYA_Libro.pdf

Nivela, M. L. H. (1997). La importancia de la observación en el proceso educativo. Revista electrónica interuniversitaria de formación del profesorado, (1), 85.)

OEA (Organización de Estados Americanos) (2009). Las transiciones en la primera infancia: una mirada internacional Macro conceptual, situación, avances y desafíos. Recuperado de http://iin.oea.org/pdf-iin/RH/Las-transiciones-en-la-primera-infancia-Una-miradaInternacional-Libro.pdf. p 35

ONU: Comité de los Derechos del Niño (2006) Observación general №7: Realización de los derechos del niño en la primera infancia, 20 septiembre 2006, CRC/C/ GC/7/Rev.1, disponible en esta dirección: http://www.refworld.org.es/ docid/4ffd3dc02.html

O'Rand AM, Krecker ML (1990) Conceptos del ciclo de vida: su historia, significados y usos en las ciencias sociales. En: Scott WR, Blake JR, editores. Revisión anual de sociología. Vol. 16. Palo Alto, CA: Revisiones anuales; 1990. pp. 241-262. DOI: 10.1146 / annurev.soc.16.1.241.

Organización para la Cooperación y el Desarrollo Económicos-OCDE (2016) Educación en Colombia, aspectos destacados 2016 Recuperado de http://www.plandecenal.edu.co/cms/media/herramientas/oecd educacion en colombi a aspectos.pdf

Pascal, Christine y Tony Bertram (2009), "listening to young citizens: the struggle to make real a participatory paradigm in research with young children", european early childhood education research journal, vol. 17, núm. 2, pp. 249-262

Patrick West, Helen Sweeting \& Robert Young (2010) Transition matters: pupils' experiences of the primary-secondary school transition in the West of Scotland and consequences for well-being and attainment, Research Papers in Education, 25:1, 21-50, DOI:10.1080/02671520802308677

Patton, Q. (1982). Métodos de evaluación cualitativa. Traducción realizada con fines didácticos, no comerciales. (Título Original: Qualitative evaluation methods. Tercera Impresión. SAGE Publications.

Peralta (2006). Articulación entre Educación parvulario y Básica cuadernos de educación infantil universidad central

(2007, mayo). Transiciones en la educación infantil. Un marco para abordar el tema de calidad. Ponencia presentada en Simposio de la OEA, Caracas, Venezuela (2018). Programas no-formales en la educación parvularia [aportes y proyecciones] ediciones Junji santiago de chile, marzo de 2018 
Pérez Salvatierra, E. (2012). La transición de segundo a tercer año de educación media municipalizada de Temuco, Chile.

Pérez Gómez, A. (1998). La cultura escolar en la sociedad neoliberal. Ediciones moratas, s.l., madrid.

Perez E, (2011). La transición en segundo a tercer año de educación media municipalizada de Temaco, Chile. Universidad de Barcelona. Tesis Doctoral programa de doctorado calidad educativa en un mundo plural recuperado http://diposit.ub.edu/dspace/bitstream/2445/42481/2/EPS_TESIS.pdfDe Cero A Siempre. D.C

Pescetti, L (2013). El juego y la escuela. Educar- Ministerio de Educación de Argentina, por Graciela Valle De Vita, Recuperado de https://www.educ.ar/recursos/118706/el-juegoy-la-escuela

Pianta, R. Cox. M., Lorriane. E, y Diane, E. (1999) transition practices. National center for Early development y leatning (NCEDL) Spotligs, 1.

Pineda, J., Méndez, M., Saucedo, F. M., \& Rodríguez, L. A. R. (2010). Trayectorias Escolares de Alumnos con Capacidades Diferentes. Revista Mexicana de Orientación Educativa, 7(19), 28-32.

Pinto, R. (2012). Principios filosóficos y epistemológicos del ser docente. San josé, costa rica: cecc/ sica. Recuperado de http://www.universidadfutura.org/wpcontent/uploads/2012/10/ principios-filosoficos-y-epistemologicos-de-ser-docente.pdf

Presidencia de la República (1991). Constitución Política de Colombia. Santa fe de Bogotá

Presidencia de la República (2011). Estrategia de Atención Integral a la Primera Infancia Presidencia de la República (2018). Política Nacional de Infancia y Adolescencia-20182030. [MEN-ICBF]. Recuperado de https://www.icbf.gov.co/sites/default/files/politica_nacional_de_infancia_y_adolesce ncia_2018_-_2030_0.pdf

Punch, S. (2002). Research with children. The same or different from research with adults? Childhood, vol. 9 (3): 321-341.

OECD Reviews of School Resources: Colombia 2018, OECD Reviews of School Resources, OECD Publishing, Paris, https://doi.org/10.1787/9789264303751en.http://www.oecd.org/education/school/OECD-Reviews-School-ResourcesSummary-Colombia-Spanish.pdf

Real Academia Española, Madrid, 1984

Redondo, P. (2004). Educación y Pobreza, entre el desasosiego y la obstinación. Buenos Aires: Paidós

(2011). Infancia, educación e igualdad. En crecer juntos para la primera infancia. encuentro regional de políticas integrales. UNICEF. Recuperado de https://www.unicef.org/educacion Libro primera infancia.pdf

(2016). La escuela con los pies en el aire: Hacer escuela, entre la desigualdad y la emancipación. (Tesis de posgrado. Universidad Nacional de La Plata). Facultad de 
Humanidades y Ciencias de la Educación. En Memoria Académica. Disponible en: http://www.memoria.fahce.unlp.edu.ar/tesis/te.1279/te.1279.pdf

Redondo, P. y Antelo, E. (2017). Encrucijadas entre cuidar y educar. Debates y experiencias. Argentina: Homosapiens.

Rodríguez, a. C. y turón, c. A. (2007). Articulación preescolar-primaria: recomendaciones al maestro. Revista iberoamericana de educación, 44 (4), 1-6

Rojas, V., Ames, P., y Portugal, T. (2010). Continuidad y respeto por la diversidad: fortaleciendo las transiciones tempranas en Perú. Amsterdam.

Rosa Violante (2009). Debates y claves para la educación de los niños pequeños - mercedes Mayol Lasalle.(editorial puerto creativo) grandes temas para los más pequeños, 31-33.

Rush, S., \& Vitale, P. (1994). Analysis for detemnining factors that place elementary students at risk. Journal of Educational Research, 87, 325-333.

Sáez, F. (2015). Articulación curricular entre educación de párvulos y educación general básica: Diseño de propuesta de intervención para la articulación curricular efectiva entre NT2 y 1EGB. Magíster. Santiago de Chile: Pontificia Universidad Católica de Chile.

Santos, B. D. S. (2014). Más allá del pensamiento abismal: de las líneas globales a una ecología de saberes. Epistemologías del sur (perspectivas), 21-66.

Salmela-Aro, K. y Tynkkynen, L. (2010). Trajectories of Life Satisfaction Across the Transition to Post-Compulsory Education: Do Adolescents Follow Different Pathways? J Youth Adolescente, 39, 870-881.

Salva, L. R., \& Lago, G. (2013, November). Trayectorias escolares de niños y jóvenes hijos de trabajadores migrantes rurales en escuelas de los niveles primario y secundario de La Plata. In VII Jornadas de Sociología de la Universidad Nacional de La Plata (La Plata, 2012).

Santillán, L. (2007). “La 'educación' y la 'escolarización' infantil en tramas de intervención local. Una etnografía en los contornos de la escuela". Revista Mexicana de Investigación Educativa, 12(3/4): 895-919.

(2012). Quiénes educan a los chicos: infancia, trayectorias educativas y desigualdad. Editorial Biblos.

Sarmiento, A. (2010). Situación de la educación en Colombia. Preescolar, básica, media y superior. Una apuesta al cumplimiento del derecho a la educación para niños, niñas y jóvenes. Gente Nueva Editorial.

Schepper-Huges, N. y Sargent, C. (1998). Small wars. The cultural politics of childhood. Londres: university of california press

Schütz, A. (1962): Collected Papers, L’Aia.

Schutz, Alfred, Luckmann Thomas (2003): Las estructuras del mundo de vida. Amorrortu. Bs. As. CITADO EN Gustavo Mariluz (2013). EL CURSO DE LA VIDA. Una mirada desde la Filosofía Fenomenológica y la Sociología del envejecimiento. X Jornadas de Sociología. Facultad de Ciencias Sociales, Universidad de Buenos Aires, Buenos Aires 
Secretaria de Educación (2012). [Resolución Número 501 de 2012]. Por medio de la cual se regula la prestación del servicio de Atención Integral a la Primera Infancia en desarrollo del Programa Buen Comienzo.

(2013) [Decreto 01277 de julio 2013] Por el cual se reglamenta el acuerdo 58 de la Alcaldía de Medellín. Medellín Todos por la vida

(2016) [Resolución 010548 de septiembre de 2016] Por medio de la cual se regula la prestación del servicio de atención integral a la primera infancia en desarrollo del Programa Buen Comienzo. Municipio de Medellín

(2017) [ Circular 000228 de 2017] Orientaciones para fortalecer el proceso de transición armónica de la educación inicial a la educación formal, Gerencia de Infancia, Adolescencia y Juventud. Departamento de Antioquia

(2018) [Resolución 201850002213 de enero 2018] Por medio de la cual se regula la prestación del servicio de educación inicial en el marco de la atención integral a la primera infancia en desarrollo del programa Buen Comienzo. Alcaldía de Madelin

(2019) Informe de tasa de matrícula deserción y reprobación

(2019) Lineamientos Conceptuales y Técnicos para la operación de las modalidades de Atención del Programa Buen Comienzo. Municipio de Medellín

Seidman, E., Allen, L., Aber, J.L., Mitchell, Ch. y Feiman, J. (1994). The impact of school transitions in early adolescence on the self-system and perceived social context of poor urban youth. Child Development, 65, 507-522.

Seoane, V. I. (2013). Géneros, cuerpos y sexualidades: experiencias de mujeres en escuelas técnicas de la ciudad de La Plata. (tesis doctoral) Facultad Latinoamericana de Ciencias Sociales- FLACSO- Argentina

(2017). Diferencia sexual y experiencias de mujeres en la educación técnica: historias de silencios y resistencias. La Aljaba. Segunda época. Revista de Estudios de la Mujer. Volumen XXI. Neuquén, Argentina

(2018). Contribuciones del Feminismo para pensar el contrato pedagógico. Primeras Jornadas Internacionales de Estudios de Género del Nordeste Argentino y Países Limítrofes. Facultad de Humanidades. El Centro Interdisciplinario de los Estudios de Género - CIDEG. Universidad Nacional del Nordeste. Resistencia. 9 y 10 de agosto de 2018. ISBN: 978-987-3619-39-7

(2019) Gubernamentalidad neoliberal y cuerpo/s docente/s: historias de violencia y desposesión, en Fernanda Saforcada y Myriam Feldfeber (comp.) La regulación del trabajo y la formación docente en el siglo XXI: miradas desde Argentina. - 1a ed. Ciudad Autónoma de Buenos Aires: Editorial de la Facultad de Filosofía y Letras Universidad de Buenos Aires. ISBN 978-987-8363-08-0

Shanahan, Michael y Glen Elder (2002), "History, agency, and the life course", en Lisa Crockett (ed.), Agency, Motivation, and the Life Course, vol. 48 del Nebraska Symposium on Motivation, Lincoln (Nebraska): University of Nebraska Press

Scharagrovsky, P. (SF). "El cuerpo en la escuela". Revista Explora. Ministerio de Educación Ciencia y Tecnología, Presidencia de la Nación. Págs. 3 a 9. recuperado de 
http://ceip.edu.uy/IFS/documentos/2015/sexual/materiales/pedagogia-

elcuerpoenlaescuela/pedagogia-elcuerpoenlaescuela.pdf

Skliar, C. (2012). La infancia, la niñez, las interrupciones. Childhood \& philosophy, 8(15), 67-81.

Southwell, M; y Vassiliades, A. (2014) "El concepto de posición docente: notas conceptuales y metodológicas", en Revista Educación, Lenguaje y Sociedad. Volumen XI, N 11. diciembre de 2014. Instituto para el Estudio de la Educación, el Lenguaje y la Sociedad. General Pico, La Pampa

Stormezan Segovia, K. (2016). Reconocimiento del género en la infancia: análisis de los significados y estrategias de aplicación del enfoque de género, programa de reparación de maltrato quilicura y programa de prevención focalizada quilicura de la fundación ciudad del niño.

Strauss, A. L., \& Corbin, J. (2002). Bases de la investigación cualitativa: técnicas y procedimientos para desarrollar la teoría fundamentada. Medellín: Universidad de Antioquia

Taylor, S. J. \& Bogdan, R. (1986). Introducción a los métodos cualitativos de investigación. Editorial Paidós, Buenos Aires.

Tenti fanfani, e. (2000). Saberes sociales y saberes escolares. Revista cero en conducta, 15, pp. 41-52.

Terigi, F. (2007). Los desafíos que plantean las trayectorias escolares. Trabajo presentado en el III Foro Latinoamericano de Educación. Jóvenes y maestras. La escuela secundaria en el mundo de hoy de la Fundación Santillana, Buenos Aires, Argentina Disponible en: $\underline{\text { http://www.ieo.edu.ar/promedu/trayescolar/desafios.pdf }}$

(2008). Los cambios en el formato de la escuela secundaria argentina: por qué son necesarios, por qué son tan difíciles. Propuesta educativa, 17 (29), dossier "Reformas de la forma escolar". Junio de 2008, pp. 63-71.

(2010). El saber pedagógico frente a la crisis de la monocronía. En Frigerio, G. y Diker, G., Educar: saberes alterados. Buenos Aires, Del estante Editorial

Tonucci, f. (2008). La misión principal de la escuela ya no es enseñar cosas. Recuperado de http://www.lanacion.com.ar/1085047-la-mision-principal-dela-escuela-ya-no-esensenar-cosas

Torrado y Guaqueta (2009). Política de primera infancia en Colombia: Un análisis desde la perspectiva de los actores involucrados en el proceso de formulación. En retos para las políticas públicas de primera infancia. Universidad Nacional de Colombia (p.79)

Toscano, A. G., Briscioli, B., \& Morrone, A. (2015). Trayectorias escolares: estrategias teórico-metodológicas para su abordaje. XI Jornadas de Sociología. Facultad de Ciencias Sociales, Universidad de Buenos. Aires, Buenos Aires.

Van Gennep, A. (1960) The Rites of Passage. Chicago: University of Chicago Press (en español: Los ritos de paso. Madrid: Taurus -1986- y Alianza -2008-). (1988). Los ritos de paso, Madrid: Taurus. Edición original, París, (1909), págs. 20-21. 
Vega y Belen (1999) desarrollo adulto y envejecimiento desde un punto de vista" sociocontextual P 801

Vegas, E. \& Petrow, J. (2007). Raising student learning in Latin America. The challenge for the 21st century. Washington DC: The World Bank

Violante, R. (2006) "Cómo enseñar a los niños pequeños". Disponible en: http:://www.infanciaenred.org.ar/educrianza/ septiembre

Viscaíno, Ramirez, y Cuéllar (2010). La política pública de primera infancia en Colombia: Algunas consideraciones en torno a su financiamiento e implementación.

Vogler, P., Crivello, G. y Woodhead, M. (2008). La investigación sobre las transiciones en la primera infancia: Análisis de nociones, teorías y prácticas. Cuadernos sobre Desarrollo Infantil Temprano $N^{\circ}$ 48. La Haya, Países Bajos: Fundación Bernard

Weil, Pierre (1993). Holística una nueva visión y abordaje de lo real. Ediciones San Pablo. Bogotá.

Woodhead, M and P. Moss (eds) (2007) Early Childhood and Primary Education: Transitions in the Lives of Young Children. Milton Keynes: Open University.

Zabalza, M. (2016). Prácticas educativas en la educación infantil. Transversalidad y transiciones. Brasil: Universidad de Santiago de Compostela recuperado de http://forpedi.com.br/downloads/forpedi anexo_ 0509121501209.pdf

Zubizarreta, A. C., Muñoz, M. P. E., \& González, J. A. (2017). Fundamentos teóricos de la educación infantil (vol. 25). Ed. Universidad de Cantabria. 


\section{Anexos}

Anexo 1- Seudónimo de los niños y niñas

\begin{tabular}{|l|l|l|l|l|l|l|l|}
\hline \multicolumn{2}{|c|}{ Muestra trabajo de campo con los niños niñas } \\
\hline Código & Nombre & Años & Grado de escolaridad & Código & Nombre & Años & $\begin{array}{l}\text { Grado de } \\
\text { escolaridad }\end{array}$ \\
\hline N1 & Niño de Transición & 5 años & Grado transición & N10 & Niña de transición & 5 años & Grado transición \\
\hline N2 & Niña de transición & 6 años & Grado transición & N11 & Niño de transición & 5 años & Grado transición \\
\hline N3 & Niña de transición & 5 años & Grado transición & N12 & Niño de primero & 7 años & Grado primero \\
\hline N4 & Niño de transición & 6 años & Grado transición & N13 & Niña de primero & 7 años & Grado primero \\
\hline N5 & Niño de transición & 6 años & Grado transición & N14 & Niño de primero & 7 años & Grado primero \\
\hline N6 & Niño de transición & 6 años & Grado transición & N15 & Niño de primero & 7 años & Grado primero \\
\hline N7 & Niña de transición & 6 años & Grado transición & N16 & Niño de primero & 7 años & Grado primero \\
\hline N8 & Niña de transición & 6 años & Grado transición & N17 & Niña de primero & 7 años & Grado primero \\
\hline N9 & Niña de transición & 6 años & Grado transición & & & &
\end{tabular}

\section{Anexo 2 Instrumento de Investigación- Guion de entrevistas a maestras}

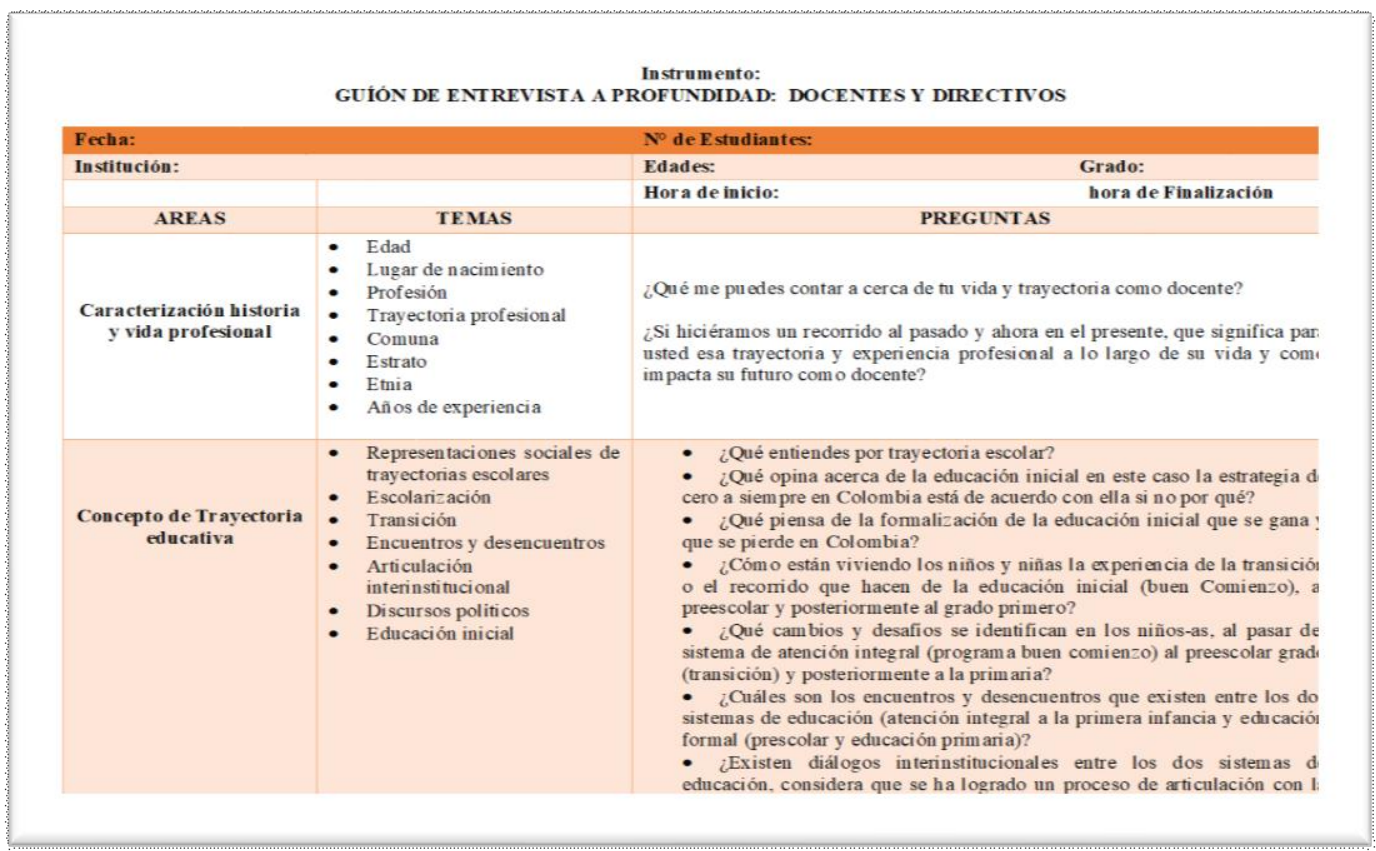


Anexo 3 Instrumento de Investigación para los niños y niñas- Enfoque mosaico

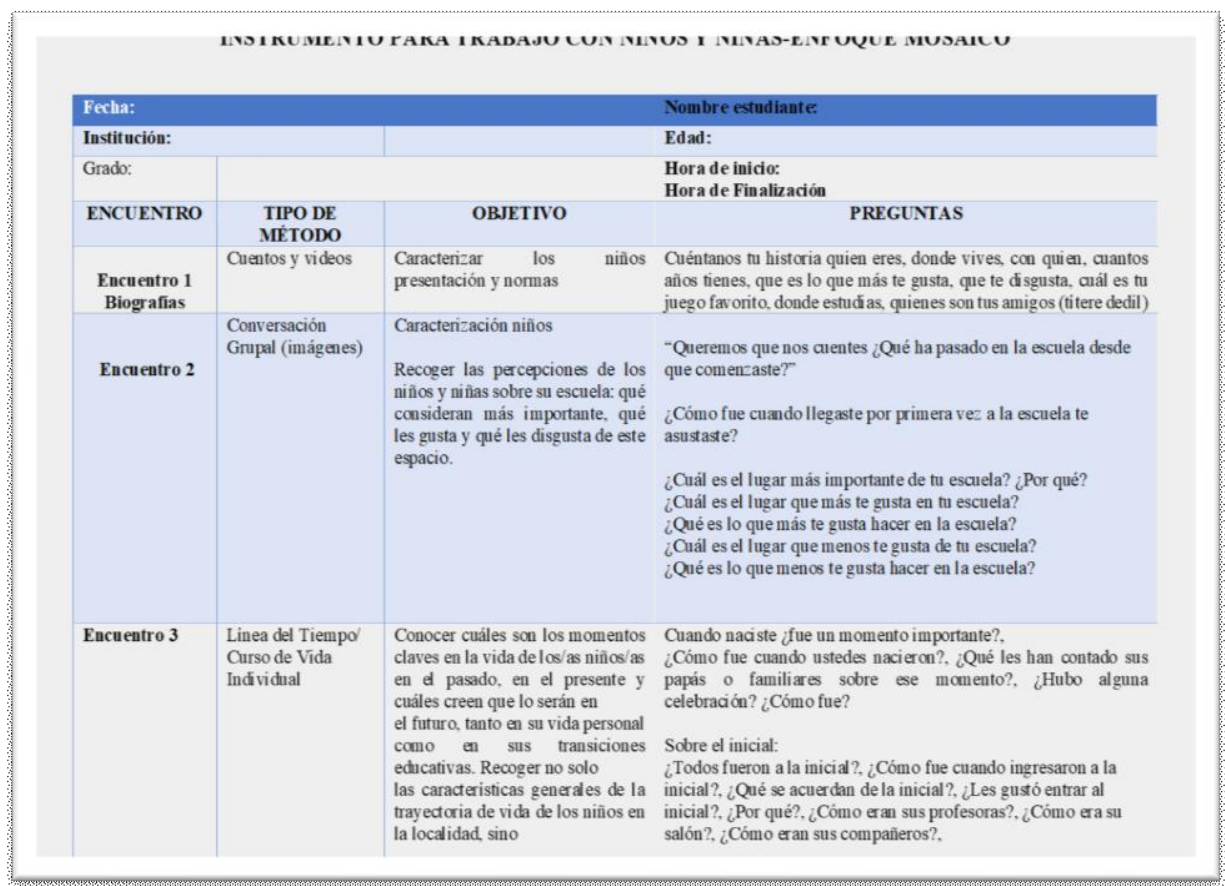

Anexo 4 Consentimiento Informado de los niños y niñas

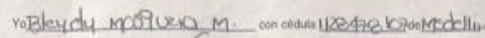

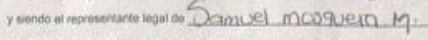

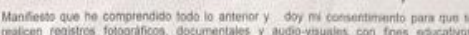

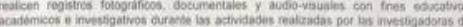

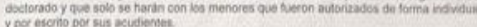

DECLARACIÓN DE RRMUS

- Hima dei neromentanto ma Bleydy mosquena mosquera cc1128. 478.107 de Modellín

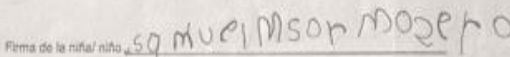

ait

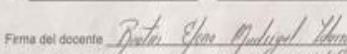

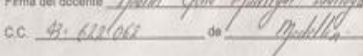

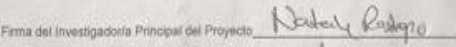

ca. 21320859

lugary tocher

Aborb 142013
(5)

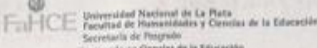

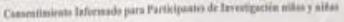

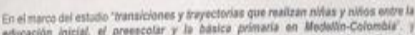

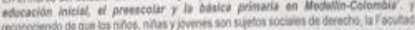

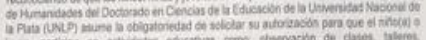

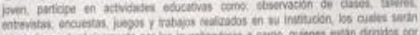

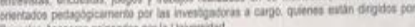

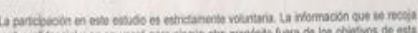

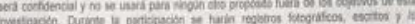

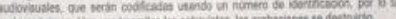

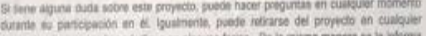
tomerto on

Se detatar is opones pera ver aprebadas o os

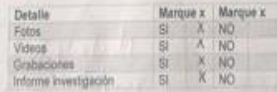




\section{Anexo 5 Consentimiento Informado de las maestras y agentes educativas}

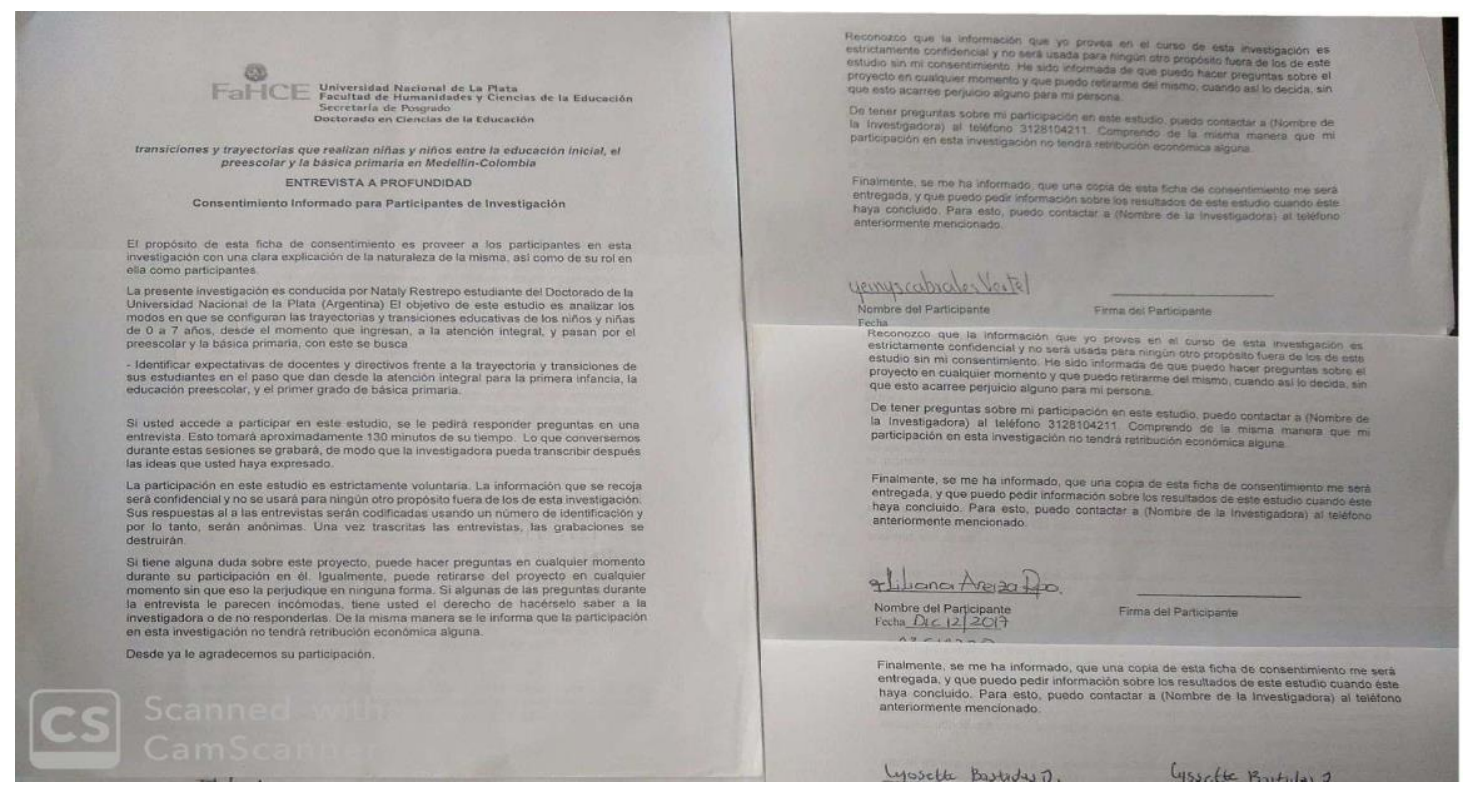

Anexo 6 -Tabla 11 de Normas políticas y orientaciones para el proceso de transición en Colombia

\section{Nombre Del Documento}

Plan Sectorial Revolución Educativa (20062010). Ministerio de Educación Nacional.

Concejo de Medellín Anexo 5 Lineamientos Educativos para el Desarrollo Integral de La Primera Infancia del Municipio Medellín Alcaldía de Medellín Programa Buen Comienzo

Concejo de Medellín [Acuerdo 58 de 2011] Política Pública de Atención Integral a la Primera Infancia.Programa Buen Comienzo

Secretaria de Educación Resolución Número 501 de (2012).

Secretaria de Educación Decreto 01277 (2013).

\section{Objeto de la norma}

Orienta y norma la articulación de la educación inicial con el ciclo de básica primaria, de manera que esta transición tenga elementos de continuidad. Para ello promoverá la implementación de proyectos pedagógicos que se adapten a las realidades cambiantes en las que se desenvuelven los niños/as, incorporando elementos de su contexto.

Lineamientos educativos para el desarrollo integral de la primera infancia del municipio de Medellín

Por medio del cual se adopta la Política Pública de Atención Integral a la Primera Infancia Buen Comienzo, se desarrolla un Sistema de Atención Integral y se modifica el Acuerdo 14 de 2004

Por medio de la cual se regula la prestación del servicio de Atención Integral a la Primera Infancia en desarrollo del Programa Buen Comienzo

Por el cual se reglamenta el acuerdo 58 de 2011, mediante el cual se adoptó la Política Publica de atención integral a la Primera Infancia Buen Comienzo, se desarrolló un sistema de Atención Integral y se modificó el acuerdo 14 de 2004 
Instituto Colombiano de Bienestar Familiar Guía Orientadora No (8) para la Transición de los Niños y Niñas desde los programas de Atención al a Primera Infancia del ICBF al Grado de Transición

Concejo de Medellín Acuerdo 54 de (2015) Por medio del cual se redefine la regulación municipal sobre la Política Pública de Primera Infancia y el Programa Buen Comienzo Gaceta Oficial 4356 Alcaldía de Medellín

Alcaldía De Medellín Decreto Secretaria de Educación Municipio de Medellín (junio 3 del 2015)

Ministerio de Educación Nacional (2015) Informe de Balance Octubre de (2014 - junio de 2015) Estrategia de Atención Integral a la Primera Infancia de Cero a Siempre

Documento De Buen Comienzo Antioquia Transiciones Armónicas en el entorno educativo el paso de la educación inicial al sistema escolar Buen Comienzo Antioquia de Cero A Siempre -ICBF Secretaría de Educación Departamental

Ministerio de Educación Nacional Decreto 1075 Por medio del cual se expide el Decreto Unico Reglamentario del Sector Educación.

Instituto Colombiano de Bienestar Familiar (2016) Ruta del proceso de transición armónica de los niños y niñas al Sistema de Educación Formal: Grado Transición

Secretaria de Educación (2016). Resolución Número 010548 Por el cual se reglamenta el acuerdo 58 de la Alcaldía de Medellín
La presente guía, organiza el proceso de articulación en diferentes niveles Nacional, Departamental y Municipal e involucra respectivamente diversos actores: niños y niñas, padres de familia, entidad administradora del servicio agentes educativos, delegados de las secretarías de educación, delegados de los centros zonales y regionales del ICB, entre otros.

Por medio del cual se redefine la regulación municipal sobre la Política Pública de Primera Infancia y el Programa Buen Comienzo.

Por el cual se adecúa la estructura de la administración municipal de Medellín, las funciones de sus organismos, dependencias y entidades descentralizadas, se modifican unas entidades descentralizadas y se dictan otras disposiciones

El informe corresponde a la ejecución de la estrategia para la Atención Integral de la Primera Infancia de Cero a Siempre en el periodo comprendido entre octubre de 2014 y junio de 2015, da cuenta en detalle de la participación de la comisión intersectorial para la Atención Integral a la Primera Infancia en la formulación del Plan Nacional de Desarrollo (2014/ 2018) Todos por un Nuevo País.

Referente para "garantizar a la población infantil entre 5 y 6 años el acceso al grado de transición y desarrollar acciones de articulación educativa, inter-institucional e intersectorial que permitan el adecuado tránsito de los niños, las niñas y su familia al grado de transición

Define las orientaciones y procedimientos para garantizar que las transiciones de los niños y las niñas en los diferentes momentos de la oferta educativa, sean armónicos y potenciadores del desarrollo, con base en los Fundamentos Políticos, Técnicos y de Gestión de la Estrategia Nacional de Atención Integral a la Primera Infancia.

El siguiente documento es un camino que permite a varias instituciones territoriales y nacionales articularse para facilitar el ingreso de los niños y niñas al grado 0 o al primer grado obligatorio de la educación formal. los momentos que se plantean en la ruta son circulares, responden en el sector educativo a lo expuesto en la resolución 07797 de 2015 de gestión de la cobertura educativa en las entidades territoriales certificadas.

Por medio de la cual se regula la prestación del servicio de Atención Integral a la Primera Infancia en desarrollo del programa Buen Comienzo. 
Ministerio de Educación Nacional (2016) Lineamiento ¡Todos Listos!!! Para Acompañar las transiciones de las niñas y los niños en el entorno Educativo.

Congreso de la Republica. Ley 1804 Política de Estado de Primera Infancia de Cero a siempre Ministerio de Educación Nacional (MEN, agosto de 2016)

Instituto Colombiano de Bienestar Familiar (2016).

Resolución (000439-2017 Alcaldía De Medellín Secretaria de Educación Municipio de Medellín (17 enero, 2017)

Ministerio de Educación Nacional (2017). Lineamiento Técnico Educación Inicial, Orientaciones para la transición educativa de los estudiantes con discapacidad y con capacidades o talentos excepcionales en la Educación Inicial, Básica y Media.

Instituto Colombiano de Bienestar Familiar (2017) Guía Orientadora para el tránsito de los niños y niñas desde los Programas de atención a la Primera Infancia del ICBF al Sistema de Educación Formal.

Secretaria de Educación Antioquia (SEDUCA) Circular 000228 (K2017090000228) Orientaciones para fortalecer el proceso de transición armónica de la educación inicial a la educación formal para el año 2017 Gerencia de Infancia, Adolescencia y Juventud.

Secretaría de Educación de Medellín Resolución 201850002213

Secretaría de Educación Programa Buen Comienzo Medellín (2017) Lineamientos Conceptuales y Técnicos para la operación de las modalidades de Atención del Programa Buen Comienzo Municipio de Medellín. ¡todos listos!!! se constituye en uno de los referentes técnicos de la educación inicial de calidad en el marco de la estrategia de Atención Integral a la Primera Infancia "de Cero A Siempre" y la Política Educativa de Colombia para acompañar las transiciones de las niñas y los niños en su ingreso al sistema educativo.

Por la cual se establece la Política de estado para el desarrollo integral de la Primera Infancia de Cero a Siempre y se dictan otras disposiciones.

Anexo de servicio preescolar integral para brindar las orientaciones, líneas y disposiciones relacionadas con la implementación de la preescolar integral para la primera infancia en el marco de la Estrategia de Cero a Siempre en los establecimientos educativos

La presente resolución regula la prestación del servicio de Atención Integral a la Primera Infancia en desarrollo del Programa Buen Comienzo en el municipio de Medellín.

Documento materializa acciones, para la atención a la población con discapacidad y con capacidades o talentos excepcionales como poblaciones de especial atención por parte del sistema educativo colombiano.

Estrategias de Articulación pedagógica para la transición de los niños y niñas de

las modalidades de atención del ICBF al grado de Transición

La Secretaría de Educación Departamental SEDUCA y la Gerencia de Infancia, Adolescencia y Juventud GIAJ en el marco del convenio 1088 de 2017 suscrito con el Instituto Colombiano de Bienestar Familiar-ICBF, en consonancia con las orientaciones del Ministerio de Educación Nacional, definieron la siguiente ruta con el fin de fortalecer el proceso de transición armónica de niños y niñas al sistema educativo formal

Por medio de la cual se regula la prestación del servicio de educación inicial en el marco de la atención integral a la primera infancia en desarrollo del programa Buen Comienzo. Alcaldía de Madelin

Este documento, "lineamientos conceptuales y técnicos para la operación de las modalidades del programa buen comienzo", es una herramienta que guía a las entidades aliadas en la prestación del servicio de Educación Inicial en territorio. 
Secretaría de Educación Programa Buen Comienzo Medellín (2018) Lineamientos Conceptuales y Técnicos para la operación de las modalidades de Atención del Programa Buen Comienzo Municipio de Medellín Secretaría de Educación Programa Buen Comienzo Medellín (2018).

Documento de orientaciones. Alcaldía Mayor de Bogotá D.C Recorrido para acompañar las transiciones efectivas y armónicas de los niños y las niñas en el entorno educativo Alcaldía Mayor de Bogotá. Secretaria de Educación: documento construido en el marco de los convenios: SE1D-ICBF-cajas de compensación familiar para la vigencia (2018)
Este documento, "lineamientos conceptuales y técnicos para la operación de las modalidades del programa buen comienzo", es una herramienta que guía a las entidades aliadas en la prestación del servicio de Educación Inicial en territorio.

El propósito del siguiente documento, es brindar herramientas conceptuales y metodológicas para profundizar en la comprensión e importancia del acompañamiento al tránsito de los niños y las niñas, desde cada uno de los componentes de la Educación Inicial en el Marco de la Atención Integral, en el distrito capital.

Elaboración propia

\section{Fotos de la experiencia}
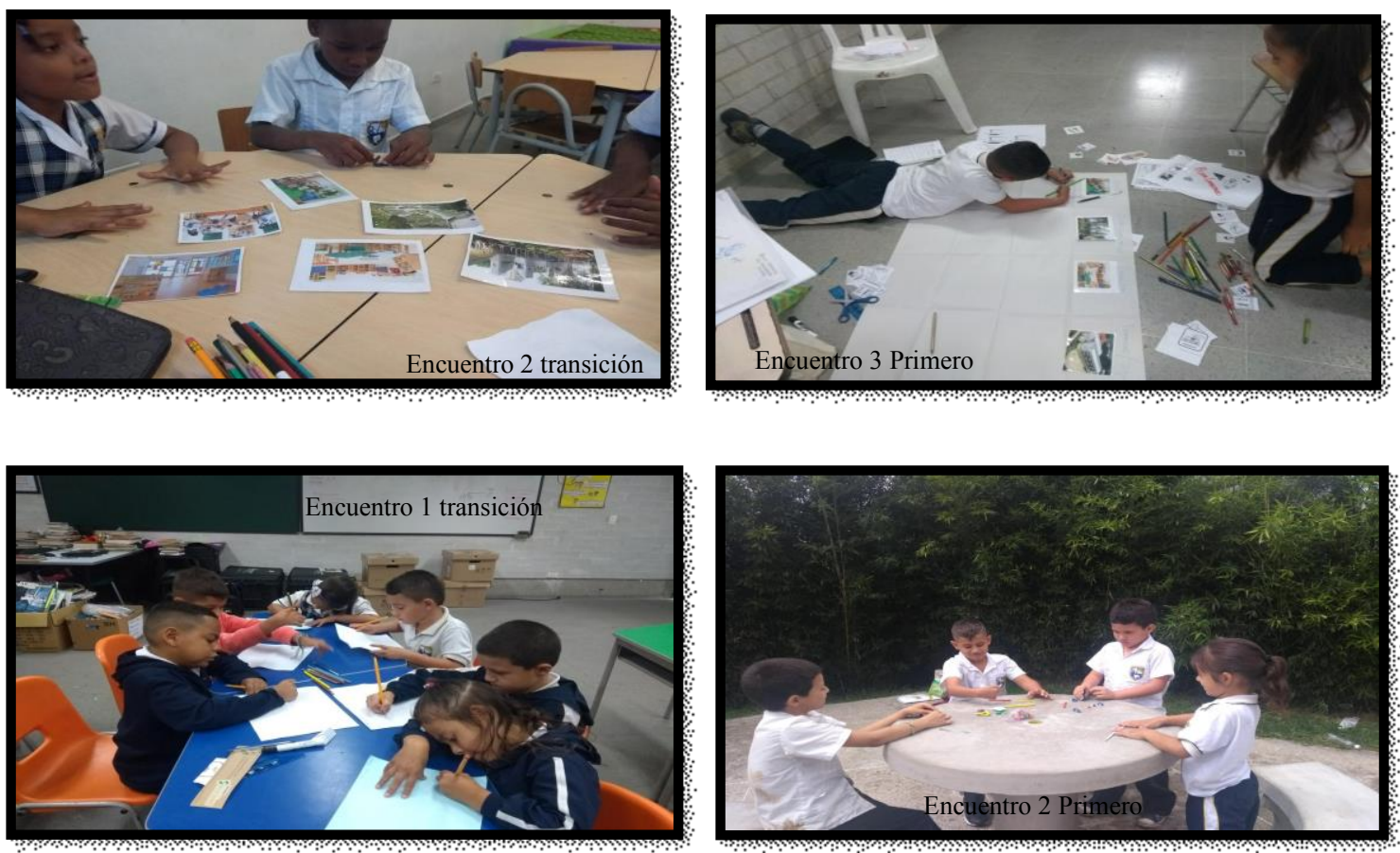

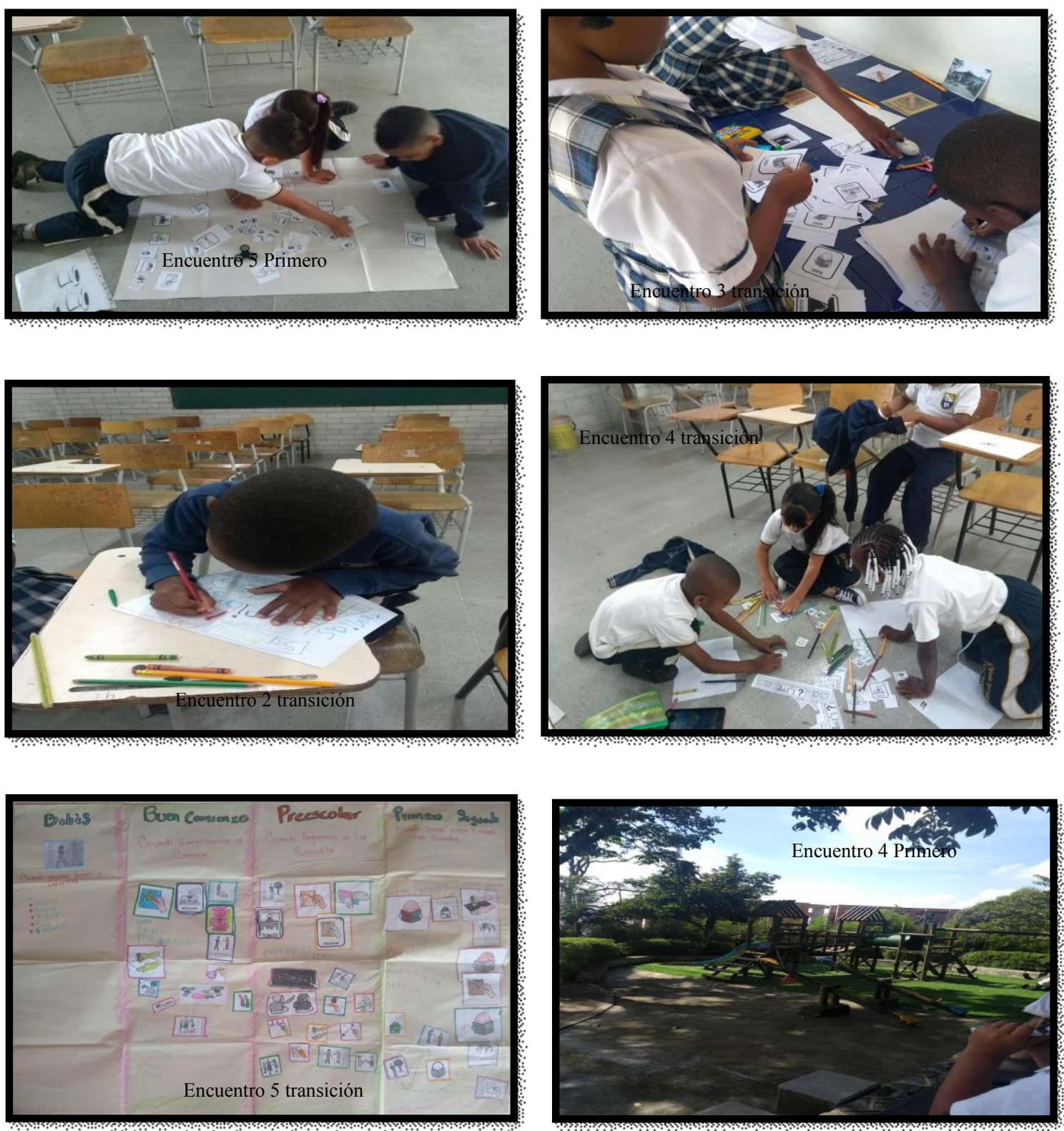

"Hablar de la escuela Infantil implica pensar en una escuela de colores que exige profundos replanteamientos, no solo en su sentido sino además en la manera de operar en los contextos sociales, culturales, políticos. Pensar la escuela hoy significa colocarse en cara a las nuevas realidades y a las exigencias de nuestros niños y niñas quienes demandan un espacio para jugar, aprender con el otro y para ser niños y niñas" (Restrepo,2020) 